\title{
FOUNDATION SOIL RESPONSE TO WIND TURBINE GENERATOR LOADING
}

by

\section{MEHMET YILMAZ}

A thesis submitted in partial fulfillment of the requirements for the degree of

MASTER OF SCIENCE

(CIVIL AND ENVIRONMENTAL ENGINEERING)

At the

UNIVERSITY OF WISCONSIN-MADISON

2014 
FOUNDATION SOIL RESPONSE TO WING TURBINE GENERATOR LOADING

$\underline{\text { Approved }}$

$5 / 14 / 2014$

James M. Tinjum, Associate Professor 


\section{Executive Summary}

Dynamically loaded wind turbine generator (WTG) foundation design requires a specialized design process due to abnormal loading conditions over a large bearing area. Multiple foundation options exist to support WTGs. A large octagonal mass of reinforced concrete is the most commonly used foundation type. Two high-capacity ( $\geq 1.5 \mathrm{MW})$ WTGs were instrumented in the upper Midwest of the US. The instrumentation was oriented to take advantage of the predominant wind direction in each site. This thesis focuses on the interpretation and analysis of data from these two instrumented WTG foundations.

Ten soil deformation gauges were installed at each site. The main purpose of the soil strain gauges $(\mathrm{SG})$ was to measure the deformation of the underlying bearing soil at different locations and depths. Pressure gauges (PG) were installed to monitor the dynamic pressure distribution underlying the octagonal WTG foundations. At one of the sites (Site A), thermal dissipation sensors and micro-electro-mechanical system accelerometers (MEMS) were installed to monitor volumetric water content change and foundation block rotation, respectively. Turbine towers were also instrumented with strain gauges to estimate moment transfer from the tower to the foundation.

Improvement of design approaches for dynamically loaded foundations, such as WTG foundations, requires knowledge of stress-strain transfer mechanisms. Data analysis from fieldinstrumented WTG foundation systems can be used to validate present-day design assumptions and to provide new and mechanically accurate approaches. Observations of contact pressure distribution, foundation soil deformation, and transferred moment from tower to foundation assist in understanding the mechanistic and dynamic behavior of WTG foundations and soil bearing response. 
Based on this research effort, changes in soil pressure and strain were highly related to wind direction and speed. At normal operating conditions, the most variation in pressure distribution was observed towards the edge of the foundation. Normalized pressure amplitude was around 0.35 (pressure/pressure average of analyzed data set) for the pressure cells locate at the edge of the foundation. Interior pressure cells (e.g., PG-2, PG-3, and PG-4), on the other hand, exhibited lower amplitudes $(\leq 0.10)$. This indicates that the outer portion of the foundation is more susceptible to stress changes. Although pressure was distributed across entire the foundation footprint, pressure response was not uniform.

Pressure shifts were observed in the cases of startup and shutdown conditions. During the shutdown sequences, greater pressure fluctuations were observed (e.g., $17 \%$ in PG-3, $48 \%$ in PG-4). Pressure data analysis indicated that maximum and minimum pressures occur during turbine shutdown. Pressure spikes were observed during shutdown varying from $2 \mathrm{kPa}$ to $10 \mathrm{kPa}$ depending on the location of the pressure cell.

Pressure cell - soil stiffness interaction is required for analysis of this type of field data. Under-representation was observed due to pressure drop in pressure cells. These decreases which under-represents the calculated static dead load of $78 \mathrm{kPa}$ are attributed cell-soil stiffness difference and 'bridging' phenomenon.

Soil strain was also non-uniform in distribution, both horizontally and vertically. The highest elastic soil deformation $(0.02 \mathrm{~mm}$ over the gage length of $300 \mathrm{~mm})$ occurred at the leeward site of the predominant wind direction. Moreover, soil deformation decreased systematically with depth. Strain level at full power production was computed as $0.006 \%$ immediately beneath the foundation and approximately $80 \%$ of this strain dissipates within 1.7 m. A commonly assumed cyclic strain level of $0.1 \%$ for design purposes (Det Norske Veritas) 
may significantly over-estimate strain levels experienced in the field for sites with stiff clay, such as these two instrumented sites in the mid-west. The observed displacement and pressure trends were symmetric depth dependent and highly correlated to wind direction and speed and location. Thermal dissipation sensors indicated that gravimetric water content does not significantly change over time as the foundation soil is shield from most environmental changes by the concrete block. The observed changes are most likely related to large seasonal changes $(23 \% \pm 2 \%)$. According to the MEMS accelerometer analysis, tilts were computed as $0.38^{\circ}$ at S30E, $0.16^{\circ}$ at $90 \mathrm{~W}$, and $0.18^{\circ}$ at $\mathrm{N} 30 \mathrm{E}$. These tilts create approximately $0.5 \mathrm{~m}$ sway (in amplitude) at the top of the WTG. 


\section{Acknowledgements}

I would like to offer special thanks to my advisors Dr. James M. Tinjum and Dr. Dante Fratta, due to their boundless help and contributions to my research. I also would like to express deep appreciation to my parents, Zeynep Yilmaz, Ali Yilmaz, and Zeki Yilmaz who have encouraged me to forward in my career.

My sincere gratitude to UW-Madison staff and students who helped me in my research including Xiaodong Wu, Stephan Schubert, Paul Lang, Jeongki Lee, Zhenzhong Wu, Linxue Ren, and Wei-Hao Zen. I would not have been able to complete my work without their help. They have always helped me in my laboratory and field work. Thanks to Dr. William (Bill) Likos for being one of my MS thesis defense committee member.

I owe thanks to my contacts at Campbell Scientific Inc., Site A, and Site B. They were always welcoming about my field trips and helpful with technical questions. Their deep technical experiences contributed our project and have helped me to complete my research successfully.

Finally, I am grateful to Turkish Republic-Ministry of National Education and Turkish Republic New York Turkish Education Attaché for their financial supports for my tuition and other expenses. Thanks to Turkish Republic government for their funding and loans. Additionally I would like to thank to US National Science Foundation (Grant No. 1238963) and US Department of Energy for the funding of in-place instrumentations. 


\section{TABLE OF CONTENTS}

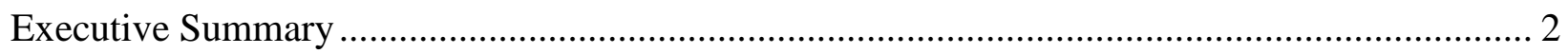

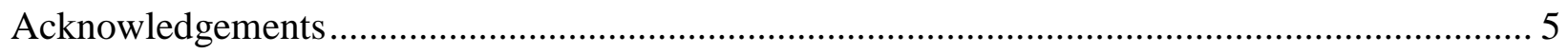

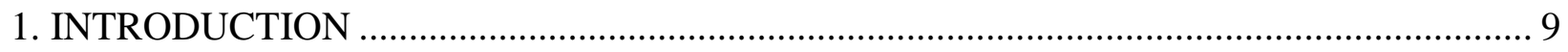

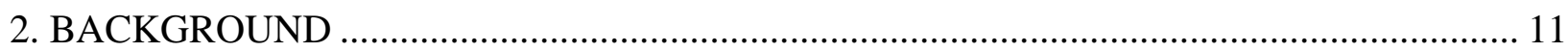

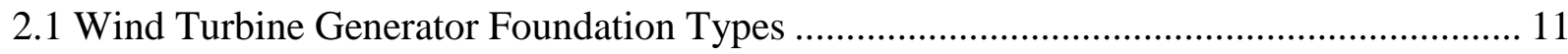

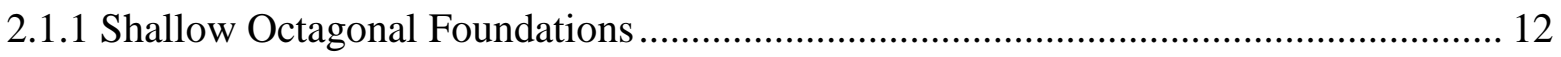

2.1.2 Short Piers, Rock-Socketed Piers and Rock Anchor Foundations ............................. 13

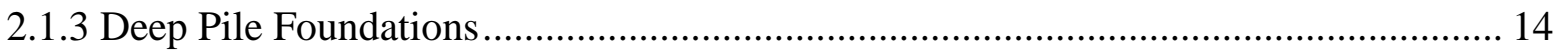

2.2 Driving Forces on Wind Turbine Generators.................................................................. 16

2.3 Design Path for Wind Turbine Generator Foundation ..................................................... 16

2.4 Wind Turbine Control and Blade Aerodynamics.......................................................... 17

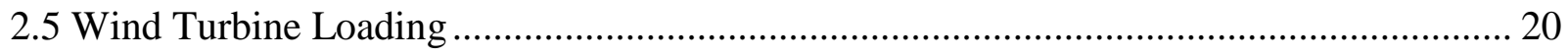

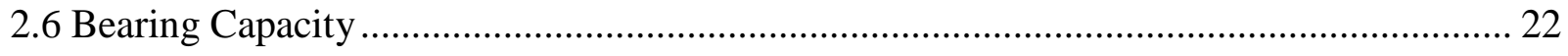

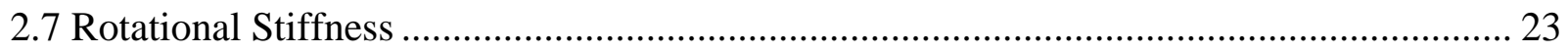

2.8 Pressure Distribution under the Footings …………........................................................ 25

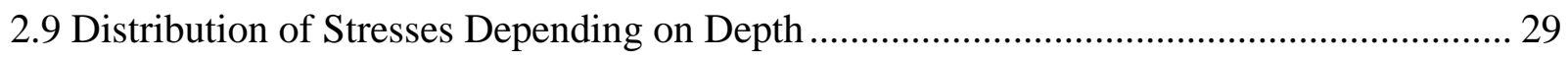

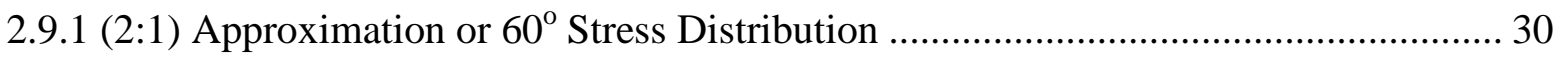

2.9.2 Boussinesq's Stress Distribution Approach ……….................................................... 31

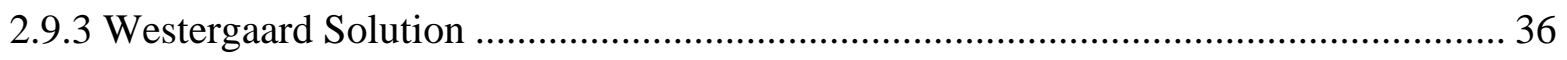

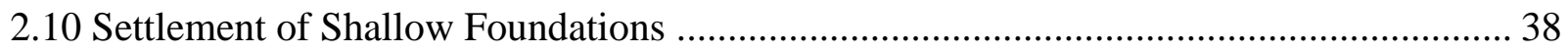

2.10.1 Immediate Settlement of Fine-Grained and Coarse Grained Soils............................ 39

2.10.2 Consolidation Settlement.................................................................................... 42 


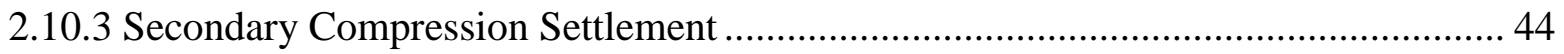

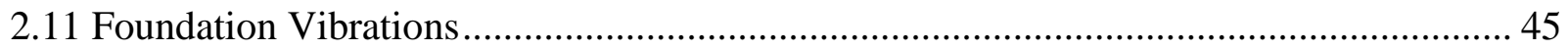

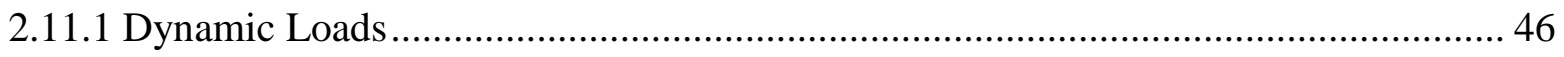

2.12 Shear Moduli and Damping ........................................................................................ 49

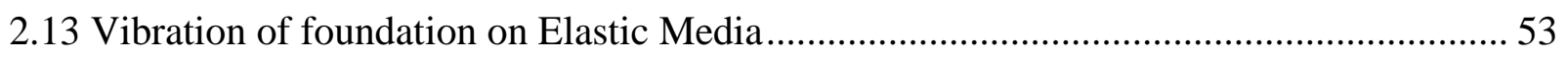

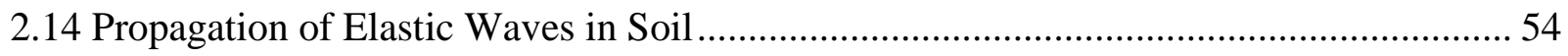

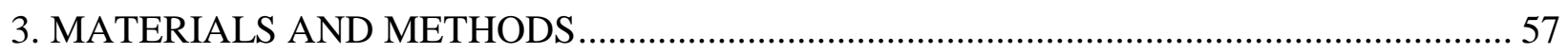

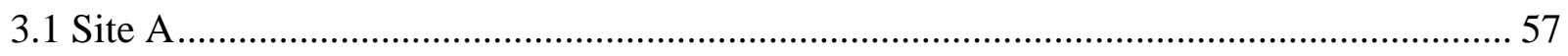

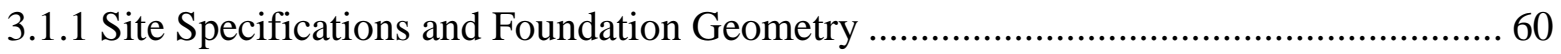

3.1.2 Soil Properties and Classification ............................................................................... 62

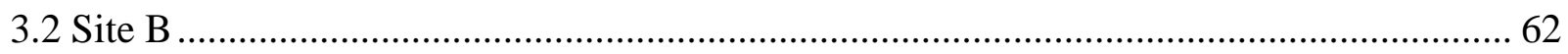

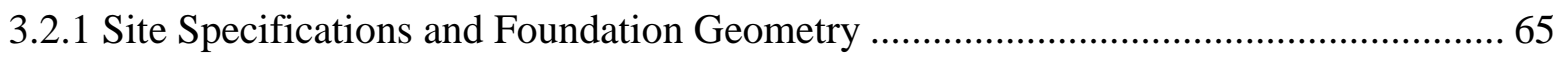

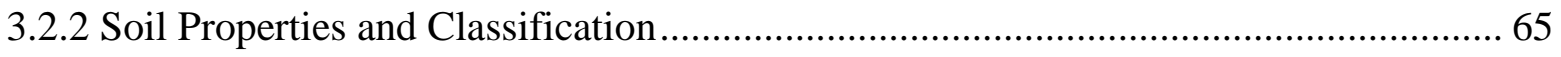

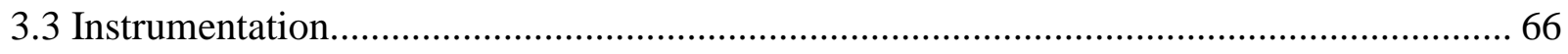

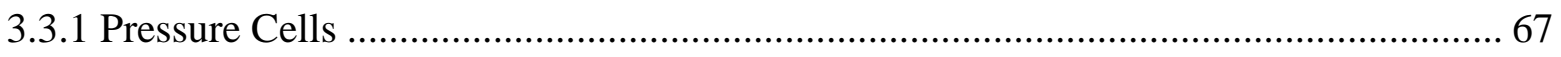

3.3.2 Soil Deformation Gauges ……………………….................................................... 72

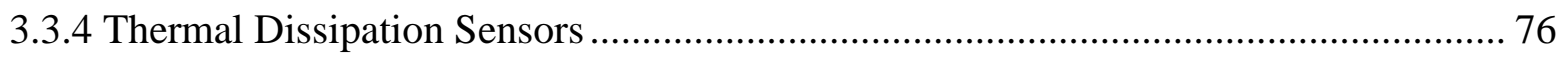

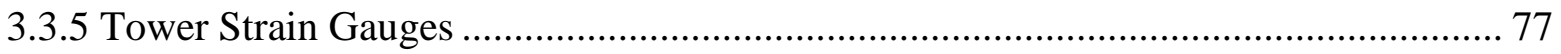

3.3.6 Micro-electro-mechanical systems (MEMS) accelerometers........................................ 80

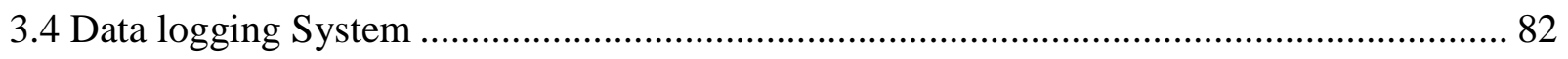

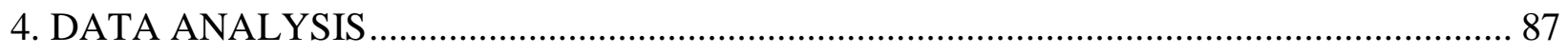

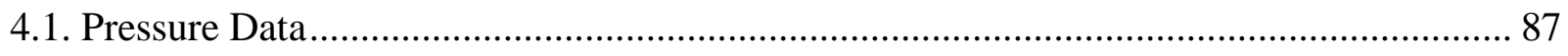

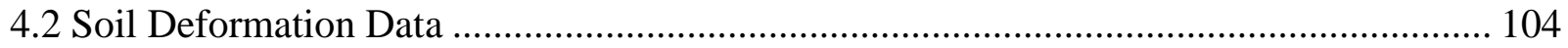


4.3 Micro-electro-mechanical (MEMS) Accelerometer Data ........................................ 115

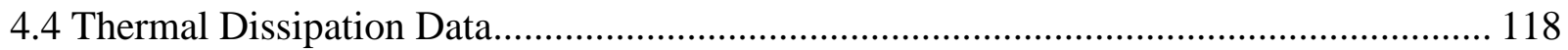

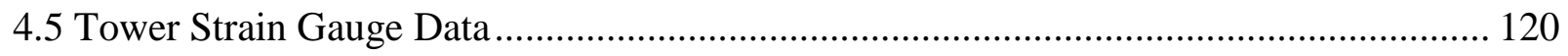

6. FUTURE RESEARCH PLAN ............................................................................. 125

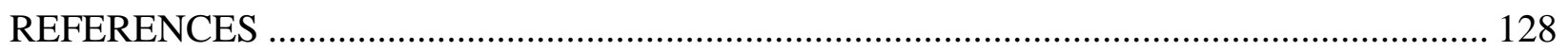

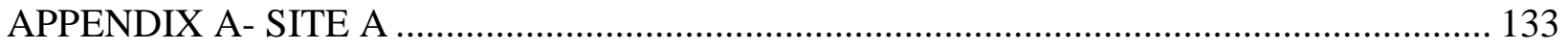

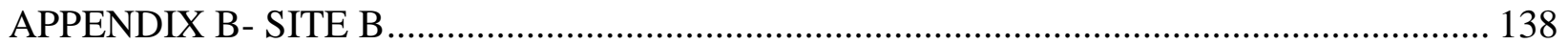




\section{INTRODUCTION}

Wind turbine generator (WTG) structures (Figure 1.1) are typically founded on massive shallow footings that are designed to transmit moderate vertical forces and large dynamic horizontal forces and overturning moments (Tinjum and Christensen 2010, Tinjum and Lang 2012). There are also other foundation strategies that are used to support WTGs such as rocksocketed piers, rock anchors, short piers, or Patrick and Henderson Tensionless Pier. Typically, shallow foundations are more economical and are designed as a large octagonal base made of reinforced concrete.

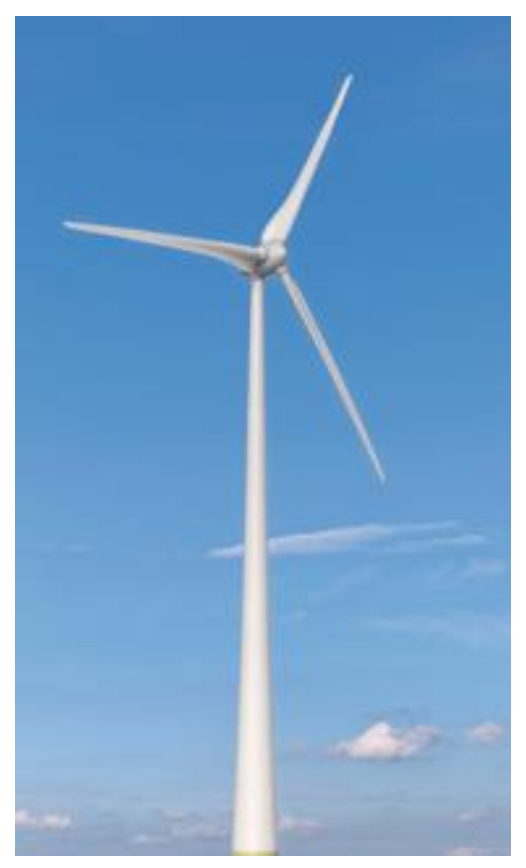

FIG. 1.1 A wind turbine generator.

The lack of experimental data and research on WTG foundations may lead a designer to use conservative assumptions. These conservative assumptions can lead to overdesigned foundations, additional costs, and reduced life-cycle cost efficiency of wind farms. The main purpose of this thesis is to present a measurement system under two in-service WTG foundations and the results associated with vertical stress, moment transfer, and deformation distribution 
through the underlying soil. The research focuses on the instrumentation and the response of the foundation soil under the horizontal and vertical loads. Dynamic loading conditions lead to uneven pressure distribution that is assumed uniform soil pressure distribution over an ovalshaped effective area offset from the center of the foundation by the system eccentricity. This assumption is mechanically incorrect and bases on semi-empirical observations (Meyerhoff 1953). This approach simplifies the design process but does not consider the effects of dynamical loads which are dominant in WTG foundation.

The shear modulus of supporting soil at appropriate strain level is required for stiffness analysis. Typically WTG foundation stiffness bases on shear degradation estimation to simplify design calculations. The stress-strain behaviors of soil at small and large strain levels are controlled by different mechanisms. At small strain level the behavior of strain-stress is controlled by the characteristics of the soil particle contacts (Santamarina et al. 2001) whereas it is controlled by slippage of particles at large strain levels (Araya et al. 1979). The stress-strain behavior is much stiffer at small strains (e.g. during wave propagation testing) than at large strains (e.g., during in-service wind turbine foundation operations). Limited research is available about true cyclic strain value for large machine foundations such as WTG foundation. Therefore, appropriate degradation curve is required for WTG foundation. A measurement approach is needed to determine the number of the cycles to reach the maximum deformation along with the magnitude of the strain that occurs beneath WTG foundations need to be developed (Pasten and Santamarina 2011).

The main purpose of this thesis is to present a measurement system under two in-service WTG foundations and. Pressure gauges were installed to observe contact pressure distribution beneath the foundation. Likewise, soil strain gauges were installed to investigate vertical stress 
and deformation distribution through the underlying soil. In addition, tower strain gauges, thermal dissipation sensors, and micro-electro-mechanical (MEMS) accelerometers were installed to observe moment transfer (from tower to the foundation), moisture change, and foundation block rotation, respectively.

\section{BACKGROUND}

\subsection{Wind Turbine Generator Foundation Types}

There are several types of wind turbine generator (WTG) foundation designs. The most appropriate and economical foundation type is determined based on conditions such as sitespecific turbine loads and geotechnical conditions. The foundation geometry and size are then designed to minimize cost while maintaining stability through the life of the structure.

WTG foundations are generally divided into two categories shallow and deep (see Figure 2.2 and 2.3). Both categories are designed to suitably handle various mechanical and dynamic behaviors. Shallow foundations, as an illustration, transmit the applied loads to the near surface of the earth. Octagonal gravity base, rock anchors, short piers are considered in the shallow foundation group. Deep foundations, on the other hand, are typically used to transmit the loads to deeper competent soil layers. Mono-pile foundations, pile and cap foundations, and patented Patrick and Henderson Tensionless Pier foundations are deep foundation options for WTGs.

In situ ground improvement may be used to improve soil properties in the shallow zone. Improvements, for example, may provide a larger stiffness to the foundation subgrade soil at foundation level. Rammed aggregate piers, horizontal soil mixing, and excavation-replacement method are considered as techniques for ground improvement. Ground stabilization methods may also increase shear strength, stability, and density of the soil. 


\subsubsection{Shallow Octagonal Foundations}

Typically, WTG systems are supported on shallow, gravity-based, octagonal foundations (Tinjum and Christensen 2010). The geometry of octagonal foundation allows the footing to support wind loads from all direction. This foundation type transmits vertical and horizontal loads (both static and dynamic) through the foundation block to the soil. The octagonal footing consists of reinforced concrete and steel rebar. The octagonal WTG foundation includes a steel pedestal section to support and anchor the tower. Figure 2.1 shows the pedestal and footing reinforcement for an octagonal WTG foundation.

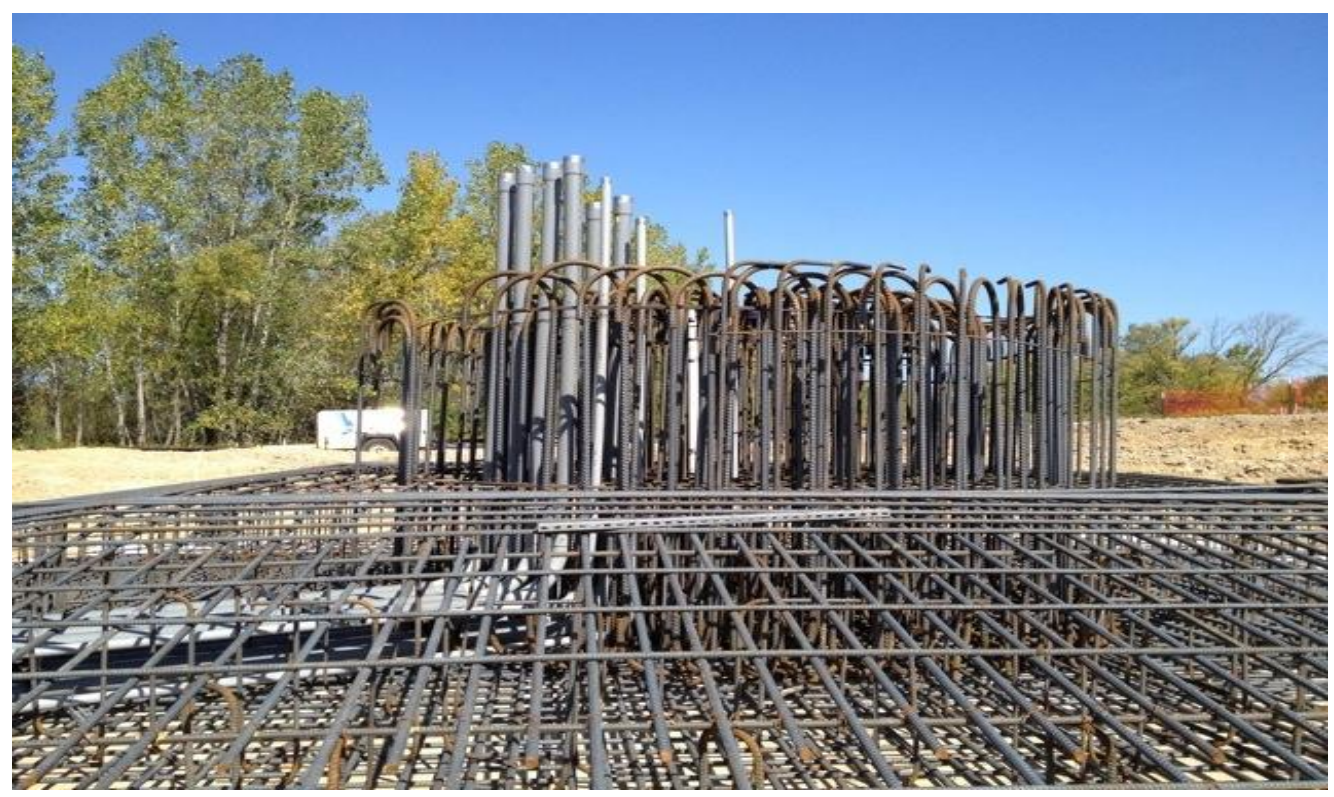

FIG. 2.1 Reinforcement in shallow octagonal foundation (Courtesy of Stephen Schubert).

Typically, the diameter of a shallow octagonal gravity footing varies from $12 \mathrm{~m}$ to $18 \mathrm{~m}$, and the volume of the concrete base may be upwards of $460 \mathrm{~m}^{3}$ (Tinjum and Christensen 2010). Shallow foundations are typically embedded $2.4 \mathrm{~m}$ to $3 \mathrm{~m}$ beneath the soil surface with approximately $0.7 \mathrm{~m}$ in edge thickness (Tinjum and Christensen 2010). 
Typically, octagonal foundation cost range from $\$ 100,000$ to $\$ 250,000$ (including concrete, rebar and labor costs) depending on the geometry of the foundation (Tinjum and Christensen 2010).

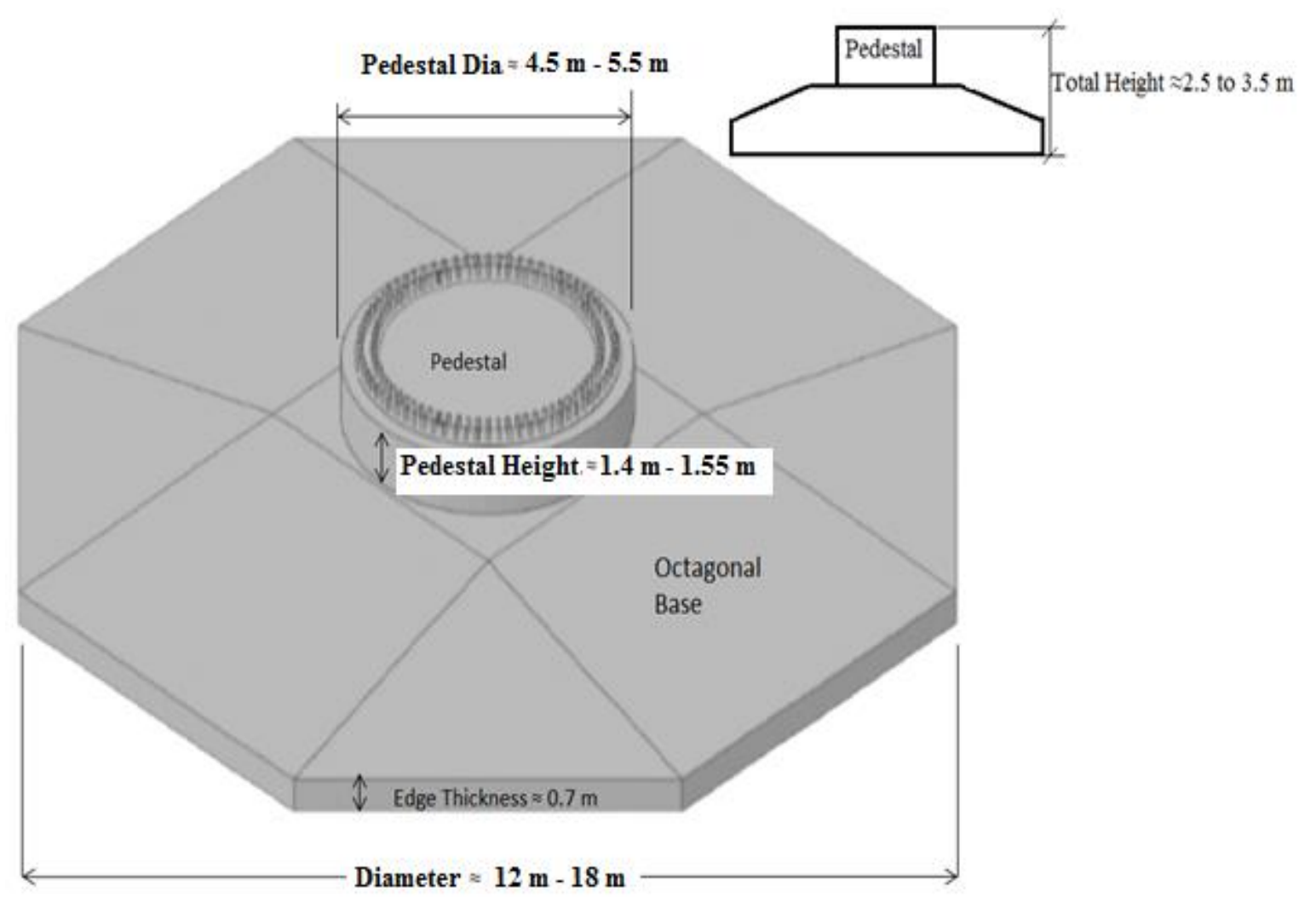

FIG. 2.2 Typical shallow octagonal foundation dimensions (adapted from Lang, 2012).

\subsubsection{Short Piers, Rock-Socketed Piers and Rock Anchor Foundations}

There are several foundation alternatives (to the shallow gravity-based option) to support WTGs. A rock-socketed pier is one of these foundation alternatives. Short piers and rocksocketed piers are mostly used when a competent soil layer exists at near the surface. Typically, rock-socketed piers support the structures by using end bearing, wall friction, and lateral earth bearing pressures (Morgan and Ntambakwa 2008).

Depending upon the geological conditions in the field, stiff bedrock may be located at shallow depth. In such cases, rock anchor foundations may be considered as an alternative WTG 
design. These foundations resist the loads throughout bearing pressure beneath the cap at the bearing layer and with steel reinforcement bars in tension (Morgan and Ntambakwa 2008). Loads are transferred from the structure to the bedrock through the anchors.

\subsubsection{Deep Pile Foundations}

Piles are mostly vertical (possibly slightly inclined) foundation members, having smaller cross-section area than shallow gravity-based foundations (Figure 2.3). These foundation types are used to transfer loads from the structure to a deeper, competent soil layer. Depending on field conditions and soil properties, deep foundations may be preferred. Deep foundation applications include sites with high ground water level, offshore construction, and sites with potential differential settlement. Additionally, deep pile foundation may be preferred when a reliable bearing layer exists at greater depth (Winterkorn and Fang 1975). According to the Morgan and Ntambakwa (2008), piles transfer forces and loads via friction and end bearing mechanisms; furthermore, piles also resist lateral. 

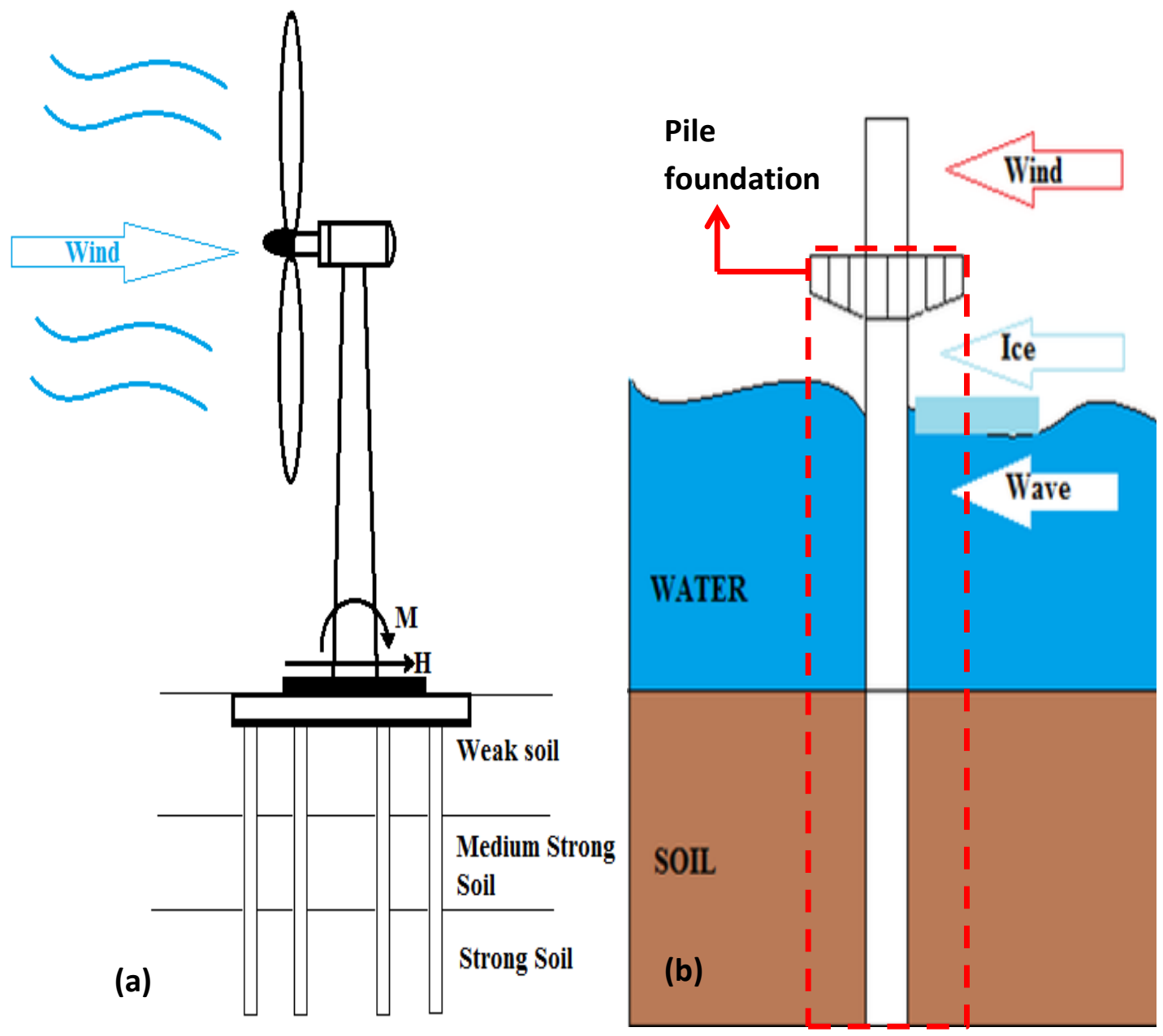

FIG. 2.3 Deep pile foundations for onshore (a) and offshore (b) applications.

\subsubsection{Tensionless Pier Wind Turbine Foundation (Patrick and Henderson Tensionless}

Pier)

Tensionless Patrick and Henderson (P\&H) Pier foundations typically consist of a large, hollow, columnar, monopole pier and backfill (Figure 2.3c). P\&H foundations can be used for deep foundation applications depending on the bedrock location under the surface. The mechanical behavior of the tensionless $\mathrm{P} \& \mathrm{H}$ foundations when exposed to horizontal loads is different than a spread foundation. The P\&H foundation type resists horizontal loads through soil located around the pier instead of friction at the footing base. Typically, tensionless P\&H piers 
vary from $8 \mathrm{~m}$ to $12 \mathrm{~m}$ and $4.5 \mathrm{~m}$ to $5.5 \mathrm{~m}$ in pier length and diameter, respectively (Tinjum and Christensen 2010).

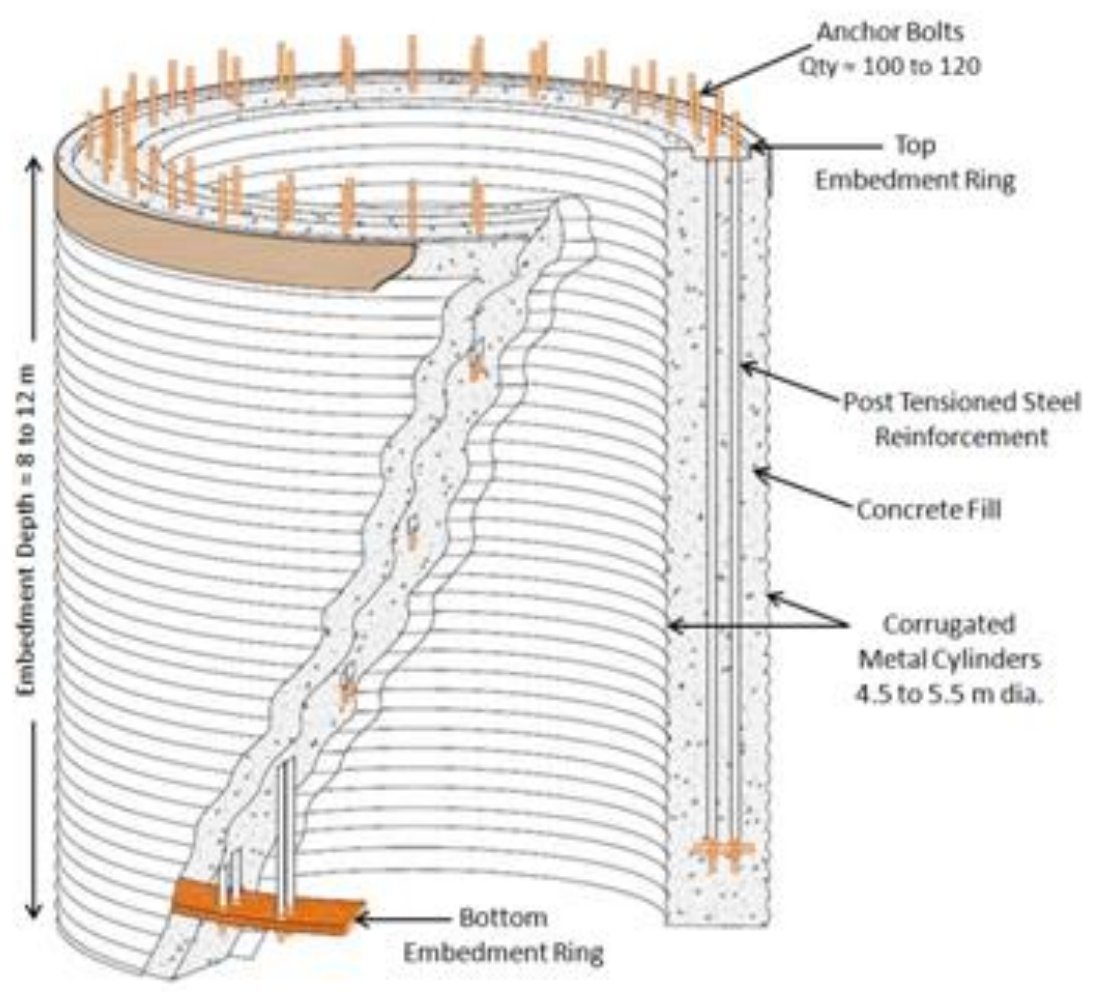

FIG. 2.3c Tensionless Pier (Lang 2012).

\subsection{Driving Forces on Wind Turbine Generators}

Wind turbines are exposed to several loads that may be eccentric, temporal (i.e., timevarying horizontal wind loads), or permanent. Driving forces consist of vertical structure weight, backfill, lateral wind, seismic, ice, mechanical, and operational loads (IEC 61400 2005). These loads play a significant role on WTG foundation design. Ice and seismic loads are mostly considered depending on the seasonal and seismic conditions of the WTG construction site.

\subsection{Design Path for Wind Turbine Generator Foundation}

Wind turbine foundation design consists of many stages and steps. These steps are summarized in a flowchart shown as Figure 2.5. The load document presents extreme and 
operating vertical and horizontal loads, moment, and stiffness requirements. The load document depends on the wind regime at the site and turbine type. A geotechnical field report presents the expected soil properties such as specific gravity, unit weight, Atterberg limits, and shear wave velocity. Given the design loads and soil properties, design checks (e.g., rotational stiffness, bearing capacity, overturning) are performed. In addition, available on- or near-site soil data such as soil borings or geophysical test outputs are reviewed before the construction of WTGs (API 2005).

\section{Wind Turbine Foundation Design Flowchart}

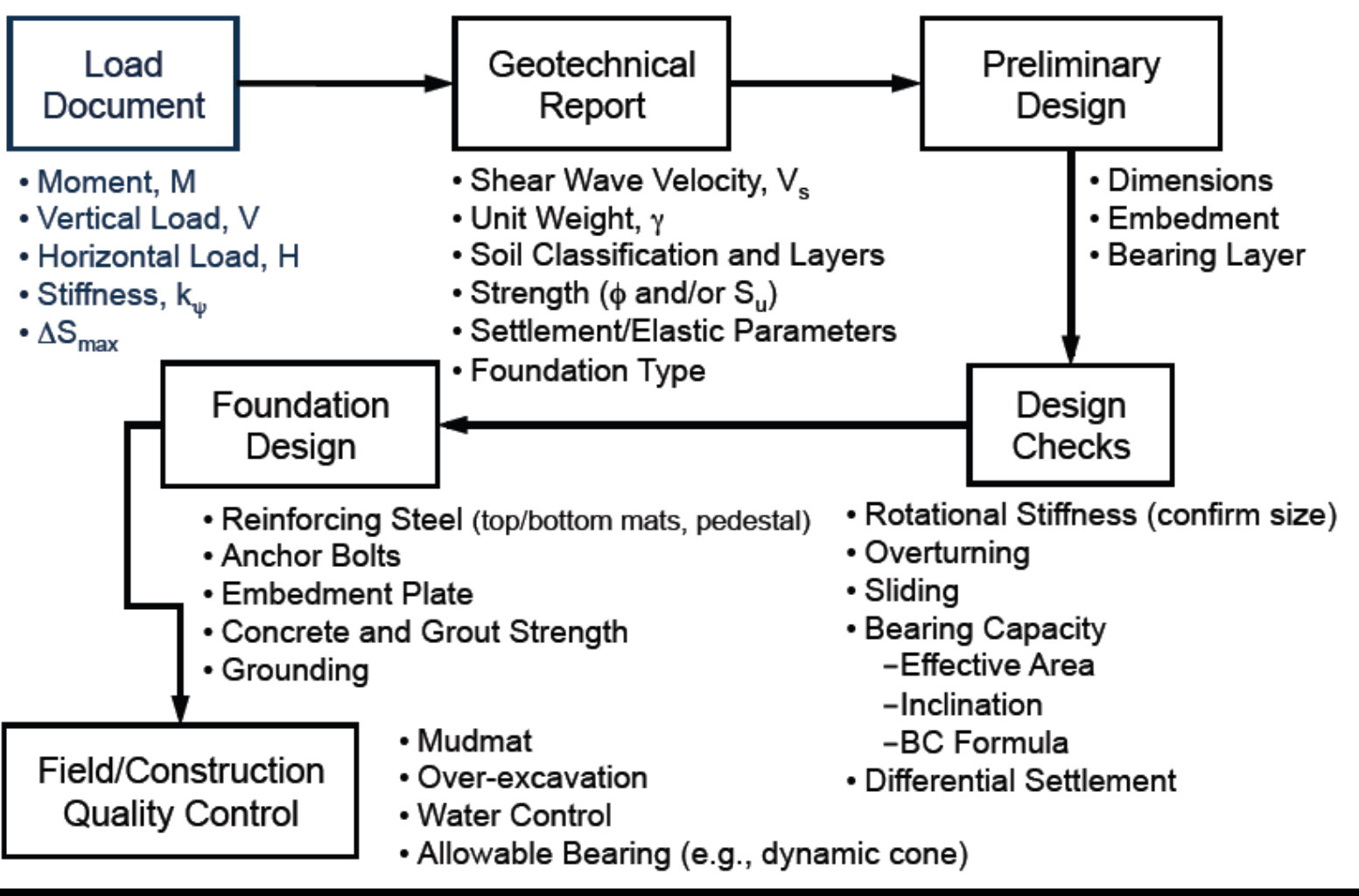

FIG. 2.4 Wind Turbine Foundation Design Path (Tinjum and Lang 2012).

\subsection{Wind Turbine Control and Blade Aerodynamics}

Wind turbine control mechanisms are highly relevant to blade aerodynamics. Differential wind velocities flow over each side of the blade and create a rotation of the WTG rotor. This 
blade rotation affects wind speed as it flows over the blade. The wind speed caused by rotation of the blades, and meteorological wind, are both considered as apparent (total) wind speed in blade aerodynamic calculations. Total wind speed creates lift and drag forces on a blade. The lift and drag components are evaluated in terms of thrust and torque (Gurit 2012). Lift emerges when a moving stream of fluid is redirected by a solid object. Flow is directed in one direction and the lift is generated in the opposite direction according to the Newton's third Law. Lift is a mechanical force and generated by the fluid interacting with the solid body (blade). In blade aerodynamics, lift force may be explained by the velocity difference between the blade and fluid, and this velocity difference creates differential pressure. Higher pressure beneath the blade causes a lifting force and rotates the rotor. There must be motion between the object and fluid for lift.

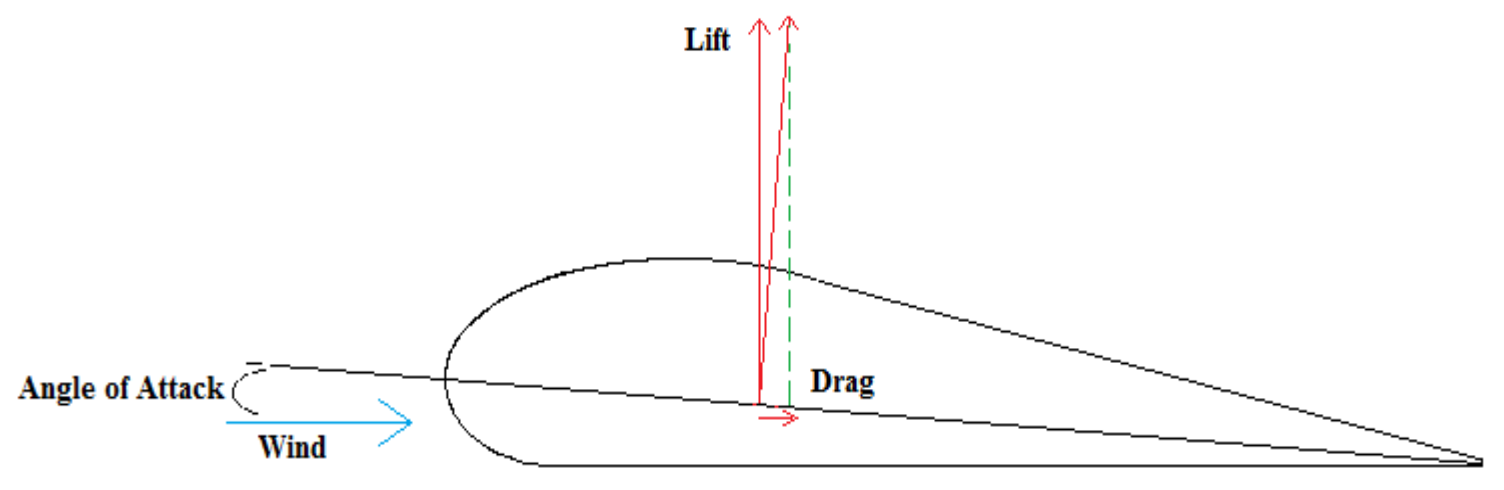

\section{FIG. 2.5 Lift and Drag Vectors.}

Typically, power is generated from the torque that originates from lift forces on the rotor set. Thrust is expressed parallel to the axis of the WTG rotor. Several types of turbines with different blade types have emerged through the years. Today, the most common blade is shaped to maximize the energy harvested from the wind that ideally approaches the Betz limit (i.e., the maximum theoretical extraction efficiency of 16/27, Figure 2.6) (Schubell and Crossley 2012). 


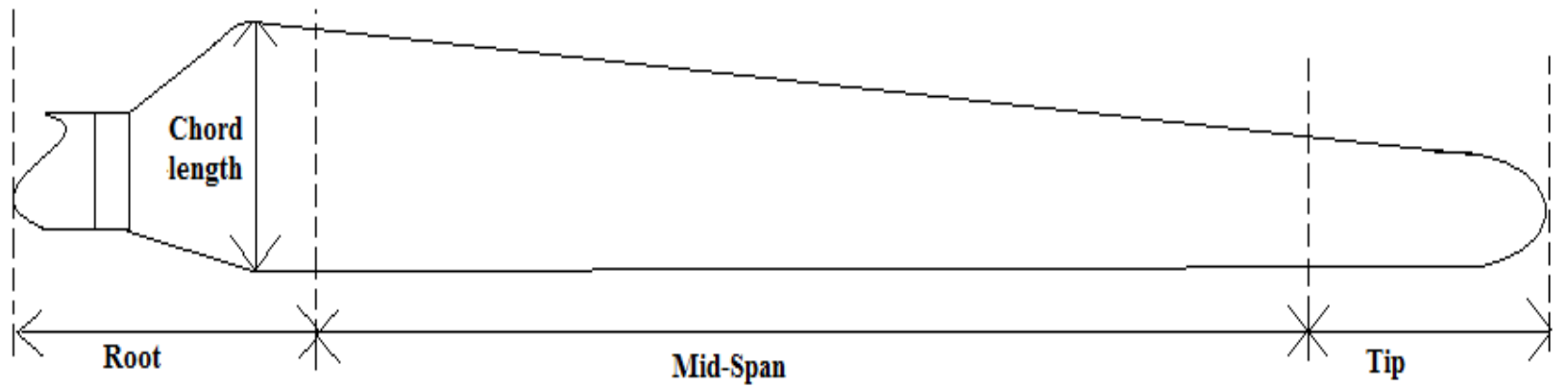

FIG. 2.6 A typical blade plan and regions (adapted from Schubell and Crossley 2012).

Worst-case scenarios are considered in WTG blade design (Gasch and Twele 2002, Schubell and Crossley 2012). For small-scale turbines (D < $70 \mathrm{~m}$ ), extreme wind conditions are evaluated as the worst-case scenario; on the other hand, in large-scale turbines blade design (D > $70 \mathrm{~m}$ ) the mass of the turbine is considered (Gasch and Twele 2002, Schubell and Crossley 2012). Multiple loading scenarios are evaluated in blade design:

- emergency stop conditions (Ahlstrom 2006, Schubell and Crossley 2012)

- extreme load (wind) conditions for in-service turbines (Burton et al. 2011, Schubell and Crossley 2012)

- parked, 50-year storm conditions (Kong et al. 2005, Schubell and Crossley 2012)

In addition, different loading scenarios are analyzed under the following load types (Burton et al. 2011, Schubell and Crossley 2012):

- aerodynamic loads

- gravitational and centrifugal loads

- gyroscopic loads

- operational loads.

Large-scale turbines have pitch control that provides an appropriate angle for the blades against oncoming wind force. The turbine control system automatically adjusts the blade angle 
depending on operative wind speed. An increase in wind speed results in an increase in angle of attack. The increase in the angle of attack continues until reaching the most suitable angle that yields the most energy from the wind.

\subsection{Wind Turbine Loading}

Shallow WTG foundation analysis is unique due to untraditional dynamic loading conditions. The loads act horizontally and vertically and create overturning moment and load eccentricity. Vertical loads include the turbine components, steel tower, concrete foundation mass, steel reinforcement, and backfill. Horizontal loads, on the other hand, consist of wind loads which vary greatly depending on wind speed and direction. These loads must be transmitted and resisted by the foundation.

Wind turbines and their foundations are designed for different loading cases such as assembly, maintenance, start-up, operation, shutdown, and emergency situations (IEC 2005). Incipient wind varies temporally. Extreme horizontal loads are transferred as increasing moment to the foundation. Thus, wind regimes are evaluated under normal and extreme conditions for load. Table 2.1 gives the specifications for various wind turbine classes with respect to reference velocity and turbulence (IEC 2005). The International Electrotechnical Commission separates wind turbines into three classes (I to III) based on reference wind speed $\left(V_{f}\right)$, with the A-C designation based on the turbulence.

Table 2.1 Turbine Classes (IEC 2005)

\begin{tabular}{|c|c|c|c|c|c|}
\hline Wi & e class & I & II & III & $\mathbf{s}$ \\
\hline$V_{\text {ref }}$ & $(\mathrm{m} / \mathrm{s})$ & 50 & 42.5 & 37.5 & Values \\
\hline A & $I_{\text {ref }}(-)$ & \multicolumn{3}{|c|}{0.16} & specified \\
\hline B & $I_{\text {ref }}(-)$ & \multicolumn{3}{|c|}{0.14} & by the \\
\hline C & $I_{\text {ref }}(-)$ & \multicolumn{3}{|c|}{0.12} & designer \\
\hline
\end{tabular}


The wind speed distribution plays a significant role on the frequency of occurrence of the load conditions. In normal design conditions, a Rayleigh distribution, with the assumption of mean value of wind speed over a time period $10 \mathrm{~min}$, is given by:

$$
P_{R}\left(V_{h u b}\right)=1-\exp \left[-\pi\left(V_{\text {hub }} / 2 V_{a v e}\right)^{2}\right]
$$

where $\mathrm{V}_{\mathrm{ave}}=0.2 \mathrm{~V}_{\text {ref }}$

The normal wind profile model is expressed as a function of elevation from the earth surface, $\mathrm{z}$, using the power:

$$
V_{(z)}=V_{h u b}\left(z / z_{h u b}\right)^{\alpha}
$$

Wind turbine design considers extreme wind conditions with against very high wind loadings. Wind models are applicable for steady or turbulent conditions and they can be used for the determination of extreme wind speed of 1-year and 50-year return periods.

\section{$\underline{\text { Steady Conditions: }}$}

In the steady extreme wind model, tolerance for short-term deviations from the mean wind direction is made by assuming yaw diversion in the variety of $\pm 15^{\circ}$.

Reoccurrence period of 50 years: $V_{e[\text { steady }]}(z)=1.4 V_{\text {ref }}\left(\frac{z}{z_{\text {hub }}}\right)^{0.11}$

Reoccurrence period of 1 year: $V_{e[s t e a d y]}(z)=0.8 x V_{e 50}(z)$

\section{Turbulent Conditions:}

For the turbulent extreme wind speed model, 10-min average wind speed can be calculated by using the following equations. The 10-min average wind speed can be calculated with 50-year and 1-year reoccurrence periods as a function of $z$.

Reoccurrence period of 50 years: $V_{[\text {turbulent }]}(z)=V_{\text {ref }}\left(\frac{z}{z_{\text {hub }}}\right)^{0.11}$

Reoccurrence period of 1 year: $V_{[s t e a d y]}(z)=0.8 x V_{50}(z)$ 
Wind speed distribution and different wind conditions are important to WTG foundation design and play a significant role for determination of the frequency of occurrence of individual load conditions for the design situations (IEC 2005). The extreme and normal wind moment, moment, shear, and vertical forces are determined by using computer simulation with site conditions and turbine type due to complexity of these parameters (Bonnett 2005).

\subsection{Bearing Capacity}

Bearing capacity is the resistive capacity of the soil formation against the applied load. Bearing pressure may be defined as the maximum contact pressure between foundation and soil before failure. There are several methods to determine the bearing capacity of the soil such as limit equilibrium, slip-line or finite element methods. Bearing capacity of a footing depends on the physical characteristics of a footing (e.g., length, depth, etc.) and mechanical properties of soil formations.

Terzaghi (1943) expanded the limit equilibrium theory from two model tests (see Equation 2.7-2.8) for continuous circular and square footings.

$$
\begin{aligned}
& q_{u l t}=1.3 c^{\prime} N_{c}+\sigma_{z D}^{\prime} N_{q}+0.4 \gamma^{\prime} B N_{\gamma} \quad \text { (Square) } \\
& q_{u l t}=1.3 c^{\prime} N_{c}+\sigma_{z D}^{\prime} N_{q}+0.3 \gamma^{\prime} B N_{\gamma} \text { (Circular) }
\end{aligned}
$$

where $\mathrm{q}$ is bearing capacity, $\gamma^{\prime}$ is effective unit weight, $\sigma_{z D}^{\prime}$ is unit surcharge, c' is cohesion, and $\mathrm{N}_{\mathrm{q}}, \mathrm{N}_{\mathrm{c}}$, and $N_{\gamma}$ are bearing capacity factors.

A reduced footing area is incorporated in calculations of the bearing capacity under eccentric loads. Figure 2.7 summarizes the reduced area locations for rectangular and circular 
footings. Typically, bearing capacity increases cause a decrease in eccentricity, that can be defined as distance from the center of the foundation to the load center (Schubert 2013)

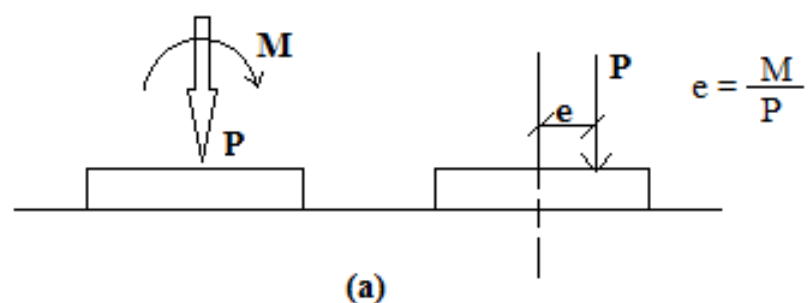

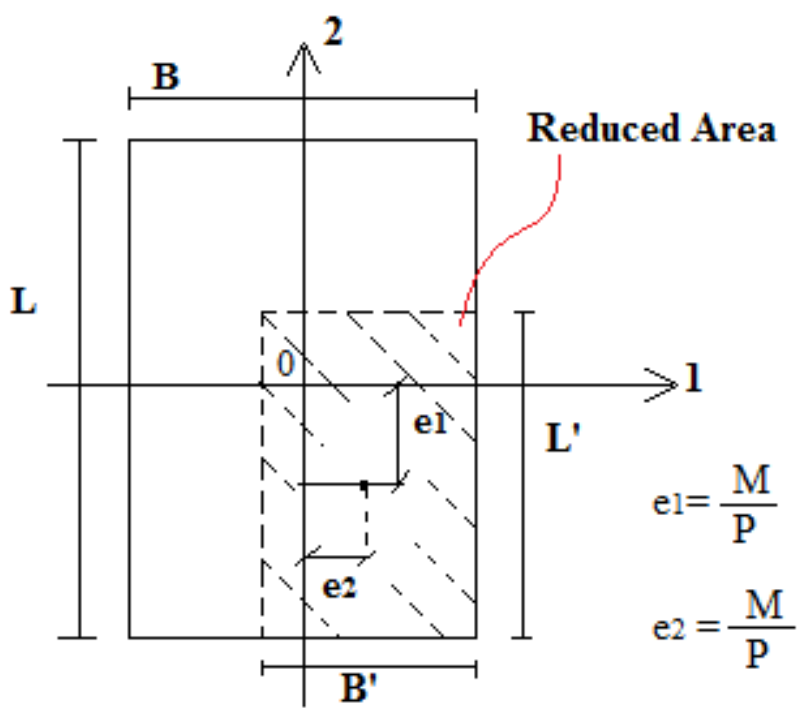

(b)

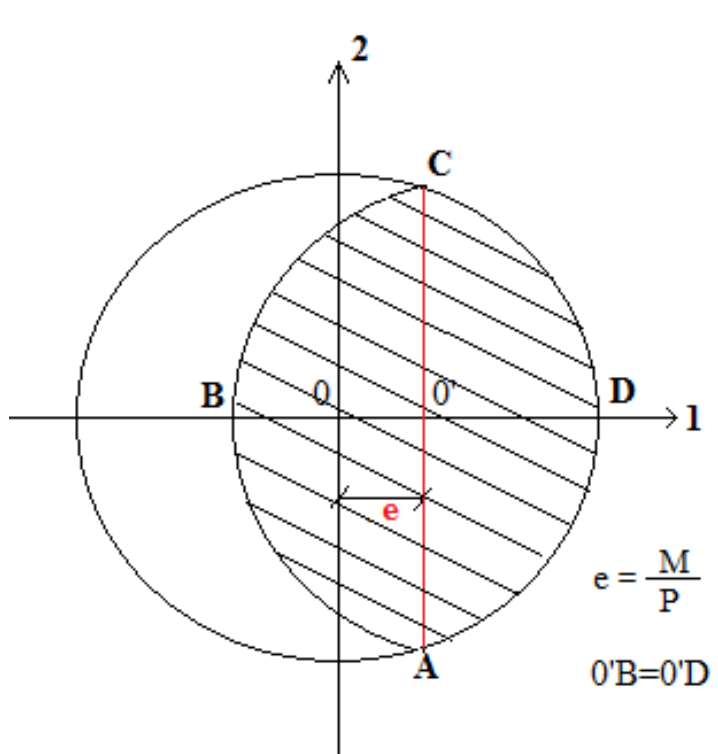

(c)

FIG. 2.7 Reduced footing area for eccentric loads (adapted from API 1987, Fang 1991) (a)

Equivalent loadings. (b) Reduced area- rectangular footing and (c) circular footing.

\subsection{Rotational Stiffness}

Wind turbine generators are placed on tall towers $(\geq 80 \mathrm{~m})$ with a high center of gravity. The wind loads on the WTG structure create large overturning moments that risk displacing the center of gravity of the system dangerously far from equilibrium. This displacement also adds stress into the system and could lead to tower buckling (IEC 2005). The rotational stiffness of the 
foundation and soil beneath the foundation prevents this type of failure from occurring. The rotational stiffness controls the amount of rotation the WTG system undergoes about the horizontal axes. For a rigid circular foundation resting on an elastic half-space subjected to rocking motion, Richart et al. (1970) provides the following equation for rotational stiffness, $k$ :

$$
k_{\psi}=\frac{8 G r^{3}}{3(1-v)}=\frac{M}{\theta}
$$

where $\mathrm{G}$ is the shear modulus, $\mathrm{r}$ is the radius of the foundation, $\mathrm{M}$ is the applied moment, and $\theta$ is the angle of rotation in radians. Det Norske Veritas (2002) extends the equation of rotational stiffness for soil over bedrock as:

$$
k_{\psi}=k_{\psi, R H W}\left(1+\frac{r}{6 h}\right)
$$

where $\mathrm{k}_{\psi, \text { RHW }}$ is the Richart-Hall-Woods parameter (Richart et al. 1970) and $\mathrm{h}$ is the thickness of the soil layer. Various modifications to the equation for two-layer infinite half-space and embedment in soil over bedrock are also available (Det Norske Veritas 2002). Table 2.2 shows similar equations for varying geometrical scenarios.

Table 2.2 Rotational Stiffness Equations (DNV/Risø 2002)

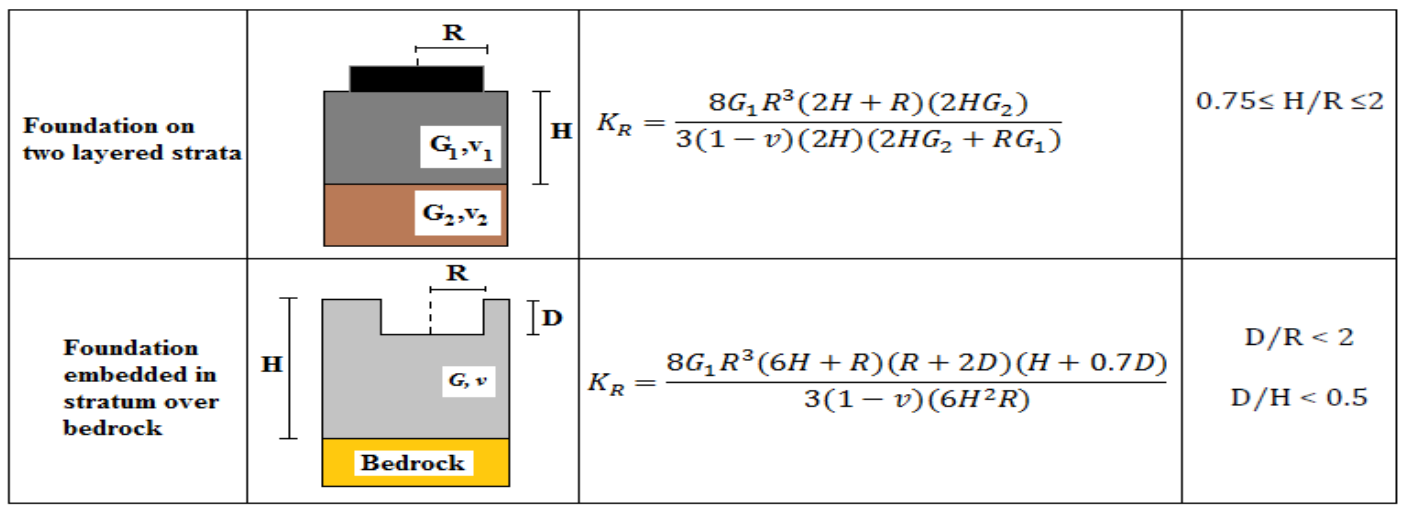

The key soil parameter in the stiffness equations is the shear modulus. Det Norske Veritas (2002) provides a methodology for estimating the shear modulus from empirical 
correlations with void ratio and overconsolidation ratio, undrained shear strength (for saturated fine-grained soil), or relative density (for coarse-grained soil). Shear modulus is typically obtained from seismic methods (Tinjum and Christensen 2010). These methods measure the shear modulus at very small strain and this value is designated as $\mathrm{G}_{\mathrm{o}}$; however, operational shear modulus decreases with increasing strain levels. For example, Det Norske Veritas (2002) proposes shear strain levels expected for dynamic soil loading induced by earthquakes, rotating machines, and wind and ocean waves:

- Earthquakes - large strains $(\geq 1 \%)$

- Rotating machines - small strains $\left(<10^{-3} \%\right)$

- Wind and ocean waves - moderate strains (<1\%, typically $0.1 \%)$

However, Det Norske Veritas (2002) gives no reference to support the listed shear strain values. A small variation in the cyclic shear strain could greatly impact the value of the shear modulus used in WTG foundation stiffness calculations (Tinjum and Lang 2012).

Pressure

\subsection{Pressure Distribution under the Footings}

Stress transfer to the foundation soil depends on the foundation radius, total vertical load, eccentricity, and the method used to determine the pressure distribution. The main simplified models concerning the bearing pressures produced by overturning moments are to vary the pressure: (1) linearly across the foundation base (Figure 2.8a) or (2) variably across an effective bearing area (Figure 2.8b-d). Det Norske Veritas (2002) recommends the use of a uniform pressure distribution applied over an oval-shaped effective area that is offset from the center by the system eccentricity, albeit without providing supporting theory. Meyerhof (1953) states that the simplest solution to the bearing pressure distribution is to assume this uniform distribution 
over an effective loading area, which supports Det Norske Veritas (2002)'s approach, but Meyerhof (1953) made this recommendation based on static loading and did not consider the dynamic loading conditions nor the non-uniform distribution of strain present under WTG foundation systems. Alternative to the uniform pressure distribution, the bearing pressure can be represented by a triangular pressure distribution. Based on approaches suggested by Meyerhof (1953), a triangular pressure distribution underneath a foundation for a system with an eccentricity $<\mathrm{B} / 6$ (Figure 2.8a), where $\mathrm{B}$ is the geometric diameter of the foundation at the base, and for a foundation system with e $>\mathrm{B} / 6$ (Figure 2.8b). However, the high edge pressures do not likely occur as depicted in Figure 2.8b. In coarse-grained soils, the stiffness is proportional to the applied overburden pressure. Because of this, the near surface soil has low stiffness and strength and would not support the high edge pressure. In fine-grained, softer soil, if the maximum edge pressure is reached, the pressure will be distributed inward until equilibrium is achieved. Furthermore, the linearity of the pressure distribution is not likely consistent across subgrades of differing stiffness (Figure 2.8d). 
(a)

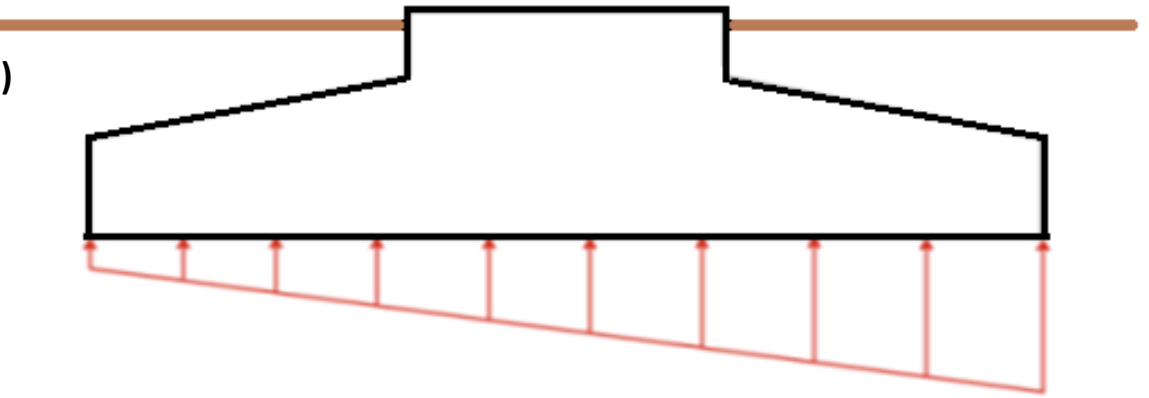

(b)

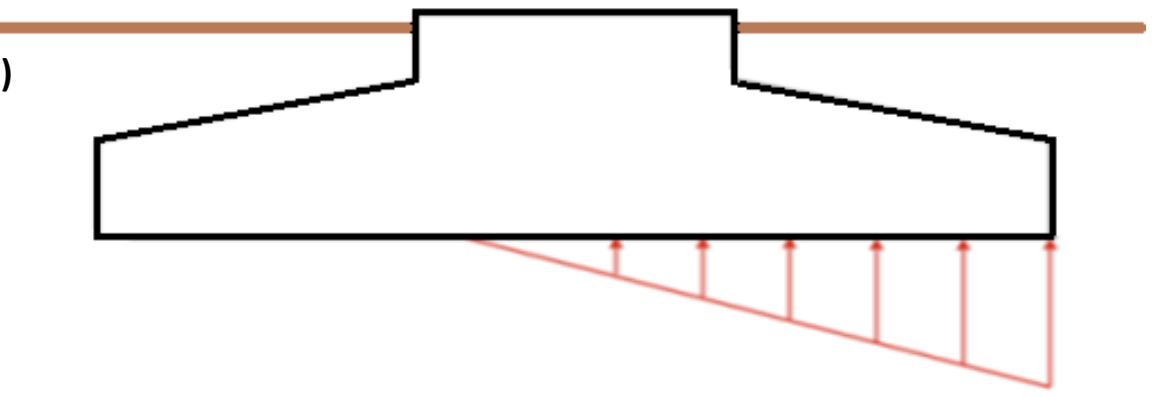

(c)

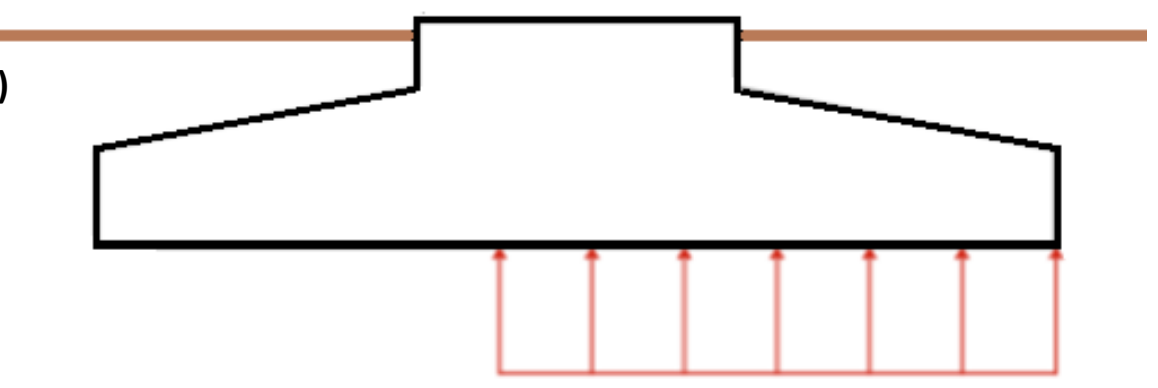

(d)

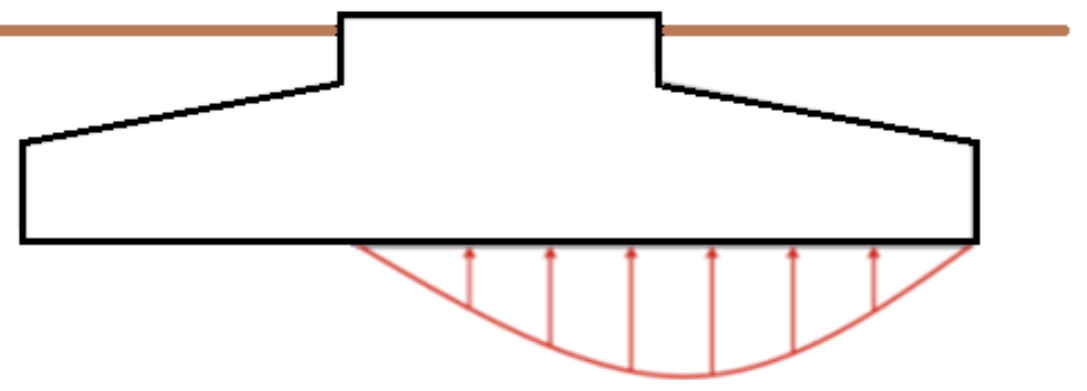

FIG. 2.8 Hypothetical pressure distribution scenarios for a WTG foundation under eccentric loading: (a) linear across the full base, (b) linear across an effective area, (c) uniform across an effective area, and (d) variable across an effective area. 
As in the case of most foundation systems, settlement in WTG foundations may occur as a result of compression of the underlying soil. In coarse-grained soil, simple settlement analysis could be done using a Schmertmann-type procedure (Schmertmann 1970, Schmertmann et al. 1978) or some other form of 'elastic' analysis. Other than the elastic half-space analysis, the methods are incremental, allowing the compressibility of soil layers within the zone of influence of the foundation to be incorporated into the analysis. However, this zone of influence has not been characterized, measured, or field-verified for the highly eccentric, cyclic, and time dependent-direction loads present in WTG.

In centrally loaded foundations, contact pressure distribution and settlement of foundation for rigid and flexible loaded areas may exhibit differential behaviors depending on the soil properties. Depending upon the elastic medium, Equation 2.11 has been developed (Jumikis 1969, Balaknishna et. al 1992):

$$
p_{e}(r)=\frac{P}{2 \pi a^{2} \sqrt{\left[1-(r / a)^{2}\right]}} \quad \text { (Circular) }
$$

where $\mathrm{a}$ is radius of footing, $\mathrm{r}$ is radial distance of point from center, $p_{e}=$ distributed load, and $\mathrm{P}$ is total load on footing. Likewise, pressure distribution could be determined by using the Equation 2.12 for strip footings:

$$
p_{e}(r)=\frac{P}{2 \pi b^{2} \sqrt{\left[1-(x / b)^{2}\right]}} \quad(\text { Strip })
$$

where $\mathrm{b}$ is the width of footing, and $\mathrm{x}$ is distance from the center line of the footing.

The contact pressure distributions under footings may be relatively non-uniform as is seen from Figure 2.9. In the case of fine grained soil, the stress is infinite at the outer edge of the rigid foundation. However, in reality, pressure is limited by the shear strength of the soil (Fang 1991) (Figure 2.9a). Coarse grained soil, on the other hand, exhibits different behavior under the 
vertical load. The pressure is less at the outer edge due to the confinement (Fang 1991). Pressure is higher at the center of the footing in coarse-grained soil, as shown in Figure 2.9b.

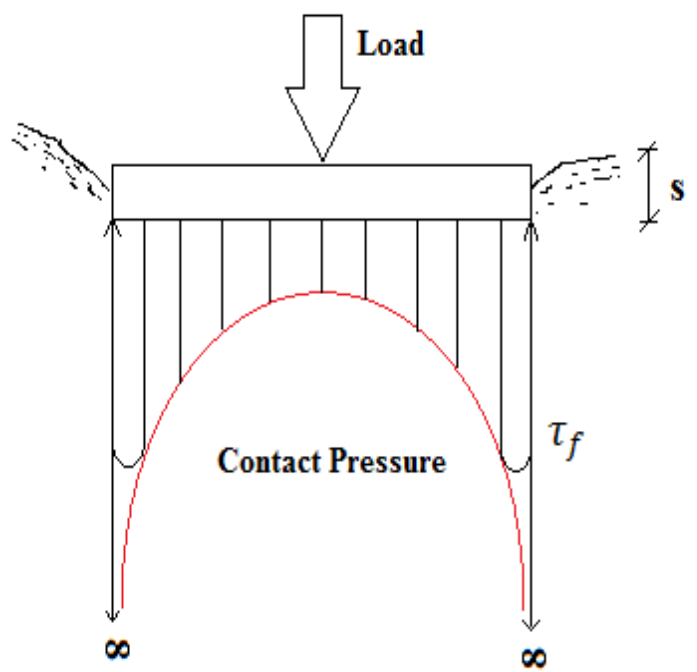

(a)

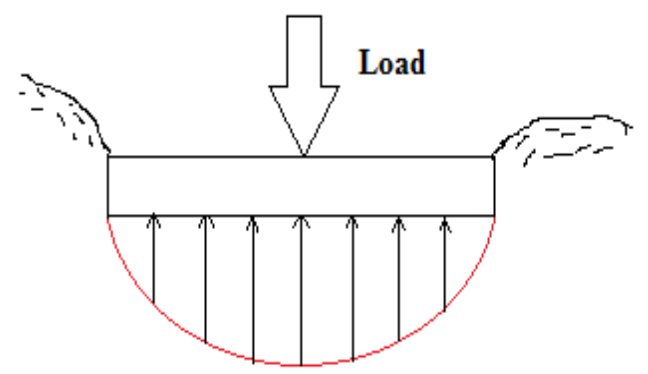

(b)

FIG. 2.9 Contact pressure distribution for rigid areas on (a) fine-grained (cohesive) and (b) coarse grained (cohesionless) soils.

\subsection{Distribution of Stress Depending on Depth}

Applied vertical load causes an increase in stress in the underlying soil layers. This phenomenon is important in settlement analysis because settlement varies proportionally to applied, realized stress. Typically, the influence factor, $I_{\sigma}$, decreases (which designates the ratio of applied vertical stress to the actual increase in stress at a point in the underlying soil) with increase in depth. Stress redistributes over a larger area as the depth increases. There are multiple methods to determine the stress distribution beneath foundations, such as a 2:1 approximation, Boussinesq distribution, or Westergaard method. 


\subsection{1 (2:1) Approximation or $6^{\circ}$ Stress Distribution}

A 2:1 approximation is one of the most common methods to determine stress distribution under foundations. The method is simply based applied stress propagation downward at the 2:1 ratio vertically. Stress dissipates in the form of a trapezoid with $60^{\circ} \theta$ inclined sides from the vertical as shown in Figure 2.10.
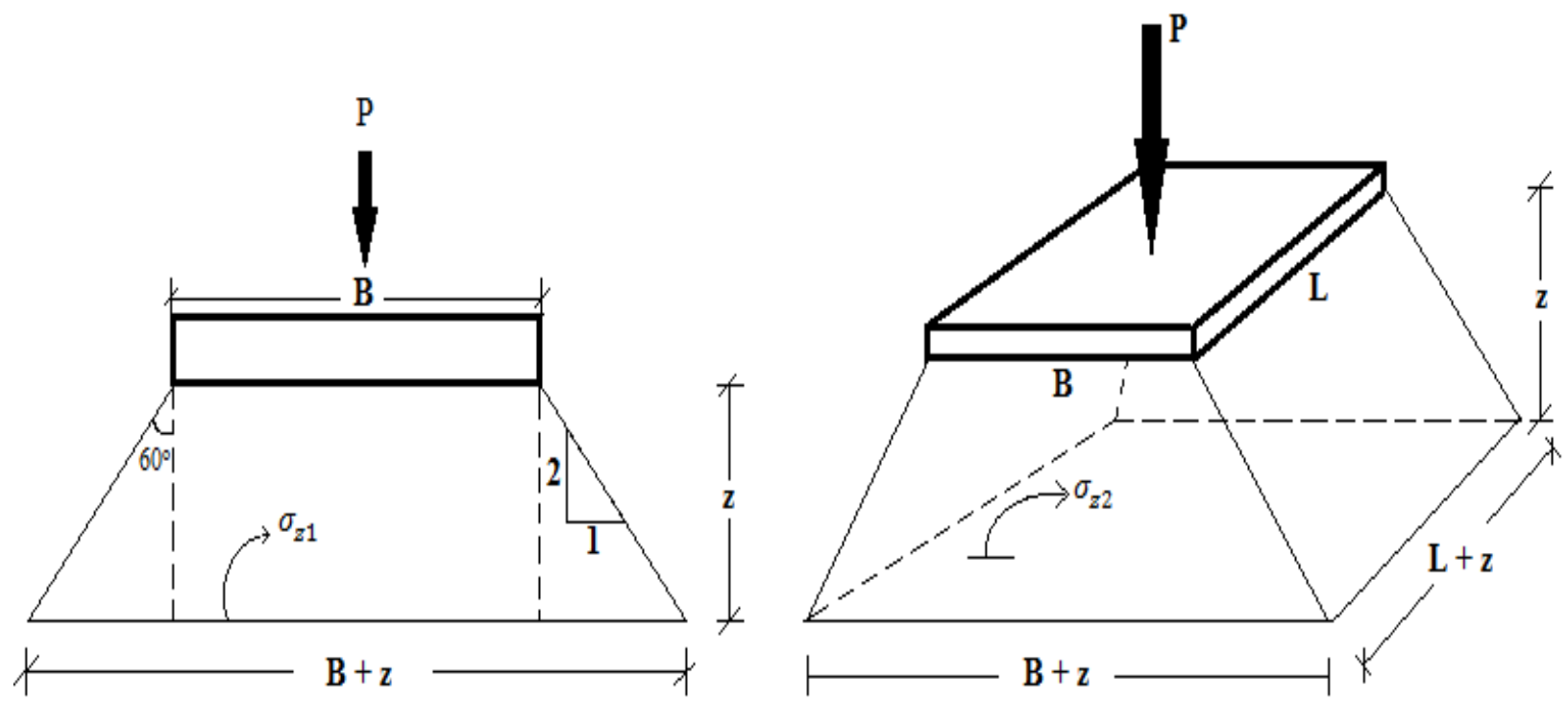

FIG. 2.10 (2:1) $6^{\circ}$ Approximation method for vertical pressure distribution.

Applied stress is equal to the ratio of the applied load (P) to width of the footing (B). In this sense, vertical stresses can be determined as:

$$
\begin{aligned}
\sigma_{z 1} & =\frac{P}{B+z} \\
\sigma_{z 2} & =\frac{P}{(B+z)+(L+z)}
\end{aligned}
$$

where $\sigma_{z 1 \text { and } 2}$ are vertical stress increases $\left(\sigma_{z 1}\right.$ is for continuous footings and $\sigma_{z 2}$ is for rectangular footings), $\mathrm{P}$ is applied load, $\mathrm{B}$ is width, $\mathrm{L}$ is length, and $\mathrm{z}$ is depth. In reality, the exact stress distribution is slightly different from approximate distribution approaches. In 
particular, the pressure concentration is generally higher at the outer edge of the footing (Figure 2.11).

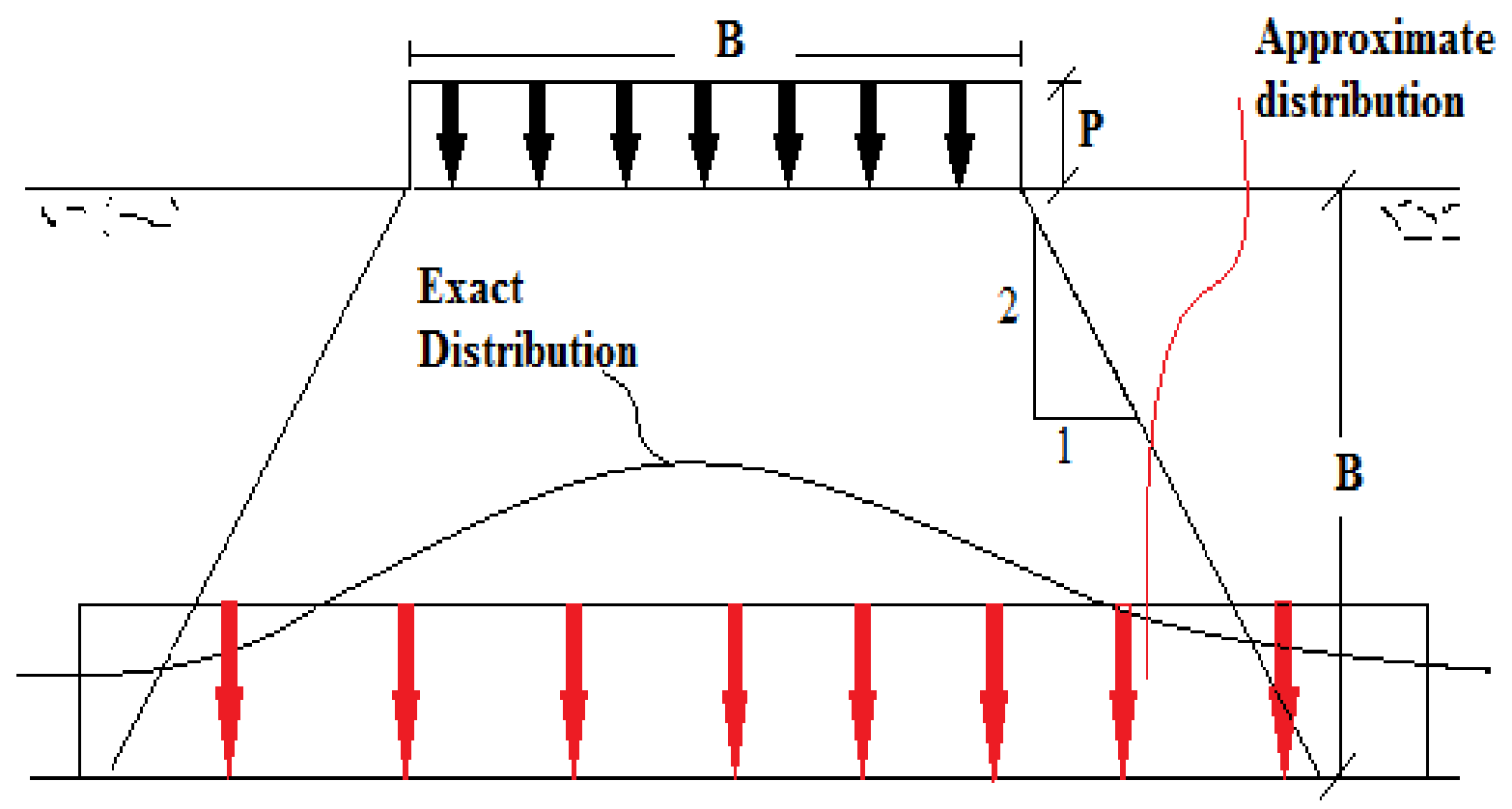

FIG. 2.11 Relationship between vertical stress below a square uniformly loaded area as determined by approximate and exact methods (from Perloff 1975, Fang 1991).

\subsubsection{Boussinesq' Stress Distribution Approach}

Another useful way to view the vertical pressure distribution is via Boussinesq' approach (1885), for uniform elastic material. In geotechnical engineering, Boussinesq' approximation allows us to estimate the stress at any point within a soil formations. Boussinesq theory requires some assumptions, including

- Elastic, semi-infinite, isotropic, homogeneous soil mass for soil formations

- Weightless soil

- A vertical point load acting on the surface. 
These assumptions may limit the validity of the theory for the foundations. Moreover, the stress distribution may change depending on different load conditions. Boussinesq presented two equations based on elastic theory. His first equation was for surface point loads:

$$
\sigma_{z}=\Delta \sigma_{v}=\frac{3 Q z^{3}}{2 \pi\left(r^{2}+z^{2}\right)^{5 / 2}}
$$

where $\mathrm{r}$ is horizontal distance between a random point A below the surface and the vertical axis through the point load $\mathrm{Q}, \mathrm{z}$ is vertical depth for point A and $\mathrm{Q}$ is applied load. Figure 2.12 represents the application of Equation 2.15 .

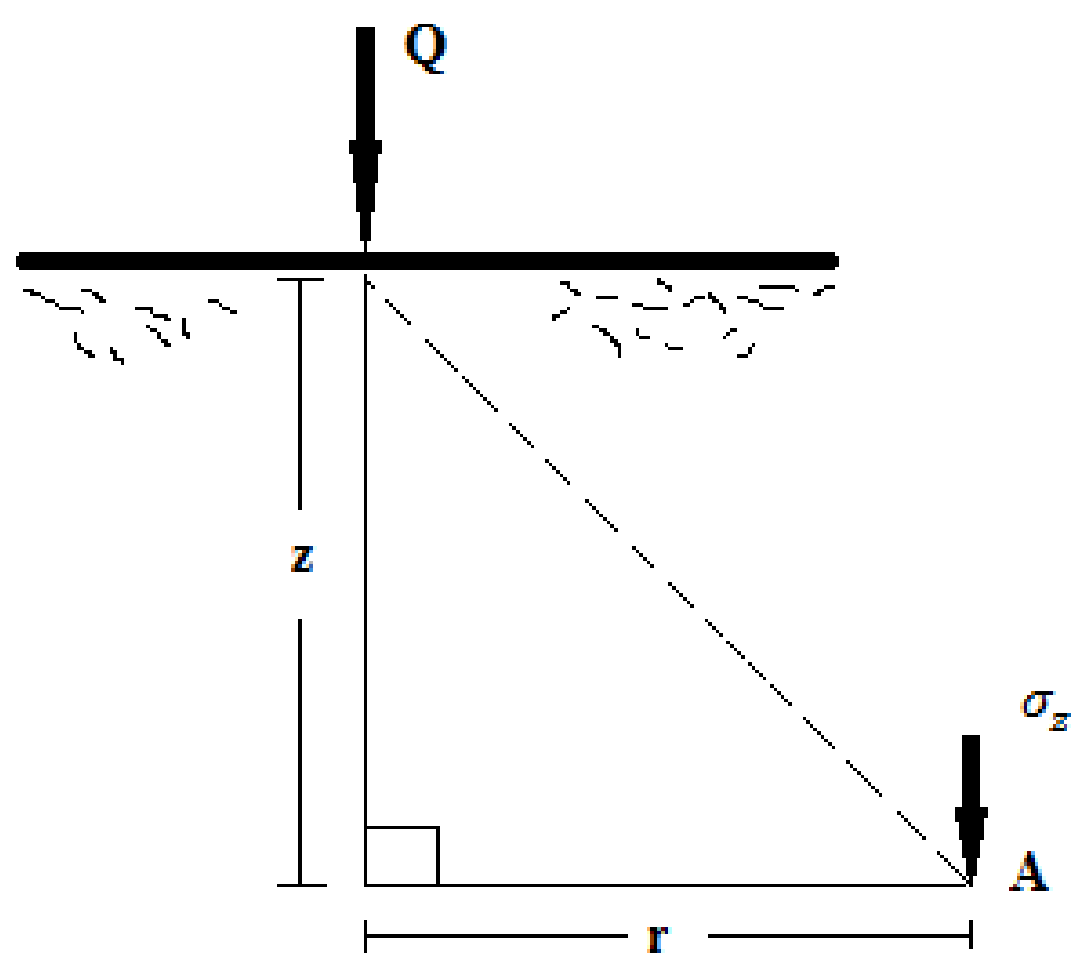

FIG. 2.12 Definition of terms for equation 2.15. 
For uniform line load conditions, the vertical stress increment can be computed from another equation at the same depth value $z$ and distance $r$ from the vertical loading axis:

$$
\sigma_{z}=\Delta \sigma_{v}=\frac{2 Q z^{3}}{\pi\left(r^{2}+z^{2}\right)^{2}}
$$

Newmark (1935) improved the applicability of stress distribution by integrating Equation 2.16. Newmark's integration provided an approximation in vertical stress increment calculation under uniformly loaded areas with the calculation based on the stress increase at a corner of an applied load (Day 1999). Based on Newmark's (1935) equation, application charts have been developed (see, for example, Figure 2.13). 


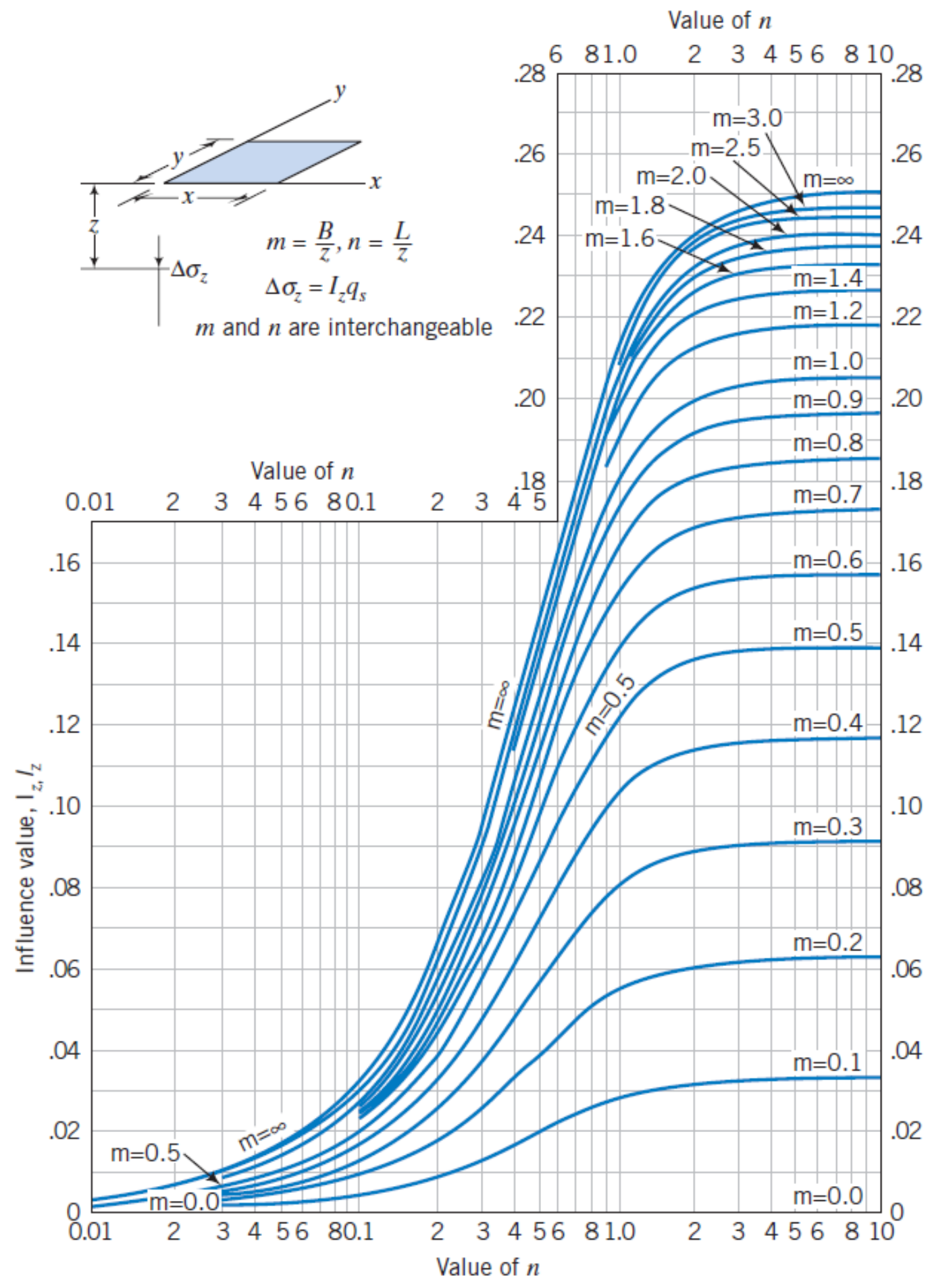

FIG. 2.13 Influence factor for calculating the vertical stress increase under the corner of a rectangle (Budhu 2007) (Original source: NAVFAC DM-7.1, 1982). 
Utilization of the chart shown in Figure 2.13 requires calculation of values for $\mathrm{m}$ and $n$, where $m$ is the ratio between width of the loaded area $B$ and depth $z$, and $n$ represent the ratio between length of the loaded area $L$ and depth $z$. From $m$ and $n$, vertical stress in terms of induced $\Delta \sigma_{z}$ is computed from the influence value.

$$
\Delta \sigma_{z}=I_{z} q_{s}
$$

Conventional pressure isobar charts have also been developed based on Boussinesq' equation. This methodology is helpful for estimating vertical pressure for circular, rectangular and square footings.

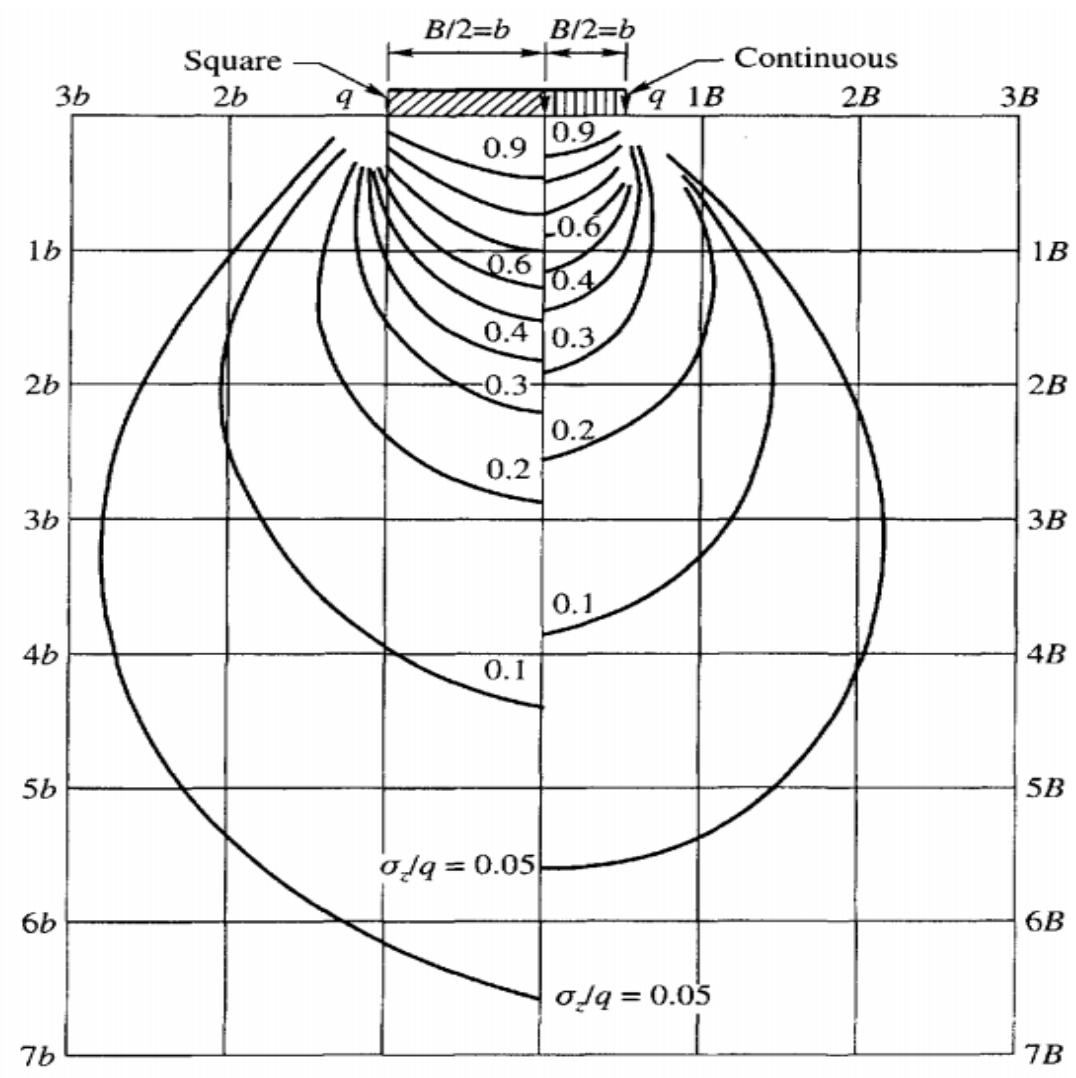

FIG. 2.14 Pressure isobars based on Boussinesq' equation for square and continuous footings (from Murthy 2003). 


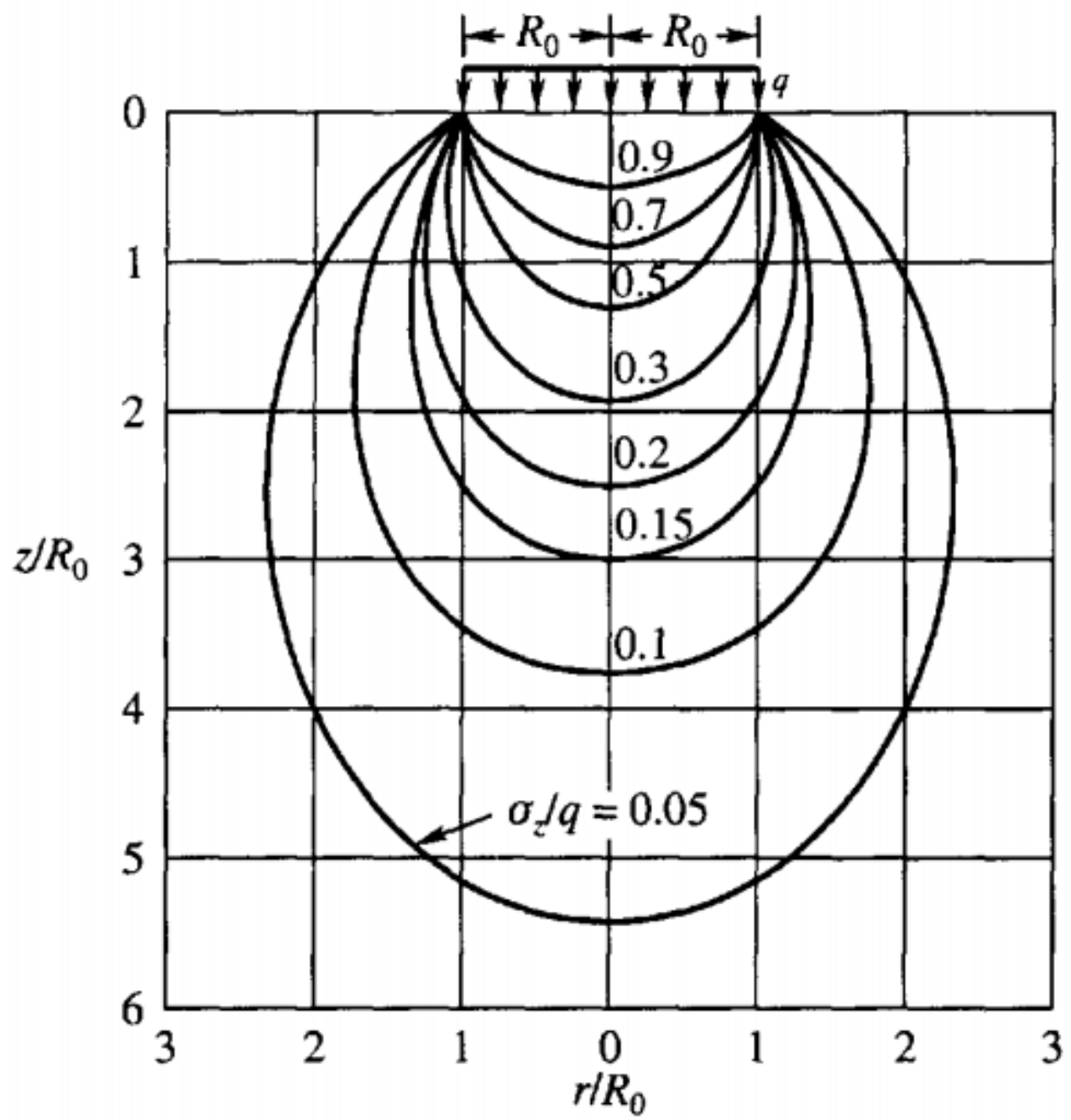

FIG. 2.15 Pressure isobars based on Boussinesq' equation for uniformly loaded circular footings (from Murthy 2003).

\subsubsection{Westergaard Solution}

Soil depositions are assumed isotropic in the Boussinesq approach; however, soil depositions are generally non-isotropic (Shroff and Shah 2003). Westergaard derived his theory from a non-isotropic soil distribution. According to the Westergaard approach, there are thin, rigid material sheets between homogenous soil deposits. These rigid sheets are assumed incompressible; therefore, only downward displacement occurs without any lateral displacement 
(Shroff and Shah 2003). Vertical stress can be computed at an arbitrary point beneath the footing by using the Westergaard equation (Shroff and Shah 2003):

$$
\begin{aligned}
& \sigma_{\mathrm{z}}=\frac{\left(\frac{\mathrm{c}}{2 \pi}\right) \cdot Q}{\left[c^{2}+\left(r / \mathrm{z}^{2}\right)\right]^{3 / 2} \cdot z^{2}} \text { in terms of } \\
& c=\sqrt{\frac{1-2 v}{2-2 v}}
\end{aligned}
$$

where $\sigma_{z}$ is vertical stress, $v$ is Poisson's ration, $Q$ is point load, $z$ is arbitrary depth under the footing, and $r$ is distance between load point axis and arbitrary selected point below the footing. For elastic materials, Poisson's ratio varies from 0 to 0.5 and, if Poisson's ratio is equal to zero, the equation for vertical stress turns to (Shroff and Shah 2003)

$$
\begin{aligned}
& \sigma_{\mathrm{z}}=\frac{\mathrm{Q}}{\pi\left[1+2\left(r / \mathrm{z}^{2}\right)\right]^{3 / 2} \cdot \mathrm{z}^{2}} \\
& \sigma_{\mathrm{z}}=K_{w} \frac{Q}{\mathrm{z}^{2}} \\
& K_{w}=\frac{1}{\pi\left[1+2\left(\mathrm{r} / \mathrm{z}^{2}\right)\right]^{3 / 2}}
\end{aligned}
$$

Pressure isobar chart developed from Westergaard's equation can be used for vertical stress evaluation of square and continuous footings (see Figure 2.16) 


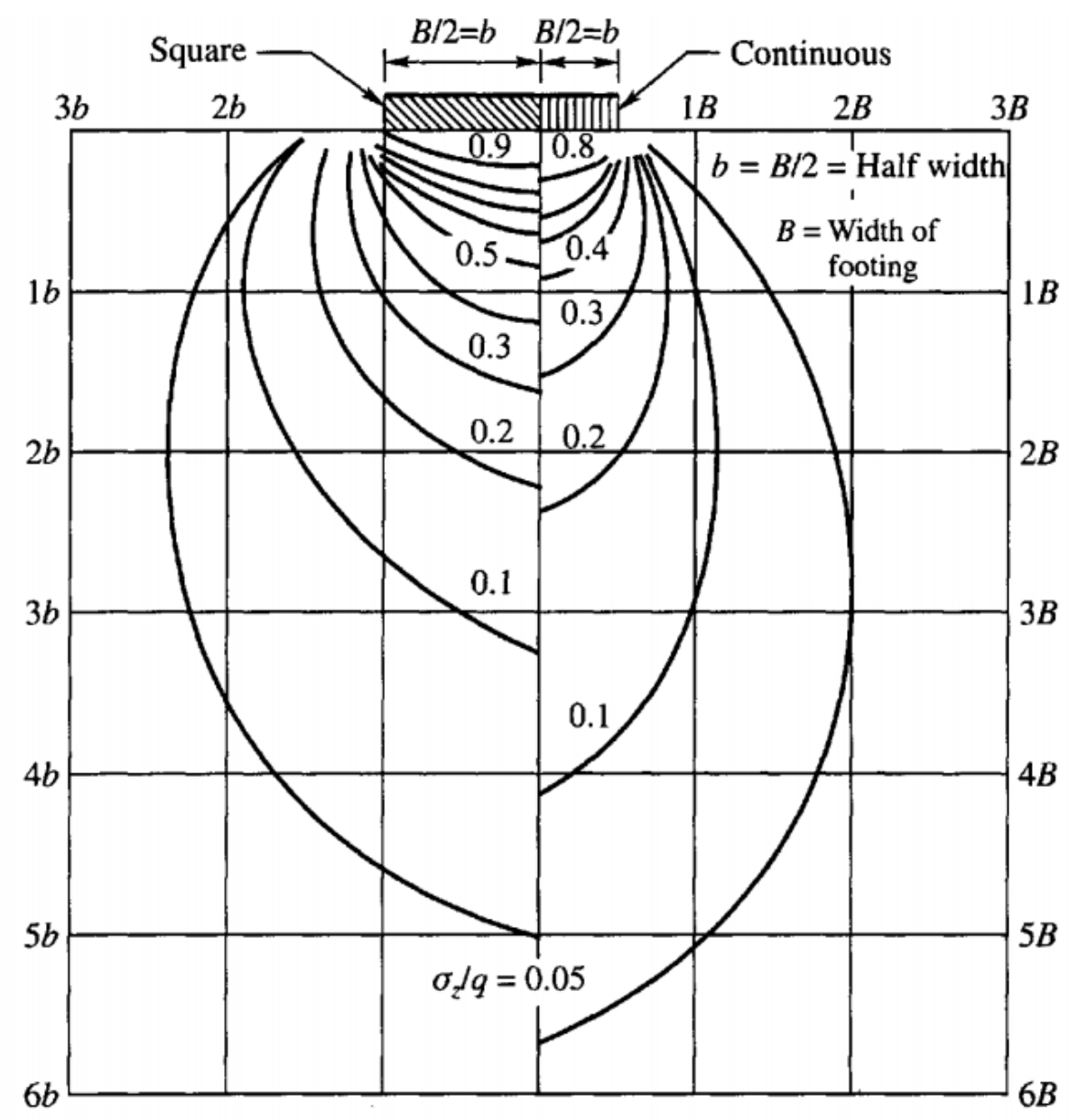

FIG. 2.16 Pressure isobars for square and continuous footings (based on Westergaard's equation) (from Murthy 2003).

\subsection{Settlement of Shallow Foundations}

The estimation of vertical displacement is a fundamental aspect of a foundation or earth structure design. Typically, total settlement of the foundation consists of three settlement components: (1) immediate or distortion settlement $S_{i}$, (2) consolidation settlement $S_{c}$, and (3) secondary compression settlement $\mathrm{S}_{\mathrm{s}}$. Figure 2.17 summaries the settlement process and $t_{d}$ refers the time at which excess pore water pressure becomes essentially zero.

$$
\mathrm{S}_{\text {total }}=\mathrm{S}_{\mathrm{i}}+\mathrm{S}_{\mathrm{c}}+\mathrm{S}_{\mathrm{s}}
$$


The primary (immediate) response of soil, to applied load, is generally not elastic (Fang 1991). Although immediate settlement is calculated with elastic theory, it is derived from the non-elastic behavior of soil.

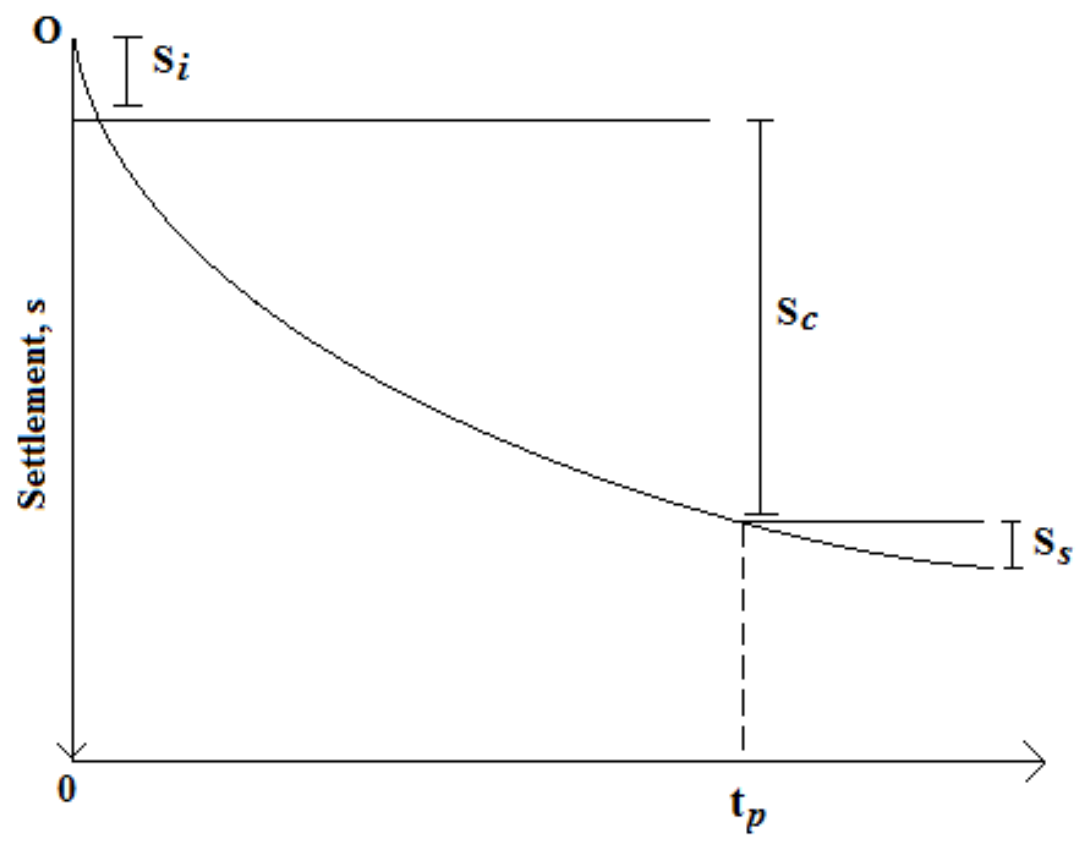

FIG. 2.17 Time- settlement history of the settlement of a shallow foundation (Perloff 1975, Fang 1991).

Consolidation and secondary compression settlement occur as consequence of water expulsion from the soil skeleton due to compressive force. The load on the soil is carried by water during the consolidation settlement period, and the consolidation period continues until zero excess hydrostatic pressure is reached. At zero excess hydrostatic pressure, secondary compression settlement conditions is considered because the soil skeleton takes all load at constant effective stress.

\subsubsection{Immediate Settlement of Fine-Grained and Coarse Grained Soils}

Linear elastic theory is used to estimate the magnitude of immediate settlement of finegrained soils. The elastic modulus $(E)$ and Poisson's ration $(v)$ are necessary to determine 
immediate settlement of fine-grained soil when the other elastic parameters, homogeneity, and isotropy (Equation 2.24) are applied. This approach is applicable and reasonable for clay soil if the applied stress is low (large safety factor). Generally, fine-grained soil is assumed to be saturated and settlement of a point on surface is calculated by the following equation.

$$
s_{i}=C_{s} q B\left(\frac{1-v^{2}}{E_{u}}\right)
$$

where $s_{i}=$ distortion (immediate) settlement, $C_{s}=$ shape and rigidity factor, $q=$ magnitude of the uniformly distributed load, $B=$ characteristic dimension of the foundation area, $E=$ Young's modulus, and $v=$ Poisson's ratio.

In foundation applications on fine-grained soil, estimated approximate initial settlements are acceptable because immediate settlement is representative of a small part of the total settlement.

In contrast, three settlement types $\left(\mathrm{S}_{\mathrm{i}}, \mathrm{S}_{\mathrm{c}}, \mathrm{S}_{\mathrm{s}}\right)$ are considered for the immediate settlement for coarse-grained soils. The settlement occurs right after loading and pore pressures are assumed to dissipate rapidly. The fundamental problem with the evaluation of the coarse-grained soil settlement is that undisturbed coarse-grained soil samples are nearly impossible to obtain and test. Therefore, empirical methods or data gained from in situ geotechnical tests (e.g., cone penetration or standard penetration tests) are used to estimate soil settlement (Burland and Burbridge 1985, Simon and Menzies 2000, Bell 2004). Schmertmann (1970) developed an often used approach to settlement of coarse-grained soil based on the following observations (Winretkorn and Fang 1975):

1) The vertical strain distribution under a uniformly loaded area at the surface of the elastic half-space;

$$
\varepsilon_{z}=\frac{\Delta p}{E} I_{z}
$$


where $\Delta p=$ intensity of the uniform load distribution, $E=$ Young's modulus and $I_{z}=$ strain influence factor.

2) Depending on the displacement results under a model foundation and finite element analysis of deformation of nonlinear materials, strain distribution exhibits similar behavior in similar linear-elastic mediums.

According to Schmertmann (1970), the settlement of coarse-grained soil is the integration of strain

$$
S_{i}=\Delta p \int_{0}^{2 B} \frac{I_{z}}{E} d_{z}
$$

Then, settlement of coarse-grained soil can be computed from

$$
S_{i}=C_{1} C_{2} \Delta p \sum_{i=1}^{n}\left(\frac{I_{z}}{E}\right)_{i} \Delta z_{i}
$$

where $I_{z}=$ strain influence factor, $E=$ Young's modulus at the middle of the $i$-th layer of thickness $\Delta z_{i}$, and $\mathrm{C}_{1}$ and $\mathrm{C}_{2}$ are correction factors. The $\mathrm{C}_{1}$ and $\mathrm{C}_{2}$ correction factors depend on settlement with time. Equations 2.28 and 2.29 summarize these correction factors $\mathrm{C}_{1}$ and $\mathrm{C}_{2}$.

$$
\begin{aligned}
& C_{1}=1-0.5\left(\frac{\sigma_{m}^{\prime}}{\Delta p}\right) \geq 0.5 \\
& C_{2}=1+0.2 \log \left(\frac{t}{0.1}\right)
\end{aligned}
$$

in which $\sigma_{\mathrm{p}}$ is effective stress at depth $\mathrm{m}, \Delta \mathrm{p}$ is net footing pressure, and $t$ is time from load application. Settlement of the footing may be relatively smaller in coarse-grained soil as compared with fine-grained soil and this settlement arises from (1) shear strain that changes the shape of soil after loading and (2) volume change (dilation or compression). Additionally, Schmertmann (1970) explained that the strain-influence factor depth relationship with a " $2 B-0.6$ distribution." The Schmertmann distribution approximates the strain influence factor as a 
triangle with a maximum value of 0.6 at $\mathrm{z} / \mathrm{B} 0.5$ and $I_{z}=0$ at the depth of $\mathrm{z} / \mathrm{B}=2$. The distribution was modified by Schmertmann (1978) in which the relative depth below the footing reaches $4 B$ in plane strain $(\mathrm{L} / \mathrm{B}>10)$ condition, whereas it reaches $2 B$ in axisymmetric condition. Figure 2.18 summaries estimation of strain influence factor in sand by using the Schmertmann method.

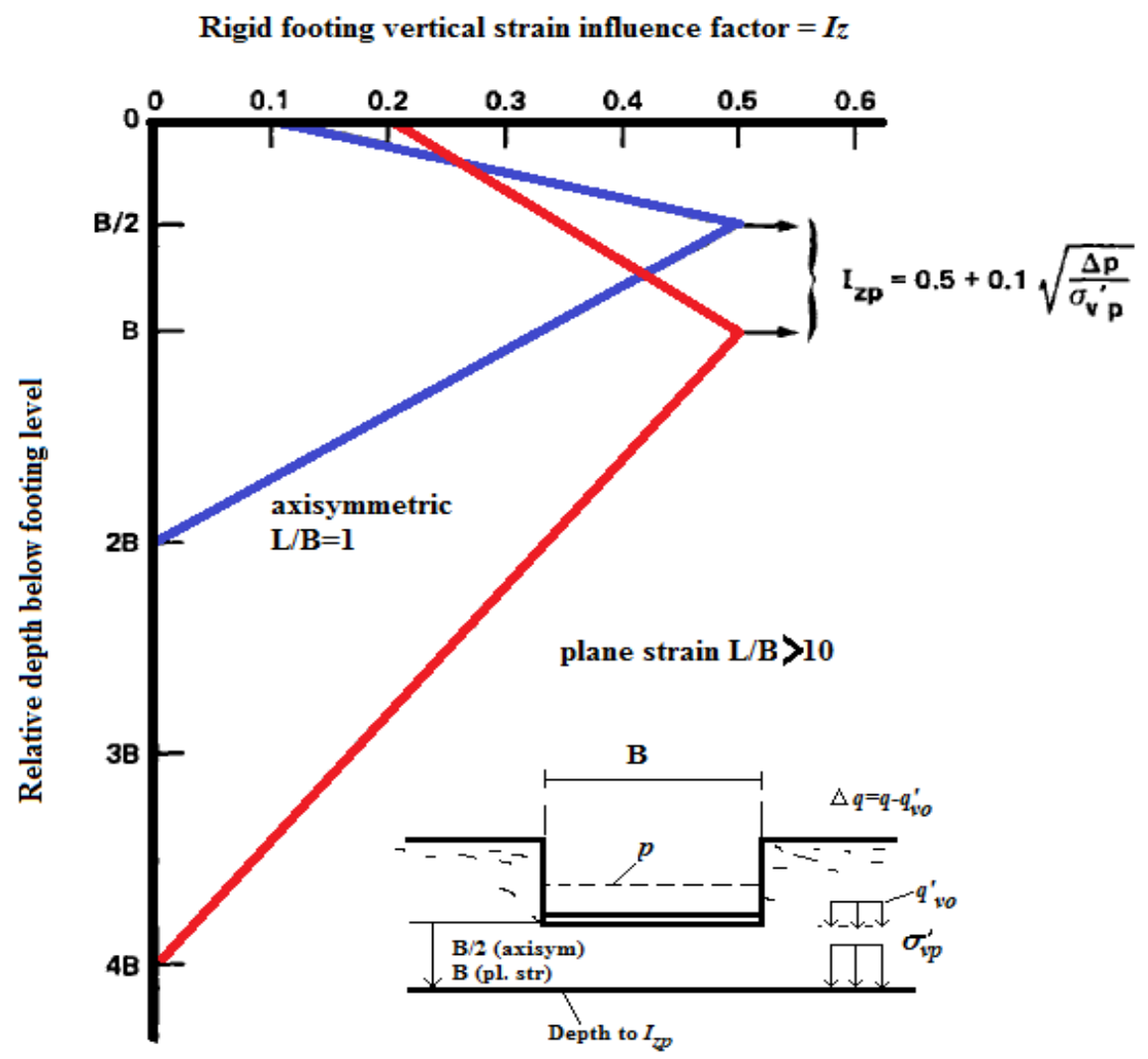

FIG. 2.18 Modified strain influence factor diagrams for use in Schmertmann method for estimating settlement over sand (Schmertmann 1978).

\subsubsection{Consolidation Settlement}

Consolidation settlement is the second part of the total settlement evaluation fine-grained soil. Applied loads are transferred to the subsoil and this causes a volumetric strain increase relevant to the increase in pore water pressure. The pore water is then expelled from soil voids 
with a resulting reduction in volume dependent on pore water pressure dissipation, effective stress increases.

Analysis of consolidation settlement assumes that strain and loading occur only in the vertical direction. This assumption simplifies the consolidation evaluation; furthermore, it is reasonable for one-dimension loading, compression, and consolidation of fine-grained soil. Consolidation settlement can be calculated by using multiple methods depending on the soil properties. If the soil deposit is normally consolidated, then additional stress form a structure, $\Delta \sigma_{\mathrm{v}}$, and existing vertical overburden stress, $\sigma^{\prime}{ }_{v o}$, are considered in calculation of the consolidation settlement. Equation 2.30 and equation 2.31 display the normally consolidated soil consolidation settlement and void ratio change, respectively.

$$
\begin{array}{cc}
S_{c}=\sum_{i=1}^{n} \Delta S c=\Delta e_{o} \frac{H_{i}}{1+e_{o}} & \left(\sigma^{\prime}{ }_{\mathrm{vo}}=\sigma_{\mathrm{p})}\right. \\
\Delta e_{o}=C_{c} \log \left(\frac{\sigma^{\prime}{ }_{v o}+\Delta \sigma_{v}}{\sigma^{\prime}{ }_{v o}}\right)_{i} & \left(\sigma_{v f}^{\prime}=\sigma_{v o}^{\prime}+\Delta \sigma_{v}\right)
\end{array}
$$

where $\mathrm{C}_{\mathrm{c}}=$ compression index, $\mathrm{e}_{\mathrm{o}}=$ initial void ratio at the middle of the $i$-th layer, $\sigma_{\mathrm{p}}=$ previous peak vertical effective stress, $\sigma_{v o}^{\prime}=$ initial vertical effective stress, $\mathrm{n}=$ number of layers, $\mathrm{H}=$ soil layer height, and $\Delta \sigma_{v}=$ applied vertical stress by structure.

Calculation of settlement in overconsolidated soil is slightly different than for normally consolidated soil. The $C_{r}$ parameter is used instead of or in addition to the $C_{c}$ index. Both of these parameters can be determined from log-scale void ratio- effective stress graphic, $e-\log \sigma^{\prime}$ (Figure 2.19). Settlement of overconsolidated soil is calculated from the following equations:

$$
\begin{aligned}
& s_{C 1}=\sum_{i=1}^{m} \frac{H_{i}}{1+e_{o}}\left[C_{r} \log \left(\frac{\sigma^{\prime} v_{\mathrm{vo}}+\Delta \sigma_{v}}{\sigma^{\prime}{ }_{v o}}\right)\right]_{i} \quad\left(\sigma_{\mathrm{vo}}^{\prime}<\sigma_{\mathrm{p}}\right) \\
& s_{C 2}=\sum_{i=1}^{n} \frac{H_{i}}{1+e_{o}}\left[C_{r} \log \left(\frac{\sigma^{\prime} p}{\sigma^{\prime} v_{v}}\right)+C_{c} \log \left(\frac{\sigma^{\prime}{ }_{v o}+\Delta \sigma_{v}}{\sigma^{\prime}{ }_{v o}}\right)_{i}\right]_{i} \quad\left(\sigma^{{ }_{\mathrm{vo}}}<\sigma_{\mathrm{p}}<\sigma^{\prime}{ }_{\mathrm{vf}}\right)
\end{aligned}
$$


where $m$ and $n$ represents the number of soil layers.

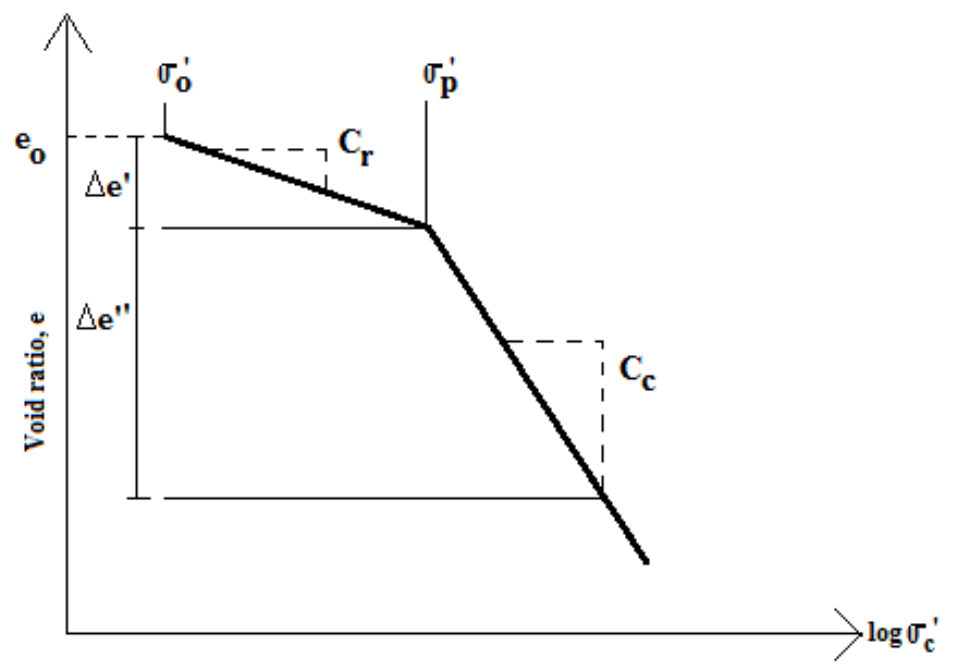

\section{FIG. 2.19 Simple one-dimensional compression for clay.}

In WTG foundation applications, consolidation behavior is dependent on additional vertical loads. Both static and cyclic loads may affect the settlement in different aspects. Permanent settlement, which arises from cyclic loading, increases depending on amplitude of cyclic load intensity for a particular $\mathrm{q}_{\mathrm{u}} / \mathrm{q}_{\mathrm{s}}$ (ultimate bearing capacity/allowable static load of intensity) ratio (Das and Shin 1998). Additionally, limited settlement occurs due to cyclic loading, in other words, number of critical cyclic loading limits the settlement in soil (Das and Shin 1996).

\subsubsection{Secondary Compression Settlement}

The third component of total settlement is secondary compression. Secondary compression is observed after excess pore water pressure has dissipated. Ladd (1973) explains secondary compression as movement of particles to find a stable arrangement, adding that particle contacts are unsteady at the end of consolidation settlement. Therefore, compressibility causes an increase in rate of secondary compression due to particle instability. Secondary compression settlement is determined form the following equation (Day 1999): 


$$
S_{s}=C_{\alpha} H_{o} \Delta \log t
$$

where $\mathrm{S}_{\mathrm{s}}=$ settlement due to secondary compression (after end of consolidation), $\mathrm{C}_{\alpha}=$ secondary compression ratio, $\mathrm{H}=$ initial thickness of fine grained soil layer, and $\Delta \log t=$ change in the $\log$ of time from the end of primary consolidation to end of design life of the structure. Secondary compression is a relatively small portion of total settlement and is negligible compared to consolidation settlement, for most soil types; however, secondary consolidation may be significant for organic soils (Holtz and Kovacs 1981, Day 1999). Since WTG systems are typically constructed on non-organic soil formations, secondary settlement is generally not relevant.

\subsection{Foundation Vibrations}

Dynamically loaded foundations oscillate depending on supporting ground and foundation properties such as geometry and inertia of the foundation. The motion of the foundation and wave energy must be considered in structural design. Due to potential harmful consequences of foundation vibration, soil foundation interaction and dynamic soil conditions require consideration.

Response of the footing (motion of the foundations) on elastic soil can be calculated by the following equation depending on the applied load,

$$
F-p A=M \frac{d^{2} \omega}{d t^{2}}
$$

where $A$ is the area of the footing, $\omega$ is the vertical displacement of the footing, and the contact pressure between foundation mass and the soil is defined by $p$. 


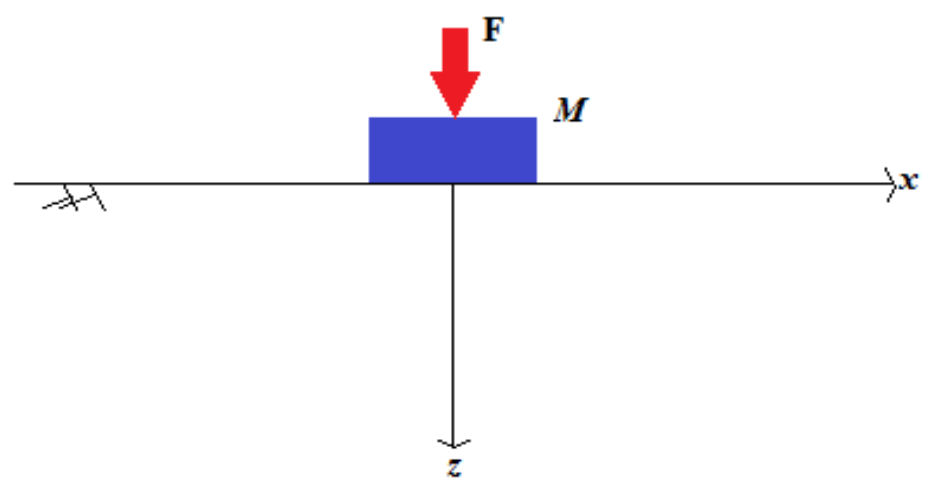

FIG. 2.20 Foundation element on soil.

To order to specify the response of foundation to vibrations, soil parameters such as density $(\rho)$, shear modulus $(G)$, and Poisson's ration $(v)$ are necessary.

The density is easy to measure; however, Poisson's ration is hard to both measure and estimate. Typically, Poisson's ratio ranges from 0.3 to 0.5 depending upon the soil formation type (Verruijt 1994).

The most critical parameter in dynamic applications is the shear modulus, which highly depends on level of soil shear strain (Verruijt 1994). Shear modulus degradation plays a significant role on stiffness calculations, which important for the structural rigidity of the system.

\subsubsection{Dynamic Loads}

Dynamic loads cause foundation motion and vibration. There are six types of foundation motions under dynamic loading (vertical, yawing, rocking, longitudinal, lateral, and pitching) and these motions may follow different trends such as harmonic motion, periodic motion, random motion, or transient motion (Winterkorn and Fang 1975). Figure 2.21 summaries the motion patterns. 


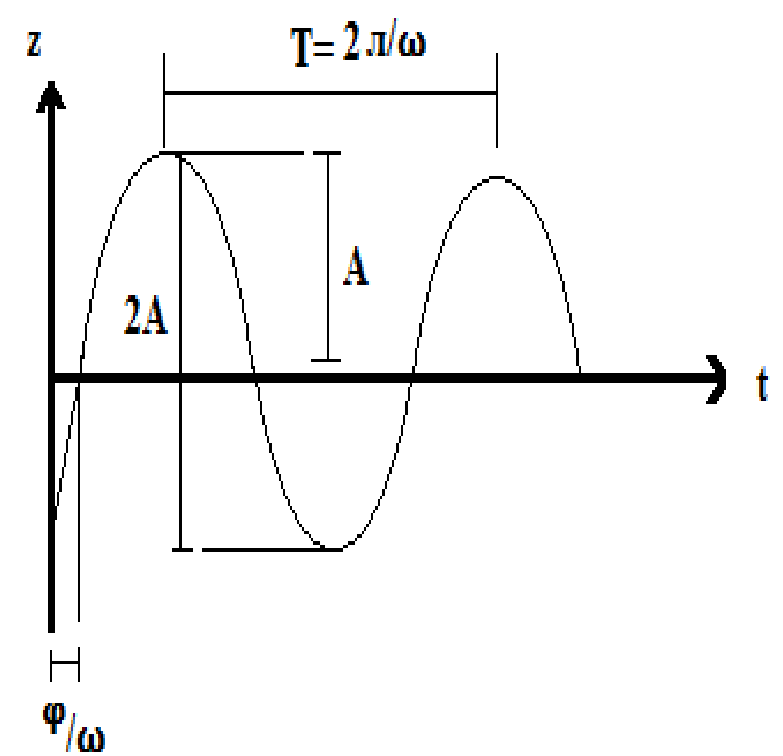

(a)

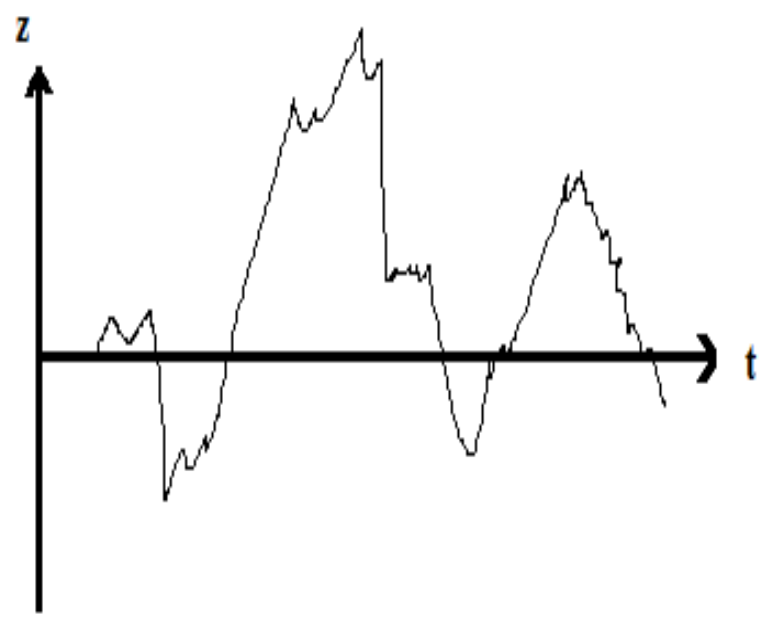

(c)

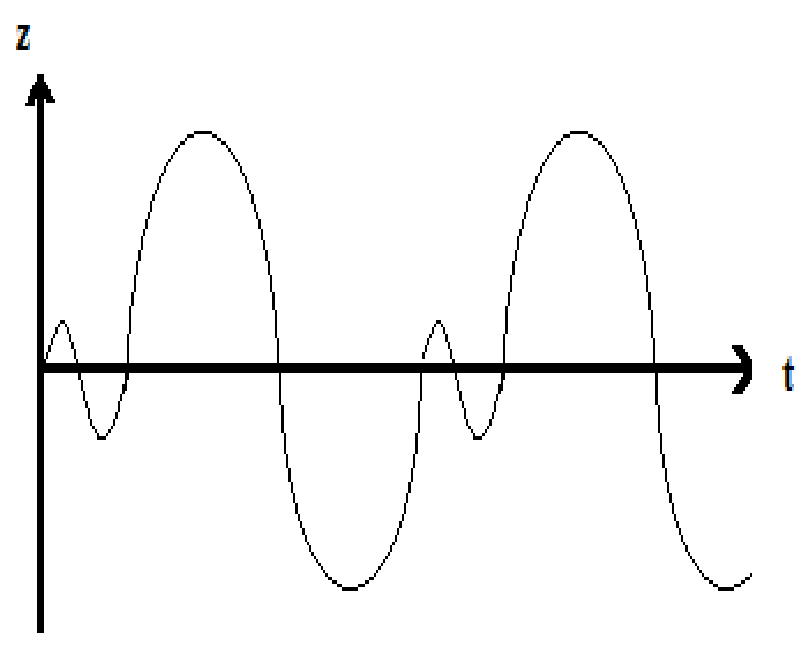

(b)

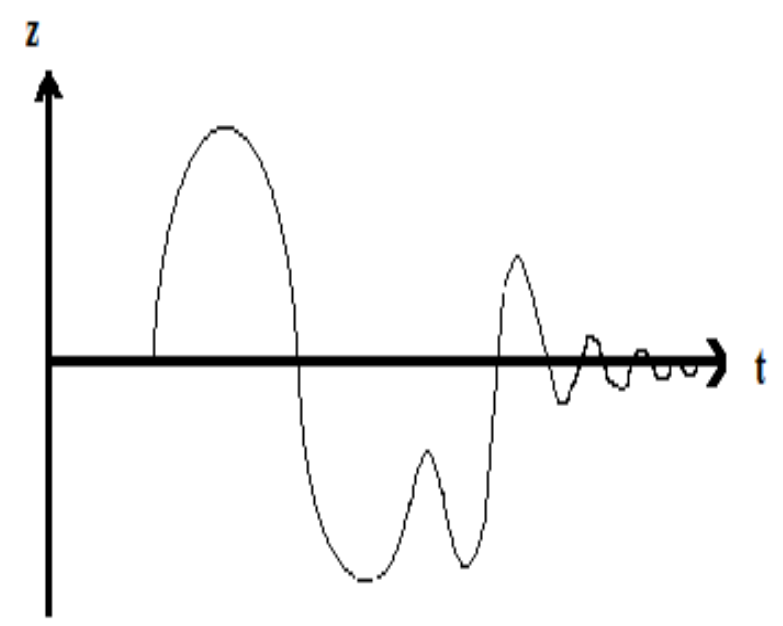

(d)

FIG. 2.21 One dimensional motions of a rigid block: (a) harmonic; (b) periodic; (c) random; and (d) transient. 
Vibrating foundations emit shear and compression waves into the soil. Dynamic parameters control these wave behaviors. For example, shearing stiffness and density of soil control S-wave propagation through the soil body (Equation 2.36). P-waves, on the other hand, propagate with a velocity that is a function of the constrained modulus, $\mathbf{M}_{\mathrm{c}}$ (Equation 2.37).

$$
\begin{aligned}
& V_{s}=\sqrt{\frac{G}{\rho}} \\
& V_{p}=\sqrt{\frac{M_{c}}{\rho}}
\end{aligned}
$$

where $G=$ shear stiffness, $\rho=$ density of soil, $V_{s}=\mathrm{S}$-wave velocity, $V_{p}=\mathrm{P}$-wave velocity, and $M_{c}=$ constrained modulus. For elastic materials, $M_{c}$ is highly connected with shear stiffness, $G$, and Poisson's ratio of the soil:

$$
V_{p}=V_{s} \sqrt{\frac{2(1-v)}{1-2 v}}
$$

Figure 2.22 summaries the relation between $V_{p} / V_{s}$ and $v$. These parameters are considered in wave propagation analysis and behavior of soil formations subjected to foundation vibration. 


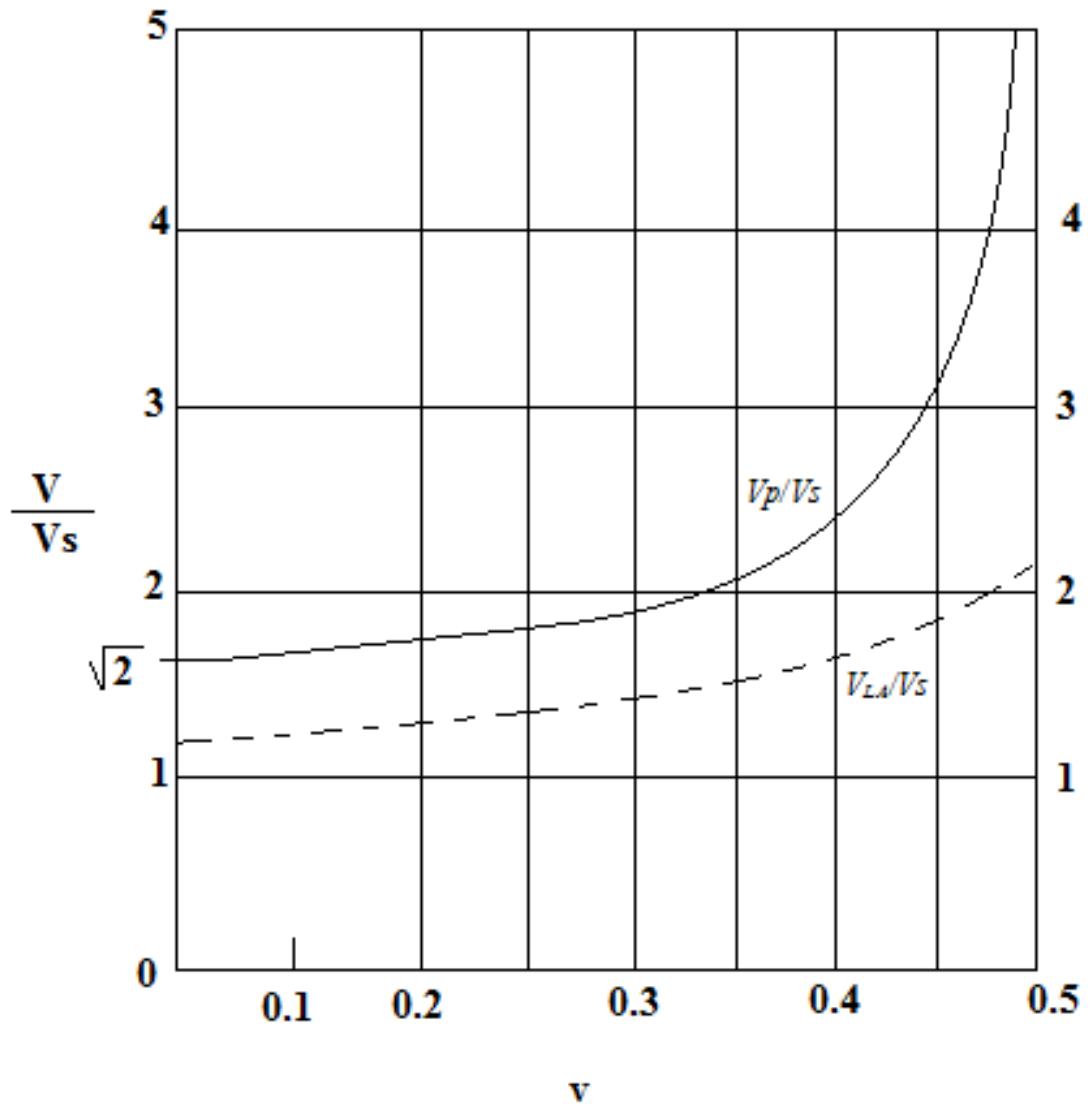

FIG. 2.22 Comparison of the actual $V_{p}$ and $V_{s}$ and "apparent" $\left(V_{L A}\right)$ wave velocities used in foundation vibration analysis (Fang 1991).

\subsection{Shear Moduli and Damping}

The cyclic shear stress-strain behavior of soil is a key to understand the behavior and responses of soil under a shear load such as those created by dynamic loads (Winterkorn and Fang 1975). Shear modulus is simply defined as the ratio of the shear stress to shear strain. An Swave velocity-density relationship can be considered for the shear modulus evaluation due to wave velocity-shear modulus interaction (Fang 1991) (Equation 2.39). 


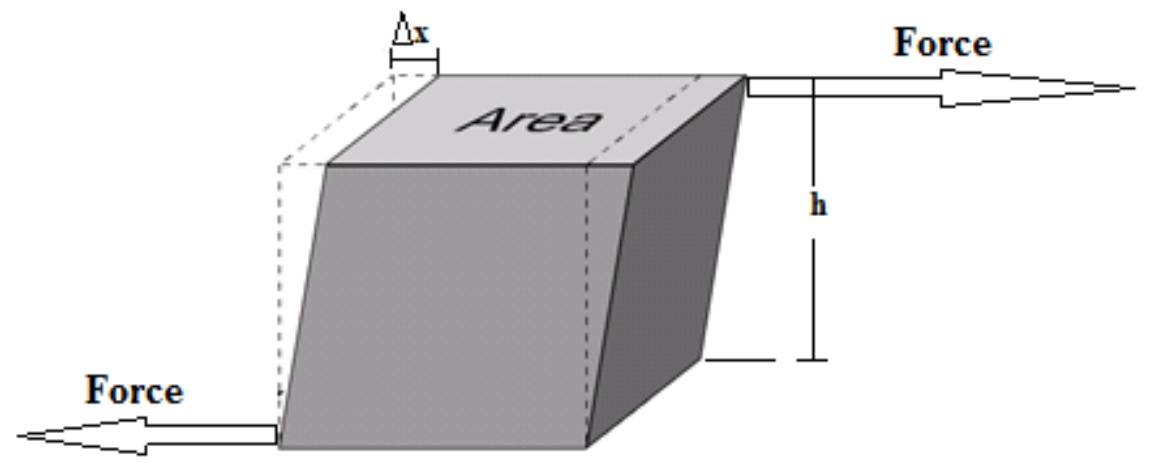

FIG. 2.23 Shear strain of materials.

$$
V_{s, \max }=\sqrt{\left(G_{\max } / \rho\right)}
$$

where $V_{s, \max }=$ S-wave velocity, $G_{\max }=$ maximum shear modulus, and $\rho=$ density. For settlement analysis, elastic modulus can be preferred instead of shear modulus. The maximum shear modulus can be converted to elastic modulus by

$$
E_{\max }=2 \times G_{\max }(1+v)
$$

where $E_{\max }=$ maximum elastic modulus, $G_{\max }=$ maximum shear modulus, and $v=$ Poisson ratio

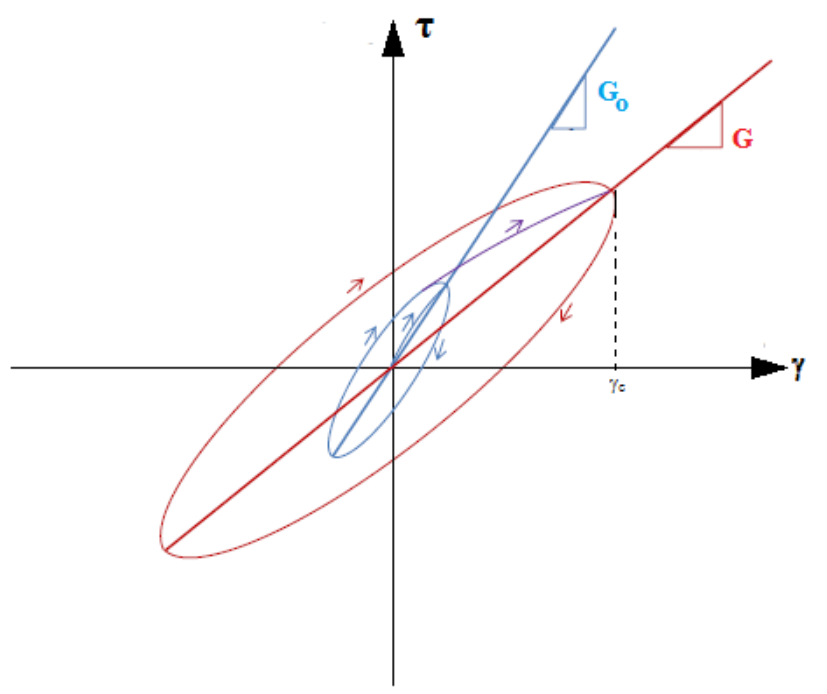

FIG. 2.24 Shear stress strain hysteresis loops (adapted from Schubert 2012). 
Damping (or damping ratio) is another parameter used in the dynamically loaded foundation design process. Damping ratio is defined as ratio of actual damping to critical damping. Damping of vibrations applied vertically to a foundation can be explained via the analogy shown in Figure 2.25.

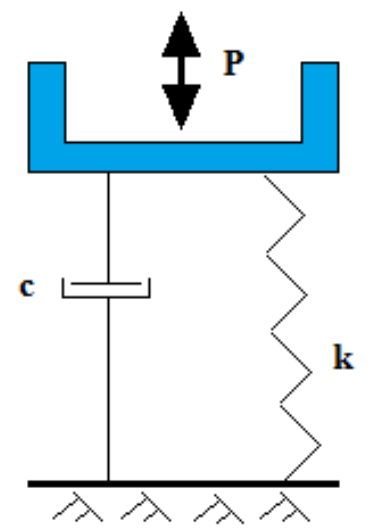

Rigid Base

FIG. 2.25 Physical interpretation of the dynamic stiffness (k) and dashpot (c) coefficient for a vertically vibrating footing.

Soil damping is an important source of energy dissipation. There are two parts in damping: radiation and hysteretic damping. NEHRP (1994) indicates that foundation damping incorporates the impact of the energy dissipation in the soil from:

- radiation of waves from foundation (radiation damping)

- hysteretic or non-elastic action on soil.

Research on the damping ratio is prevalent in the geotechnical literature. In particular, significant research on hysteretic damping exists. As an illustration, Seed et al. (1986) proved that the damping ratio decreases with an increase in confining pressure. Figure 2.26 summaries the damping ratio-confining pressure relation (Seed et. al. 1986). 


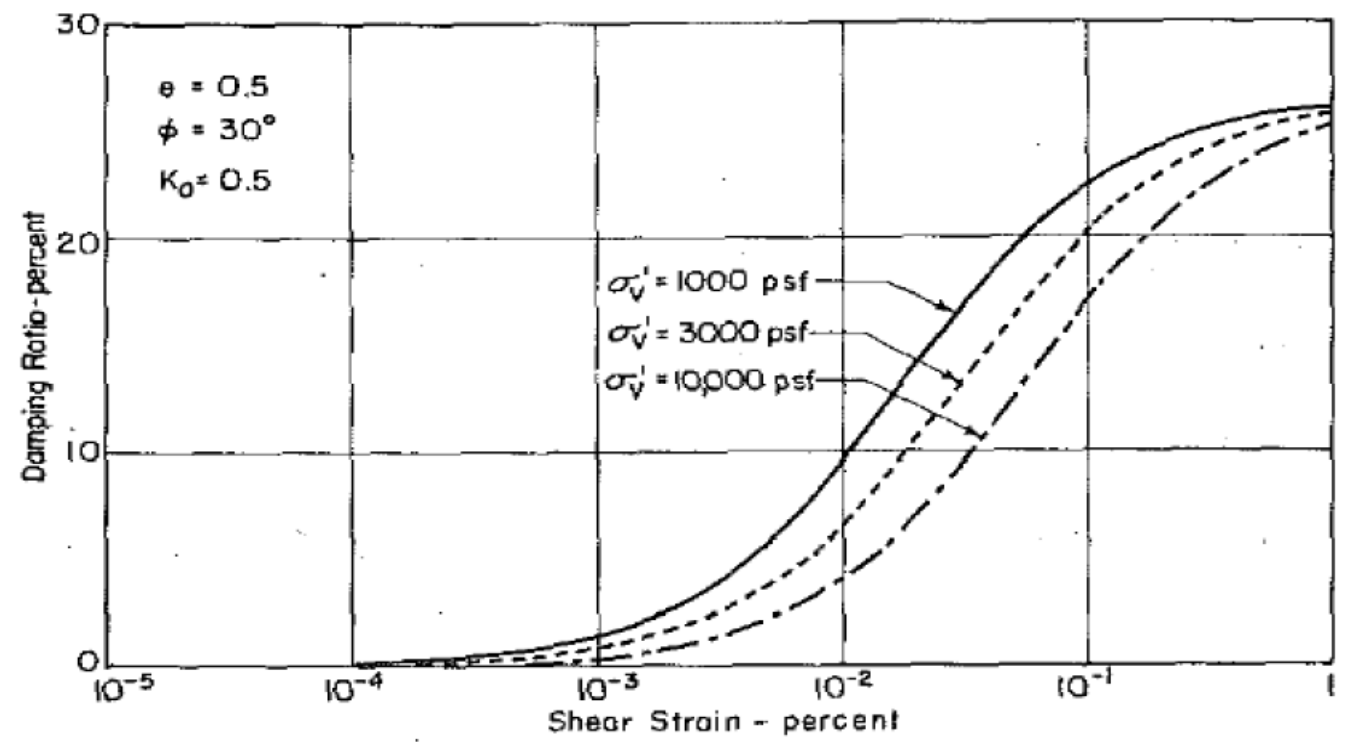

FIG. 2.26 Relationship of damping ratio to confining pressure.

The shear modulus of soil changes depending on magnitude of the shear strain that occurs. Strain level is an important parameter to determine the control mechanism of the shear modulus. At small strain levels, shear modulus is controlled by deformation properties of particle contacts. At high strain level, slippage of the particles controls the shear modulus. Effective confining pressure, degree of saturation, stress history, void ratio, temperature, and frequency of vibration are additional factors in shear modulus degradation, confining effective stress and void ratio are two of the more important parameters influencing $G_{\max }$ of all types of soils (Fang 1991).

High confining pressure creates higher shear wave velocity than low confining pressures. Based upon this relation and Equation 2.39, a direct relationship between confining pressure and shear modulus is obtained (Richard et. al. 1970).

Fang (1991) mentions that frequency or the rate of loading has no considerable impact on $G_{\max }$ for fine-grained and coarse-grained soils. Figure 2.27 shows the variance of the variation of the shear modulus degradation for normally consolidated soils based on plasticity index and 
granular soil as a function of cyclic strain value. Det Norske Veritas (2002) recommended 0.1\% as a typical cyclic shear strain value for the calculation of WTG foundation stiffness.

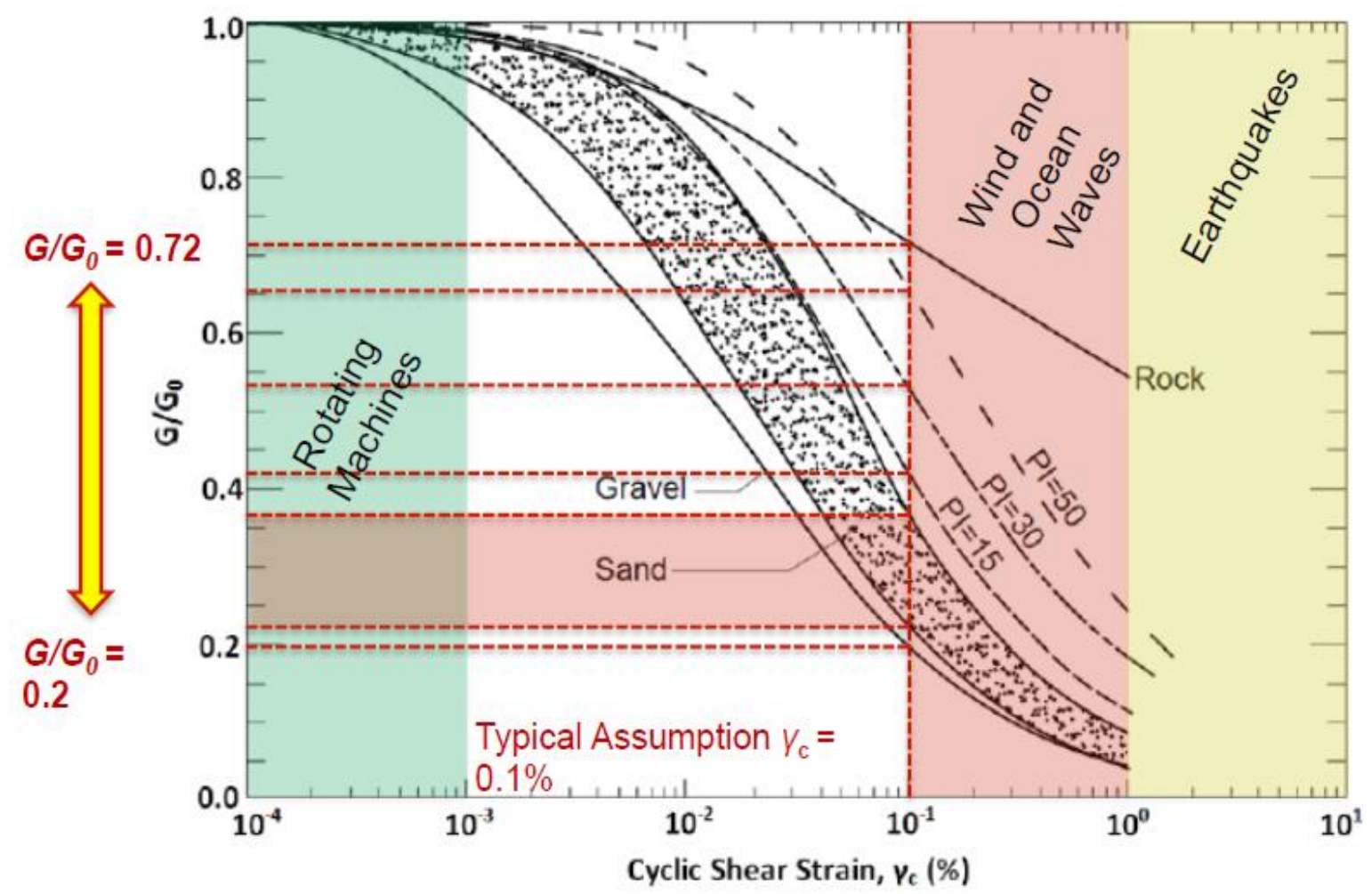

FIG. 2.27 Shear modulus degradation curves for different types of soils (after Sykora et al. 1992, and Vucetic and Dorby 1991).

\subsection{Vibration of foundation on Elastic Media}

Typically, a foundation is assumed to rest on an elastic, homogenous, isotropic, and semifinite soil (Winterkorn and Fang 1975). Thus, elastic theory may be used to provide approaches for the foundation responses when excited in vertical, horizontal, rocking, and torsional modes of vibration.

Rigid circular foundation responses on elastic half-space, as an illustration, have been represented by limped mass-spring dashpot system (Lysmer 1965 and Lysmer and Richart 1966). Equation 2.41 expresses the Lysmer's analogy in terms of mass-spring-dashpot system as 


$$
m \ddot{z}+\frac{3.4 r_{o}^{2}}{(1-v)} \sqrt{G \rho} \dot{z}+\frac{4 G r_{o}}{(1-v)} z=Q
$$

Figure 2.28 summaries rigid circular foundation resting on elastic, half-space, isotropic, and semi-finite medium.

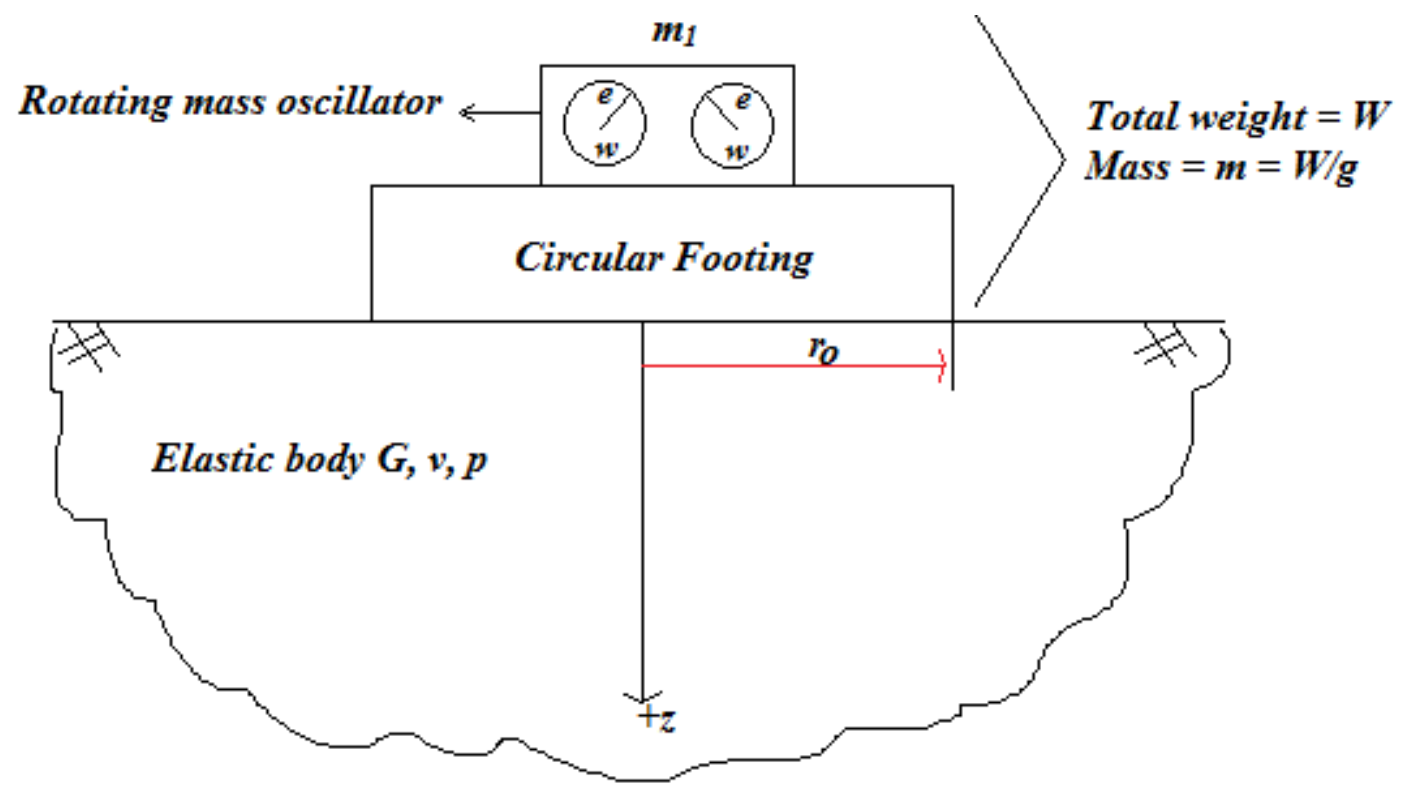

FIG. 2.28 Rotating mass oscillator with circular footing resting on semi-finite elastic body (Winterkorn and Fang 1975).

\subsection{Propagation of Elastic Waves in Soil}

Multiple alternatives are available to evaluate the wave propagation velocity in soil such as the Pulse Method and the Resonant Column Method.

The resonant column test is a method to determine the wave bahavior. A cylindrical column of soil is contained within a membrane and placed in a triaxial test apparatus. The soil is subjected to longitudinal or torsional mode of vibration. Input vibration frequency is changed till resonant conditions are achieved. The main purpose of the resonant column test is to provide necessary information based on this resonant frequency, sample geometry, and end resistance conditions for wave propagation velocity calculation under specific test conditions. The resonant 
column test can also be used to evaluate the wave propagation velocity at small strain levels and to rebuild more optimum shear modulus reduction curve for stiffness analysis in WTG foundation design.

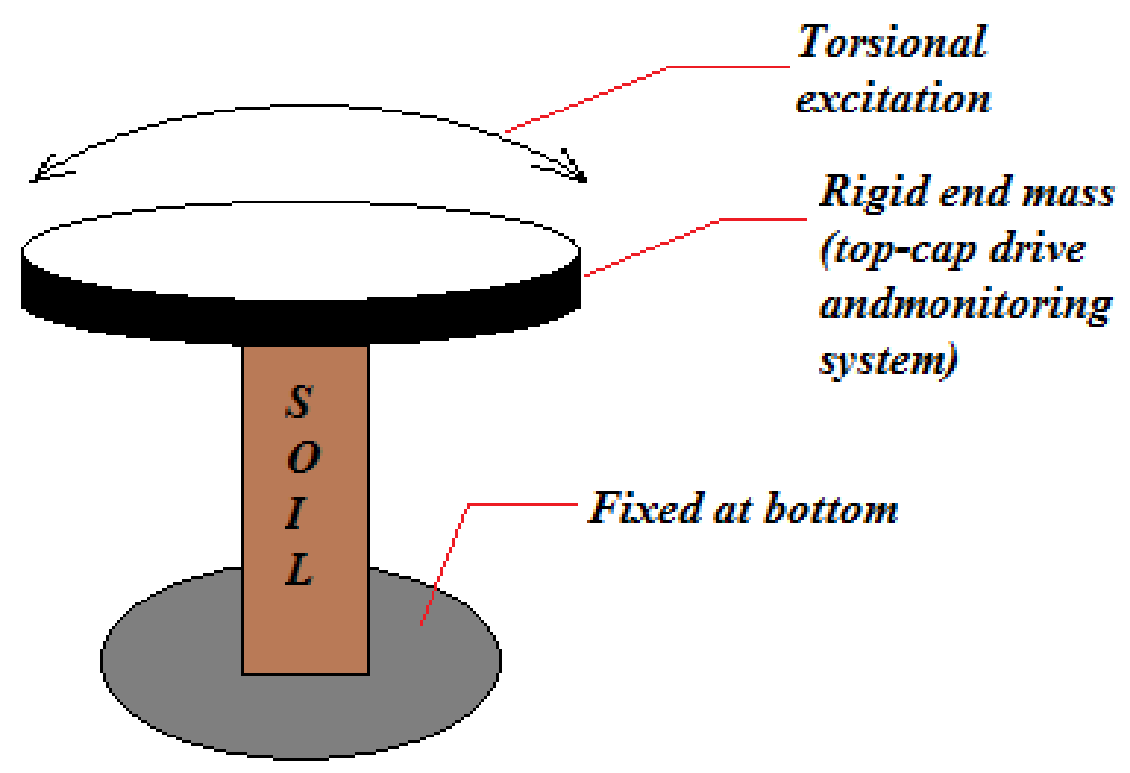

\section{FIG. 2.29 Example of resonant column test.}

For the frequency and larger strain levels, cyclic triaxial method is used to determine dynamic material properties of soil. Typically, cyclic triaxial measurement systems consists of deformation transducers, load cell, pore pressure, and cell pressure transducers (Figure 2.30).

In general, cyclic triaxial test results are used to determine cyclic soil strength and soil ability to resist shear stresses induced in the soil mass due to cyclic loading such as WTG dynamic loads. Cyclic triaxial strength test are applicable to isotropically consolidated specimens at different levels of effective confining pressure (ASTM D5311/D5311M). 


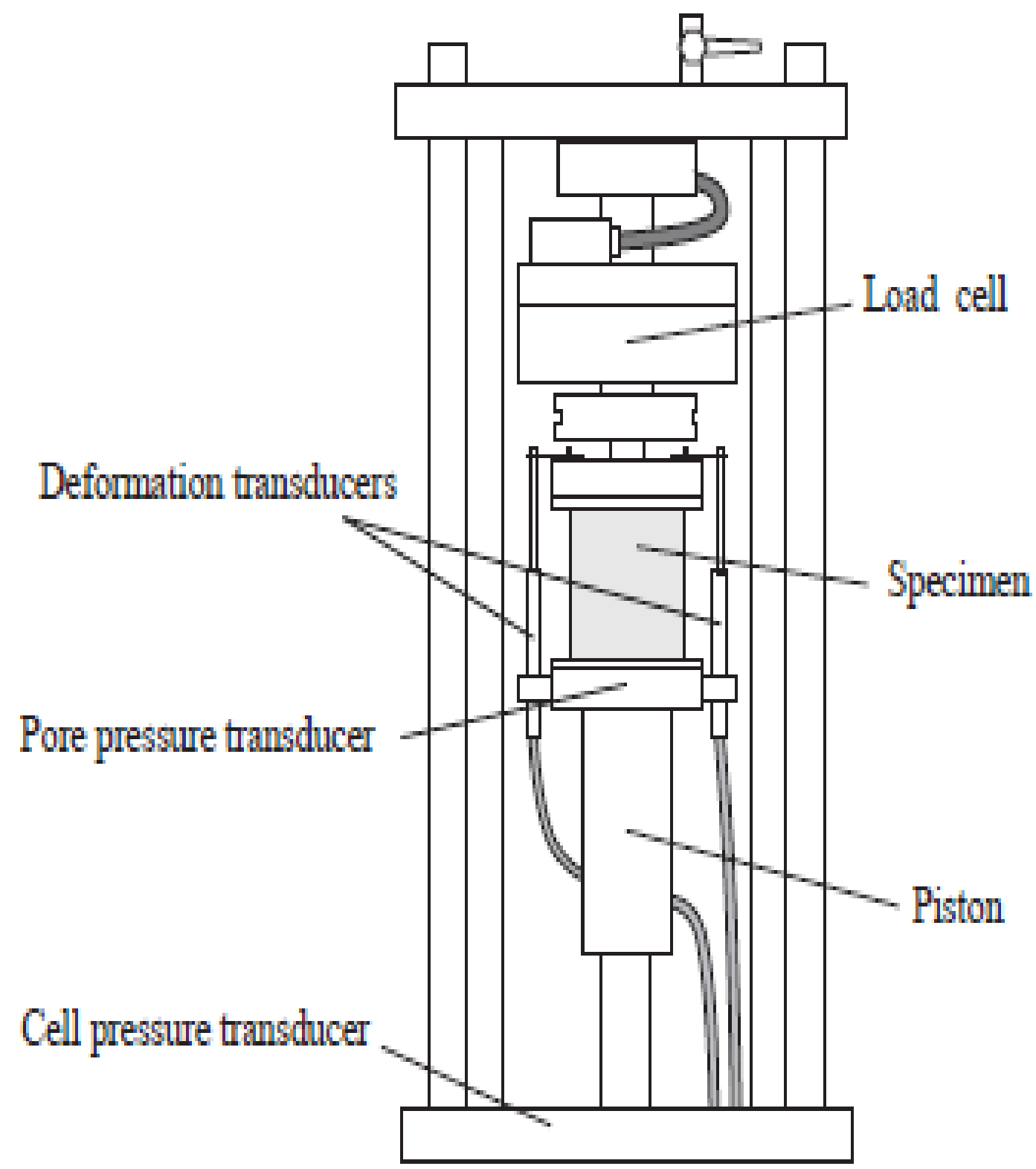

FIG. 2.30 Cyclic triaxial test. 


\section{MATERIALS AND METHODS}

WTG foundations at two separate sites (Site A and Site B) were instrumented prior to construction to monitor the in-service mechanical and dynamic responses of foundation soil subgrade under vertical and horizontal loadings. Specifically, data relating to contact pressure distribution and soil strain has been collected. Instruments were installed into the underlying foundation soil and on the interior wall of the towers. Both sites were instrumented with the same type of instruments and methodology. However, different layouts were employed to take the advantage of the predominant wind direction at each site.

\subsection{Site A}

Site A is located in the upper Midwest of United States. The site has an 1.65-MW Vestas V82 wind turbine. The Vestas V82 has 82-m diameter and 5,821 $\mathrm{m}^{2}$ swept area, and operates at nominally 14.4 revolutions per minute (rpm). Cut-in and cut-out speeds are $3.5 \mathrm{~m} / \mathrm{s}$ and $20 \mathrm{~m} / \mathrm{s}$, respectively. Figure 3.1 displays the power production and power coefficient at the corresponding wind speed. The power curve indicates that the most efficient electrical production is generated at around $13.5 \mathrm{~m} / \mathrm{s}$. In other words, as the wind speed rises above the cutin speed, the level of electricity rises rapidly. However, above $13.5 \mathrm{~m} / \mathrm{s}$, the output reaches the limit that electrical generator is capable of. The Vestas V82 operates in ambient temperature variation from $-30{ }^{\circ} \mathrm{C}$ to $+40{ }^{\circ} \mathrm{C}$ (Vestas V82 Manual). 


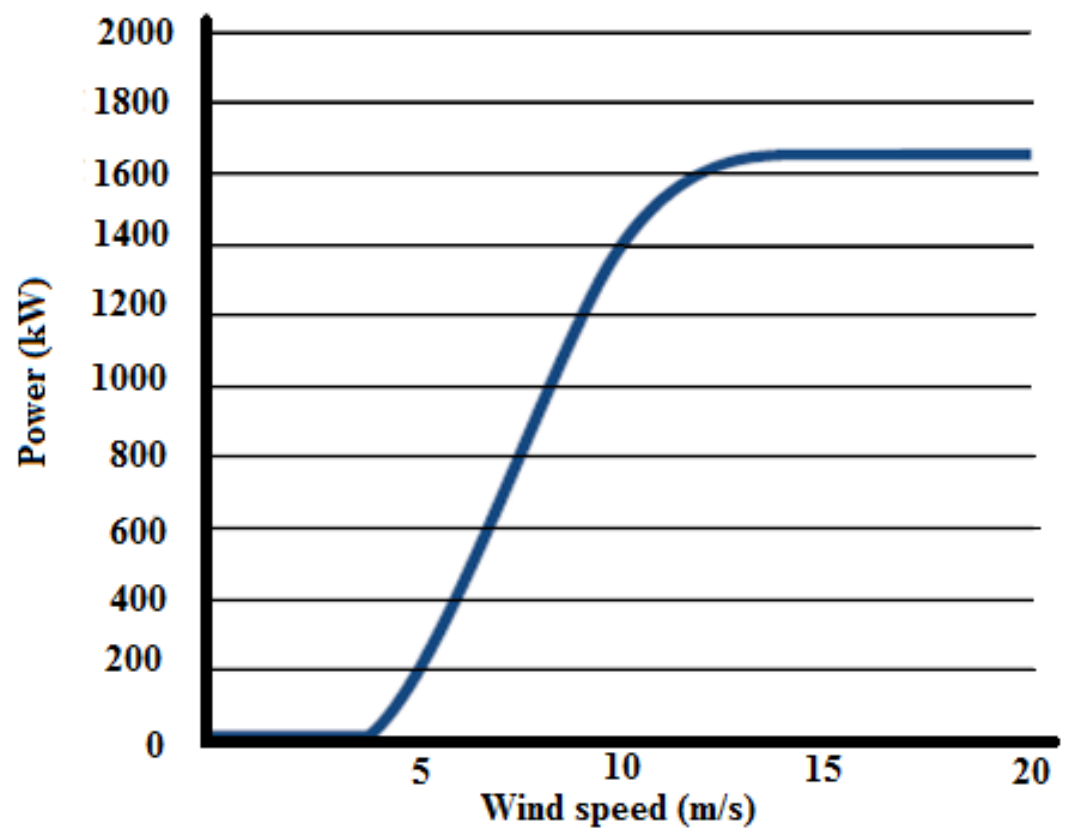

(a)

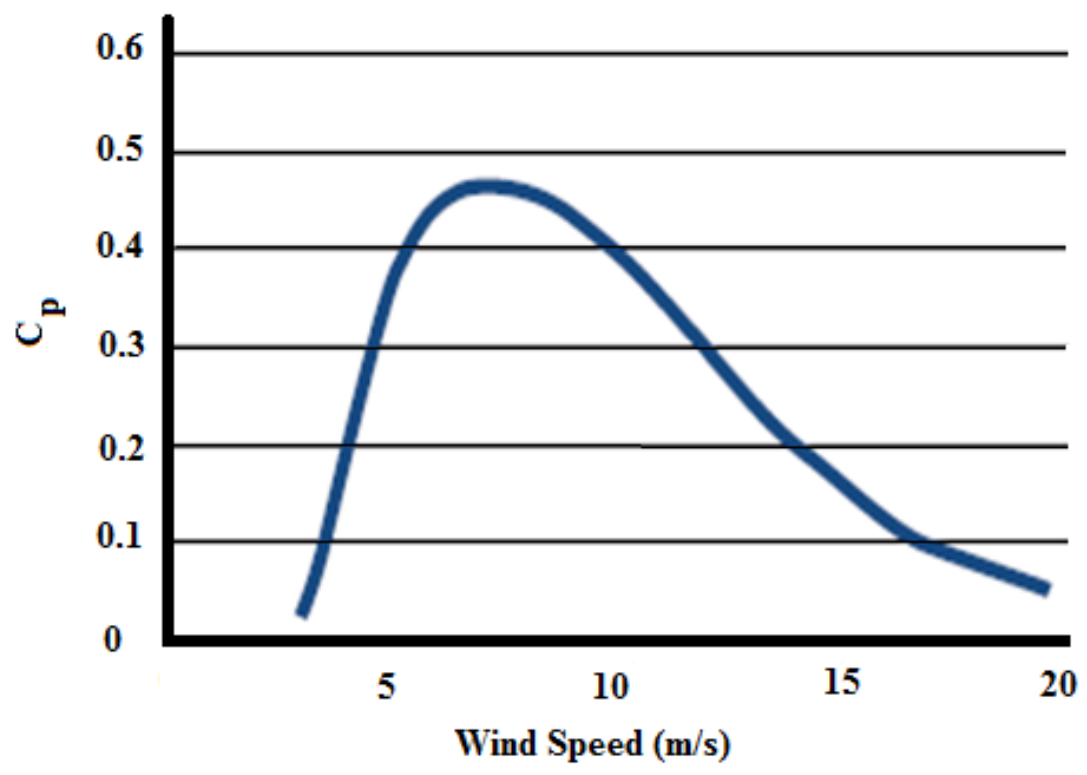

(b)

FIG. 3.1 Power (a) curve and (b) power coefficient curve for Vestas V82. 


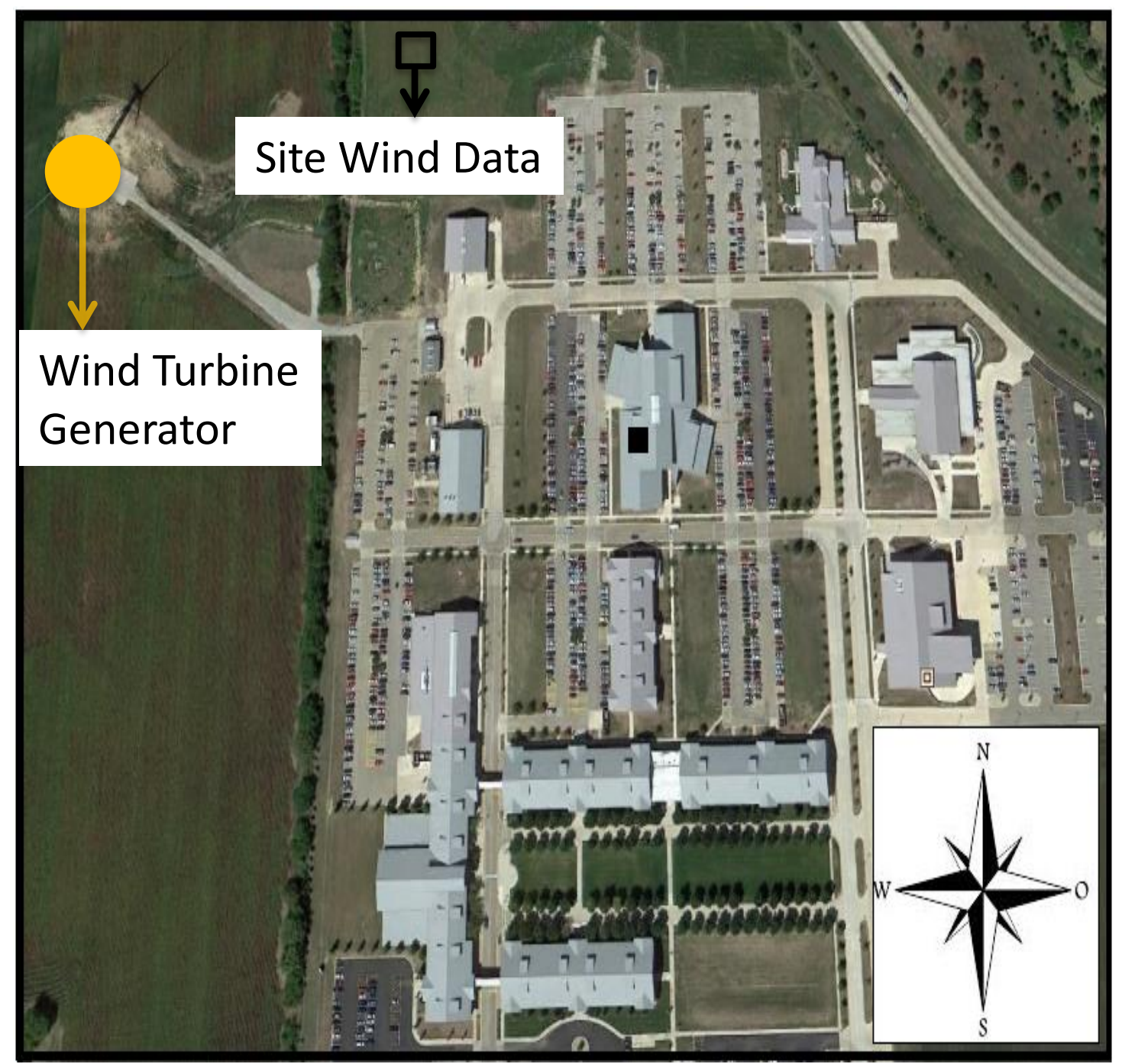

FIG. 3.2 Site A - Turbine location.

Wind data was obtained from the nearby met-tower and correlated to a long-term distribution. Then, correlated wind data were verified with nearby airport data. Based upon this data assessment, the predominant wind direction was determined as SSW (Figure 3.3). A Weibull function was used to model the wind distribution with a resulting shape factor of 2.3 and scale factor of 8.22 . 


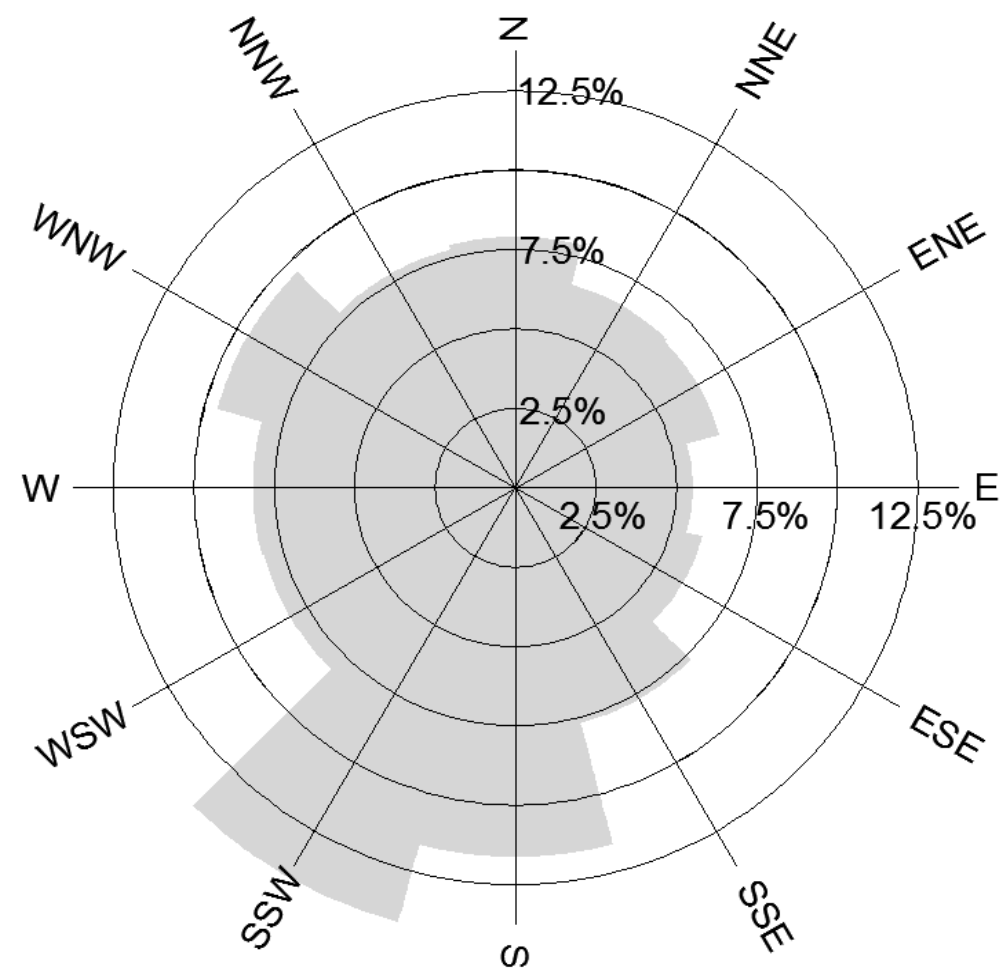

(a)

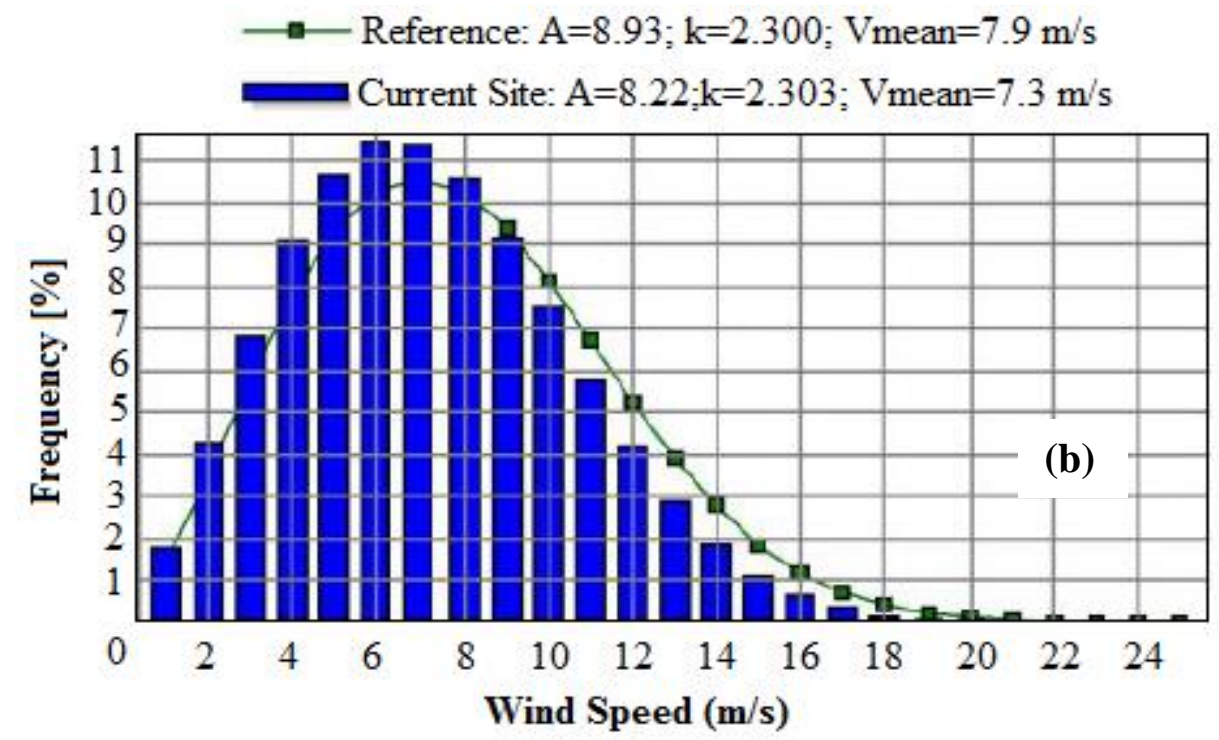

FIG. 3.3 Site A wind rose (a) and Weibull distribution (b).

\subsubsection{Site Specifications and Foundation Geometry}

Standard penetration tests (SPT) were performed to obtain soil samples and to determine the soil properties before construction. Two boreholes were drilled to different depth (7.62 $\mathrm{m}$ and 
$15.24 \mathrm{~m}$ below ground surface). Four Shelby tubes were pushed to soil to obtain undisturbed soil samples. A low plasticity clay layer observed at the near surface with a trace amount of gravel and sand through the layer.

An octagonal base gravity foundation was chosen to support the WTG system. The diameter and embedment depth of the foundation are $16.46 \mathrm{~m}$ and $2.69 \mathrm{~m}$, respectively. For the design, a minimum safety factor of the foundation against overturning and sliding were 1.5; moreover, a safety factor of 5 was calculated for bearing capacity.

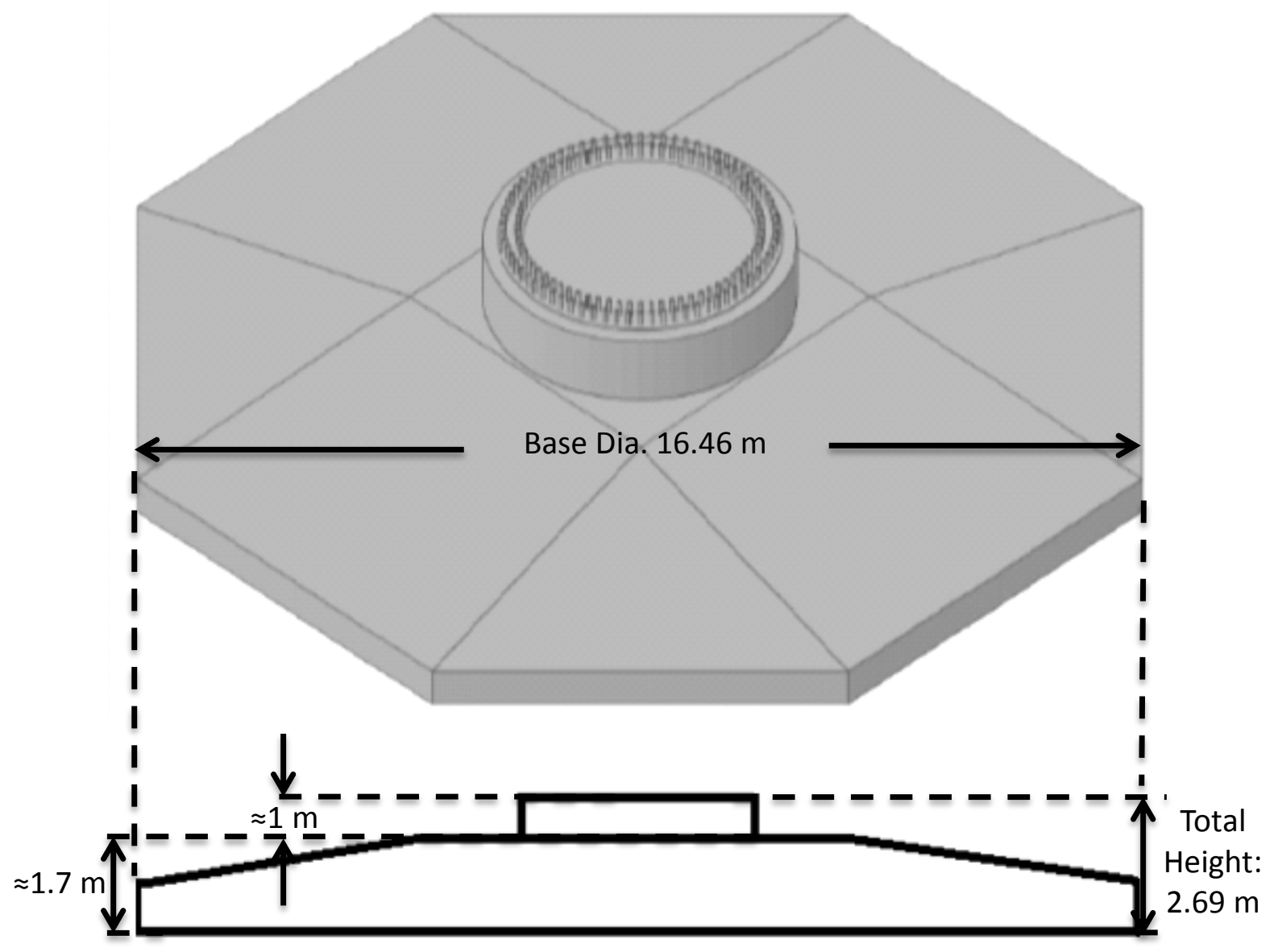

FIG. 3.4 Shallow octagonal gravity-based foundation. 


\subsubsection{Soil Properties and Classification}

Atterberg limits and particle-size methods were conducted to classify the soil according to The Unified Soil Classification System (USCS) ASTM. Undisturbed and disturbed soil samples were obtained. Sieve analysis (ASTM D6913-04) and hydrometer (ASTM D422-63) tests were conducted on soil samples to determine particle-size distribution. Likewise, hydrometer testing was implemented on soil passing No. 200 sieve (75 $\mu \mathrm{m}$ in diameter). The particle size analysis indicated predominantly fine-grained material (73\% P200 for shallow soil and 93\% P200 for the deeper soil). Results are shown in Appendix A. The shallow soil had plastic limit (PL) of 13 and liquid limit (LL) of 34. The deep soil had slightly lower PL and LL of $11 \%$ and $27 \%$ respectively.

Based on the USCS (ASTM D2487-11), the shallow soil classified as lean clay with sand (CL) and the deep soil classified as lean clay (CL). The natural density of the soil was computed at $2.125 \mathrm{~g} / \mathrm{m}^{3}$ with a water content of $15.45 \%$. Accordingly, dry unit weight and dry density were

computed as $18.05 \mathrm{kN} / \mathrm{m}^{3}$ and $1.84 \mathrm{~g} / \mathrm{cm}^{3}$, respectively. Additional information and test results are displayed in Appendix A.

\subsection{Site B}

Site B is located in the upper Midwest of the United States. There are two high capacity (1.5 MW) Vensys 82 direct drive turbines at Site B; however, only one of the turbines was instrumented for this project. 


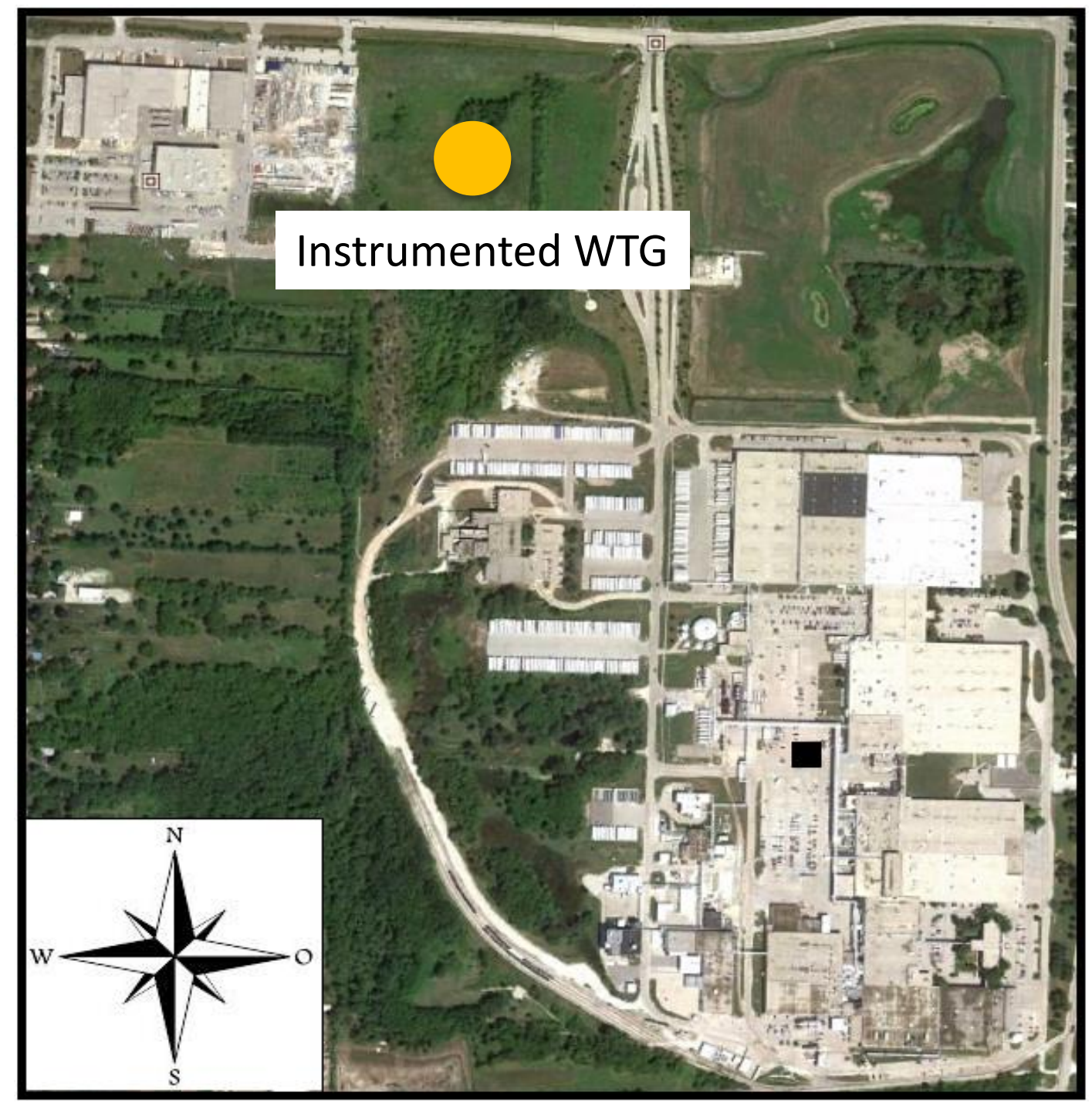

FIG. 3.5 Site B - A schematic tribune location.

The WTGs at Site B generate a portion of in-house electrical energy. Figure 3.6 displays the output power and thrust coefficient $\left(\mathrm{C}_{\mathrm{T}}\right)$ as a function of field wind speed. 


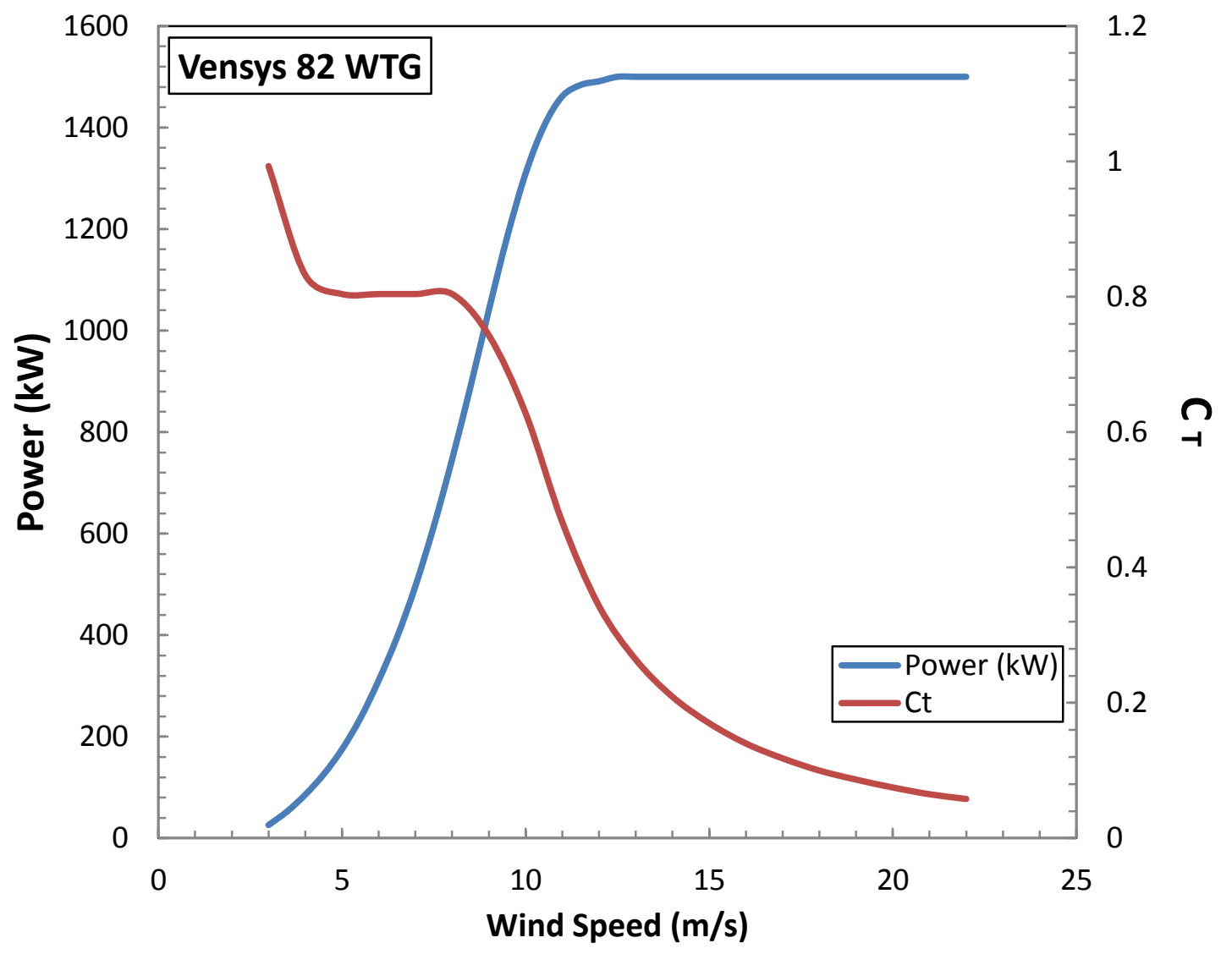

FIG. 3.6 Vensys 82 power curve and thrust curve.

For Site B, nearby airport wind data were extrapolated to the WTG construction site. The wind data shows a predominant NNE wind; however, the data also shows westerly winds for a good part of the year. Therefore, the predominant wind direction was chosen as a westerly wind in Site B, and the instrumentation layout was aligned accordingly. Figure 3.7 displays the wind rose for Site B. 


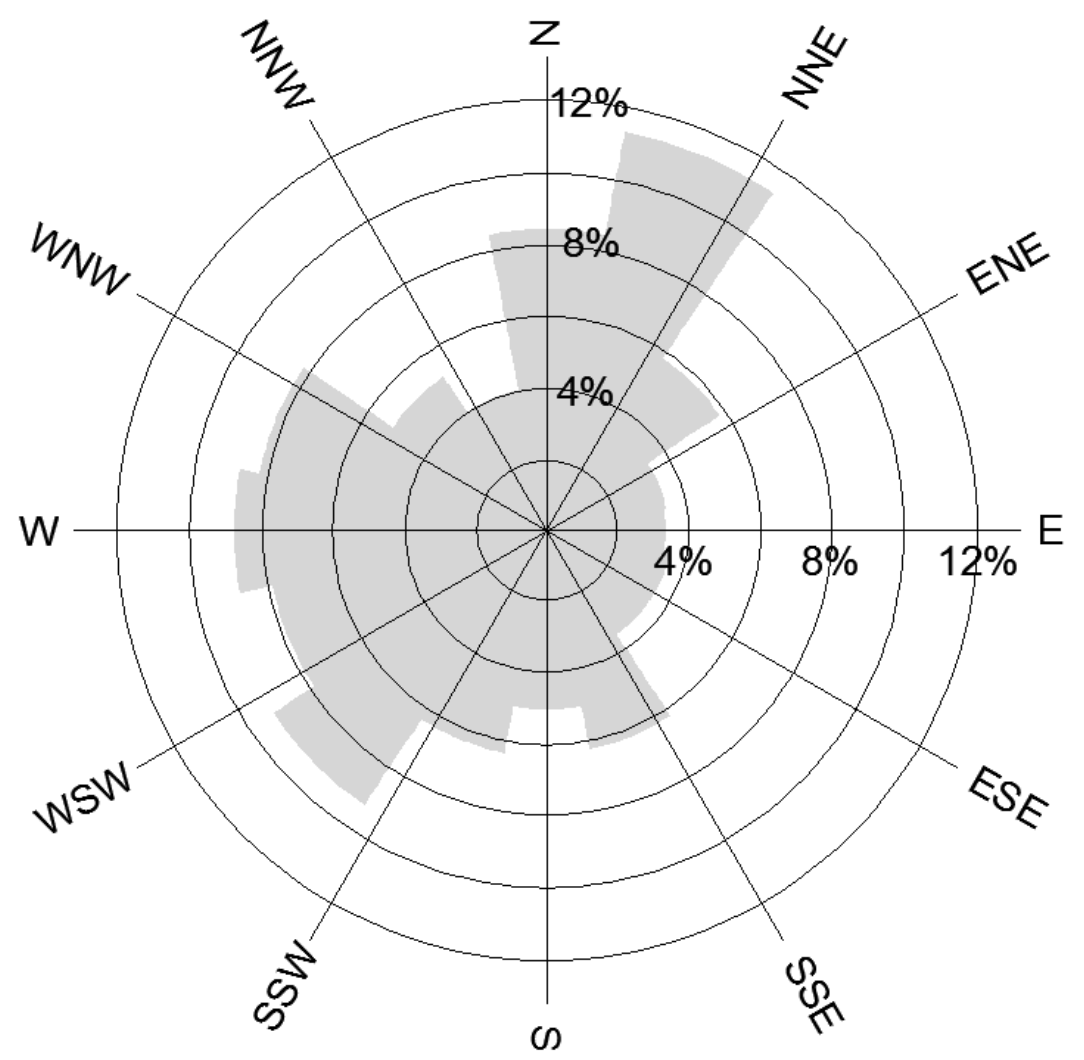

FIG. 3.7 Site B wind rose.

\subsubsection{Site Specifications and Foundation Geometry}

For Site B, a shallow octagonal foundation was installed (Figure 3.4). The diameter of the foundation in Site B $(15.85 \mathrm{~m})$ is slightly smaller than the Site A $(16.46 \mathrm{~m})$ foundation. Total height of the foundation is $4.26 \mathrm{~m}$, with an embedment of $3.05 \mathrm{~m}$ below ground surface. Unfactored horizontal and vertical loads from the load document were $667.4 \mathrm{kN}$ and $2269.1 \mathrm{kN}$, respectively. Unfactored overturning moment was 47,736 kN.m.

\subsubsection{Soil Properties and Classification}

SPTs and boings were advanced at Site B to determine the physical properties of the soil. Additionally, several Shelby tubes were pushed to obtain undisturbed soil samples. The soil profile was relatively uniform with soil classifying as lean clay (CL) in the shallow subsurface 
(approximately $1.6 \mathrm{~m}$ to $3 \mathrm{~m}$ below the surface). The unconfined compressive strength of the stiff clay layer was in the range of $72 \mathrm{kPa}$ to $431 \mathrm{kPa}$. Table 3.1 summaries the geotechnical result for both sites.

Table 3.1 Geotechnical Results

\begin{tabular}{|l|c|c|}
\cline { 2 - 3 } \multicolumn{1}{c|}{} & SITE A & SITE B \\
\hline Foundation Diameter $(\mathrm{m})$ & 16.46 & 15.85 \\
\hline Foundation Side length $(\mathrm{m})$ & 6.81 & 6.55 \\
\hline Embedment Depth $(\mathrm{m})$ & 2.69 & 3.05 \\
\hline $\begin{array}{l}\text { Unfactored Extreme Overturning Moment } \\
\text { (kN.m) }\end{array}$ & 49,603 & 47,736 \\
\hline Unfactored Horizontal Force $(\mathrm{kN})$ & 730 & 667.4 \\
\hline Unfactored Vertical Force $(\mathrm{kN})$ & 2340 & 2269.1 \\
\hline Liquid Limit & $34 *$ & 23 \\
\hline Plastic Limit & $13^{*}$ & 11 \\
\hline Classification (ASTM D2487-11) & $\mathrm{CL}$ & $\mathrm{CL}$ \\
\hline Max Dry Density (at water content $8 \%)\left(\mathrm{kN} / \mathrm{m}^{3}\right)$ & 19.6 & \\
\hline Max Dry Density (at water content $14 \%)\left(\mathrm{kN} / \mathrm{m}^{3}\right)$ & 18.2 & 2.125 \\
\hline Density (ASTM D7263-09) $\left(\mathrm{g} / \mathrm{cm}^{3}\right)$ & 2.15 & 12 \\
\hline Water Content $(\%)$ & 14 & 1.89 \\
\hline Dry Density (g/cm $\left.{ }^{3}\right)$ & 1.84 & 18.42 \\
\hline Dry Unit Weight (kN/m ${ }^{3}$ ) & 18.05 & \\
\hline
\end{tabular}

(*Site A shallow soil)

\subsection{Instrumentation}

This research focuses on measurement and analysis of contact pressure distribution, soil deformation beneath the WTG foundation, and moment transfer from the turbine tower to the foundation block. As such, geotechnical instruments and sensors were placed under the foundation base before the construction of the foundations and interior walls of the turbine towers. For both research sites, similar methodology was followed. However, instruments were oriented to align with the predominant wind direction. 
Figure 3.14 and Figure 3.15 summarize the instrumentation layout for both sites. Pressure cells were oriented depending on predominant wind direction. Nine pressure cells were installed; five were oriented along the predominant wind direction axis. Two pressure cells were installed along two lines $70^{\circ}$ from the predominant wind direction. Cells 2, 4, 6, and 8 were placed $2.85 \mathrm{~m}$ from the center of the foundation, while cells $1,5,7$, and 9 were placed $10 \mathrm{~m}$ from the center

\subsubsection{Pressure Cells}

Nine Geokon Model 3500 contact earth pressure cells (PG) were installed at each site. The pressure cells are of the hydraulic type in which two steel flat plates are welded and separated by a small amount of hydraulic fluid. Mechanically, pressure measurement of the cell is based on pressure- electrical signal conversion. External loads create a pressure increase in the hydraulic fluid and these pressure increases are converted to electrical signals, which are transmitted throughout a signal cable to the data logger.

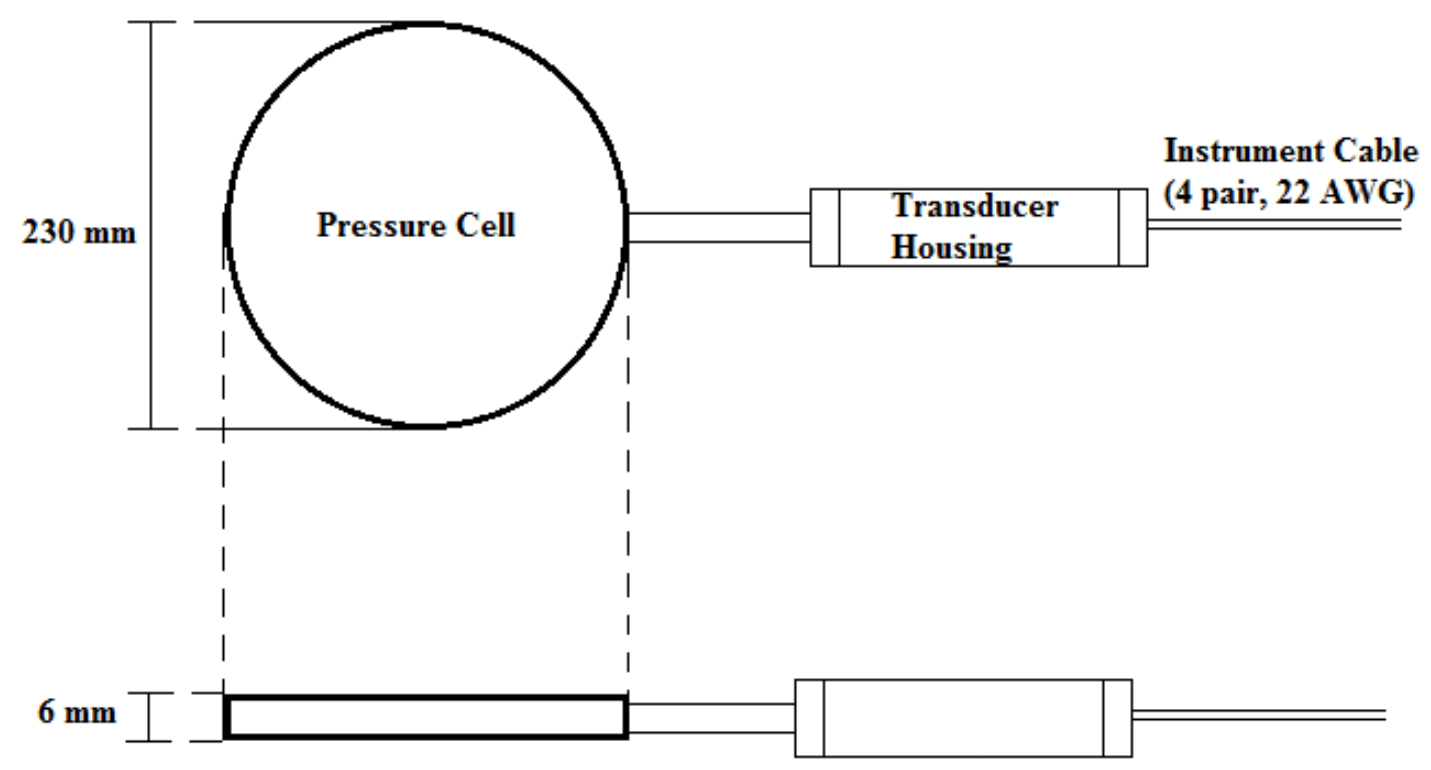

FIG. 3.8 Model 3500 circular earth pressure cell. 
The potential concern with pressure cells is the non-equal stiffness interaction between soil deposit and pressure cell. Ideally, pressure cells should be as stiff as the soil; however, in reality, this is nearly impossible to achieve. Thus under- or over-registration problems may be observed. There are several factors leading to over- or under-pressure registration. As an illustration, if the cell is less compressible (or stiffer) than soil, it will over-register the stress around the cell which is sheltered by the cell. Figure 3.9 shows this issue schematically.

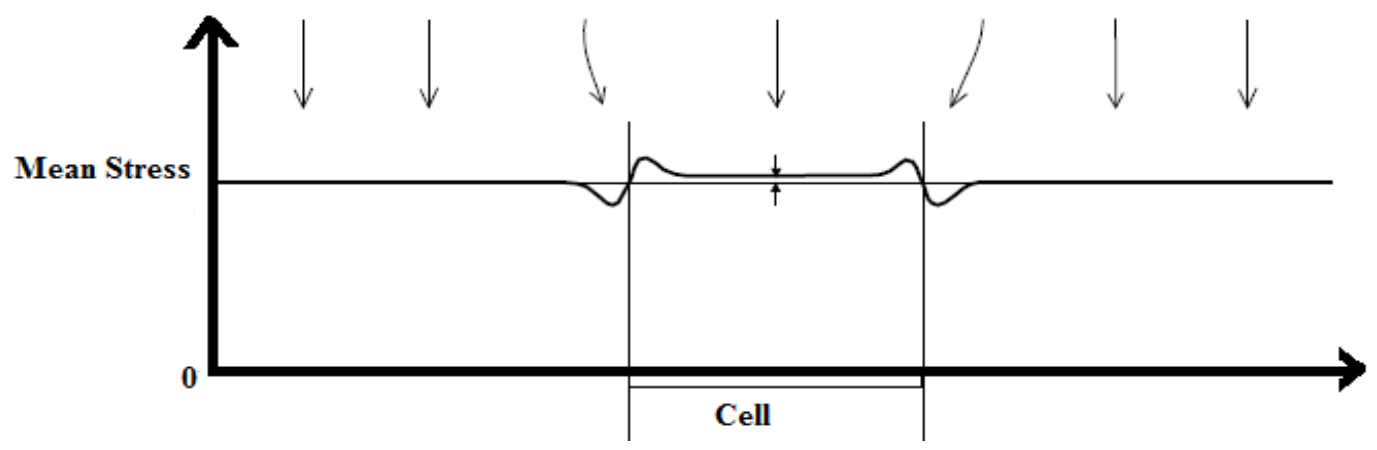

FIG. 3.10 Stress redistribution- soil is less stiff than cell (Geokon Instruction Manual, Model 3500 Earth Pressure Cells).

If the soil is stiffer, the de-stressed zone around the cell becomes larger and the cell will over-register the mean stress (Figure 3.11).

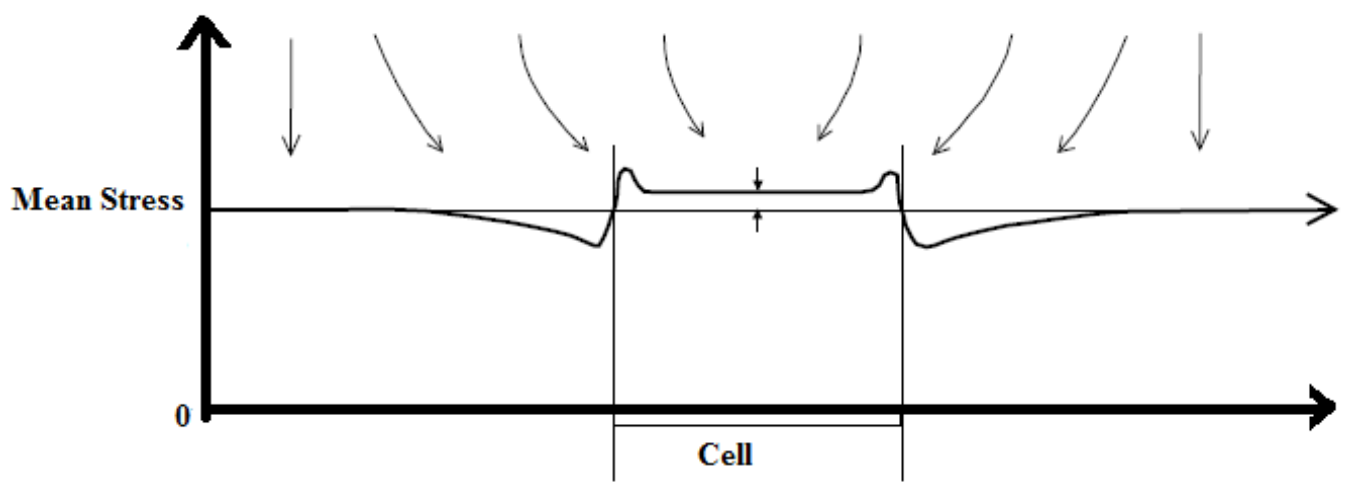

FIG. 3.11 Stress redistribution- strong soil and stiff cell (Geokon Instruction Manual, Model 3500 Earth Pressure Cells). 
If the soil zone is relatively stiff, "bridging" may occur which causes under-registration in the cells. In this scenario, the cell is more compressible than the surrounding soil. Figure 3.12 summaries redistributed stresses for this "bridging" scenario.

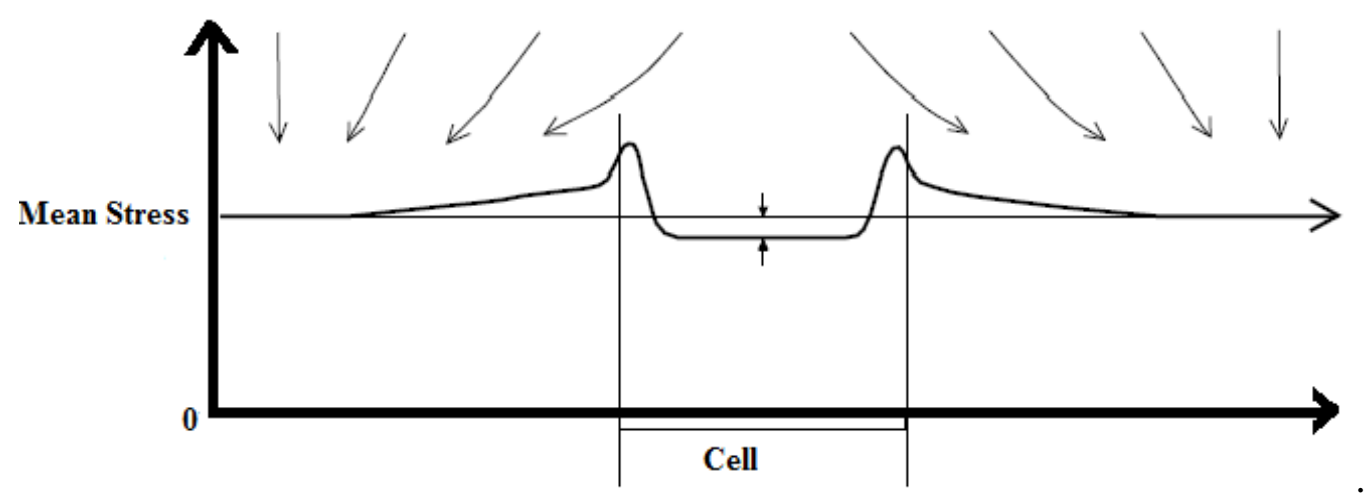

\section{FIG. 3.12 Stress redistribution- soil stiffer than cell (Geokon Instruction Manual, Model 3500 Earth Pressure Cells).}

Nine shallow excavations (> $20 \mathrm{~cm}$ in width and approximately $3 \mathrm{~cm}$ in depth) were dug below foundation grade and the pressure cells were carefully placed into these pockets. Quickrete ${ }^{\circledR}$ all-purpose sand was placed below and above each pressure cell (sand layer thickness was about $2 \mathrm{~cm}$ ).
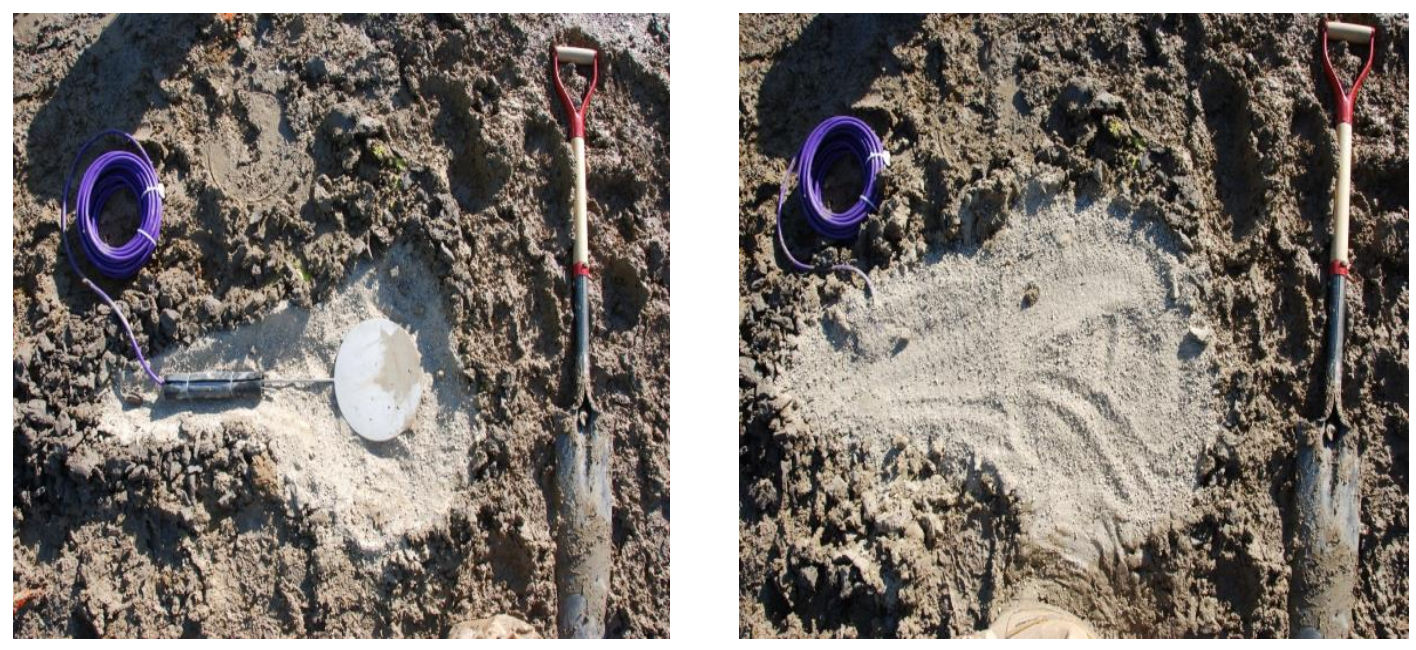

FIG. 3.13 Pressure cell installation. 


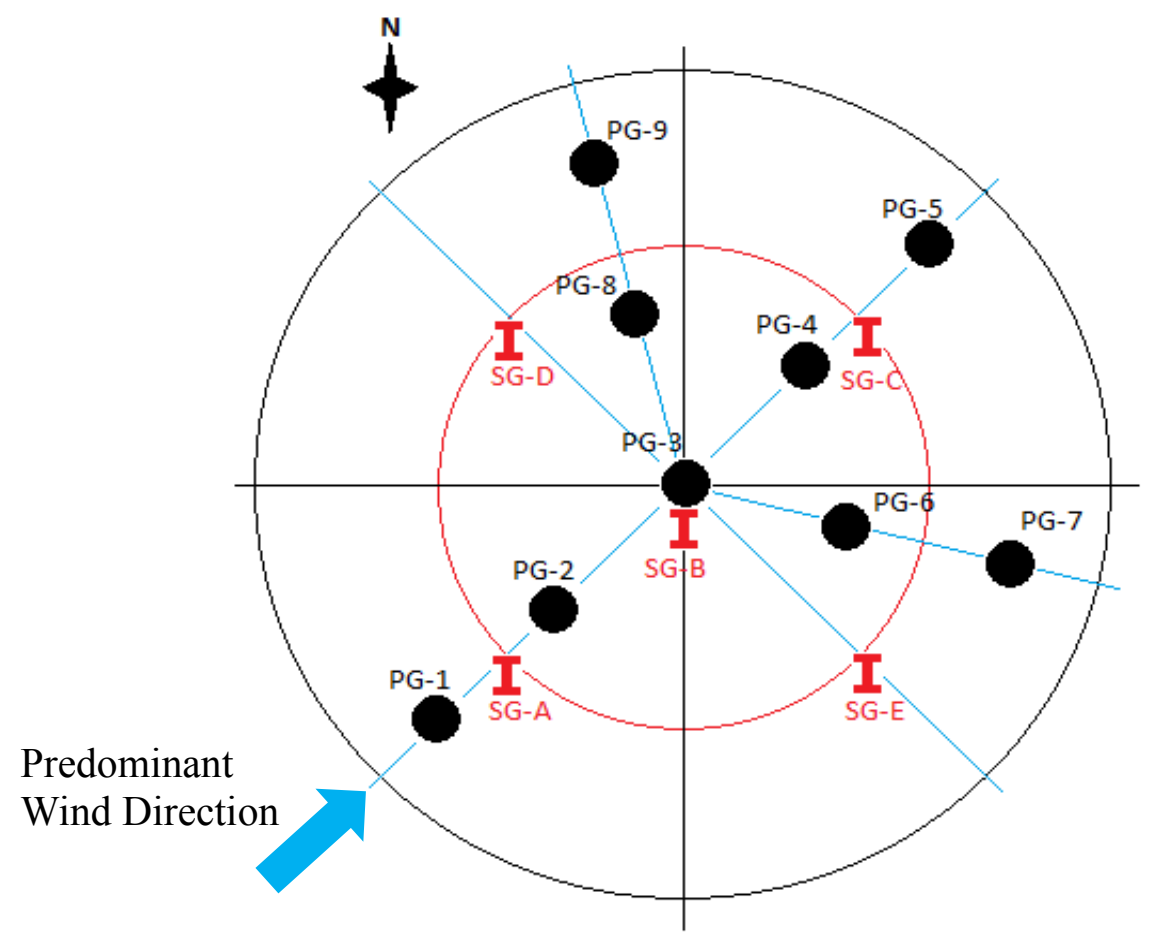

FIG. 3.14 Instrumentation layout for Site A.

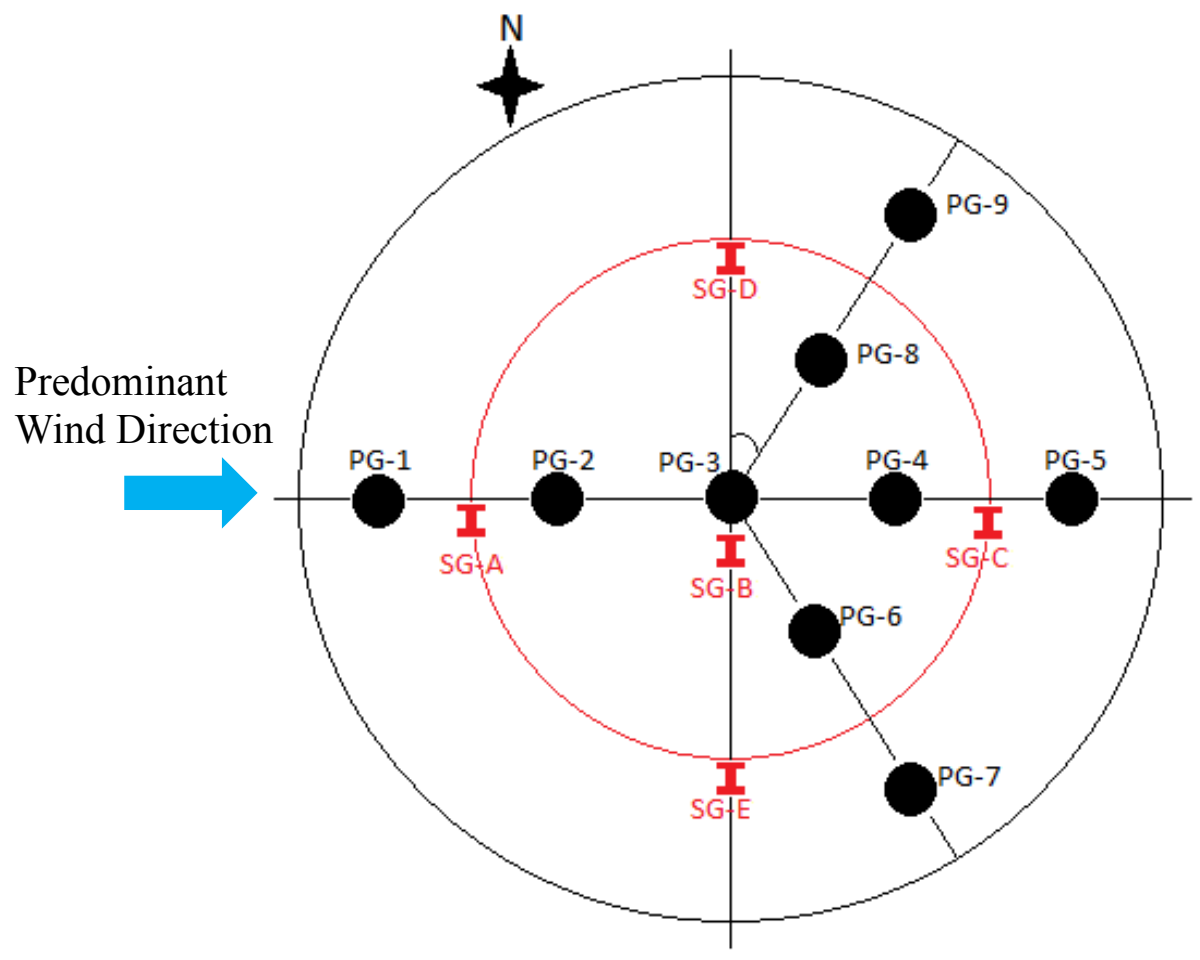

FIG. 3.15 Instrumentation layout for Site B. 
The applied stress on a pressure cell is determined as

$$
P=\left(R_{1}-R_{0}\right) x G
$$

where $\mathrm{P}=$ applied load in $\mathrm{kPa}, \mathrm{R}_{1}=$ current, $\mathrm{R}_{0}=$ initial output reading in $\mathrm{mV}$, and $\mathrm{G}$ is gage factor. Initial readings are typically determined during installation immediately prior to loading the cells. Table 3.1 and 3.2 summaries the initial readings and gage factors for Site A and Site B.

Table 3.1 Site A-Pressure Cells Initial Readings

\begin{tabular}{|c|c|}
\hline PRESSURE CELL & INITIAL READING (V) \\
\hline PG-1 & 0.166 \\
\hline PG-2 & 0.153 \\
\hline PG-3 & 0.151 \\
\hline PG-4 & 0.134 \\
\hline PG-5 & 0.113 \\
\hline PG-6 & 0.145 \\
\hline PG-7 & 0.148 \\
\hline PG-8 & 0.139 \\
\hline PG-9 & 0.143 \\
\hline
\end{tabular}

* Gage factors for pressure cells in Site A are all same and equal to $50 \mathrm{kPa} / \mathrm{V}$.

Table 3.2 Site B-Pressure Cells Initial Readings

\begin{tabular}{|c|c|c|}
\hline PRESSURE CELL & GAGE FACTOR (kPa/V) & INITIAL READING (V) \\
\hline PG-1 & 49.92 & 0.129 \\
\hline PG-2 & 50.10 & 0.171 \\
\hline PG-3 & 49.92 & 0.110 \\
\hline
\end{tabular}




\begin{tabular}{|c|c|c|}
\hline PG-4 & 50.01 & 0.176 \\
\hline PG-5 & 49.93 & 0.165 \\
\hline PG-6 & 49.92 & 0.149 \\
\hline PG-7 & 49.91 & 0.186 \\
\hline PG-8 & 49.84 & 0.208 \\
\hline PG-9 & 49.86 & 0.217 \\
\hline
\end{tabular}

\subsubsection{Soil Deformation Gauges}

Ten soil deformation gauges (Geokon 4430 vibrating wire deformation meters) were installed beneath the each WTG foundation. The deformation was measured with a vibrating wire strain gauge in series with a precision music wire spring which coupled with a movable shaft within the deformation gauge. As the shaft moved in or out of the sensor, the spring tension variation was converted to deformation. The main purpose of the soil strain gauges (SG) was to measure the deformation of the underlying soil at different locations and depths. The instruments have the ability to measure displacement up to $12.5 \mathrm{~mm}$, and the total length of the deformation meter is $300 \mathrm{~mm}$; thus, the maximum strain measurement is $4.17 \%$. Soil strain gauges were also installed according to predominant wind direction. Eight deformation gauges were installed along the predominant wind direction axis and two were placed perpendicular to the predominant wind direction (Figures 3.14 and 3.15). Three deformation gauges were located at the center of the foundation at different depth and four were placed at varying depths on the leeward site. Figure 3.16 displays locations of the deformation gauges at different depths for both sites. Deformation meters were placed into averaged boreholes. Quickrete ${ }^{\circledR}$ all-purpose sand was used 
as and backfill compacted with a concrete vibrator during the gauges placement. Figure 3.17 is a photo of the soil gauge installation process.

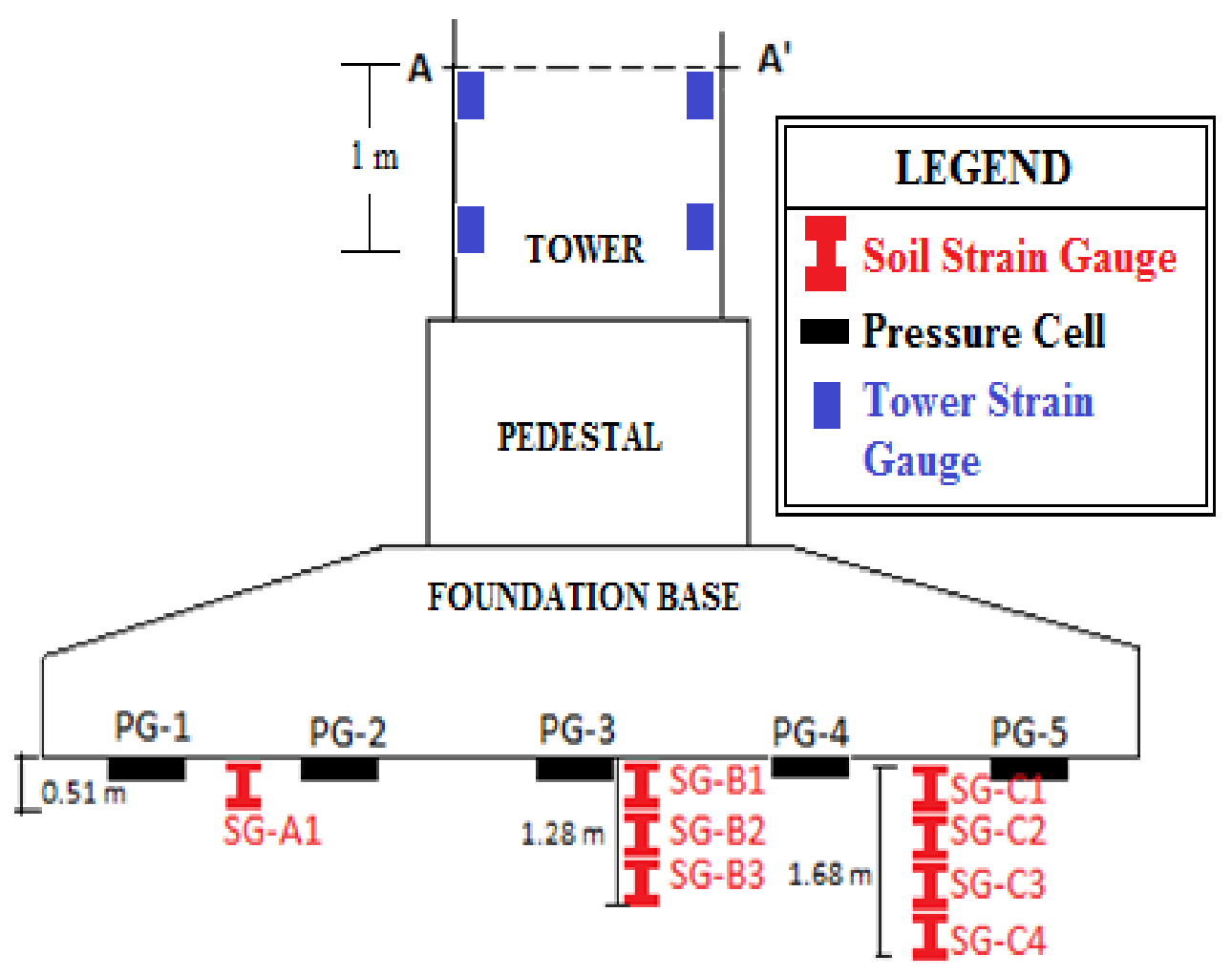

FIG. 3.16 Instrumentation cross section for both sites. 


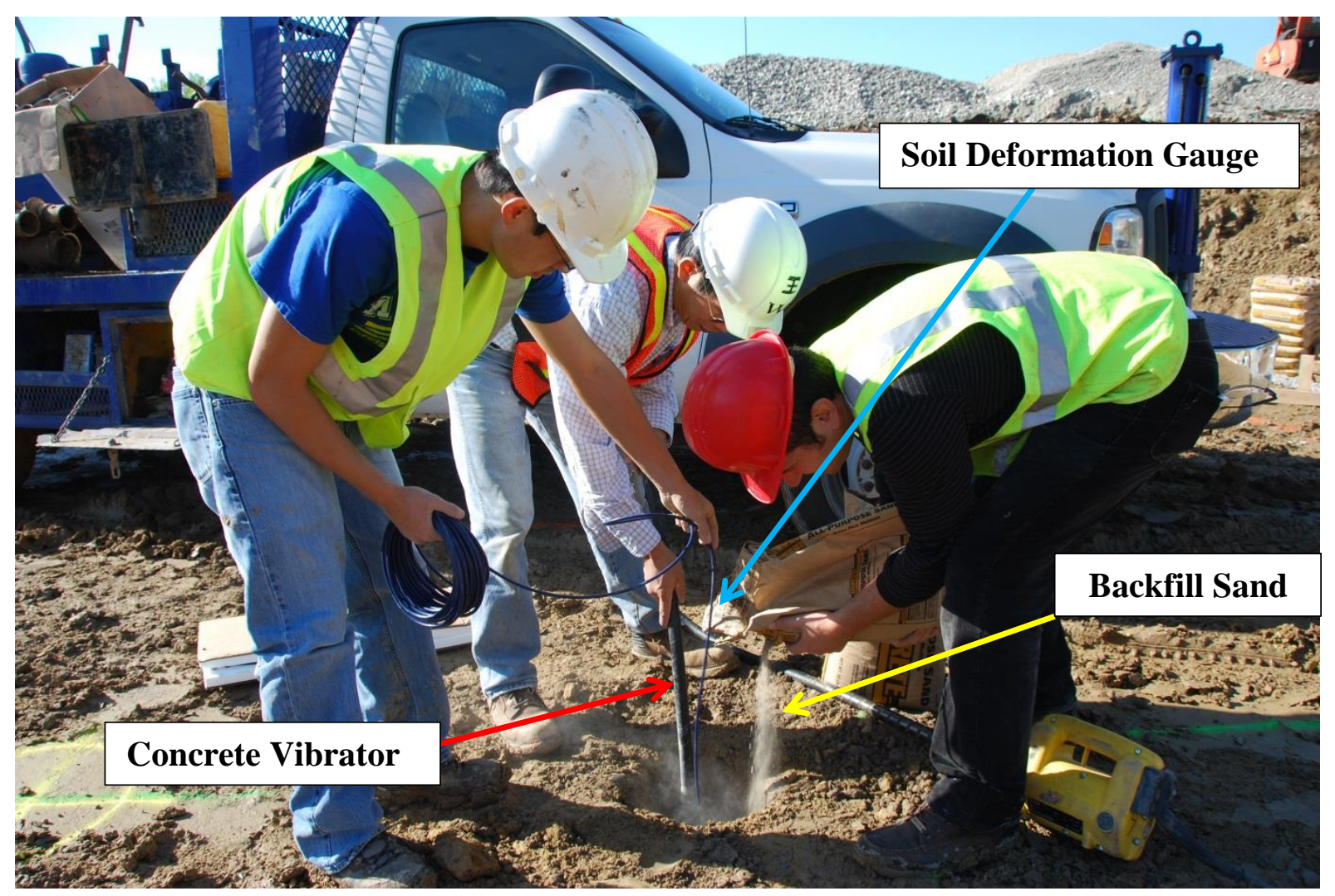

FIG. 3.17 Soil deformation gauge installation.

Soil deformation is determined with frequency data from deformation sensors.

Temperature, noise ratio, and amplitudes are also recorded. Strain change due to temperature fluctuation requires consideration. Initial readings and gage factors provided by manufacturer are shown in Table 3.3 and 3.4.

Table 3.3 Site A-Soil Deformation Gage Initial Readings and Gauge Factors

\begin{tabular}{|c|c|c|c|c|}
\hline $\begin{array}{c}\text { Deformation } \\
\text { Gauge }\end{array}$ & $\begin{array}{c}\text { Gage Factor } \\
\text { (mm/digit) }\end{array}$ & $\begin{array}{c}\text { Initial Readings } \\
\text { (Digits) }\end{array}$ & $\begin{array}{c}\text { Corrected } \\
\text { Initial Readings } \\
\text { (Digits) }\end{array}$ & $\begin{array}{c}\text { Temperature } \\
\text { ( } \mathbf{0} \text { C) }\end{array}$ \\
\hline SG-1 & 0.002399 & -4492.994 & 4492.944 & 5.64 \\
\hline SG-2 & 0.002401 & -4491.230 & 4491.230 & 6.13 \\
\hline SG-3 & 0.002408 & -4509.069 & 4509.069 & 6.18 \\
\hline SG-4 & 0.002407 & -4499.185 & 4499.185 & 8.03 \\
\hline
\end{tabular}




\begin{tabular}{|c|c|c|c|c|}
\hline SG-5 & 0.002410 & -4481.587 & 4481.587 & 7.09 \\
\hline SG-6 & 0.002407 & -4502.386 & 4502.386 & 7.02 \\
\hline SG-7 & 0.002411 & -4503.225 & 4503.225 & 7.91 \\
\hline SG-8 & 0.002400 & -4501.222 & 4501.222 & 9.89 \\
\hline SG-9 & 0.002395 & -4489.089 & 4489.089 & 5.82 \\
\hline SG-10 & 0.002408 & -4500.953 & 4500.953 & 4.10 \\
\hline
\end{tabular}

Table 3.4 Site B-Soil Deformation Gage Initial Readings and Gauge Factors

\begin{tabular}{|c|c|c|c|c|}
\hline $\begin{array}{c}\text { Deformation } \\
\text { Gauge }\end{array}$ & $\begin{array}{c}\text { Gage Factor } \\
\text { (mm/digit) }\end{array}$ & $\begin{array}{c}\text { Initial Readings } \\
\text { (Digits) }\end{array}$ & $\begin{array}{c}\text { Corrected } \\
\text { Initial Readings } \\
\text { (Digits) }\end{array}$ & $\begin{array}{c}\text { Temperature } \\
\left({ }^{\mathbf{0}} \mathbf{C}\right)\end{array}$ \\
\hline SG-1 & 0.002327 & -4763.792 & 4763.792 & 16.3 \\
\hline SG-2 & 0.002775 & -4693.475 & 4693.475 & 18.8 \\
\hline SG-3 & 0.002336 & -4550.996 & 4550.996 & 19.4 \\
\hline SG-4 & 0.002327 & -4775.694 & 4775.694 & 18.3 \\
\hline SG-5 & 0.002327 & -4560.587 & 4560.587 & 19.2 \\
\hline SG-6 & 0.002766 & -4556.993 & 4556.993 & 17.7 \\
\hline SG-7 & 0.002332 & -4561.185 & 4561.185 & 17.4 \\
\hline SG-8 & 0.002320 & -4546.017 & 4546.017 & 19.5 \\
\hline SG-9 & 0.002337 & -4715.983 & 4715.983 & 20.2 \\
\hline SG-10 & 0.002408 & -4640.187 & 4640.187 & 21.0 \\
\hline
\end{tabular}

Frequency of the vibrating wired sensors are computed in units of "digits." The following equations show the equivalency of digits to terms of period and frequency: 


$$
\begin{aligned}
& \text { Digits }=\left(\frac{1}{\text { Period }}\right)^{2} \times 10^{-3} \\
& \text { Digits }=\frac{H z^{2}}{1000}
\end{aligned}
$$

Digits are converted deformation magnitudes by using the following equation:

$$
D=\left(R_{1}-R_{0}\right) \times C \times F
$$

where $\mathrm{D}=$ deformation $(\mathrm{mm}), \mathrm{R}_{1}=$ current reading, $\mathrm{R}_{0}=$ initial reading, $\mathrm{C}=$ calibration factor, and $\mathrm{F}=$ conversation factor. Correction of strain due to fluctuation in temperature is.

$$
D_{\text {corrected }}=\left(\left(R_{1}-R_{0}\right) x C\right)+\left(\left(T_{1}-T_{0}\right) x K\right)+L_{C}
$$

where $\mathrm{R}_{1}=$ current reading, $\mathrm{R}_{0}=$ initial reading, $\mathrm{C}=$ calibration factor, $\mathrm{T}_{1}=$ current temperature, $\mathrm{T}_{0}=$ initial temperature, $\mathrm{K}=$ thermal coefficient, and $\mathrm{L}_{\mathrm{C}}=$ correction for gage length.

\subsubsection{Thermal Dissipation Sensors}

Thermal dissipation sensors were installed to record water content change in foundation soil. Four thermal dissipation sensor were installed under the Site A turbine foundation at three locations. Thermal dissipations sensor are a type of ceramic sensors and they correlates the thermal conductivity of a system with surrounding water moisture. The thermal dissipation sensors were calibrated before installation with field site soil sample. Several moisture measurements were executed on the soil at different soil water contents to calibrate the sensors.

Three locations were determined for the thermal sensors (Figure 3.18). Each of sensors was placed at different depth. TD-1 at 610-mm, TD-2 at 660-mm, TD-3 at 610-mm, and TD-4 at $510 \mathrm{~mm}$ depth. 


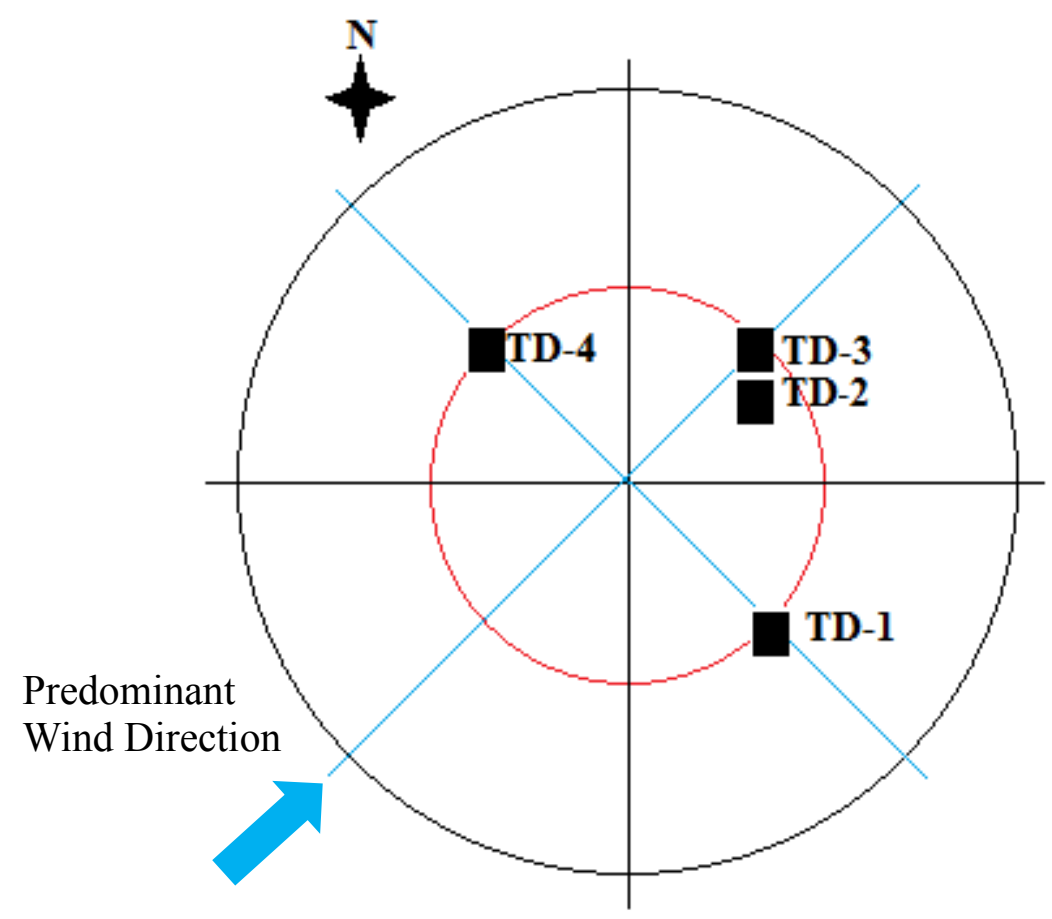

FIG. 3.18 Site A Thermal dissipation sensor layout.

\subsubsection{Tower Strain Gauges}

Forces transmitted from the WTG tower to the foundation were monitored to compute the transferred moment from the tower to the foundation base. This is achieved with two sets of optical strain gauges installed on the inside of the WTG tower. Strain values at two different heights are used to calculate equivalent transmitted moment at the base of the WTG tower. These calculated equivalent moments are used to determine the shear force transferred to the foundation block. Optical strain gauges were mounted on the interior wall of the WTG tower with equidistance $\left(120^{0}\right)$ from each other. Figure 3.19 summaries the tower optical strain gauges locations. 


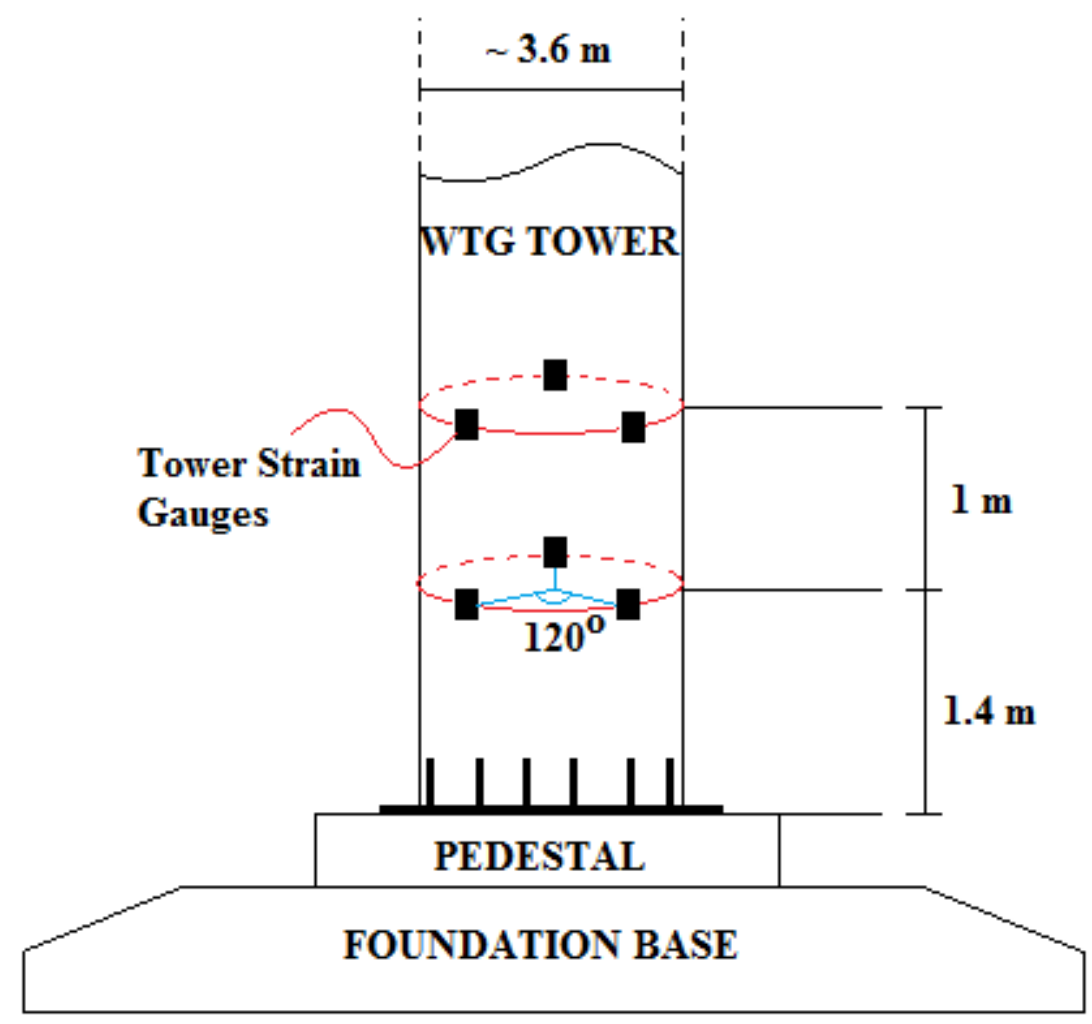

FIG. 3.19 Tower strain gauges locations.

Tower strain gauges allow for the estimation of the applied dynamic load direction and time history as well as applied moment transfer. This dynamic load direction and time history estimation is based on transferred moment and shear force variations. Because of applied loading, an internal shear force develops along the axis of the beam. To design a durable beam or a vertical vessel, the maximum shear force and moment values are required. Generally, bending moment and shear force are determined as a function of the length of the beam or vessel and applied force. At the minimum equivalent moment point, shear force reaches a maximum value. Figure 3.20 displays the variation of the shear force $(\mathrm{V})$ and moment $(\mathrm{M})$ throughout the length of a beam. 


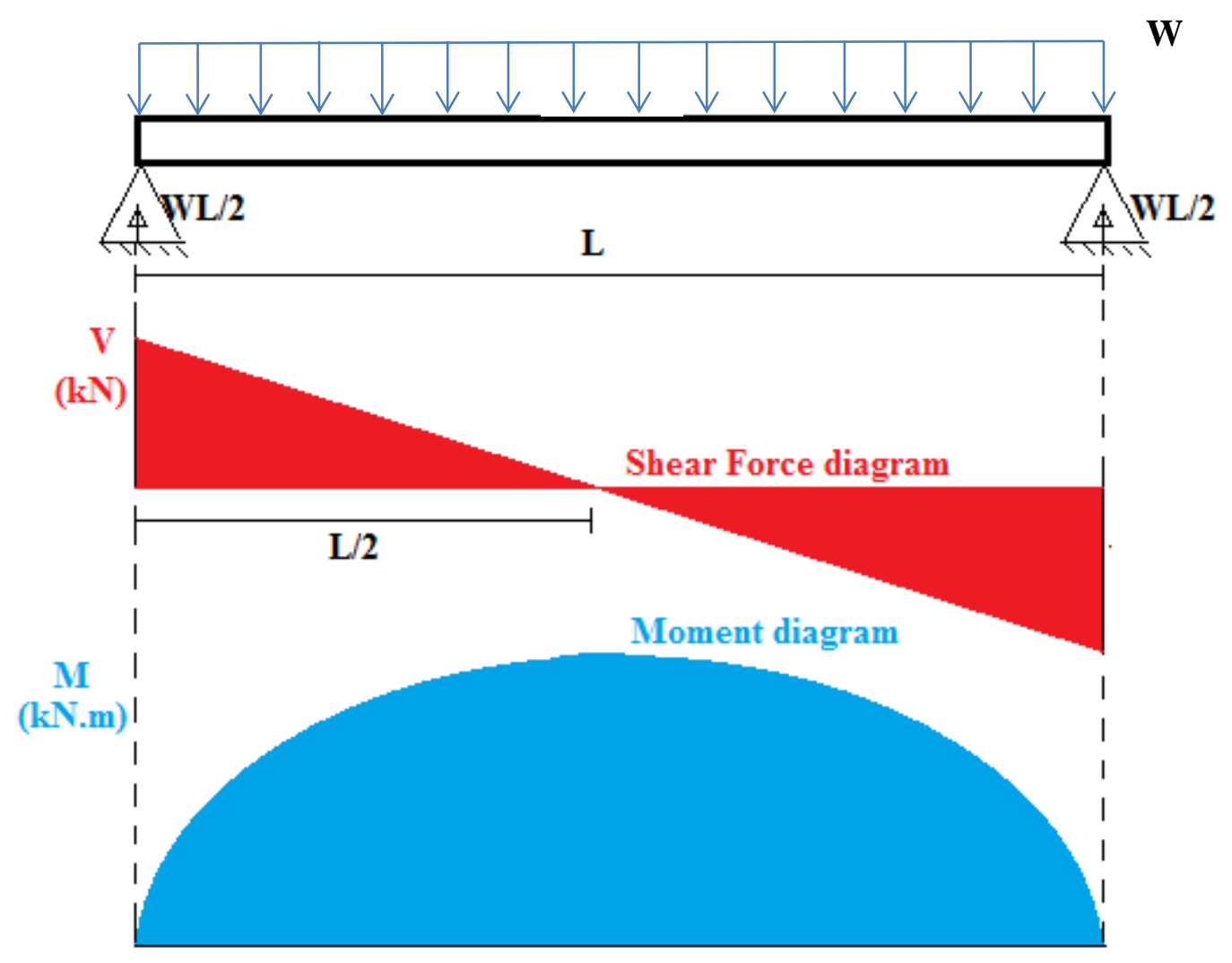

FIG. 3.20 Shear force and moment diagrams.

The moment is determined by using combination of the Hooke's Law (Eq. 3.6) and stress formula (Eq. 3.7).

$$
\begin{aligned}
& \sigma=E . \varepsilon \\
& \sigma=\frac{M \cdot c}{I} \\
& M=\frac{E \cdot \varepsilon \cdot I}{C}
\end{aligned}
$$

where $\mathrm{M}=$ moment, $\mathrm{E}=$ modulus of elasticity, $\varepsilon=$ strain, $\sigma=$ stress, $\mathrm{c}=$ distance to center of shape, and $I=$ moment of inertia. Shear force is computed through the change in calculated moment and the distance between tower gauges:

$$
V=\frac{\partial M}{\partial z}
$$


where $\mathrm{V}=$ shear force, $\partial M=$ change in moment, and $\partial z=$ vertical distance between two gauges.

Twelve optical strain gauges were mounted inside each WTG tower in total. The first set of tower strain gauges were mounted $1.4 \mathrm{~m}$ above the tower base. The second set was mounted $2.4 \mathrm{~m}$ above the tower base (Figure 3.19). Additionally, twelve "dummy" gauges were mounted perpendicular to the strain gauges on the interior wall of the towers. Dummy gauges are used to eliminate temperature strain effects caused by change in temperature.

The temperature effect was accounted for through full-bridge circuits. Four strain gauges (two of them are dummy gauges) were placed in each full-bridge circuit. The full-bridge circuit is excited with $\mathrm{V}_{\mathrm{i}}$ voltage. The output voltage is measured between each couple of measuring and dummy gauges (between point A and B) (Figure 3.21)

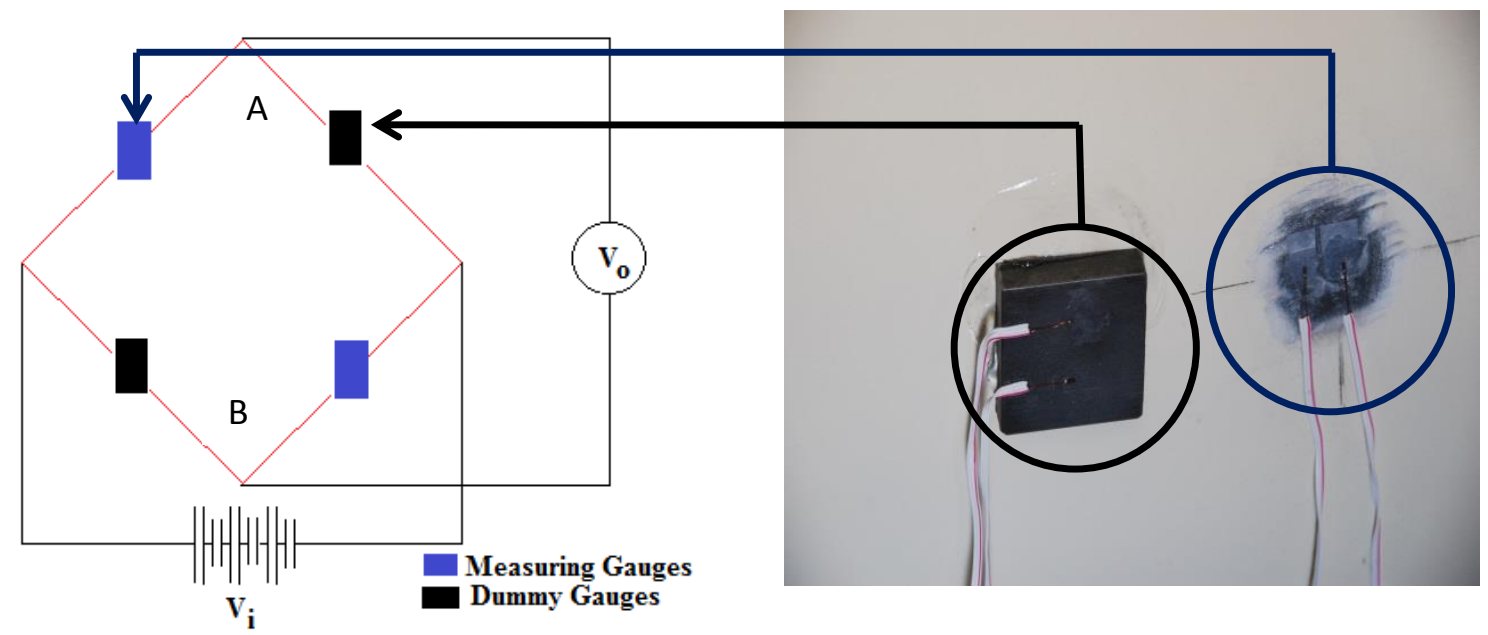

FIG. 3.21 Tower strain gauges full-bridge wiring.

\subsubsection{Micro Electro Mechanical systems (MEMS) accelerometers}

MEMS accelerometers were installed to monitor rotations in the foundation block. Typically, MEMS accelerometers are used to measure the acceleration, tilt, shock, or vibration of points on or in the ground or a structure (Dunnicliff 1988). Three MEMS accelerometers were placed at the bottom of the tower with $120^{\circ}$ separation (Figure 3.22 ). These three instruments 
allow for the estimation of the movement of the foundation block in different dictions. MEMS accelerometers were only installed at Site A. Figures 3.22 and 3.23 display the positioning and installation, respectively, of MEMS accelerometers

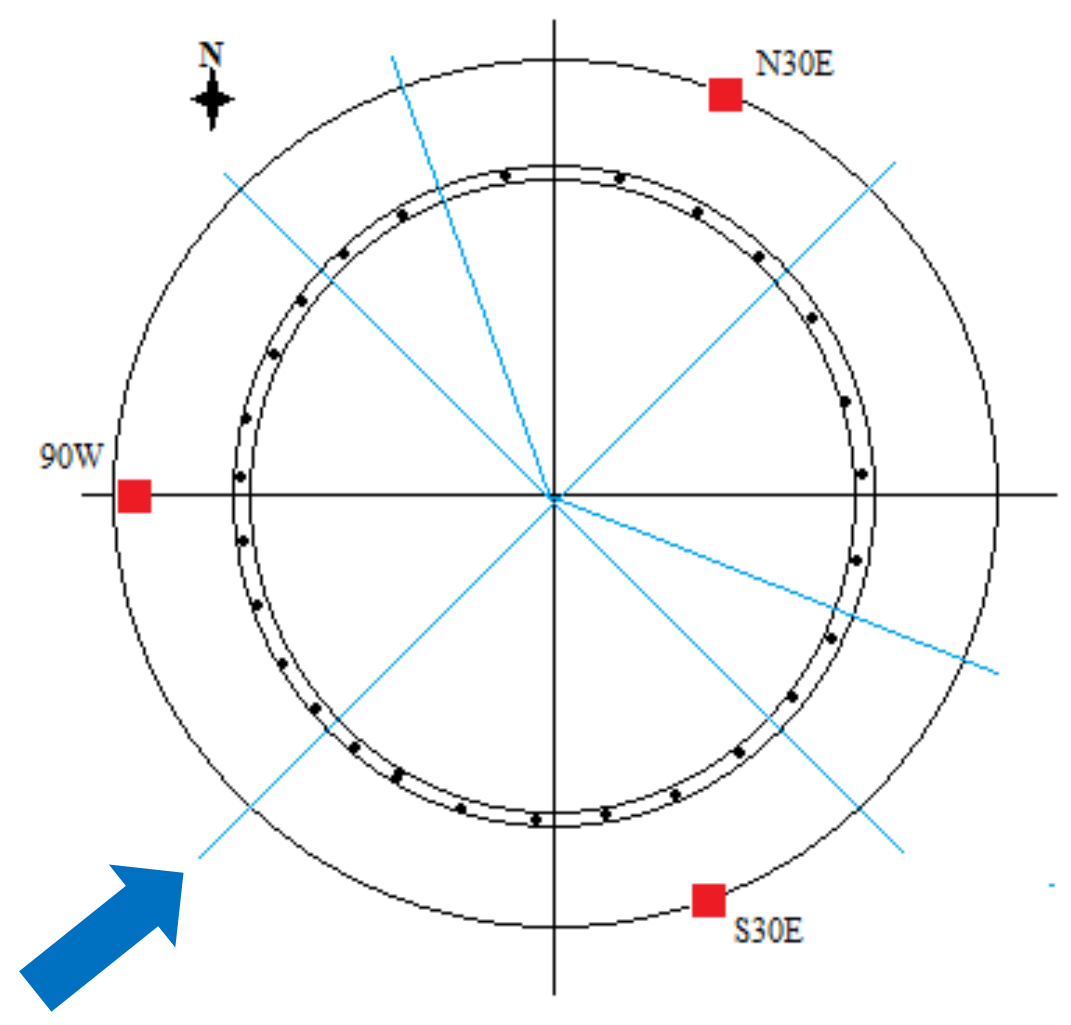

FIG. 3.22 Location of MEMS accelerometers at the bottom of the tower. 

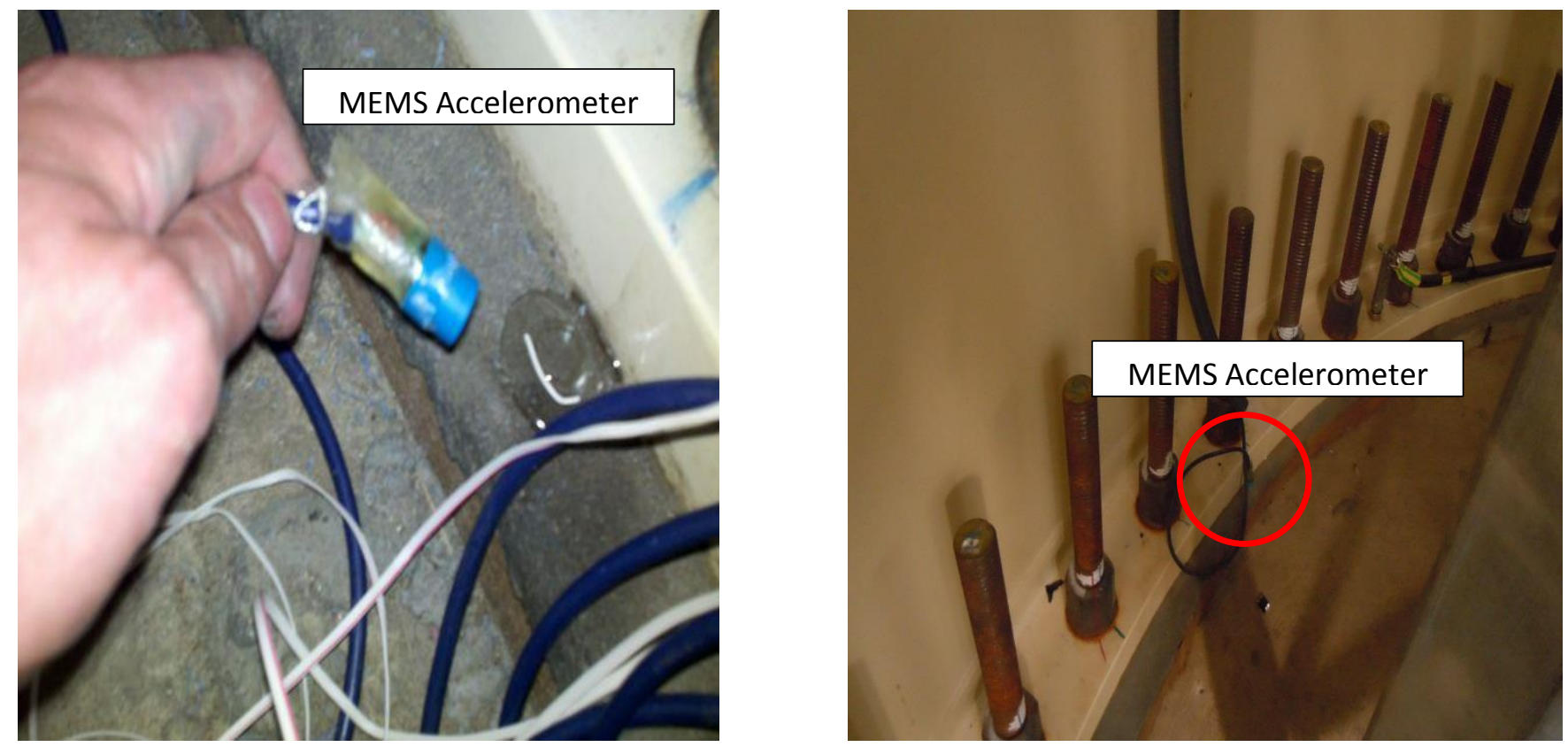

FIG. 3.23 MEMS accelerometers installation.

\subsection{Data logging System}

To record and evaluate the mechanical and dynamic behavior of the WTG foundation system, sensor responses must be converted to an intelligible signal version. A CR 3000 (Cambell Scientific, Inc.) data logger was installed at each site. The CR 3000 records the analog voltage and pulse signals, representing these magnitude numerically, and these numerical values are then analyzed by the user. 12-V DC electricity is used to power the CR 3000 data logger. The data logger has a backup battery to protect the program, memory, and clock in case of power losses. 


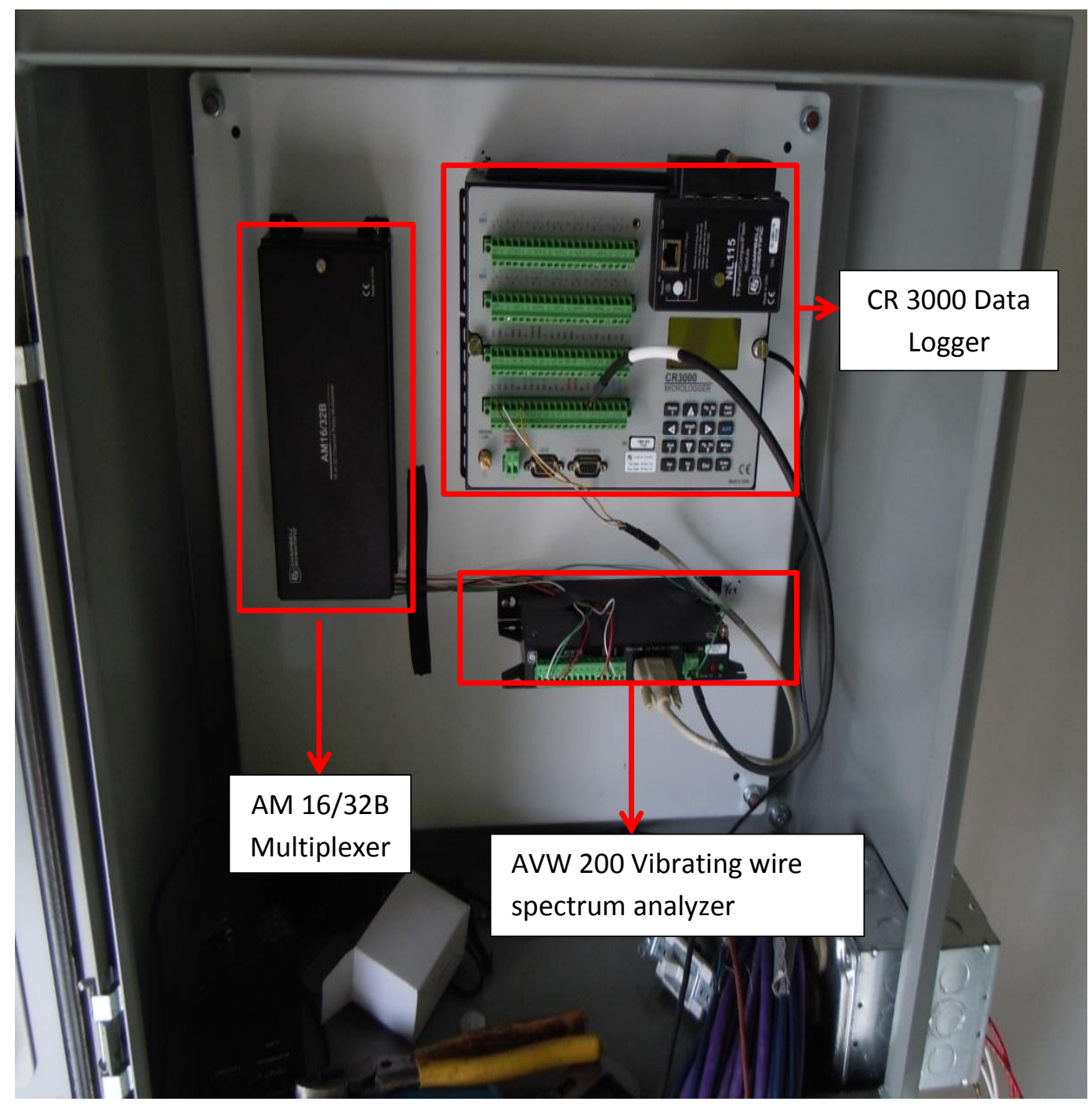

FIG. 3.24 CR 3000 data logger (no-wired). 


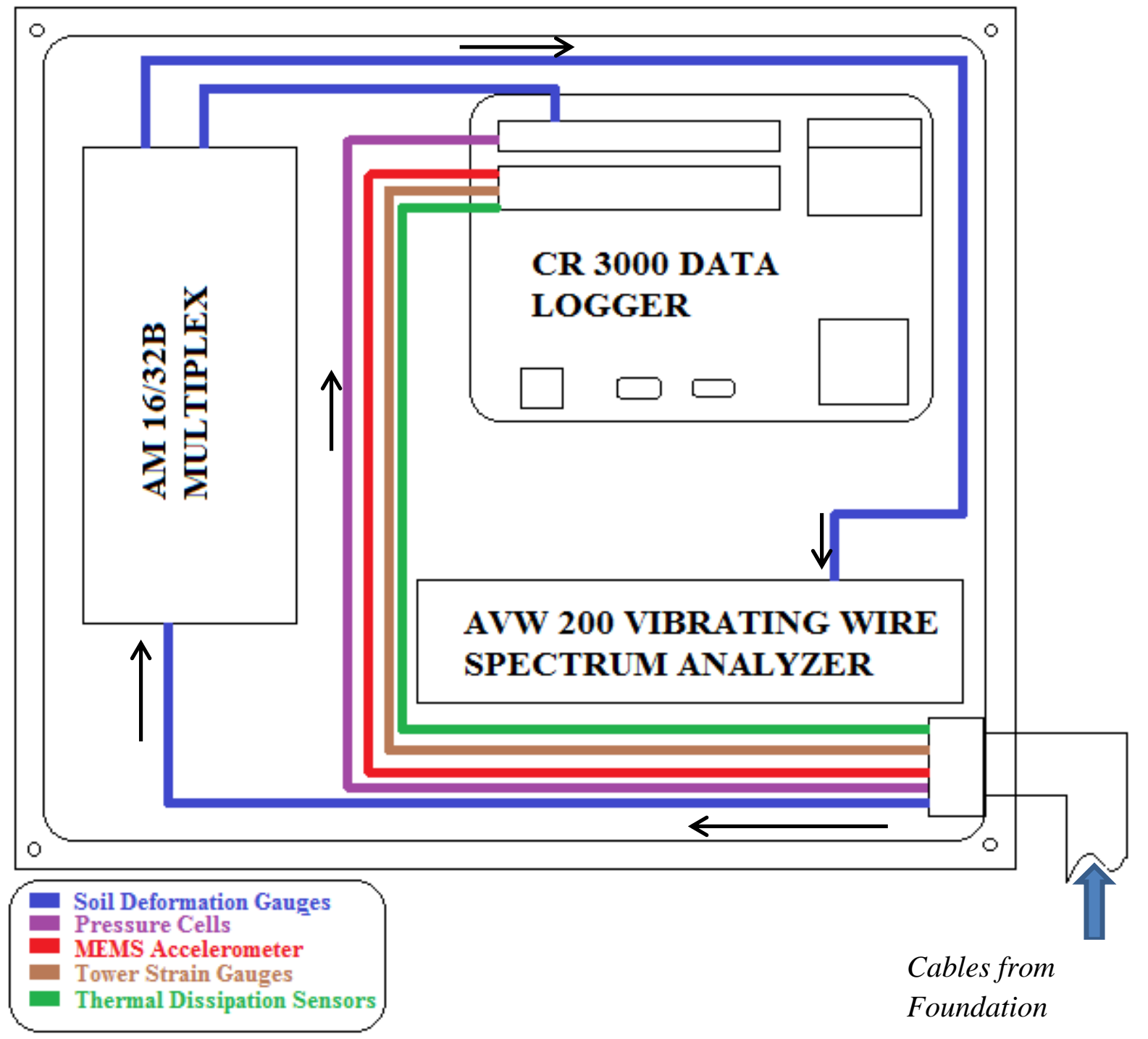

FIG. 3.25 Schematic of logical board. 


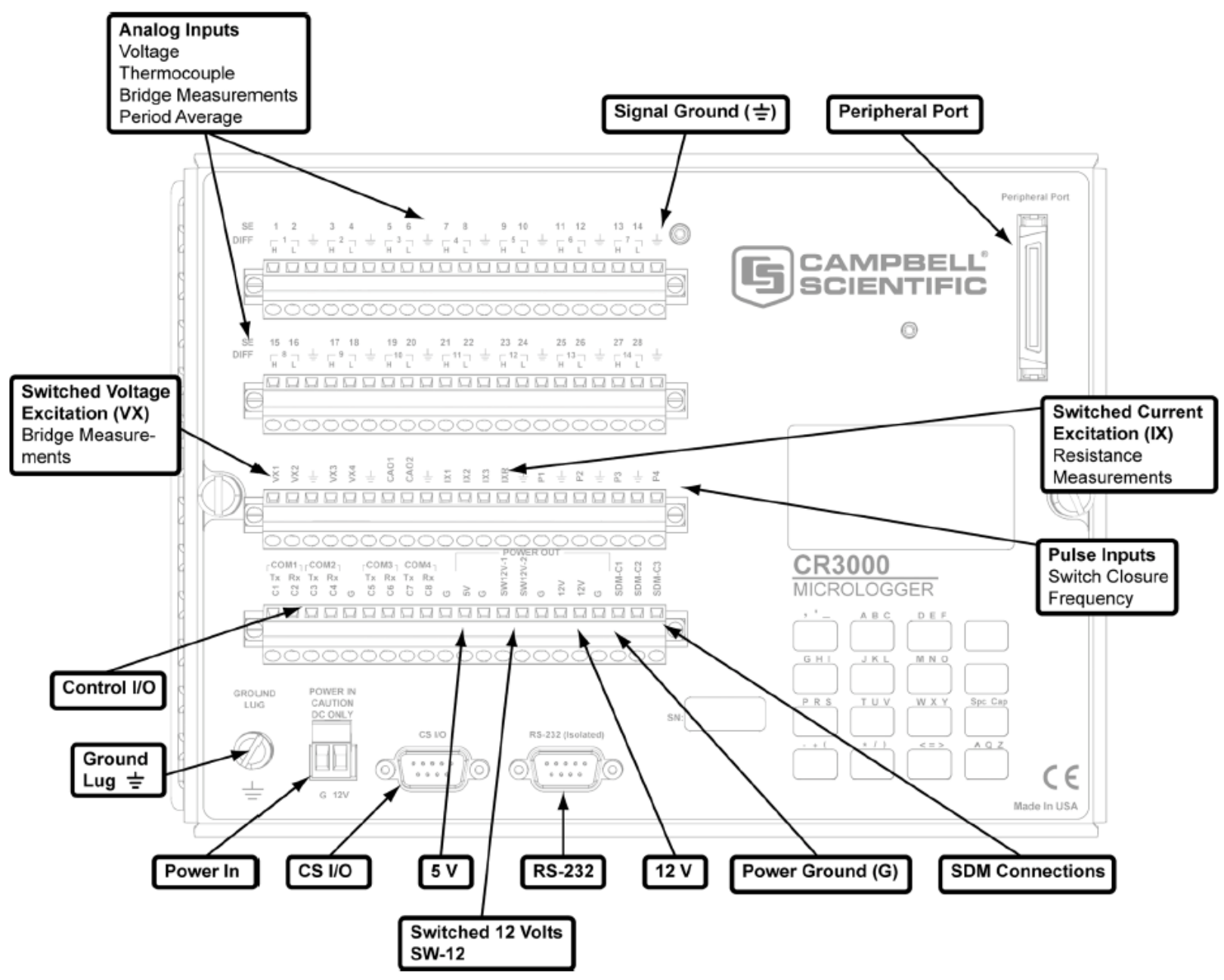

FIG. 3.26 Wiring panel (CR 3000 Operator's Manual)

There are 28 channels with one signal reading ability each (Figure 3.25 and 3.26). The channels allow reading more data ability to the data logger. Tower strain gauges, MEMS accelerometers, and pressure cells are directly connected to the data logger. Thermal dissipation sensors do not required frequently sampling thus, they were directly connected to the AW 16/32B multiplexer

Soil strain gauge data are read through the AM16/32B multiplexer and AVW 200 vibrating wire spectrum analyzer (Figure 3.24). The soil gauge data reading takes two seconds, 
which includes switching process time in the multiplexer. Based upon this, the scan for the soil deformation gauges was programmed to 30 s. During the scanning process, frequency, amplitude, and thermistor outputs are recorded. 


\section{DATA ANALYSIS}

Shallow WTG foundation analysis is unique due to geometry and eccentric, temporal loading conditions. Because utility-scale WTGs are relatively new (first appearing in the US circa 2000), limited field data have been collected that documents the response and performance of a WTG foundation.

Wind turbines and their foundations are designed for different loading cases such as assembly, maintenance, start-up, normal operation, shutdown and emergency situations (IEC 2005). To evaluate the field response of soil below a WTG foundation and to create mechanistically correct approaches to WTG foundation design mentioned cases needed to be considered in WTG foundation design. Field data were obtained regularly by manual download.

Approximately one year of data was obtained from both sites. These data have been analyzed under different wind conditions (i.e., high-wind conditions or no-wind cases) and operating situations such as shut-down or start up cases.

\subsection{Pressure Data}

Pressure data were evaluated under different loading and operating conditions. Increases and decreases were observed in pressure as a function of the time. Shutdown conditions caused $52 \%$ increases (the highest pressure change) in pressure PG-2. Furthermore, stress redistribution occurred depending on wind speed and direction changes. Figure 4.1 shows a comparison of normal operating and turbine shutoff conditions at Site A. Fairly even pressure distribution and small fluctuations ( $<1.5 \mathrm{kPa}$ and mostly following the wind response) were observed at the normal conditions. During the shutoff, sudden stop of the blade rotation yield high frequency $(\approx$ $0.3 \mathrm{~Hz})$, high amplitude $(1.2 \mathrm{kPa})$ cell pressure responses. The fluctuations occur due to the rocking motion of the WTG system. The frequency of the tower was computed as $0.26 \mathrm{~Hz}$. 

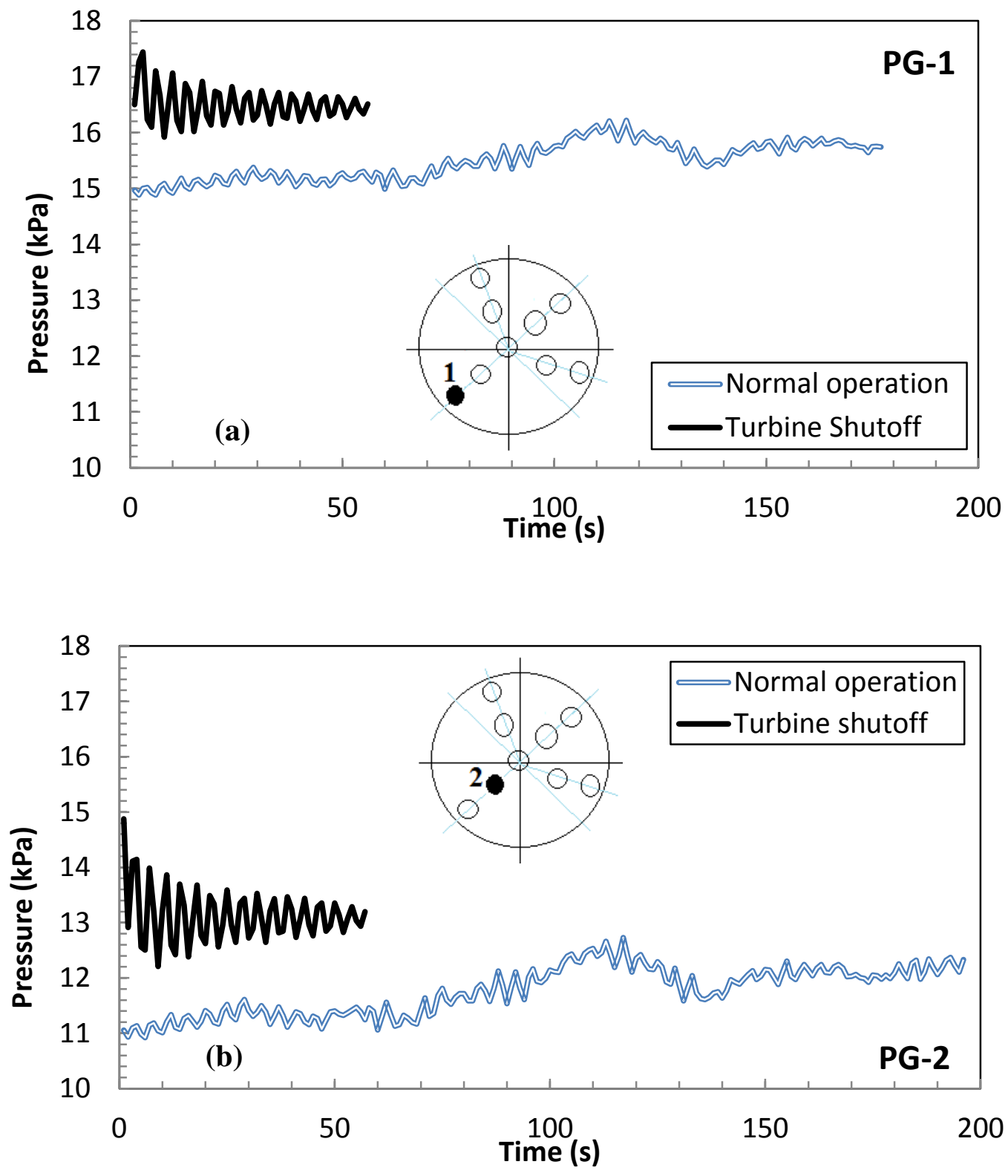

FIG. 4.1 Normal operation and shutdown conditions pressure changes for PG-1 (a) and PG-2 (b) at Site A.

The response of PG-3 (Figure 4.3, Site A) is relatively lower than the other cells because it locates at the moment point (assumed everything uniform) of the foundation block and exhibits smaller pressure variance. The amplitude and fluctuation of the pressure is more linear in distribution during the shutdown (Figure 4.2). Additionally, pressure switches were observed 
during the shutdown, the pressure distribution changes and pressure cells show a spike in pressure (from $2 \mathrm{kPa}$ to $10 \mathrm{kPa}$ ). When the turbine comes to halt, maximum and minimum pressures were recorded in each cell.

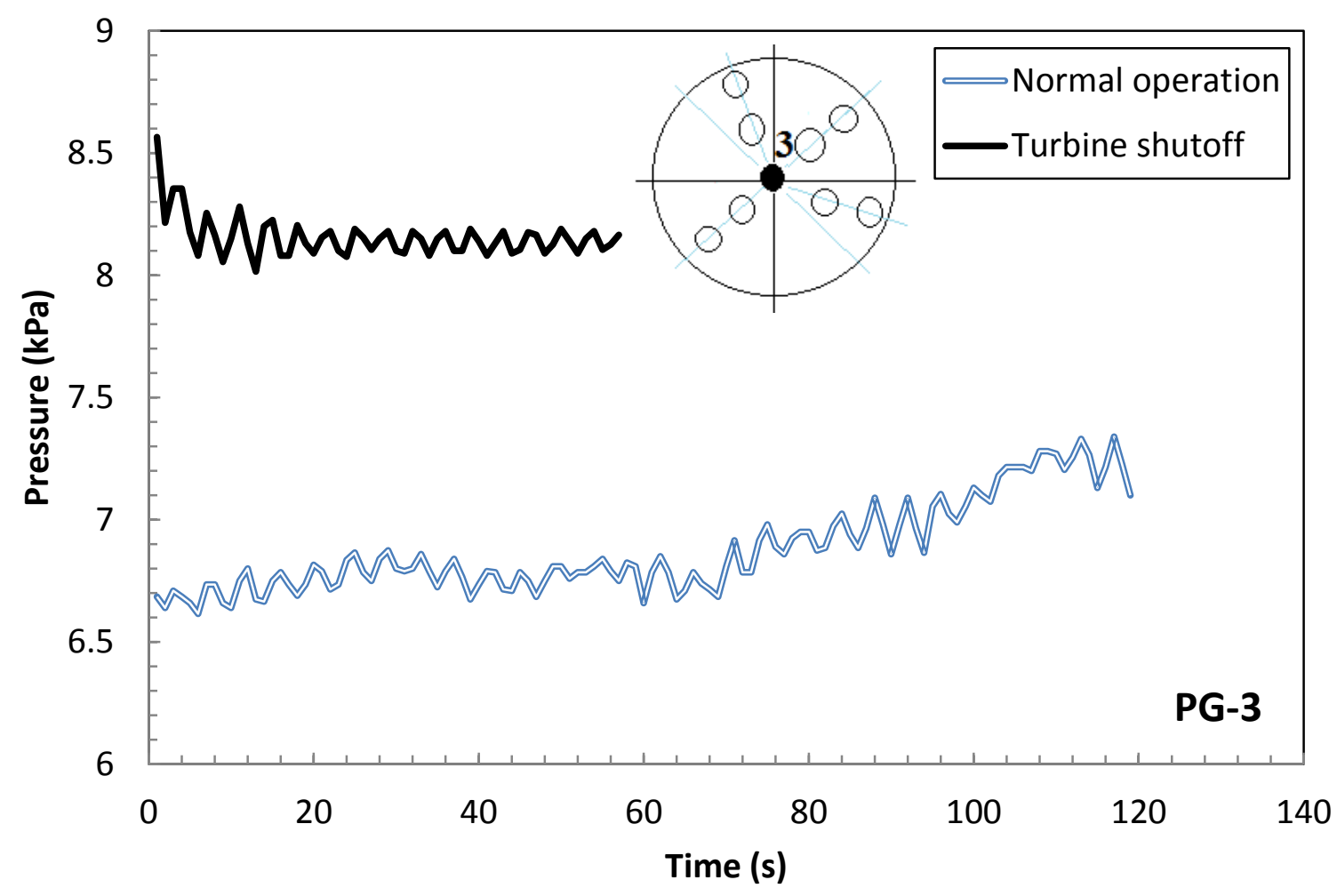

FIG. 4.2 Normal operation and shutdown conditions pressure changes for PG-3, Site A. 


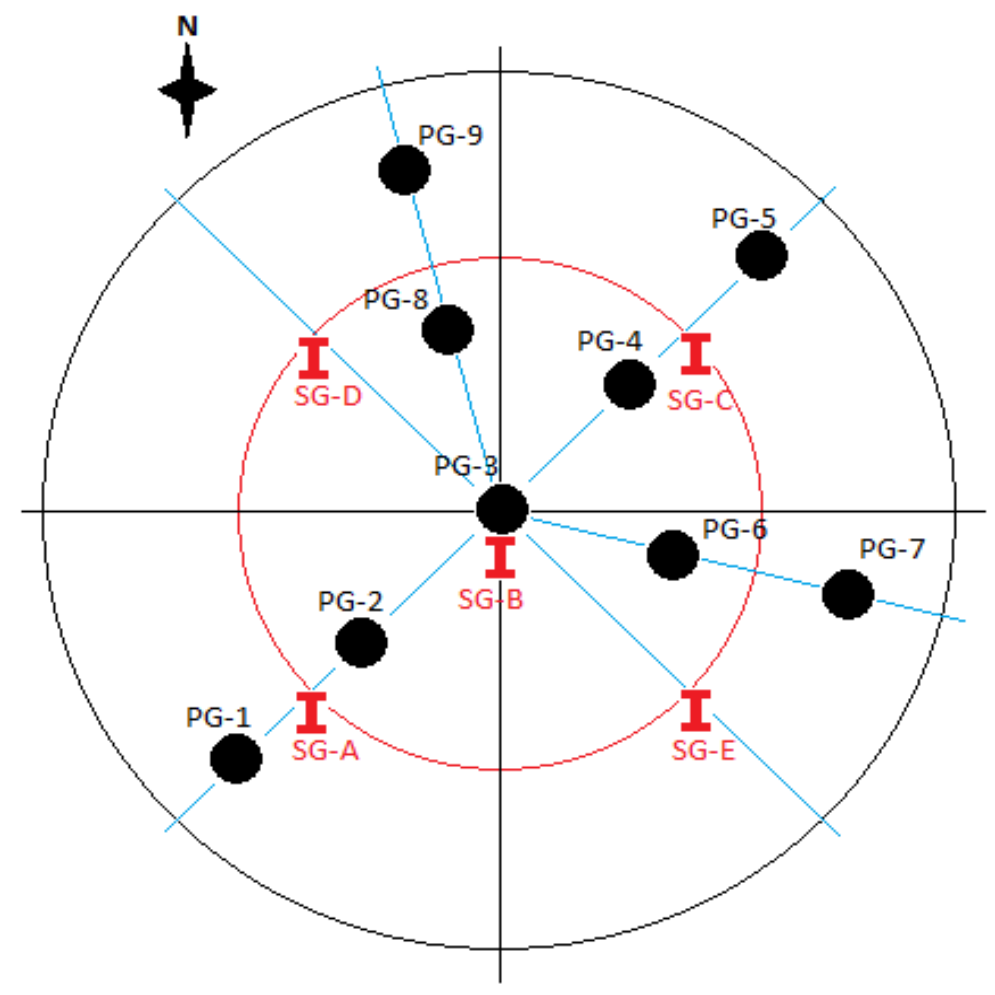

\section{FIG. 4.3 Instrumentation layout Site A.}

Figure 4.4 summaries the operational response of the foundation soil during the shutdown of the turbine. Fluctuations were measured by the pressure cells during turbine shutdown. PG-1 and PG-5 experienced pressure increase and decrease before and after shutdown. The spike in pressure at PG-1 and corresponding decrease in pressure at PG-5 (locational, asymptotic to each other) demonstrates that operational conditions such as shutdown indeed require consideration during development of the design load conditions for a WTG and its supporting foundation. 


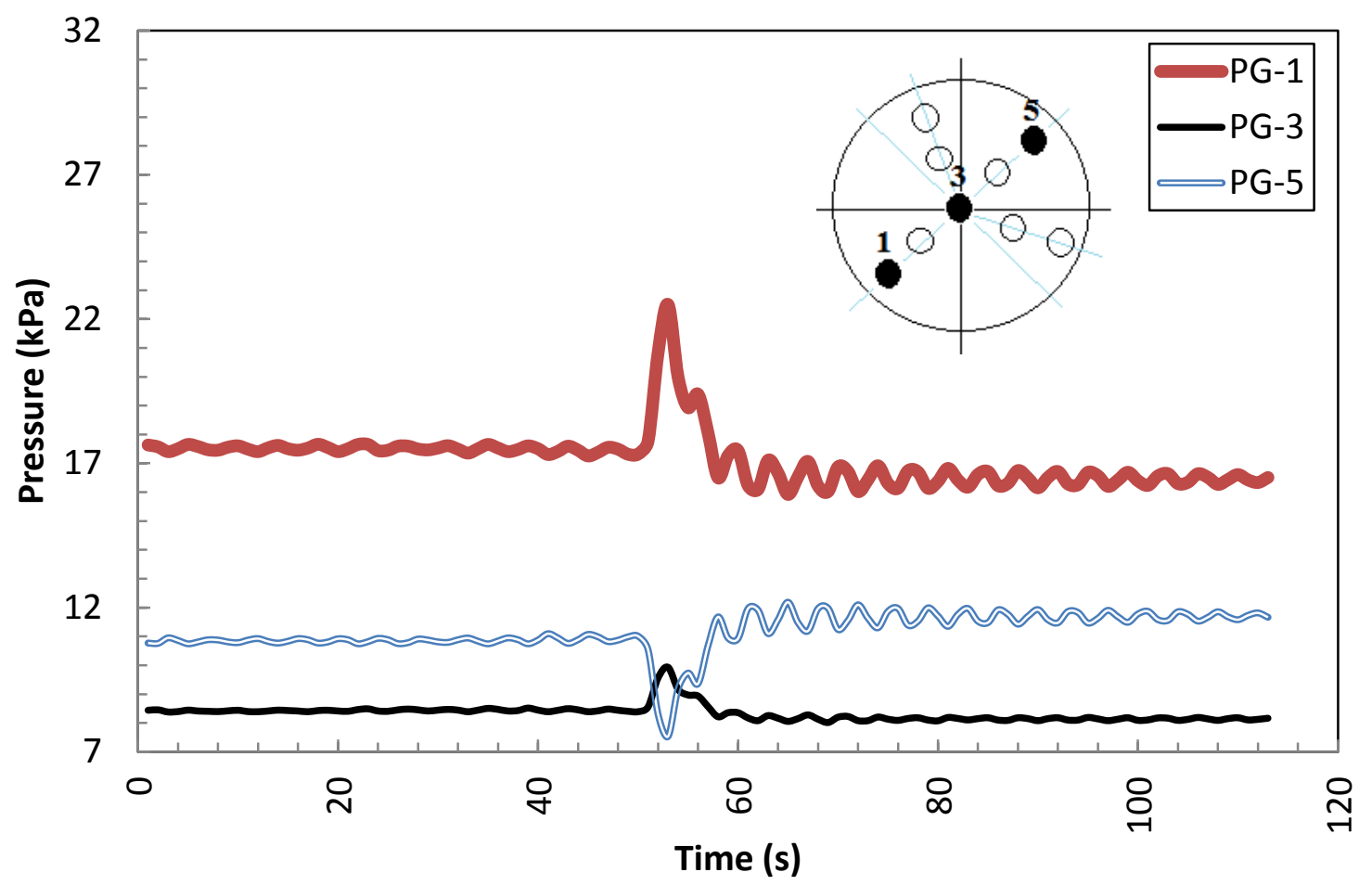

FIG. 4.4 Shutdown condition pressure analysis for PG-1, PG-3 and PG-5, Site A.

Likewise, PG-6, PG-7 and PG-9 were analyzed during turbine shutdown. PG-6 and PG-7 exhibited the same trends in response; however, the amplitudes were. Pressure decreases were recorded in pressure at PG-6 and PG-7 as $4 \mathrm{kPa}$ and $1.5 \mathrm{kPa}$, respectively. This significant numerical difference may derive from the layout of the cells. Moreover, the spike in pressure occurs at the same time point at PG-6 and PG-7. Figure 4.5 displays the responses of the PG-6 and PG-7 in shutdown conditions. 


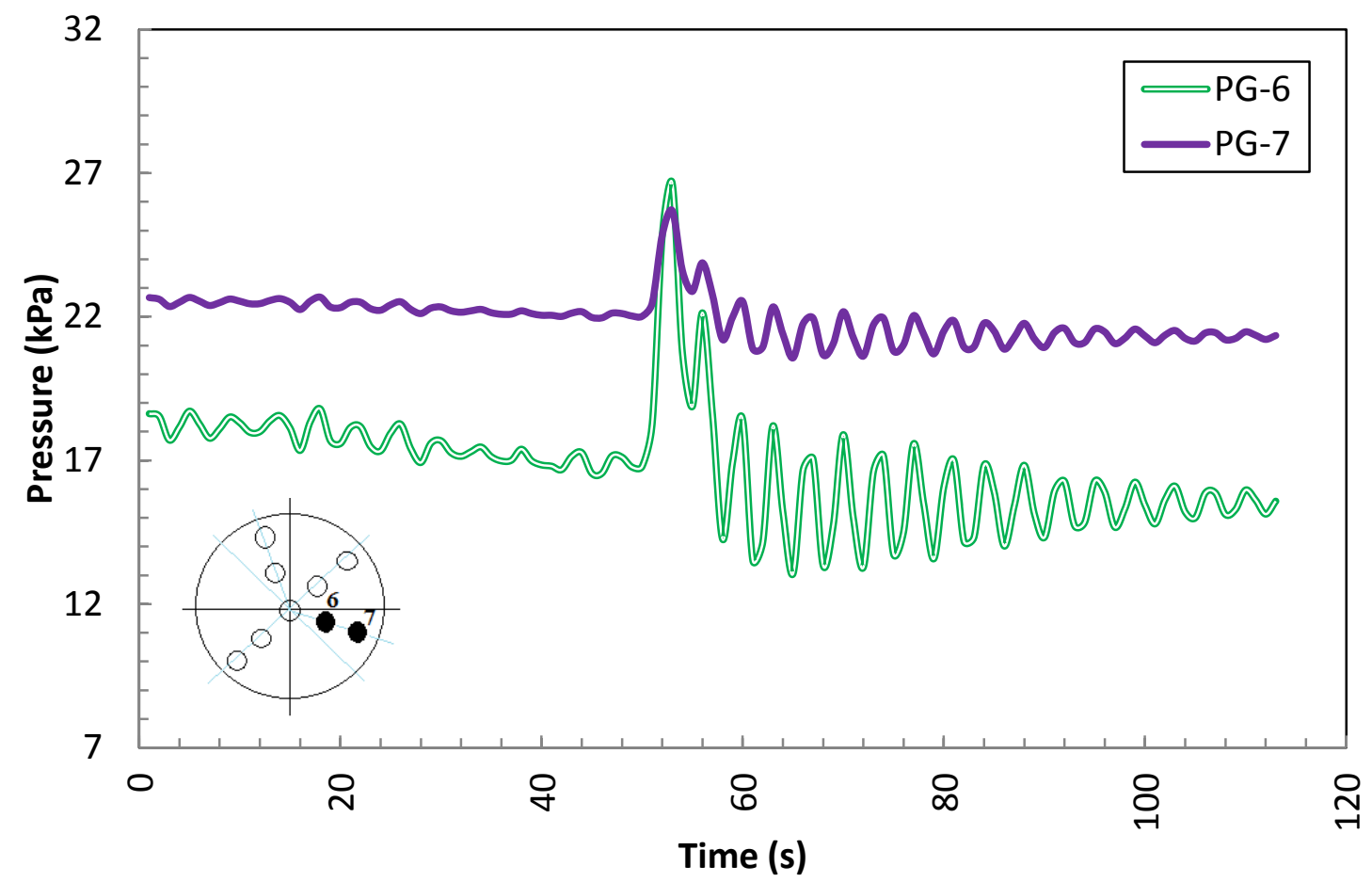

FIG. 4.5 Shutdown condition pressure analysis for PG-6 and PG-7, Site A.

Figure 4.6 displays the symmetric but opposite responses of PG-2 and PG-4. In the similar manner, PG-7 and PG-9 works opposite to each other in different pressure amplitudes (Figure 4.7). The amplitude of the pressure right after the pressure spike is slightly higher in PG9. 


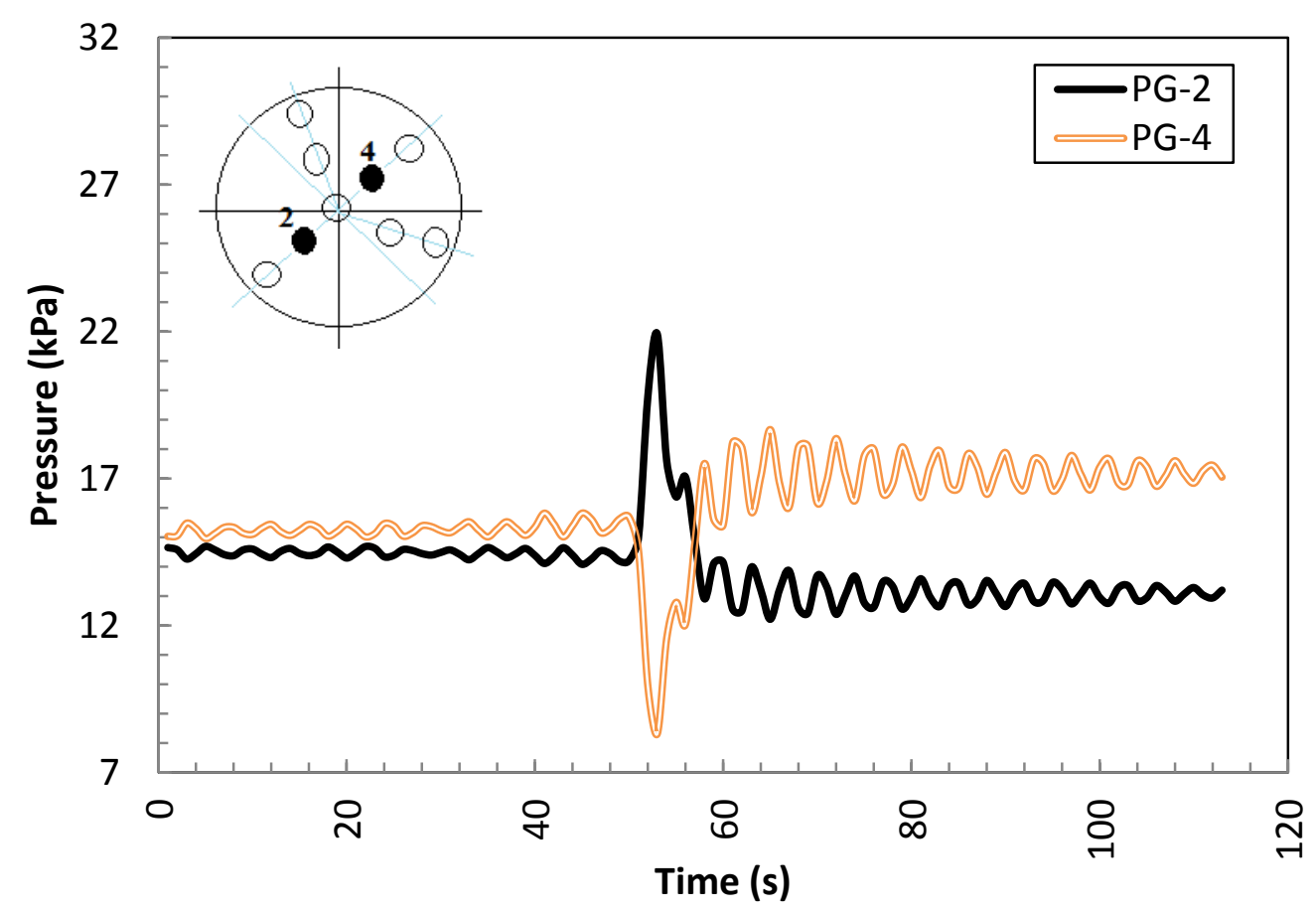

FIG. 4.6 Shutdown condition pressure analysis for PG-2 and PG-4, Site A.

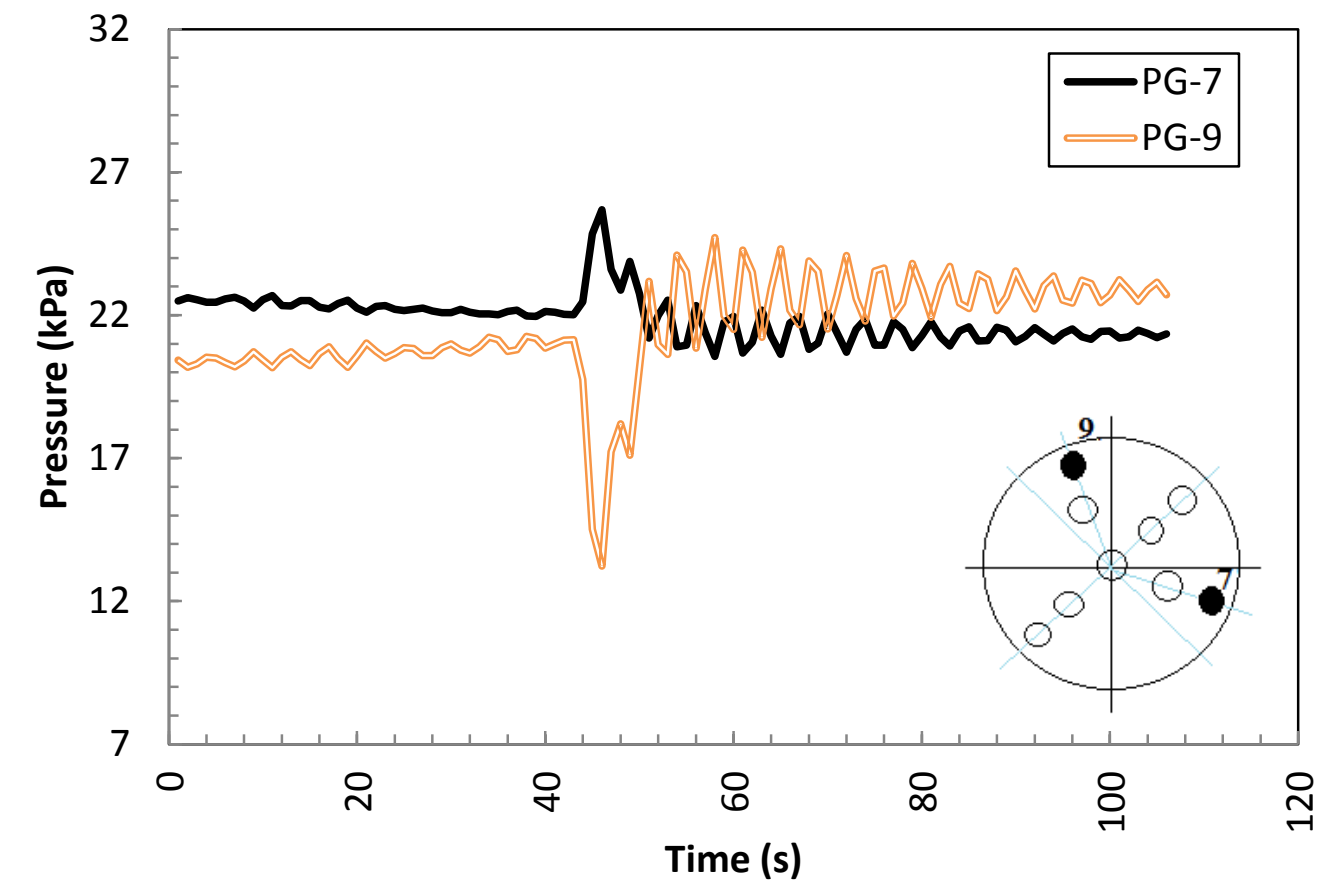

FIG. 4.7 Shutdown condition pressure analysis for PG-7 and PG-9, Site A. 
Furthermore, pressure data were analyzed over normal operating and start-up conditions to compare pressure response over a particular time frame. Figure 4.8 shows the pressure change and shifts at startup and corresponding wind change can be followed from Figure 4.9. The cells, which are aligned along the incipient wind direction axis, were evaluated over the startup period. Pressure data were normalized by dividing average pressure reading over the non-operating period with pressure. This method was preferred to show all the cells' pressure fluctuations in the same plot. A shift was observed in pressure distribution when the wind speed attains cut-in speed and blades rotation starts. The highest response was observed at the PG-1 therefore, this section of the foundation could be evaluated as critical region in WTG foundation design because of the higher edge pressure.

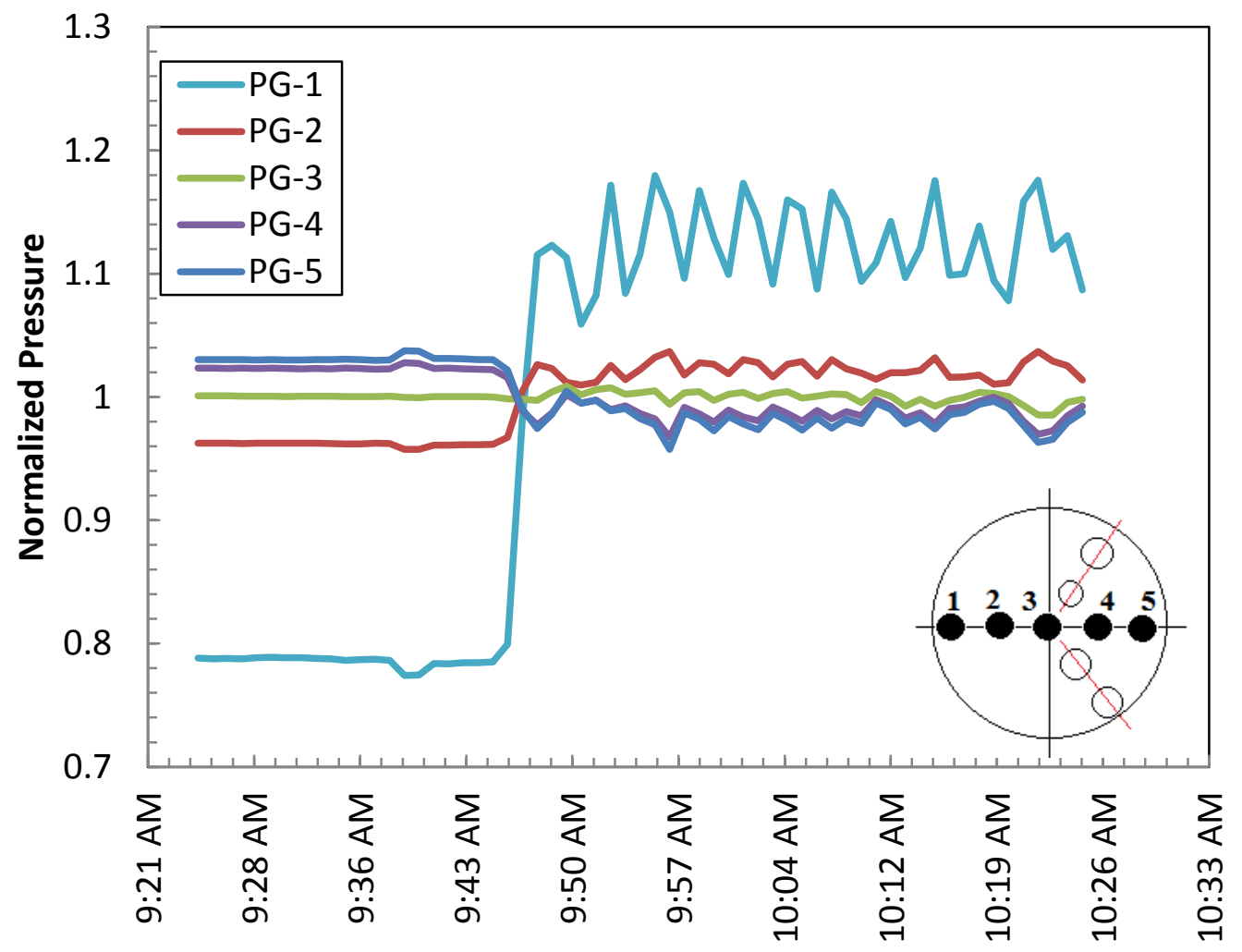

FIG. 4.8 Isolated pressure cel1s, 2, 3, 4, and 5 in startup condition on 11/3/2013-Site B. 


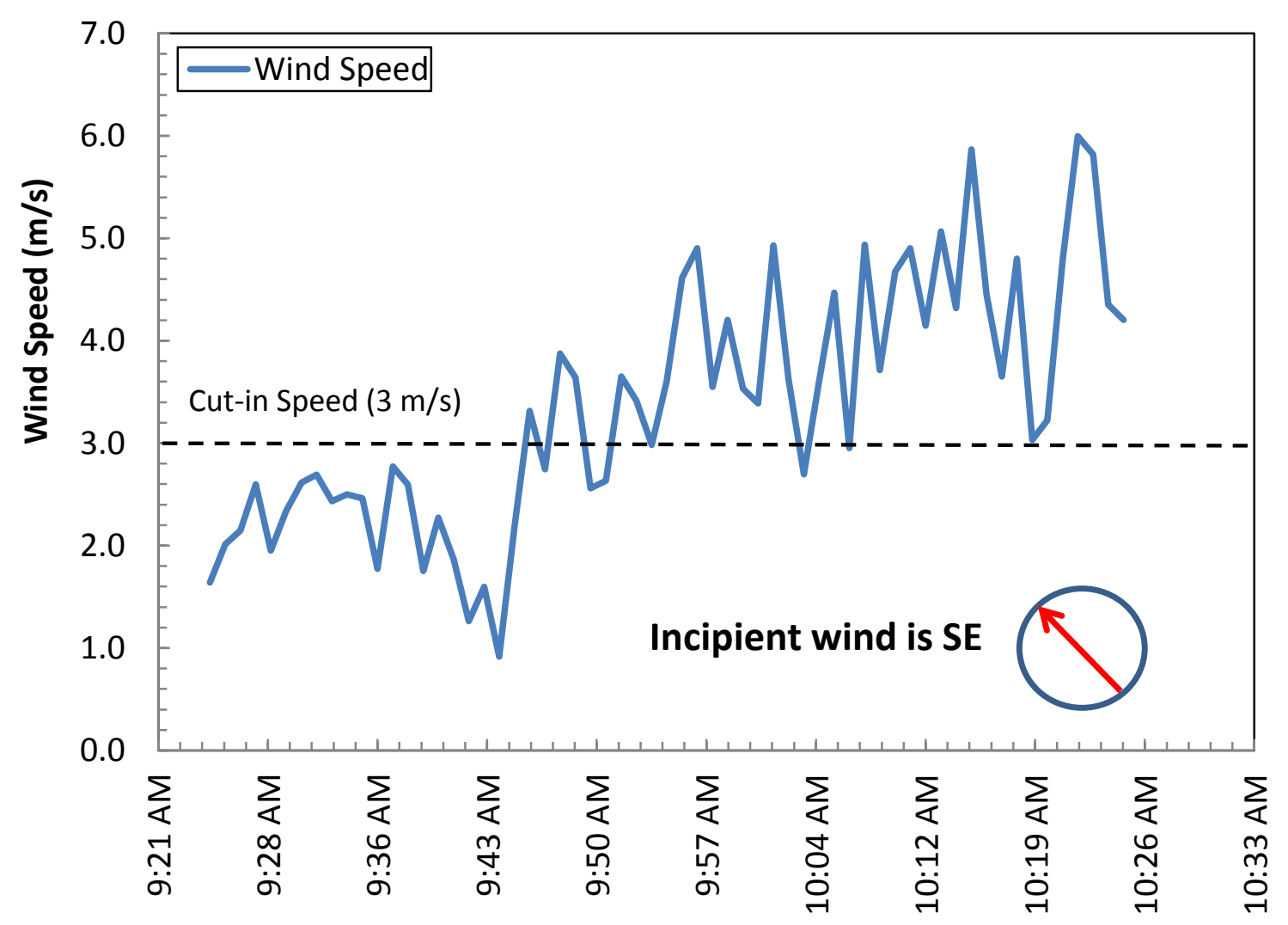

FIG. 4.9 Wind speed on 11/03/13-Site B.

Greater variations were observed in pressure cells that are located towards the edge of the foundation block during normal operating conditions. When the pressure data is normalized to starting pressure $\left(P_{i}\right)$ the highest amplitudes are observed in PG-1 and PG-9 (see Figure 4.10b). Additionally, soil properties and stress transmitting plays significant role on pressure redistribution beneath the foundation. The most significant outcome of this particular time frame $(11 / 5 / 1310: 55,12: 07 \mathrm{pm})$ is the well-correlated cell responses and well correlated cells wind relation. 

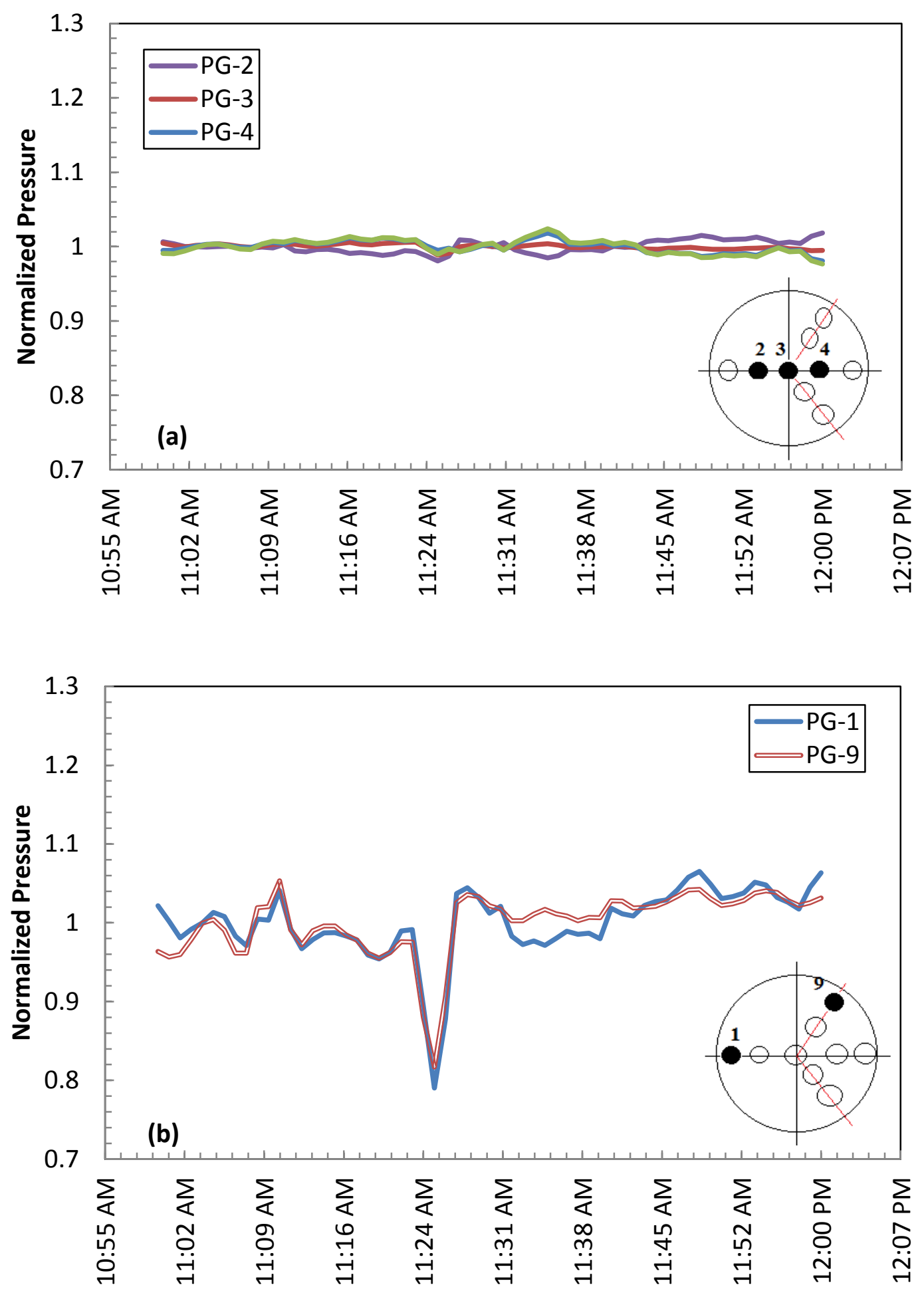

FIG. 4.10 Foundation soil pressure during normal operating condition on 11/5/2013-Site B. 

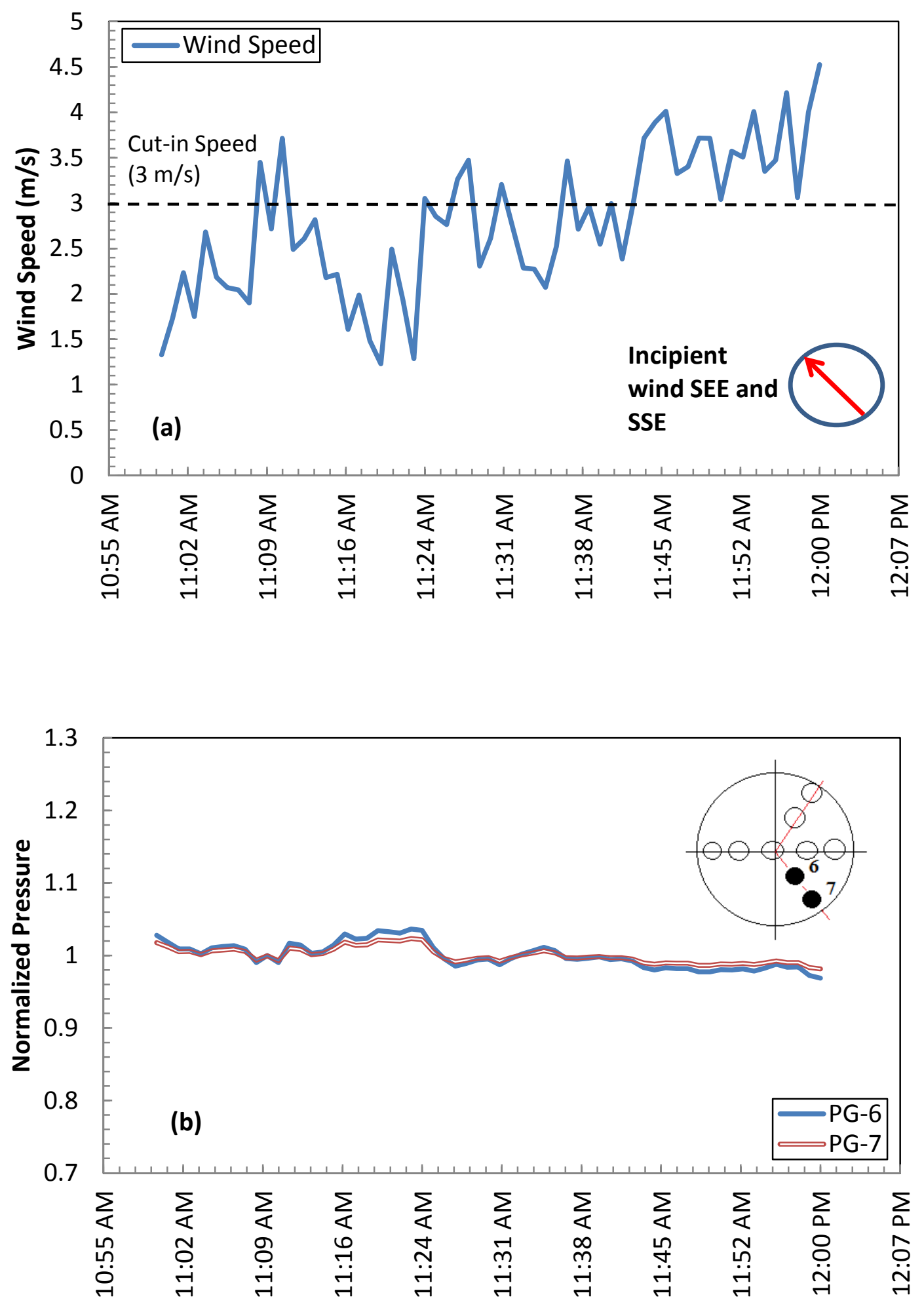

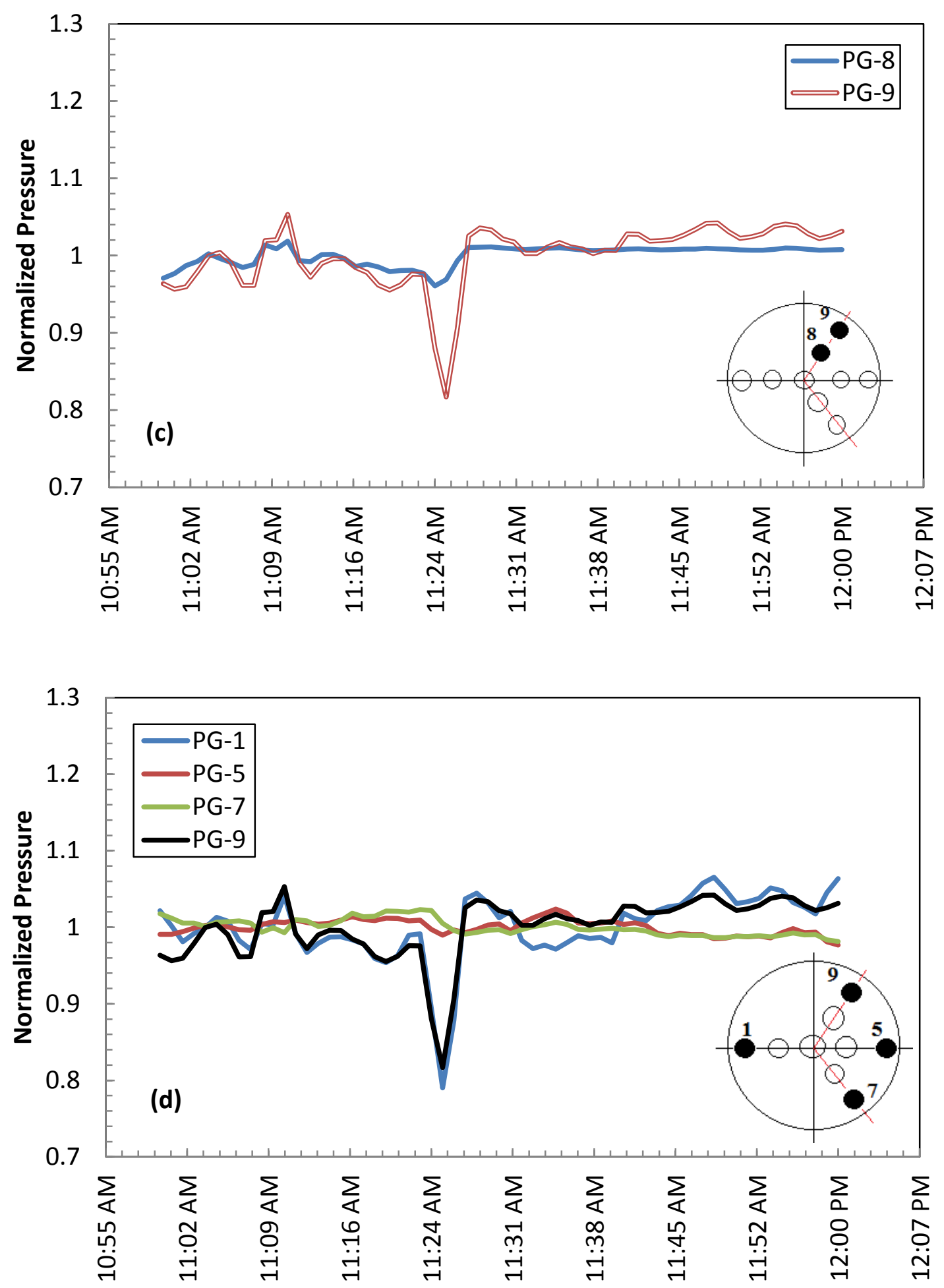

FIG. 4.12 Wind speed (a) and foundation soil pressure during normal operating condition at PG-6, 7 (b), PG-8, 9 (c) and PG-1, 5, 7, 9 on 11/5/2013-Site B. 
Whereas edge pressure cells exhibit higher pressure variation, pressure cells locate along the predominant wind direction show the smallest pressure variation (Figure 4.10a). Especially, PG-3 deviates less from the average and shows the lowest variation in pressure due to the location of the cell and less sensitive sway response (Figure 10a).

Expected bearing pressures were computed as $63.98 \mathrm{kPa}$ and $69.44 \mathrm{kPa}$ by using the vertical static loads for Site A and B, respectively. However, unexpected pressure issue has been observed at Site B. Under-registration issue has occurred in the contact pressure cells and lower pressure values have been obtained from the pressure cells due to "bridging". Several potential hypotheses may explain unexpected redistributions of the pressure such as installation sensitivity, over or under compaction during the cell installation, soil/cell stiffness ratio or soil bridging issue around the pressure cells. Table 4.1 displays the possible factors affecting measurements from pressure cells. 
Table 4.1 Major Factors Affecting measurements with Embedded Earth Pressure Cells (Dunnicliff 1988)

\begin{tabular}{|c|c|c|}
\hline FACTOR & DESCRIPTION OF ERROR & CORRECTION METHOD \\
\hline $\begin{array}{l}\text { Aspect Ratio (Ratio of } \\
\text { cell thickness to } \\
\text { diameter) }\end{array}$ & $\begin{array}{l}\text { Cell thickness alters stress field } \\
\text { around cell }\end{array}$ & $\begin{array}{l}\text { Use relatively thin cells }(\mathrm{T} / \mathrm{D}< \\
1 / 10)\end{array}$ \\
\hline $\begin{array}{c}\text { Soil/cell stiffness ratio } \\
\text { (ratio of soil stiffness to } \\
\text { cell stiffness ) }\end{array}$ & $\begin{array}{l}\text { May cause cell to under or over- } \\
\text { register. Error will change if soil } \\
\text { stiffness change }\end{array}$ & $\begin{array}{c}\text { Design cell for high stiffness and } \\
\text { use correction factor }\end{array}$ \\
\hline Size of cell & $\begin{array}{c}\text { Very small cells; scale effects and } \\
\text { placement errors. Large cells; non- } \\
\text { uniform bedding }\end{array}$ & $\begin{array}{l}\text { Use intermediate size of cell: } \\
\text { Typically } 230-300 \mathrm{~mm}\end{array}$ \\
\hline Stress-Strain Behavior & $\begin{array}{l}\text { Measurements influenced by } \\
\text { confining conditions }\end{array}$ & $\begin{array}{l}\text { Calibrate cell under near-usage } \\
\text { conditions }\end{array}$ \\
\hline Placement Effects & $\begin{array}{c}\text { Physical placement and backfilling } \\
\text { causes alterations of material } \\
\text { properties and stress field around } \\
\text { cell }\end{array}$ & $\begin{array}{l}\text { Use placement technique that } \\
\text { causes minimum alteration of } \\
\text { material properties and stress } \\
\text { field }\end{array}$ \\
\hline $\begin{array}{l}\text { Eccentric, nonuniform, } \\
\text { and point loads }\end{array}$ & $\begin{array}{c}\text { Soil grain size too large for cell size } \\
\text { used nonuniform bedding causes } \\
\text { nonuniform loading }\end{array}$ & $\begin{array}{c}\text { Increase active diameter cell. } \\
\text { Take great care to maximize } \\
\text { uniformity of bedding. Use hyd. } \\
\text { cells (grooved) }\end{array}$ \\
\hline $\begin{array}{l}\text { Concentrations of normal } \\
\text { stress at the edge of cell }\end{array}$ & $\begin{array}{c}\text { Causes cell over or under-register, } \\
\text { depending on stiffness of cell } \\
\text { relative to soil }\end{array}$ & $\begin{array}{c}\text { Use grooved thick active face and } \\
\text { thin layer of liquid }\end{array}$ \\
\hline Deflection of active face & $\begin{array}{c}\text { Excessive deflection of active face } \\
\text { changes stress distribution around } \\
\text { cell by arching }\end{array}$ & Use thin layer of liquid \\
\hline Corrosion and moisture & $\begin{array}{l}\text { May cause failure of cell by } \\
\text { attacking cell materials }\end{array}$ & $\begin{array}{c}\text { Use appropriate material and high } \\
\text { quality waterproofing }\end{array}$ \\
\hline $\begin{array}{l}\text { Dynamic stress } \\
\text { measurement }\end{array}$ & $\begin{array}{l}\text { Response time, natural frequency } \\
\text { and inertia of cell cause errors }\end{array}$ & $\begin{array}{l}\text { Use appropriate type of cell and } \\
\text { transducer, together with dynamic } \\
\text { calibration }\end{array}$ \\
\hline
\end{tabular}

Well-correlated cell responses before and after under-registration issue weakened instrument-induced possibilities and the problem was associated with the soil-cell interaction. Figures 4.13 and 4.14 show the pressure distribution decrease in year. The highest decreases in 
pressure were observed in pressure cells 7, 9, and 5. The pressure decrease varies from $12 \mathrm{kPa}$ to $83 \mathrm{kPa}$ depending on the location of the cells.

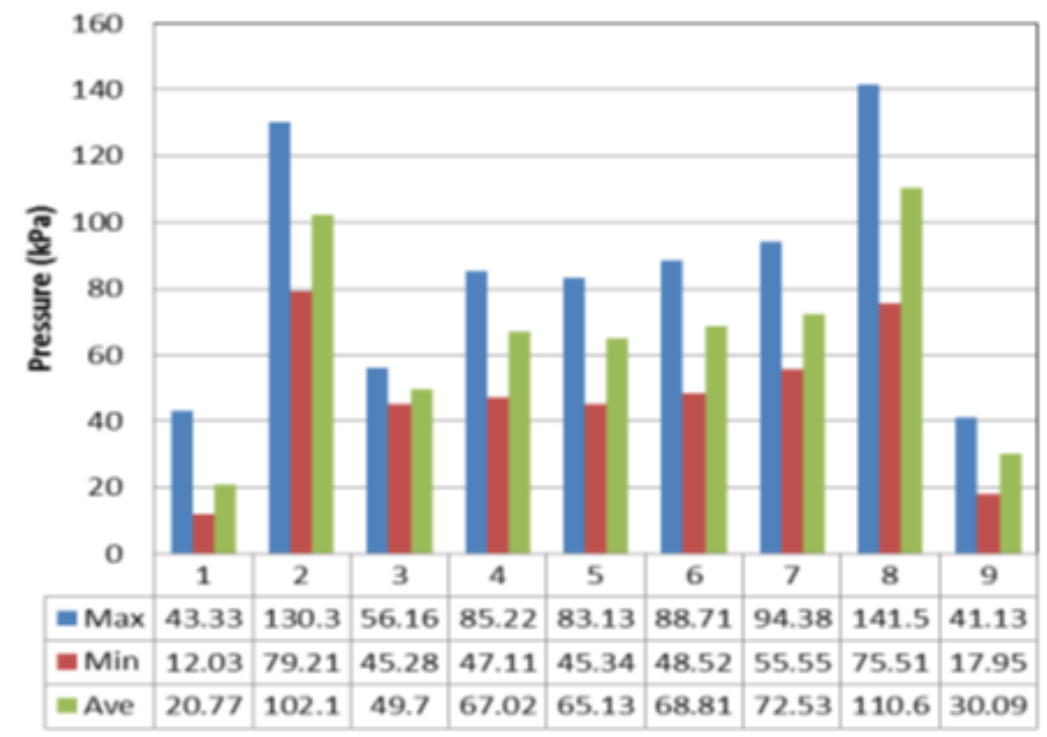

FIG. 4.13 Pressure distribution on 1/14/13 (turbine in-service) Site A.

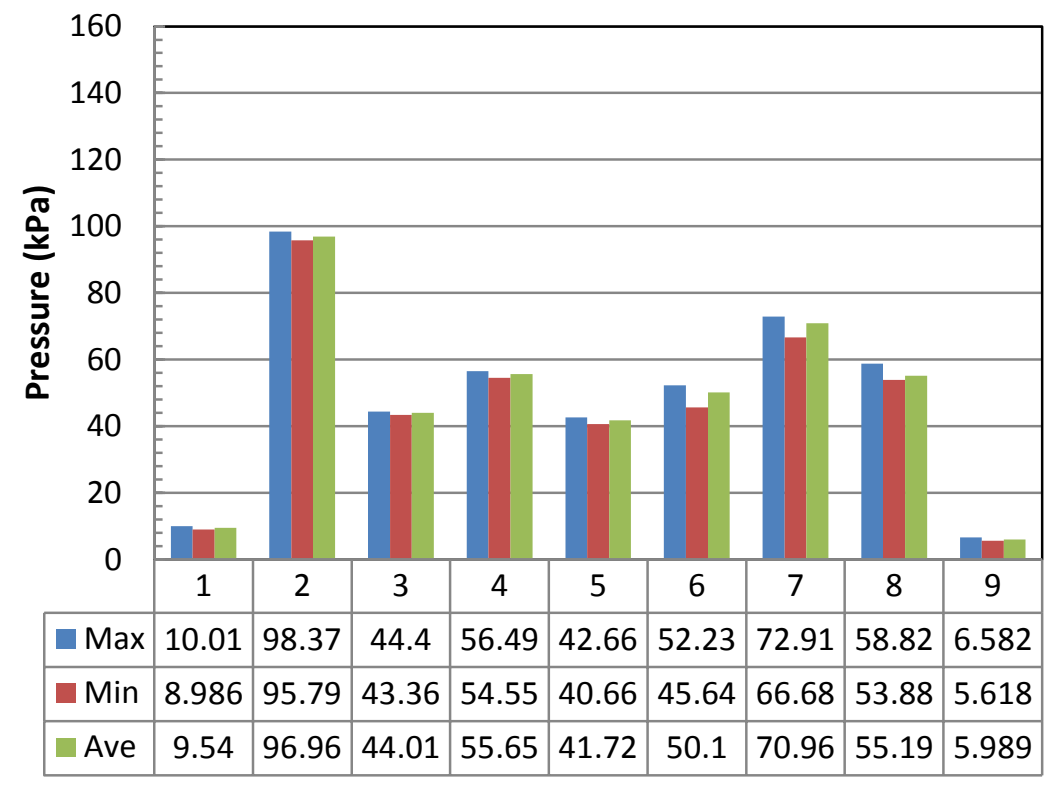

FIG. 4.14 Pressure distribution on 11/3/13 (turbine in-service) Site A. 
Soil-cell interaction was evaluated under stiffness parameter. In a stiff soil, the cell may be less stiff than surrounded soil. In such cases, cells will under-register than the mean stress as the stresses tend to bridge around the cell (Geokon 2013). Figure 3.12 summaries potential bridging issues and stress changes in the case that bridging occurs.

Horizontal wind load is a variable external force. An increase in wind speed creates larger horizontal loading and stress redistribution during the wind event. To evaluate this variability, stress distribution before and after wind events were observed. Figures 4.15 and Figure 4.16 show stress distribution and redistribution during a wind event at Site B. Positive and negative pressure shifts were observed. The highest pressure difference during the wind event was recorded in PG-2 as $4.02 \mathrm{kPa}$. The second highest pressure change was recorded in PG-1 as 2.48. Pressure gauges 4,5 , and 8 displayed negative stress shifts as $-0.88,-1.07$, and 0.7 , respectively. Minimum positive pressure change was observed in pressure gauge 3 as expected. The location of the PG-3 may be considered as the limiter parameter to explain the low pressure responses because PG-3 was placed on balance (moment) point therefore, pressure variation of PG-3 is much smaller than other pressure gauges' responses. 


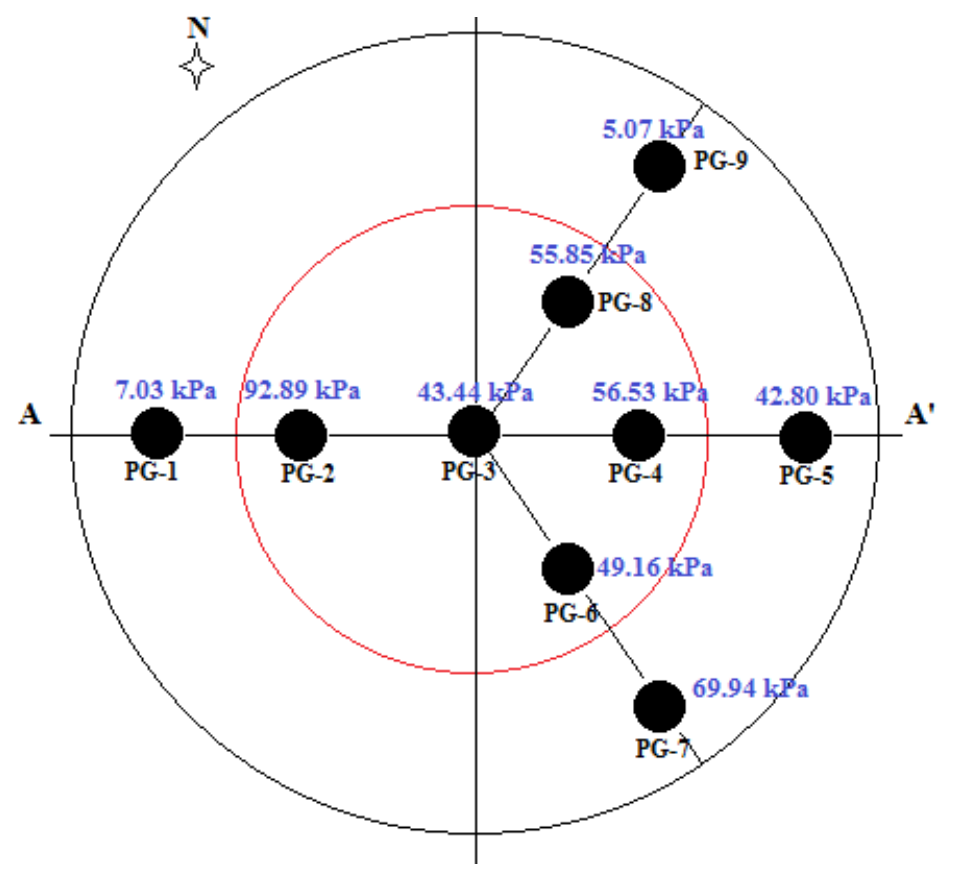

FIG. 4.15 A pressure distribution before wind event (Site B)

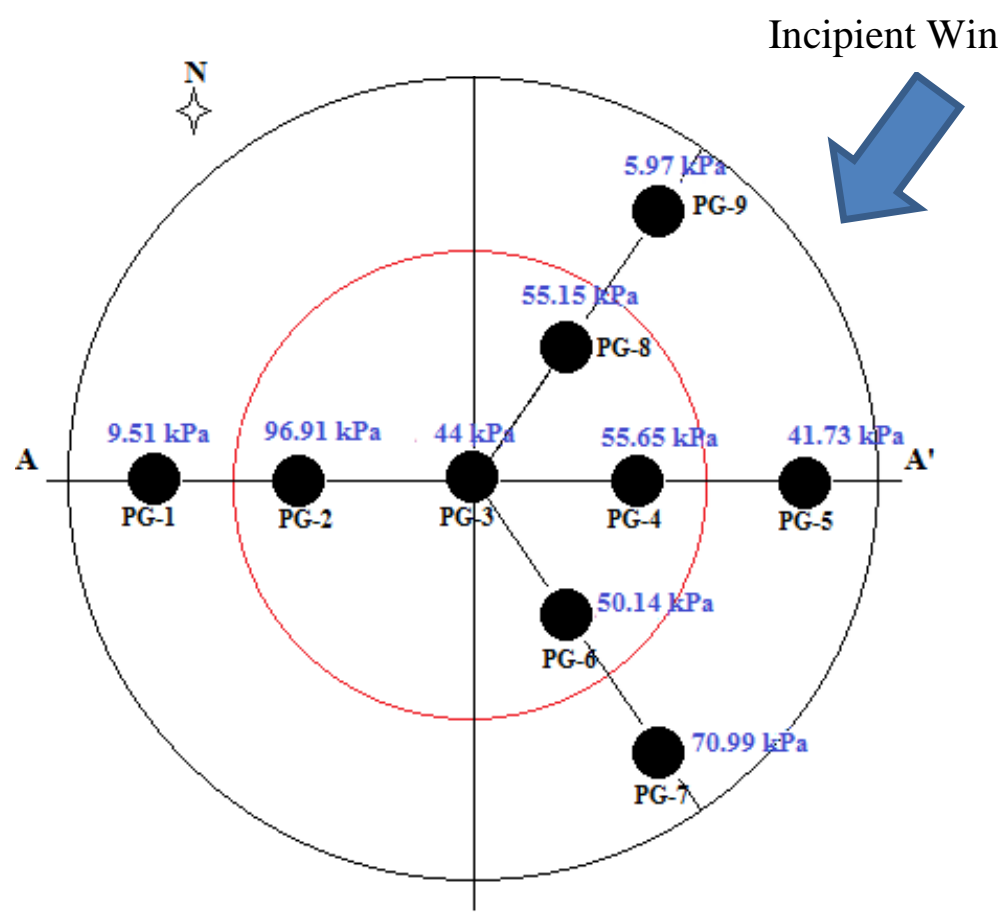

FIG. 4.16 A pressure distribution after wind event (Site B) 


\subsection{Soil Deformation Data}

The main purpose of the soil strain gauges (SG) was to measure the deformation of the underlying soil at different locations and depths. The instruments have displacement measurement ability up to $12.5 \mathrm{~mm}$, with measurement accuracy to $0.1 \%$ (with polynomial expression) and resolution to $0.025 \%$ FSR. Eight deformation gauges were installed along the predominant wind direction axis and two were placed perpendicular to the predominant wind direction (Figures 4.17 and 4.18). Three deformation gauges were located at the center of the foundation at different depths and four were placed at varying depths on the leeward site of the predominant wind (Figure 4.20).

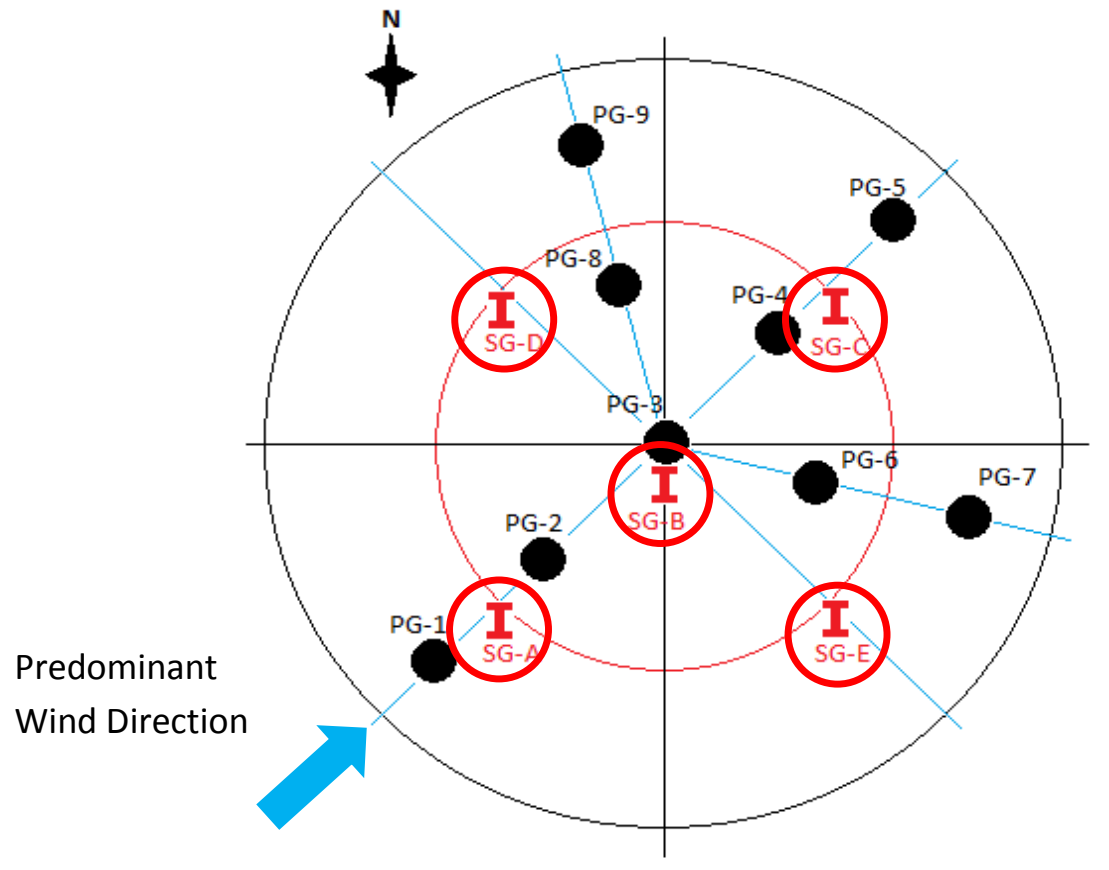

FIG. 4.17 Soil deformation gauge layout for Site A. 


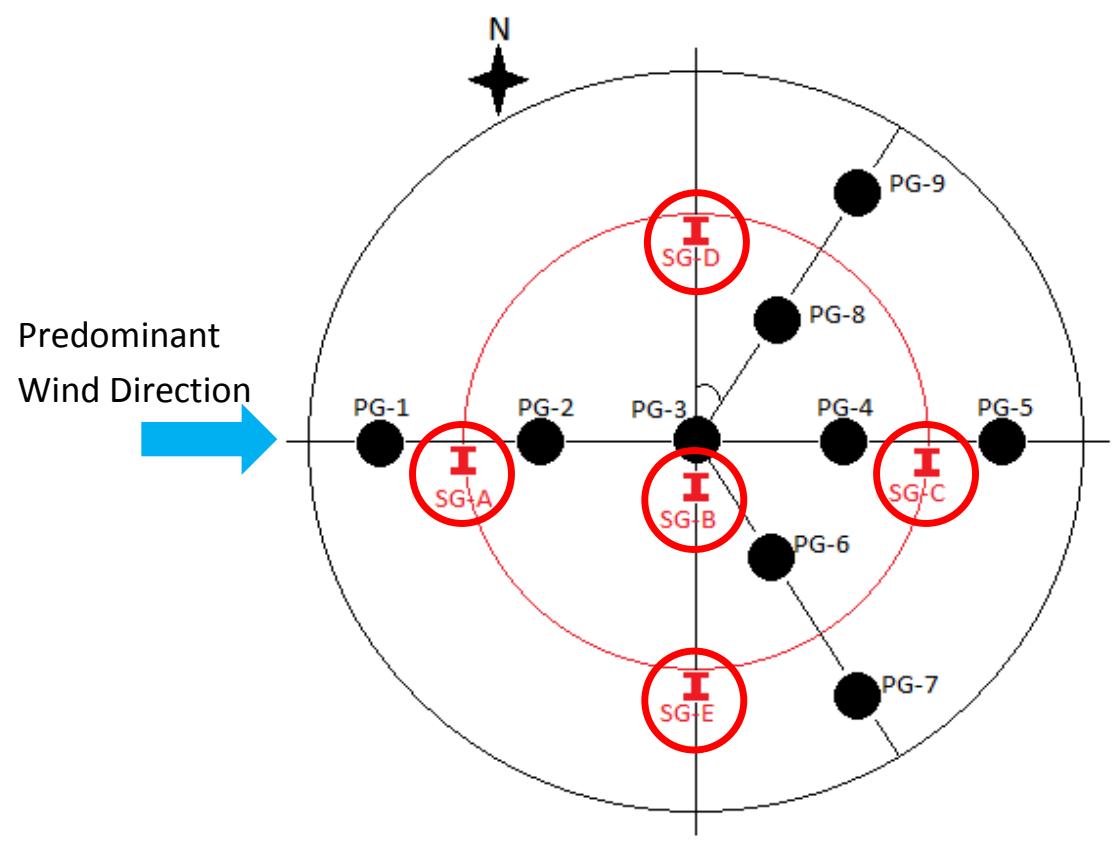

FIG. 4.18 Soil deformation gauge layout for Site B.

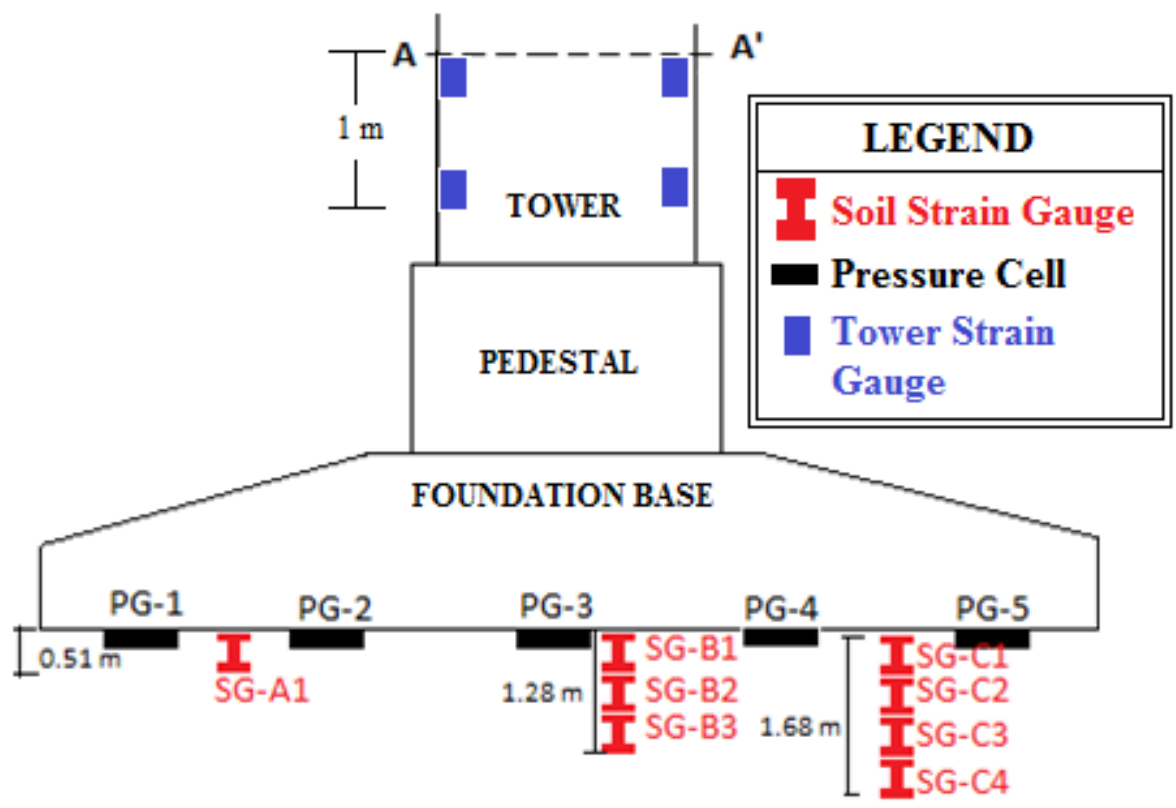

FIG. 4.19 Instrumentation cross-section for both sites. 
During a typical start-up period, the greatest amount of displacement occurred at strain gauges SG-C1, C2, C3 and C4 due to the predominant wind direction from the opposite side of the foundation at Site B (Figure 4.20). These soil strain gauges show the same trend but with different displacement ratios beneath the foundation (Figure 4.20). Depending on depth of the sensor and the magnitude of the horizontal loading, measured displacements change in the underlying foundation soil. For example, SG-C1, located closest to the surface, shows the greatest deformation beneath the foundation; SG-C4, located at greatest depth below foundation, shows the lowest displacement. The positive and negative deformation in response to changes in wind magnitude show the dynamic nature of the foundation

The soil gauges displayed an expected trend of decreasing soil deformation with increasing depth based on Boussinesq stress distribution approach. Figure 4.22 shows wind speed change in a particular timeframe, and this increase in wind speed causes the same increasing trend in soil deformation (Figure 4.21). 


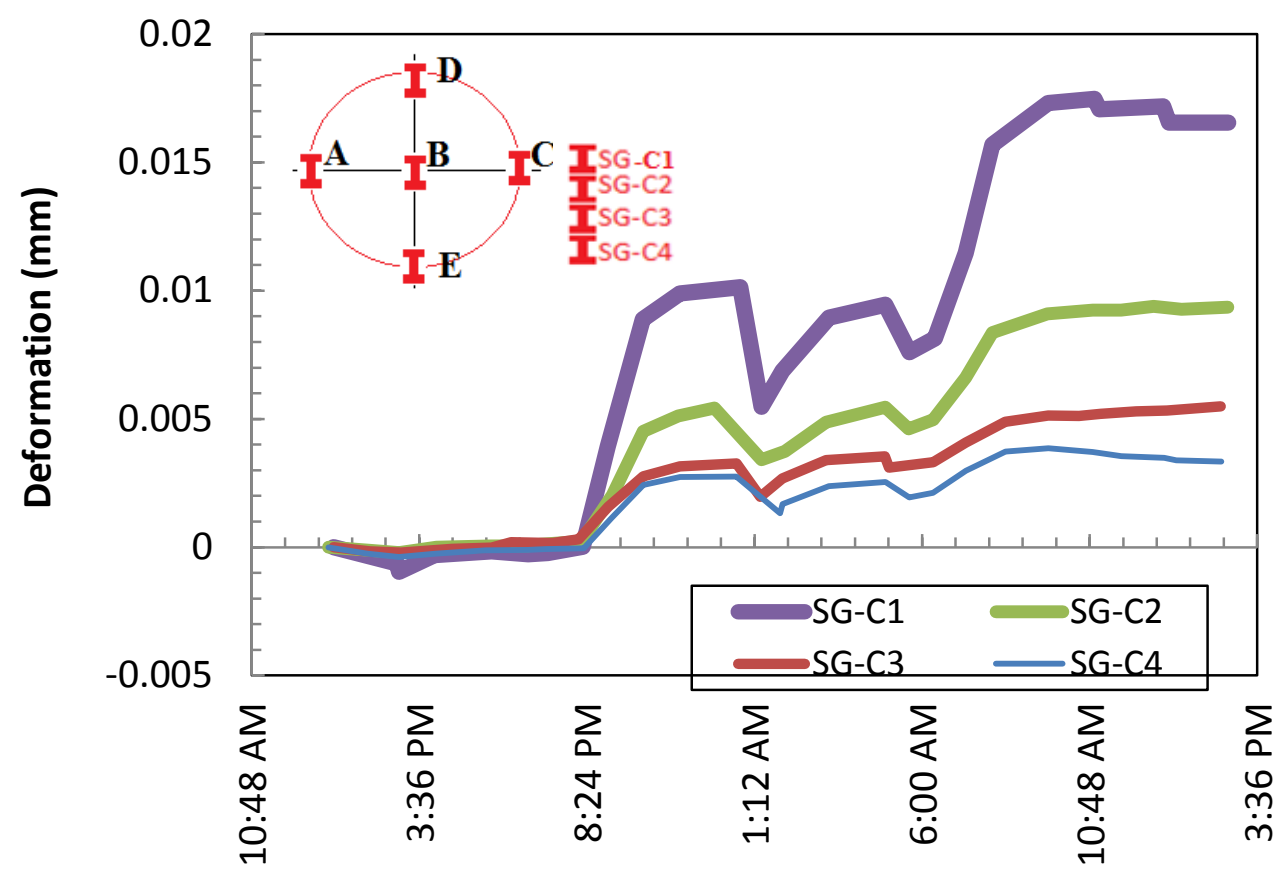

FIG. 4.20 Isolated deformation in gauges SG-C1, C2, C3 and C4 for Site B on 2/10/2013

Site B.

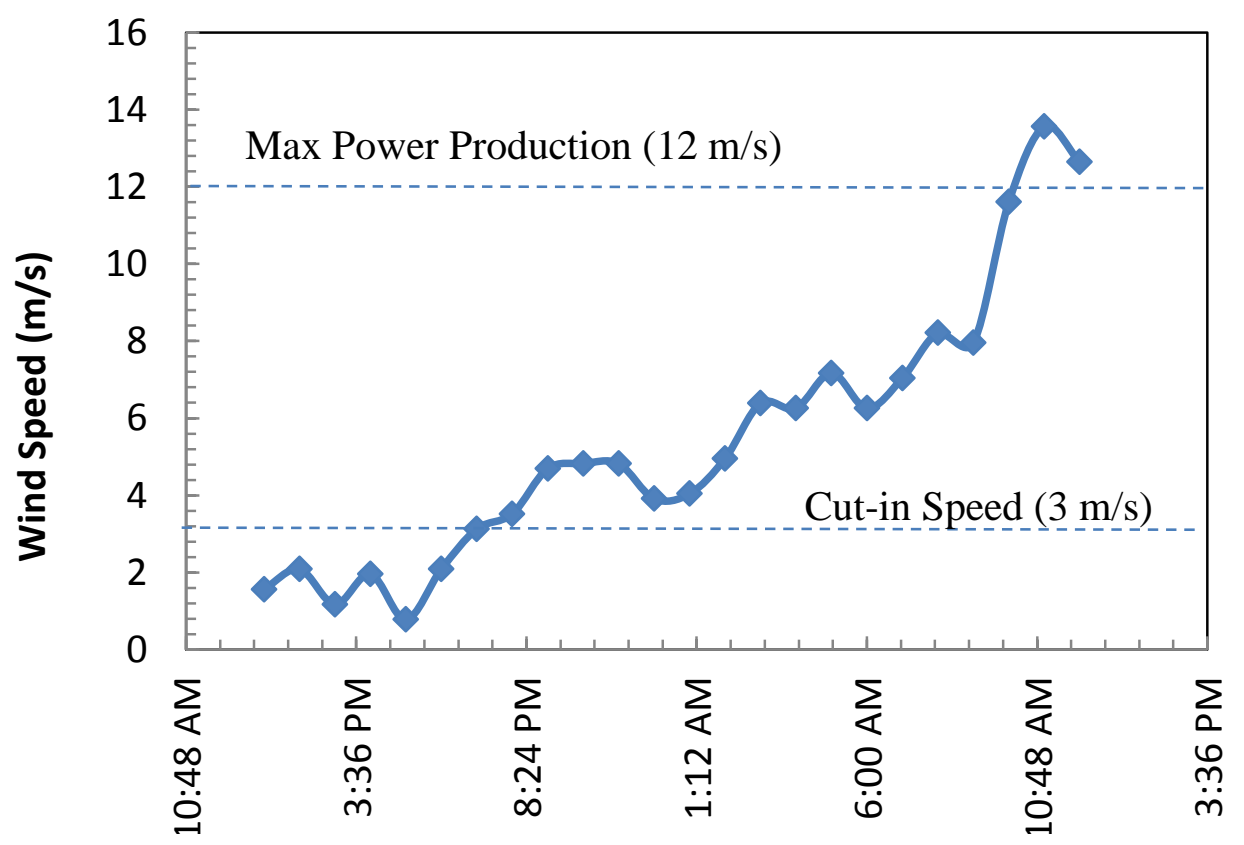

FIG. 4.21 Wind speed for Site B on 2/10/2013 Site B. 
Depending on wind magnitude and distance from the center of the foundation, the magnitude of response of the strain gauges changed. SG-E and SG-D in Site B were analyzed with-respect-to location. These two soil gauges are located at the same depth and both are perpendicular to the predominant wind direction axis (Figure 4.18). Figure 4.22 shows the deformation change at SG-E and SG-D along with the wind magnitude. In this particular timeframe, S and S-SE directional winds compress SG-D, while SG-E is extended. The gauge data show the same variation in opposite directions as expected; however, the amount of the deformation in the soil is different. The response of the soil underlying the foundation changes from one edge of the foundation to another edge, and the expansion response of the SG-E is approximately 1.5 times the deformation recorded by SG-D (Figure 4.23). In this study, field measurements show that cyclic soil deformation and pressure distribution beneath the foundation ranged from $0.0005 \mathrm{~mm}$ to $0.02 \mathrm{~mm}$. Moreover, soil deformation decreased systematically with depth. Strain level at full power production was computed as $0.006 \%$ immediately beneath the foundation and approximately $80 \%$ of this strain dissipates within $1.7 \mathrm{~m}$. Observed displacement trends were symmetric and highly correlated to wind direction. Based upon measured elastic deformation immediately beneath the foundation $(0.006 \%)$ and dynamic test results (resonant column test) $\mathrm{G} / \mathrm{G}_{\mathrm{o}}$ was computed as 0.75 (Wu 2014). Additionally, $\mathrm{G}_{\mathrm{o}}$ and $\mathrm{G}$ values were computed as $42,247 \mathrm{kPa}$ and $30,418 \mathrm{kPa}$, respectively. Shear wave velocity was also determined as $141 \mathrm{~m} / \mathrm{s}$ (Equation 2.39). Stiffness was calculated by using $\mathrm{G}_{\mathrm{o}}$, G/Go, and assumed Poisson's ratio of 0.2 (unsaturated CL). Magnitude of the stiffness was computed as 419.76 MN.m based upon $\mathrm{G} / \mathrm{G}_{\mathrm{o}}$ of 0.75 (Figure 4.22a). The typical assumption of cyclic shear strain value is $0.1 \%$ for WTG foundation design (DNV Risø 2002) (Figure 2.27). To compare stiffness magnitudes at assumed and measured cyclic strain levels, $\mathrm{G} / \mathrm{G}_{\mathrm{o}}$ was determined as 0.19 at $0.1 \%$ strain and 
stiffness was computed as 106.3 MN.m. The actual field-measurement stiffness is much higher than common calculations for design.
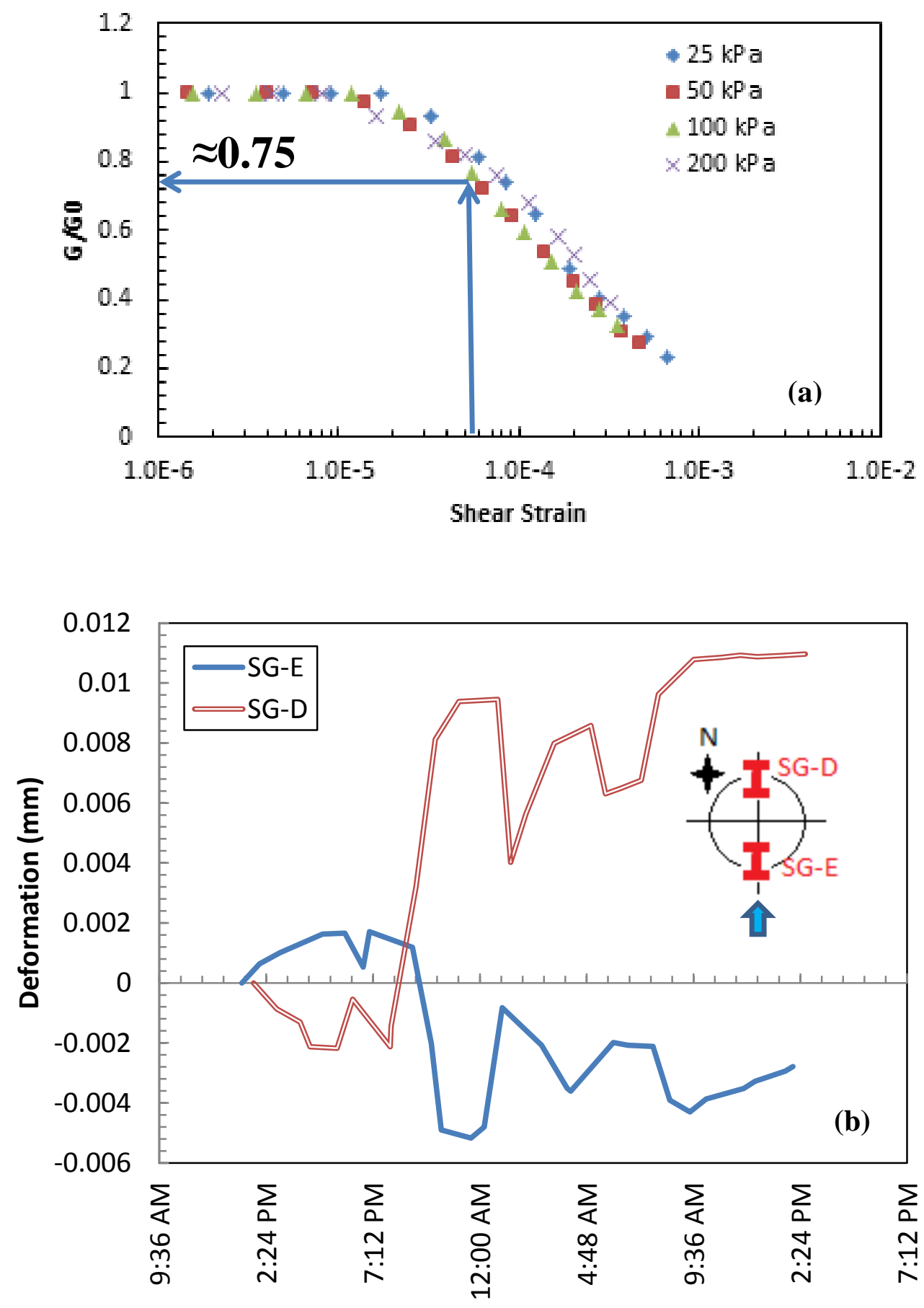

FIG. 4.22 Shear modulus degradation curve (Wu 2014) (a) and isolated deformation in strain gauges $E$ and $D(b)$ on 2/10/2013 Site $B$. 


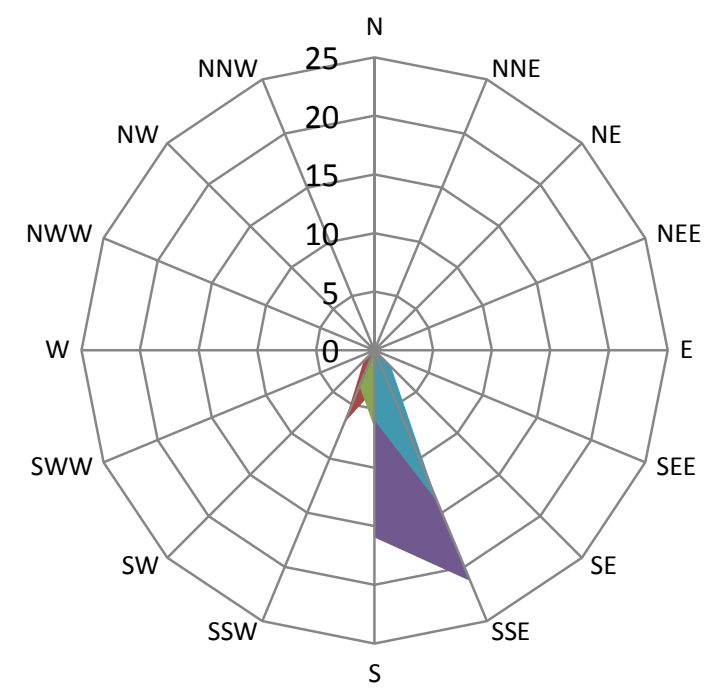

$$
\begin{aligned}
& 0-3 \mathrm{~m} / \mathrm{s} \\
& -3-6 \mathrm{~m} / \mathrm{s} \\
& 6-9 \mathrm{~m} / \mathrm{s} \\
& 9-12 \mathrm{~m} / \mathrm{s} \\
& 12-15 \mathrm{~m} / \mathrm{s} \\
& 15-18 \mathrm{~m} / \mathrm{s} \\
& 18-21 \mathrm{~m} / \mathrm{s} \\
& 21-24 \mathrm{~m} / \mathrm{s} \\
& 24+\mathrm{m} / \mathrm{s}
\end{aligned}
$$

\section{FIG. 4.23 Wind rose for Site B on 02/09/14 (9:36 AM - 7:12 PM)}

Figure 4.24 shows deformation values and distribution trends over a particular time frame. The initial wind speed is around $5 \mathrm{~m} / \mathrm{s}$. In the first 3 hours, the wind decreases until the cut-in speed is reached, and the turbine halts due to low wind velocity. The shutdown situation allows deformation redistribution analysis in terms of shutdown and startup cases. The soil deformation signatures are highly correlated with the wind speed, and the soil strains with respect to location of the soil deformation gauges responds accordingly. Measured strain was $0.006 \%$ under this particular operating condition. The strain was computed by dividing deformation value at SG-C1 $(0.02 \mathrm{~mm})$ to deformation meter length $(300 \mathrm{~mm})$. 


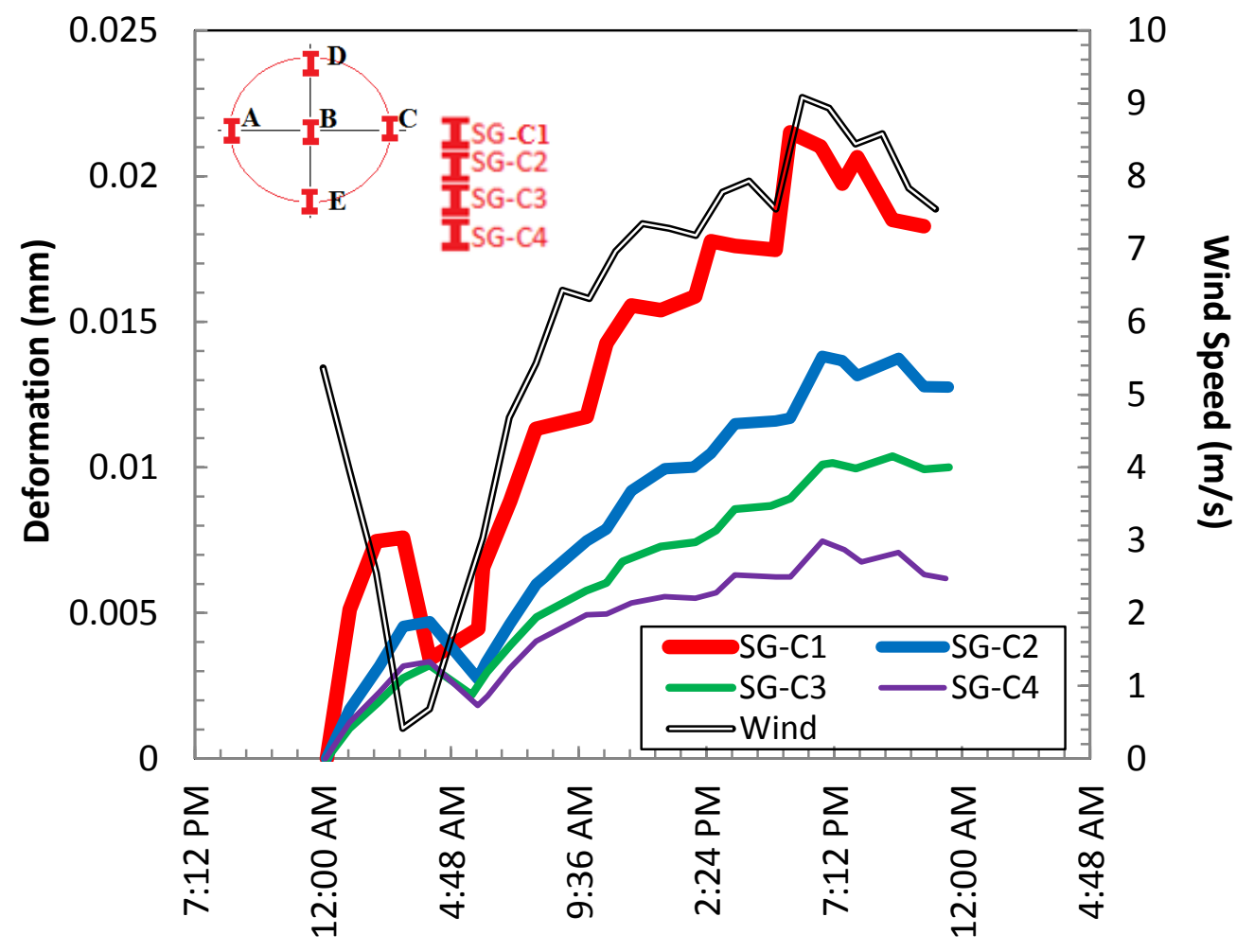

FIG. 4.24 Isolated deformation in strain gauges SG-C1, SG-C2, SG-C3, SG-C4 and wind on $01 / 10 / 13-01 / 11 / 14$ at Site B.

Soil strain gauges SG-A, SG-B1, and SG-C1 were analyzed for the deformation trend along the predominant wind direction axis (Figure 4.25) for Site B. Likewise, in Figure 4.26, soil gauges SG-E and SG-D were evaluated for soil deformation change on the axis perpendicular to the predominant wind direction. Observed displacement trends were symmetric and highly correlated to wind direction. 


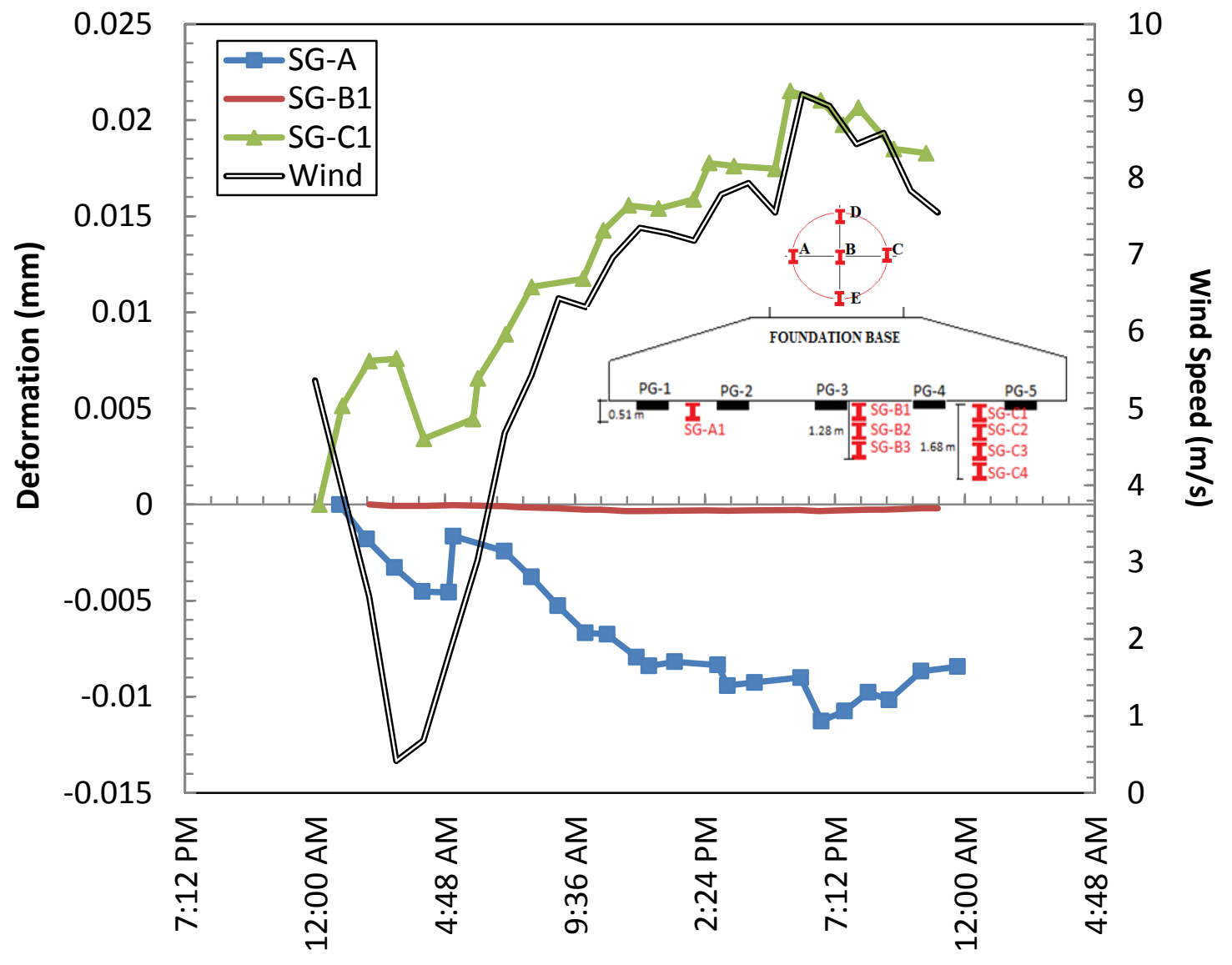

FIG. 4.25 Isolated deformation in strain gauges SG-A1, SG-B1, SG-C1 and wind 01/10/14 01/11/14 at Site B. 


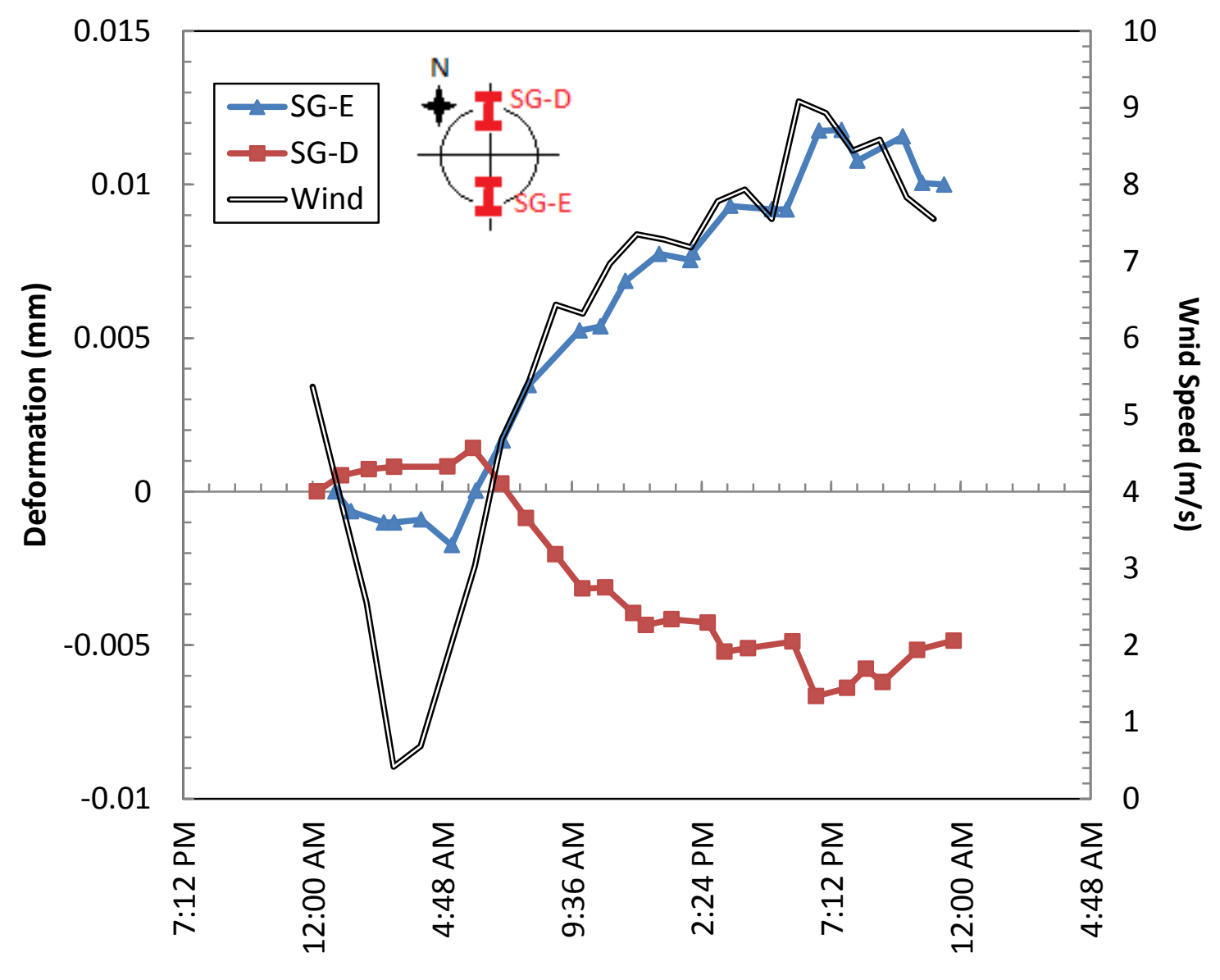

FIG. 4.26 Isolated deformation in strain gauges SG-D, SG-E, and wind on 01/10/14 01/11/14 Site B.

Figure 4.27 displays all soil deformation data on the same plot. Soil gauges in borehole C (SG-C1, SG-C2, SG-C3, and SG-C4) and soil gauge E displayed the highest deformation due to incipient wind direction, as expected. 


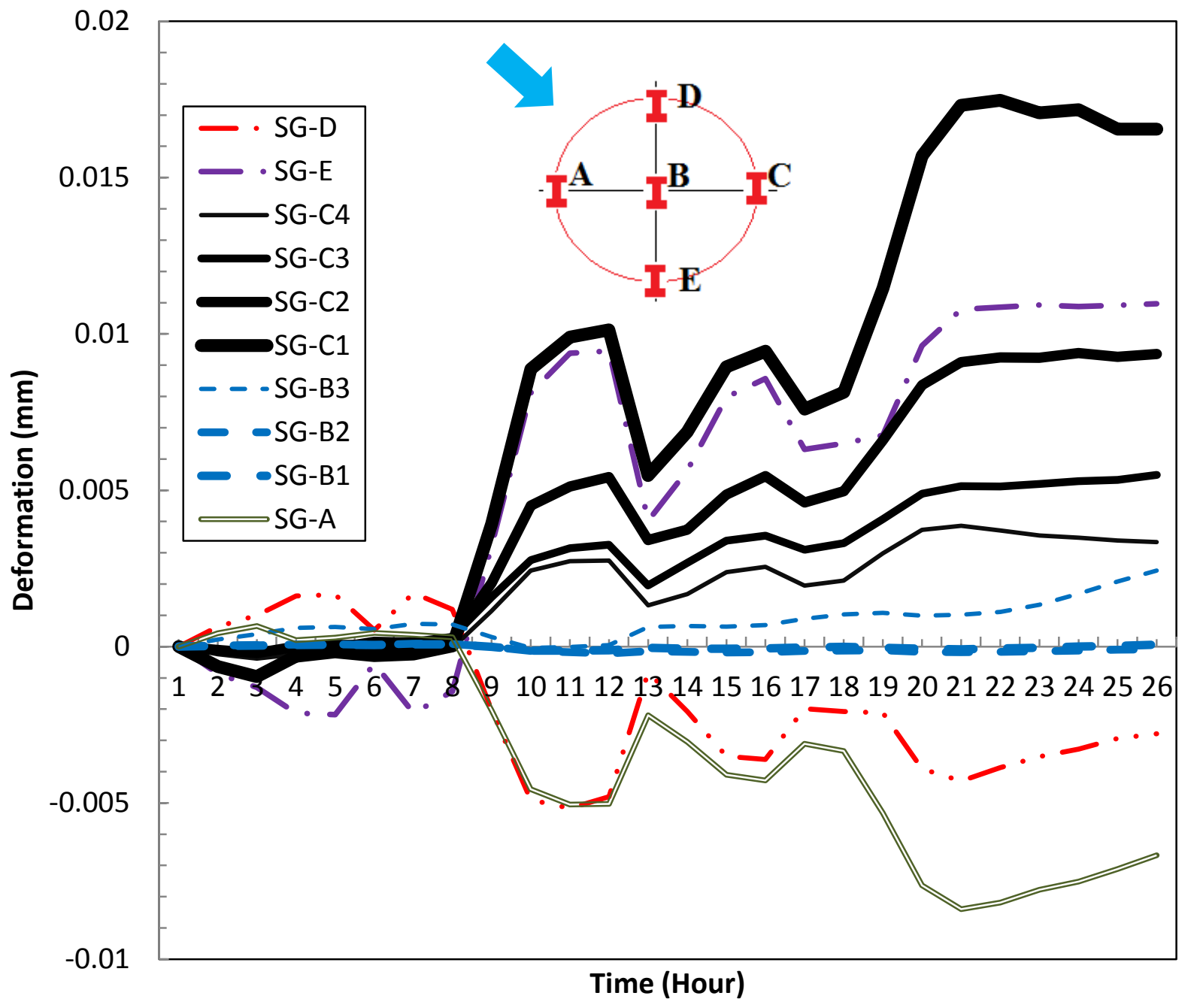

FIG. 4.27 Soil deformation gauges for 2-d period in February Site B.

In this study, field measurements show that cyclic soil deformation and pressure distribution beneath the foundation ranged from $0.0005 \mathrm{~mm}$ to $0.017 \mathrm{~mm}$. More deformation was observed beneath the foundation on the leeward site of the predominant wind direction. Observed displacement trends were symmetric depending on the location of the instrument and predominant wind direction and highly correlated to wind speed and direction. 


\subsection{Micro-electro-mechanical (MEMS) Accelerometer Data}

MEMS were installed to monitor the rotation of the foundation in different directions. They were installed at Site A only. There was no significant foundation block movement according to the MEMS rotation analysis. The highest deviation from $1650 \mathrm{mV}$ (the zero g-level) was observed in N30E MEMS accelerometer as $30 \mathrm{mV}$. S30E and 90W did not deviate from $1650 \mathrm{mV}$ by more than $-10.78 \mathrm{mV}$ and $-2.98 \mathrm{mV}$, respectively. The acceleration is $0.006649 \mathrm{~g}$ at the S30E, $0.002845 g$ at the $90 \mathrm{~W}$, and $0.003148 g$ at the N30E (Figure 4.28). Based upon accelerations analysis, tilts were computed by taking the inverse sine of the determined accelerations (in terms of $g$ ). Tilts were computed as $0.38^{\circ}$ at $\mathrm{S} 30 \mathrm{E}, 0.16^{\circ}$ at $90 \mathrm{~W}$, and $0.18^{\circ}$ at N30E.

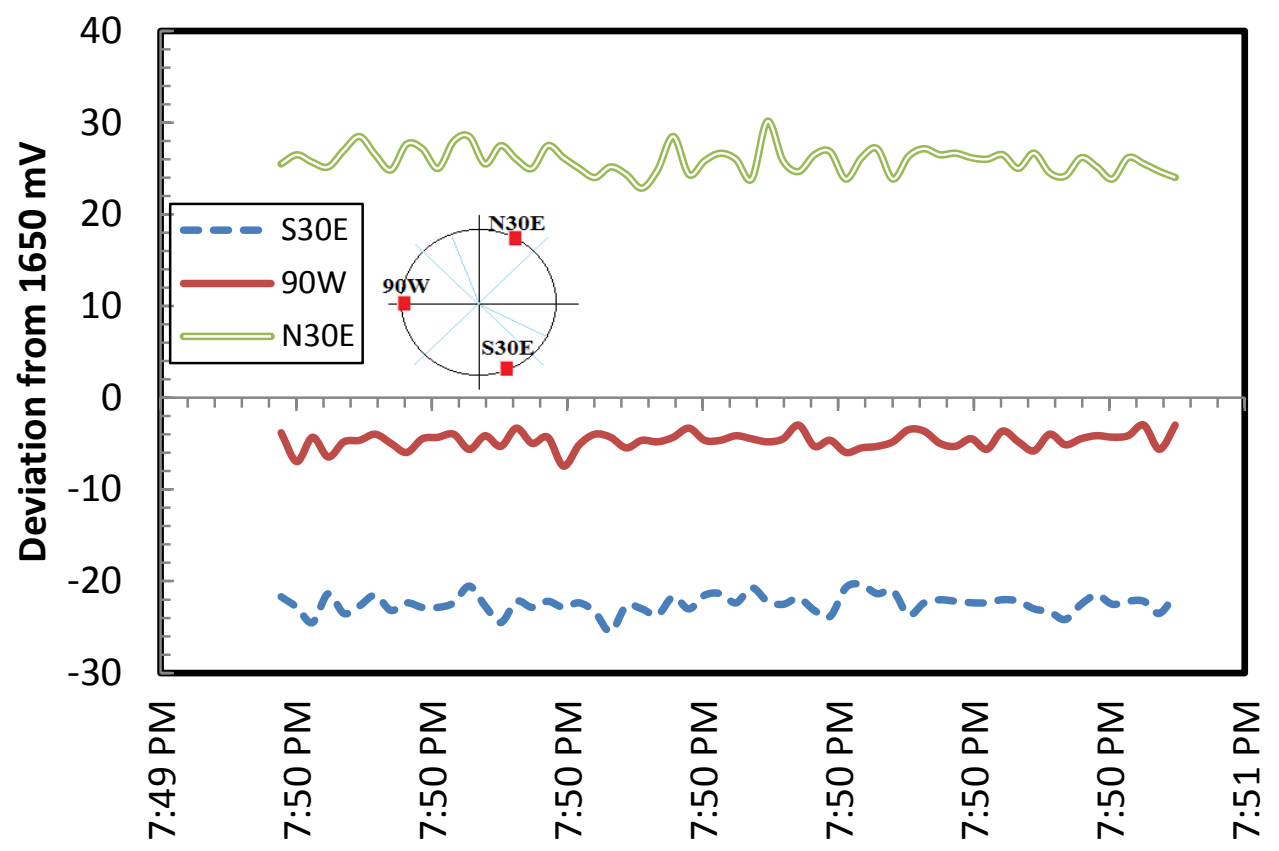

FIG. 4.28 MEMS accelerometer reading on 09/06/14 Site A. 
The deviations from the mean of the data sets were also analyzed. The highest deviation was computed at the $\mathrm{N} 30 \mathrm{E}$ as $4.39 \mathrm{mV}$. The smallest deviation was observed at $90 \mathrm{~W}$ as $1.87 \mathrm{mV}$ (Figures 4.29, 4.30, and 4.31).

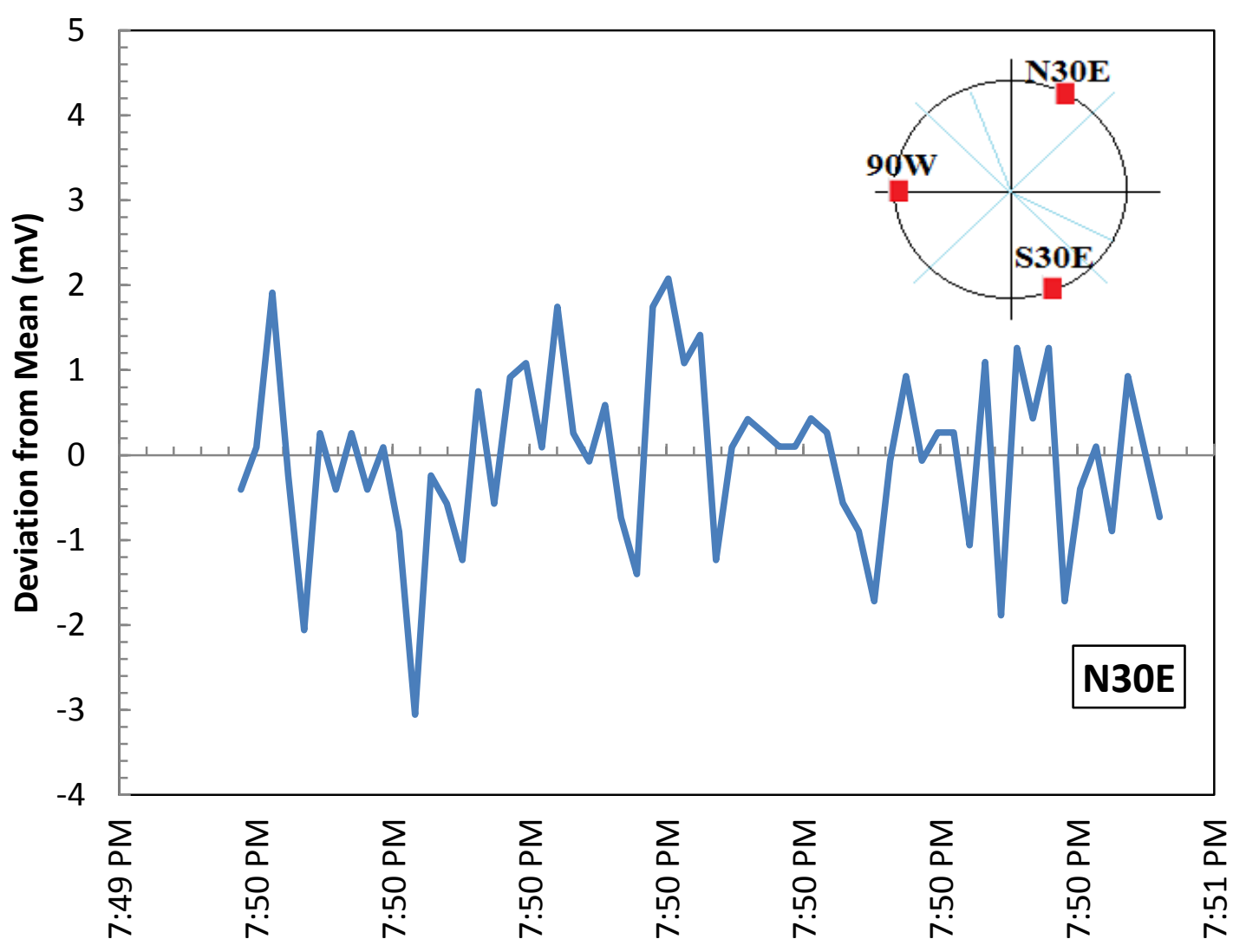

FIG. 4.29 Isolated MEMS accelerometer N30E on 09/06/13 Site A. 


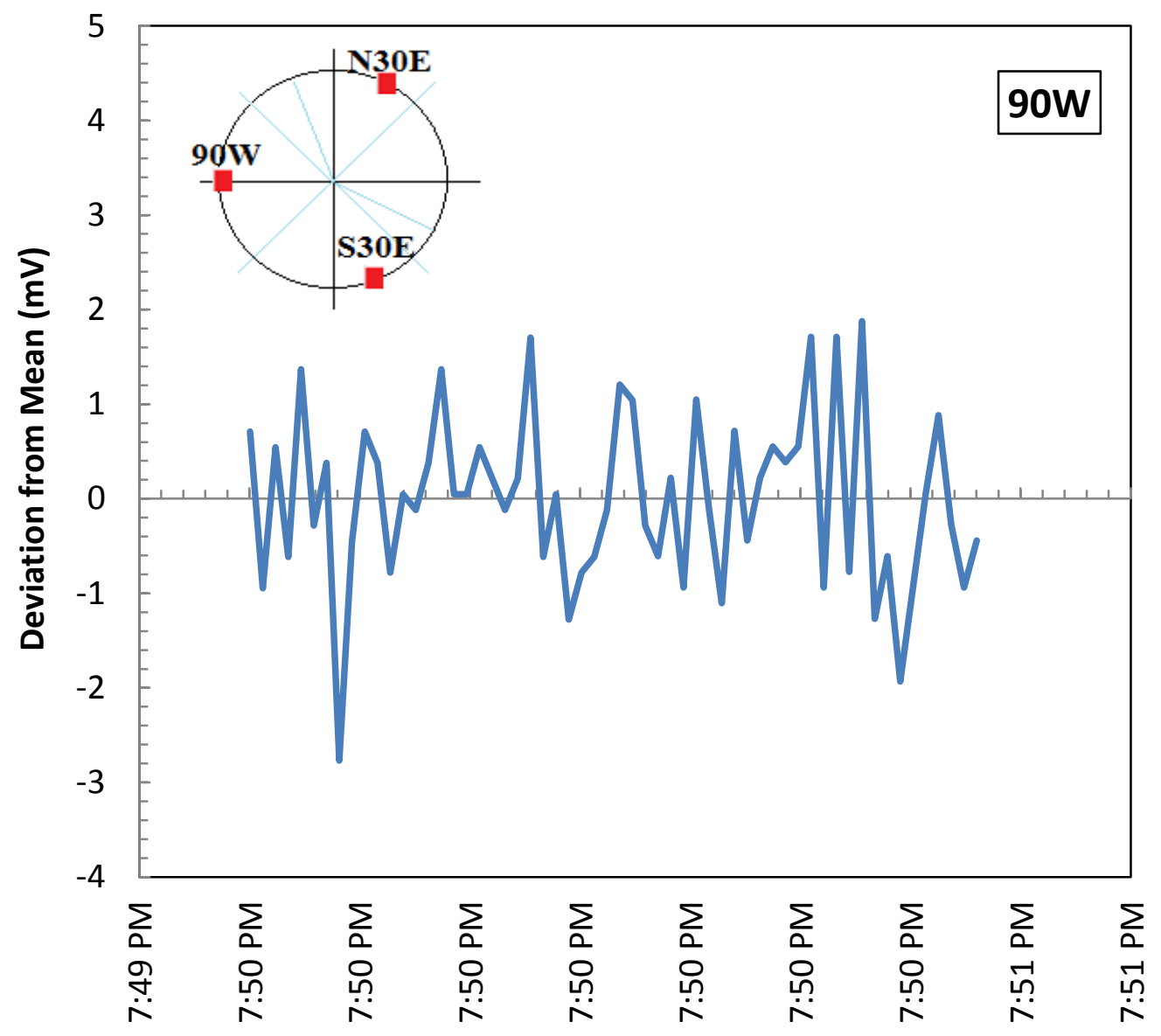

FIG. 4.30 Isolated MEMS accelerometer 90W on 09/06/13 Site A. 


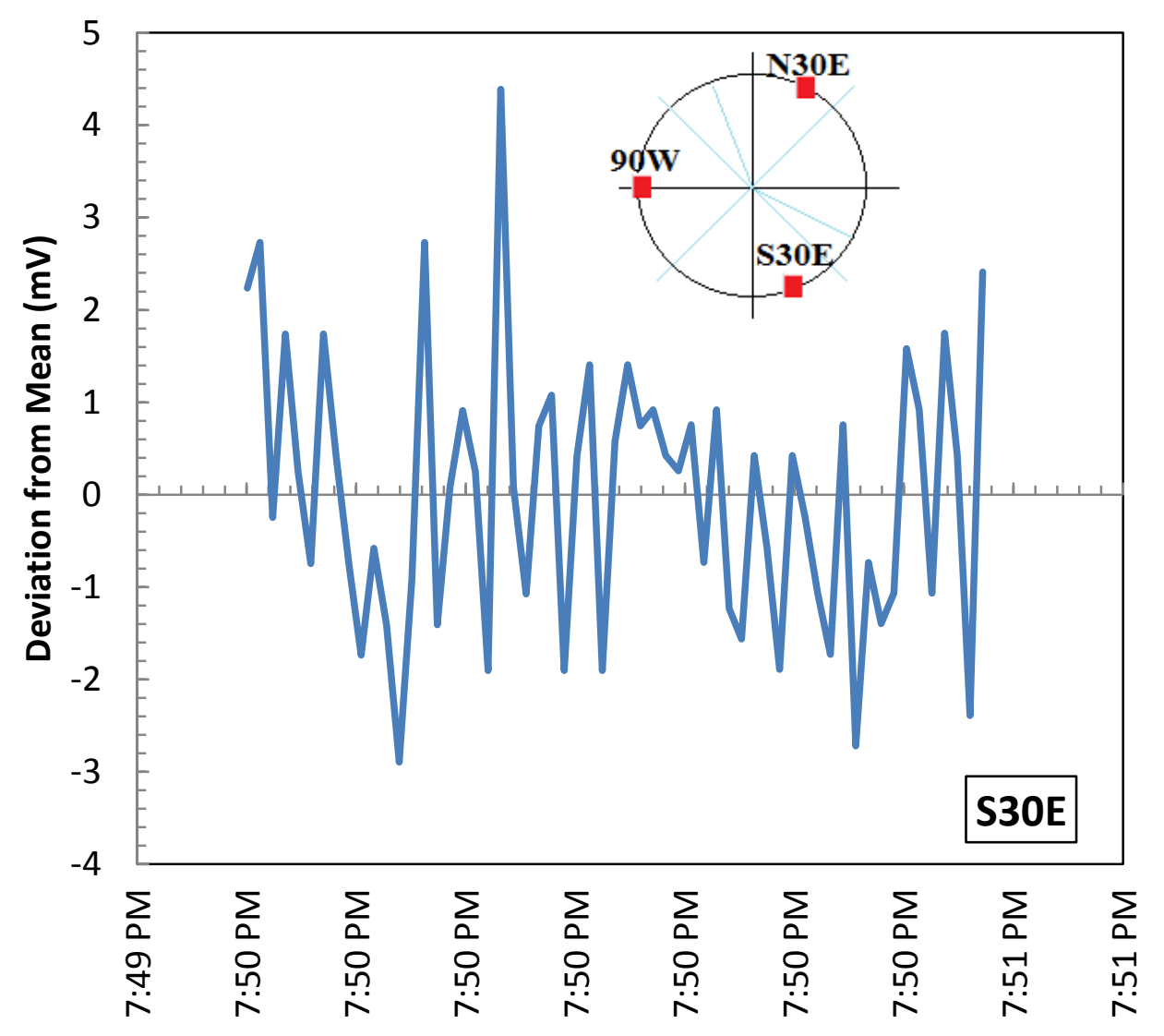

FIG. 4.31 Isolated MEMS accelerometer N30E on 09/06/13 Site A.

\subsection{Thermal Dissipation Data}

Thermal dissipation sensors were installed to monitor water content change. Thermal sensors were only installed at Site A. Thermal dissipation follows a constant trend, as shown on Figures 4.32 and 4.33 . The only substantial consequence from thermal dissipation data analysis is seasonal gravimetric water content change. The gravimetric water content slightly decreases between June and September. Whereas the water content follows a steady trend around 25\% in June, it decreases to $23.5 \%$ in September. 


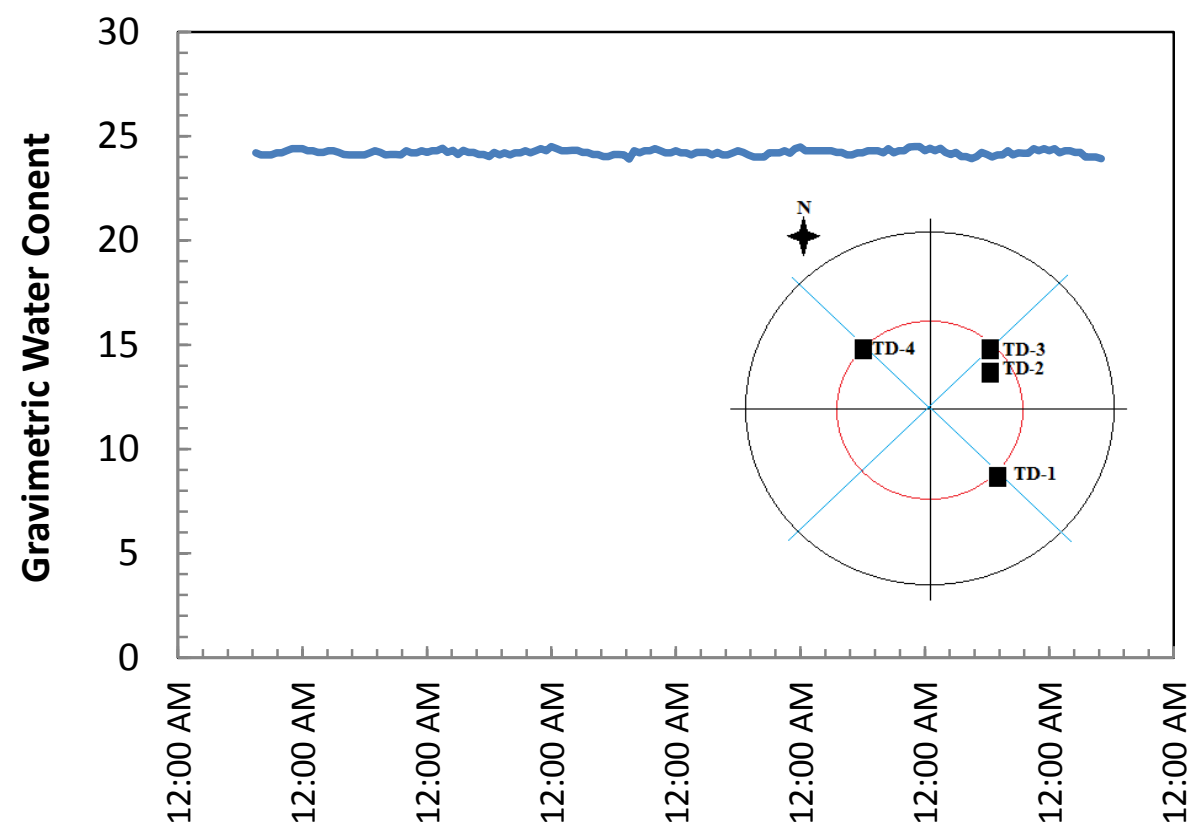

FIG. 4.32 Thermal dissipation sensor TD-3 on 06/20/12 - 06/24/12 Site A.

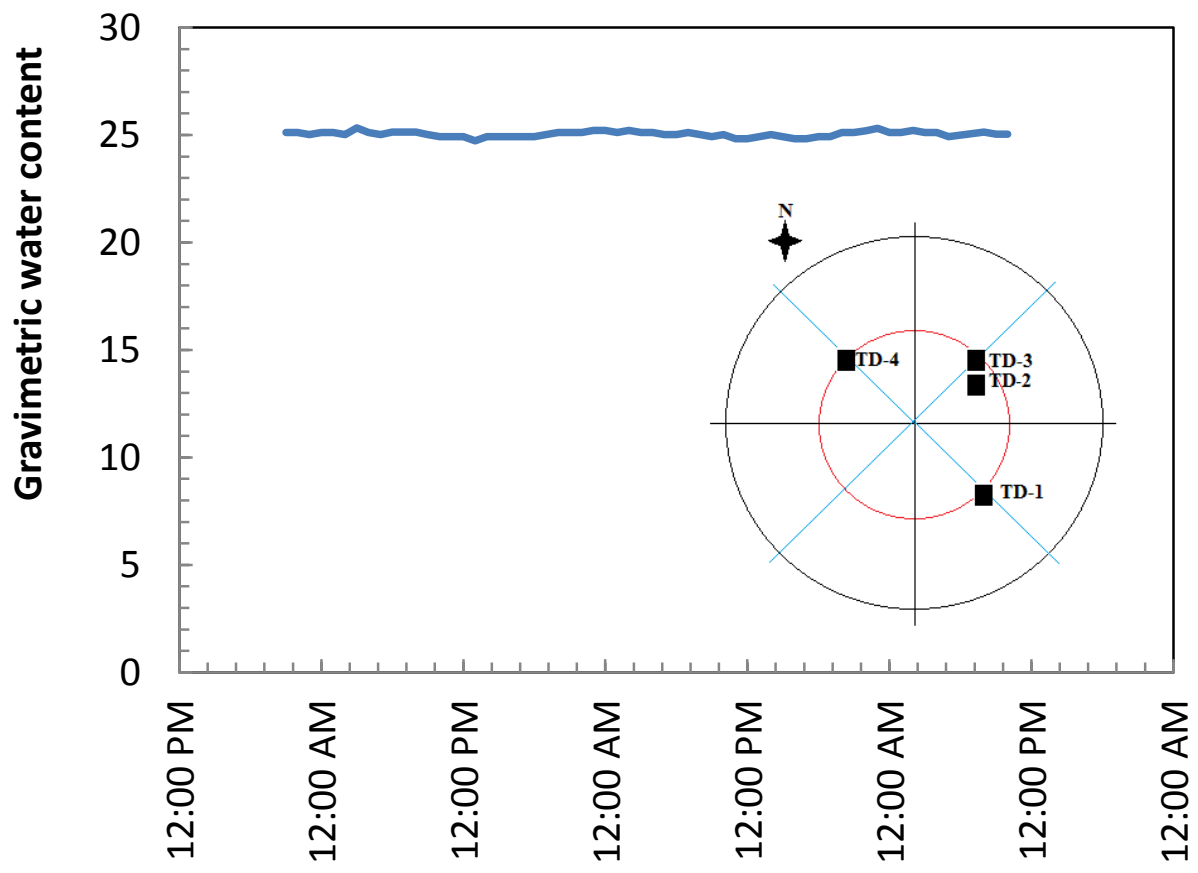

FIG. 4.33 Thermal dissipation sensor TD-3 on 09/02/12 - 09/06/12 Site A. 


\subsection{Tower Strain Gauge Data}

Tower strain gauge (TSG) analysis is based on input and output voltage and strain gauge resistance. The output voltage is measured between points A and B (Figure 3.21). The output voltage was computed as

$V_{0}=V_{i}\left[\frac{R_{1}}{R_{1}+R_{2}}-\frac{R_{3}}{R_{3}+R_{4}}\right]$

where $\mathrm{V}_{0}=$ output voltage, $\mathrm{V}_{\mathrm{i}}=$ input voltage, and $\mathrm{R}_{1,2,3,4}=$ resistance at respective position. Tower gauge strain calculation follows from

$\frac{\delta V_{0}}{V_{i}}=\frac{G F}{4}\left(2 . \varepsilon_{\text {tower }}\right)$

where $\delta V_{0}=$ change in output voltage, $\mathrm{GF}=$ gauge factor, $\mathrm{V}_{\mathrm{i}}=$ excitation voltage, and $\varepsilon=$ strain. Depending on the given equation, tower strain gauges were analyzed. According to the analysis, lower and upper strain gauge responses were highly correlated to each other. However, magnitudes of strain levels were unexpected. Higher strain was observed at the bottom strain gauge as would be expected as moment increases with distance from applied load.

Table 4.2 Unstressed Voltage Ratios (Site B)

\begin{tabular}{|c|c|c|c|c|c|}
\hline $\begin{array}{c}\text { TG-1 } \\
(\mathrm{mV} / \mathrm{V})\end{array}$ & $\begin{array}{c}\text { TG-2 } \\
(\mathrm{mV} / \mathrm{V})\end{array}$ & $\begin{array}{c}\text { TG-3 } \\
(\mathrm{mV} / \mathrm{V})\end{array}$ & $\begin{array}{c}\text { TG-4 } \\
(\mathrm{mV} / \mathrm{V})\end{array}$ & $\begin{array}{c}\text { TG-5 } \\
(\mathrm{mV} / \mathrm{V})\end{array}$ & $\begin{array}{c}\text { TG-6 } \\
(\mathrm{mV} / \mathrm{V})\end{array}$ \\
\hline-0.09846 & -0.16119 & -0.05203 & -0.19296 & -0.5059 & -0.48878 \\
\hline
\end{tabular}

Tower strain varied around a common value as is seen from Figures 4.35 to 4.36. The strain gauges 1, 2, 5, and 6 have relatively close amplitudes in strain distribution. Gauges 3, and 4, on the other hand, exhibit small amplitudes in strain distribution. The strain averages of the bottom and top gauges are around $12 \mu \varepsilon$ and $10 \mu \varepsilon$, respectively. The recorded strains at the gauges 3 
and 4 are relatively small (Figure 4.34). This may be related with the direction of effective wind and moment.

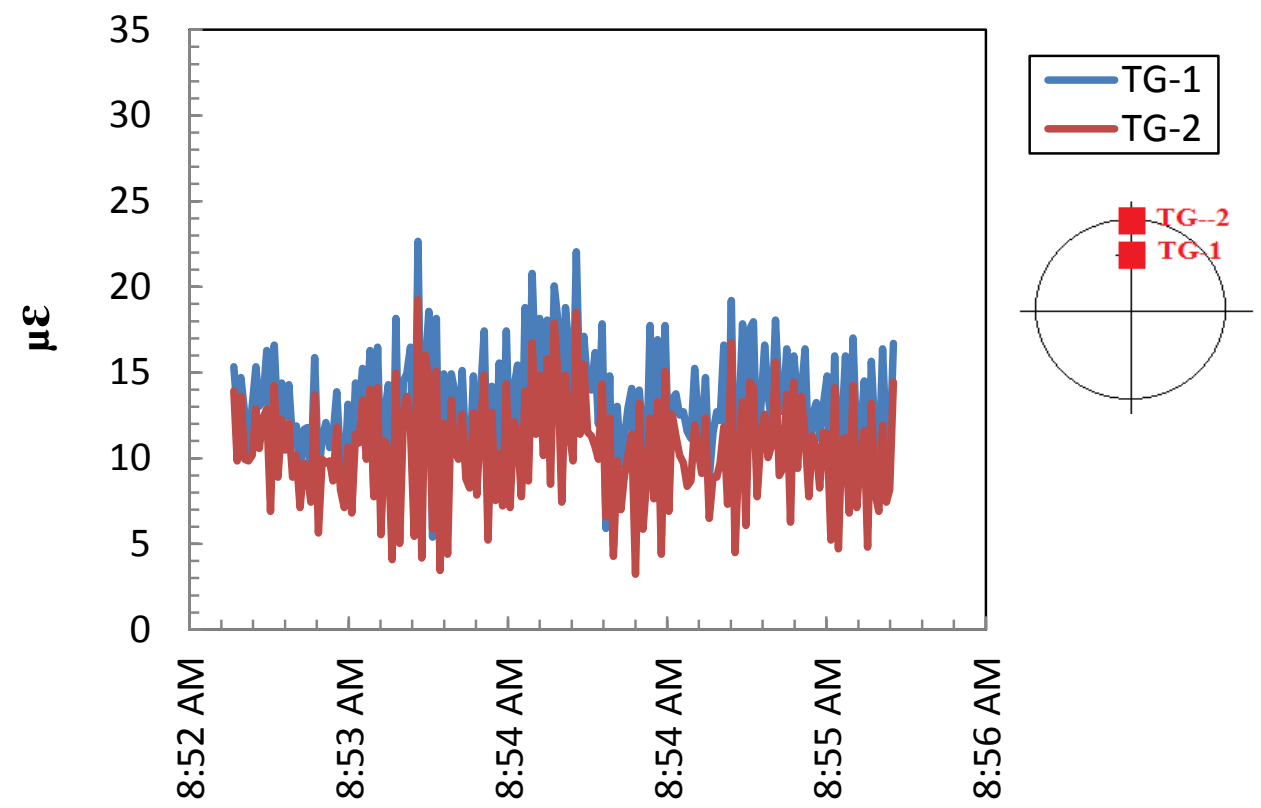

FIG. 4.34 Isolated strain gauges 1 and 2 strain distribution on 10/30/2013 Site $B$.

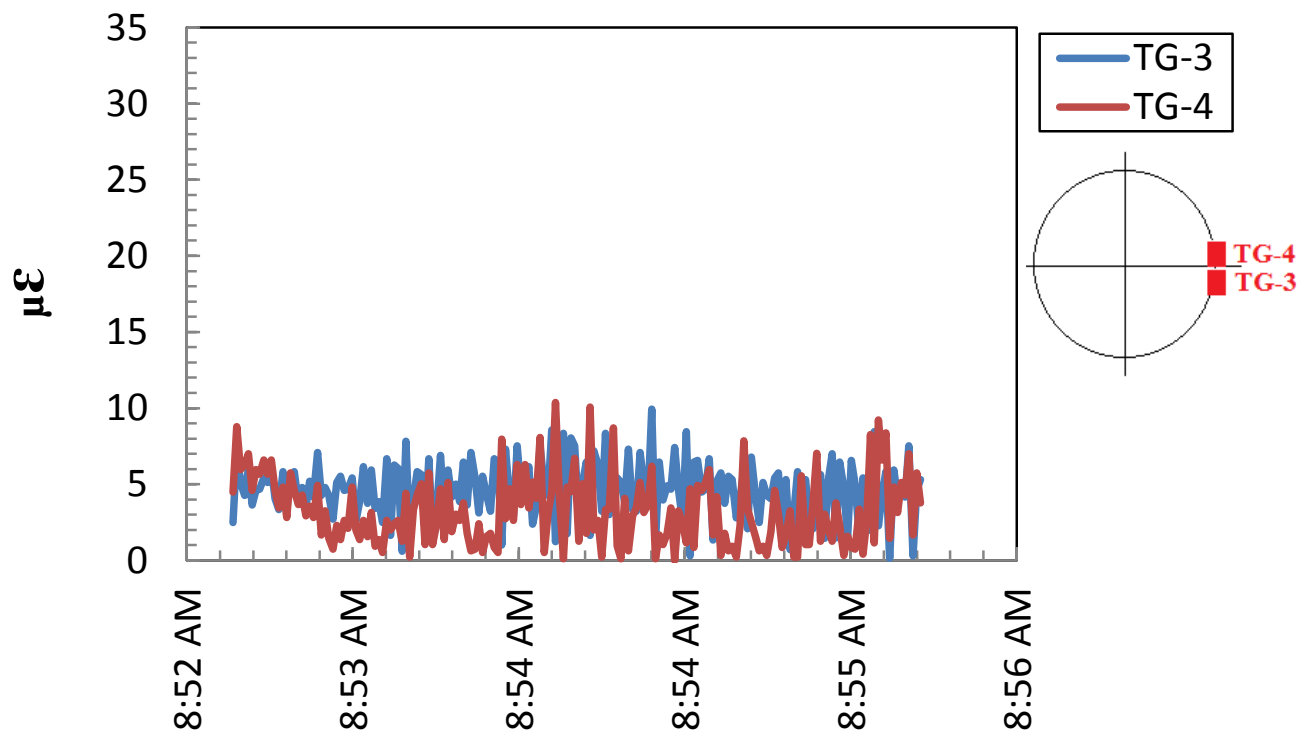

FIG. 4.35 Isolated strain gauges 3 and 4 strain distribution on 10/30/2013 Site $B$. 


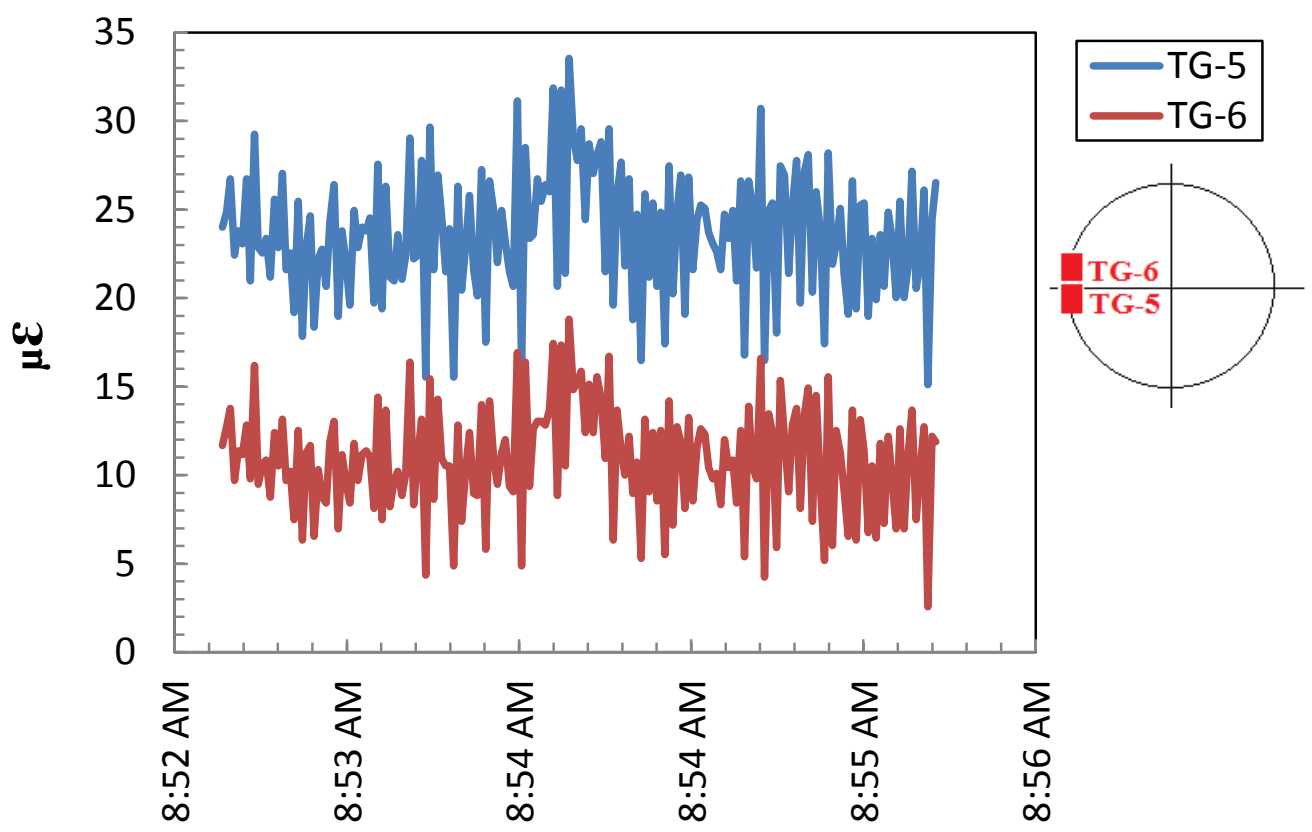

FIG. 4.36 Isolated strain gauges 5 and 6 strain distribution on 10/30/13 Site B.

Figure 4.37, Figure 4.38, and Figure 4.39 show that moment increases along the tower as the base approaches. TSG-1, TSG-3, and TSG-5 displayed higher moment depending on the strain increase. At the TSG-3 and TSG-4, a moment switch was observed. This may be related with the applied moment direction or wind direction change. Overturning moment and horizontal base shear of the tower are $47,736 \mathrm{kN}-\mathrm{m}$ and $667.4 \mathrm{kN}$, respectively according to the manufacturer load document. Observed highest equivalent moment $(\approx 1400 \mathrm{kN}-\mathrm{m})$ is relatively smaller than $47,437 \mathrm{kN}-\mathrm{m}$. Moment represents smaller than $25 \%$ of extreme moment when the turbine is operating. Emergency condition is not likely dominating the overturning condition. Shear force was recorded as $460 \mathrm{kN}$ between TG- 1 and TG-2 which is below than $667.4 \mathrm{kN}$. 


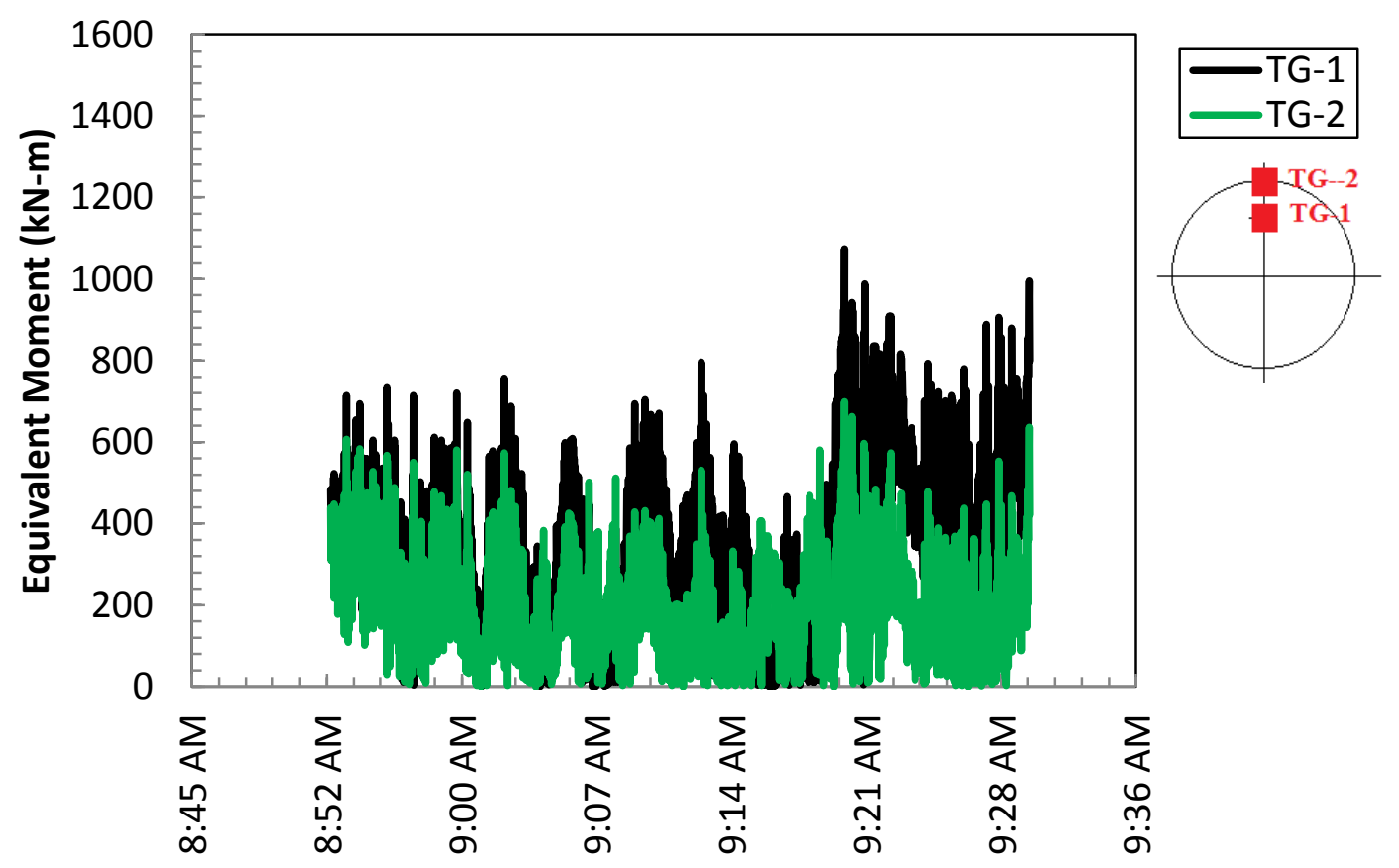

FIG. 4.37 Isolated strain gauges 1 and 2 moment distribution on 10/30/13 Site B.

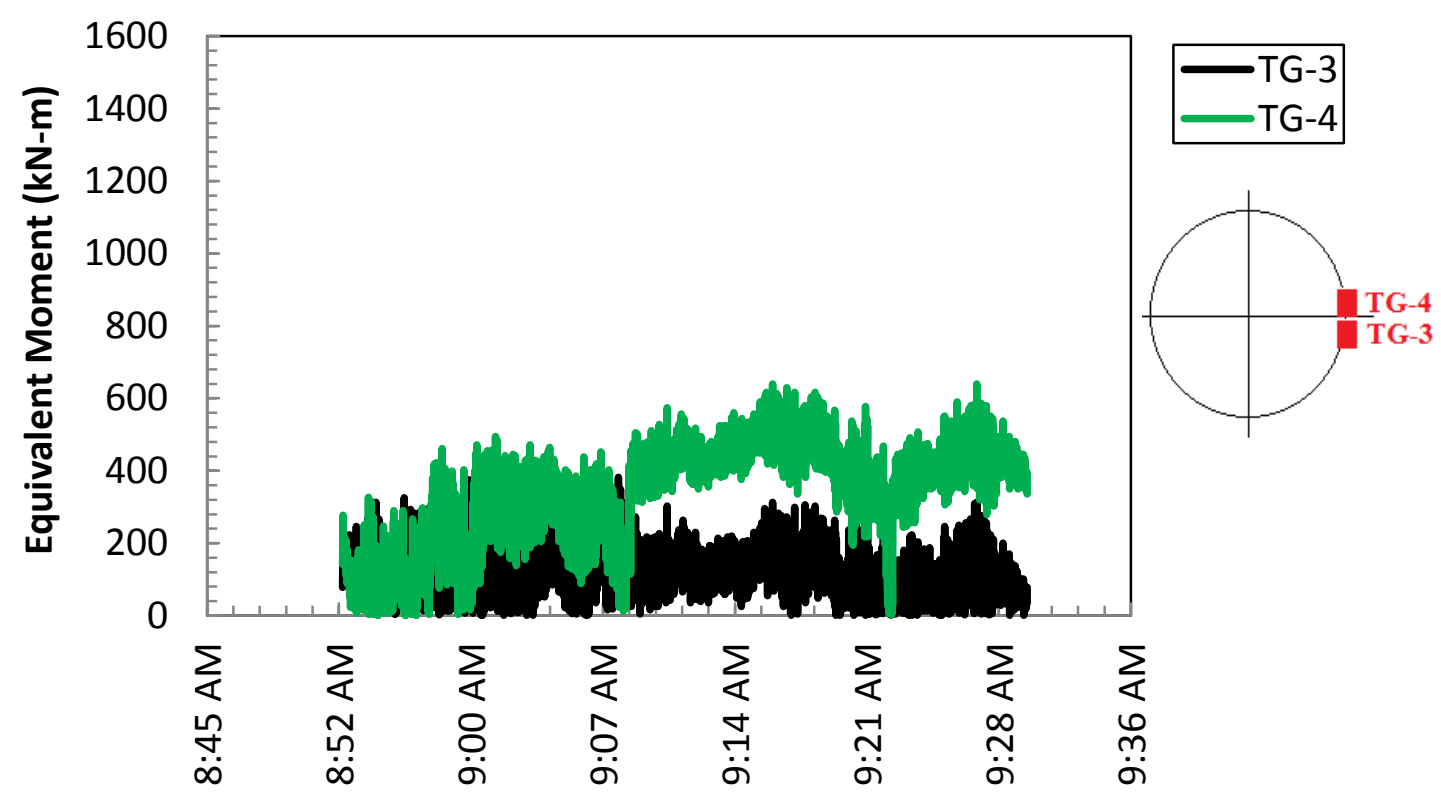

FIG. 4.38 Isolated strain gauges 3 and 4 moment distribution on 10/30/2013 Site B. 


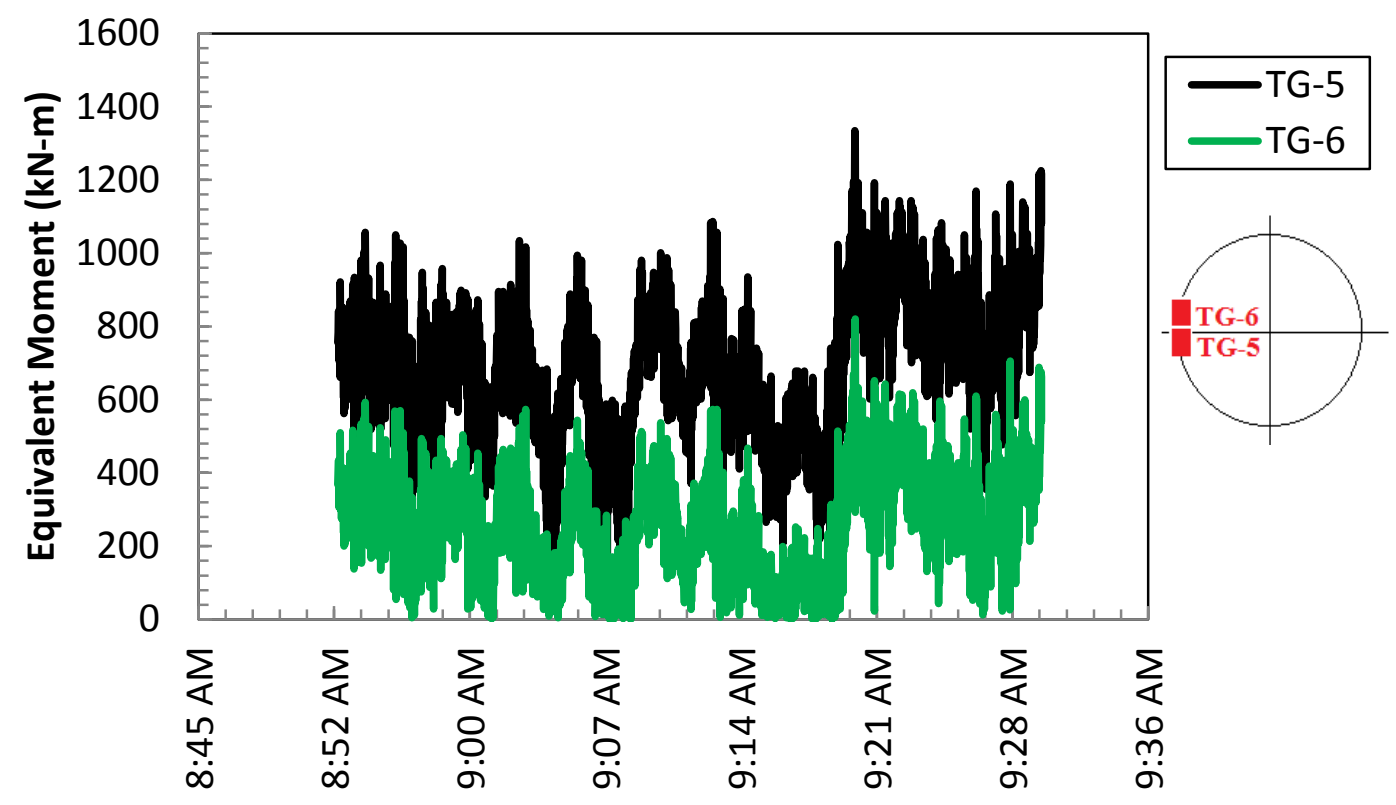

FIG. 4.39 Isolated strain gauges 3 and moment distribution on 10/30/2013 Site B.

Shear forces between the top and bottom gauges were analyze. Figure 4.40 summaries the shear force trend in a 60-s time frame. The shear force between TSG-5 and TSG-6 is relatively higher than forces between TSG-1, 2 and TSG-3, 4 .

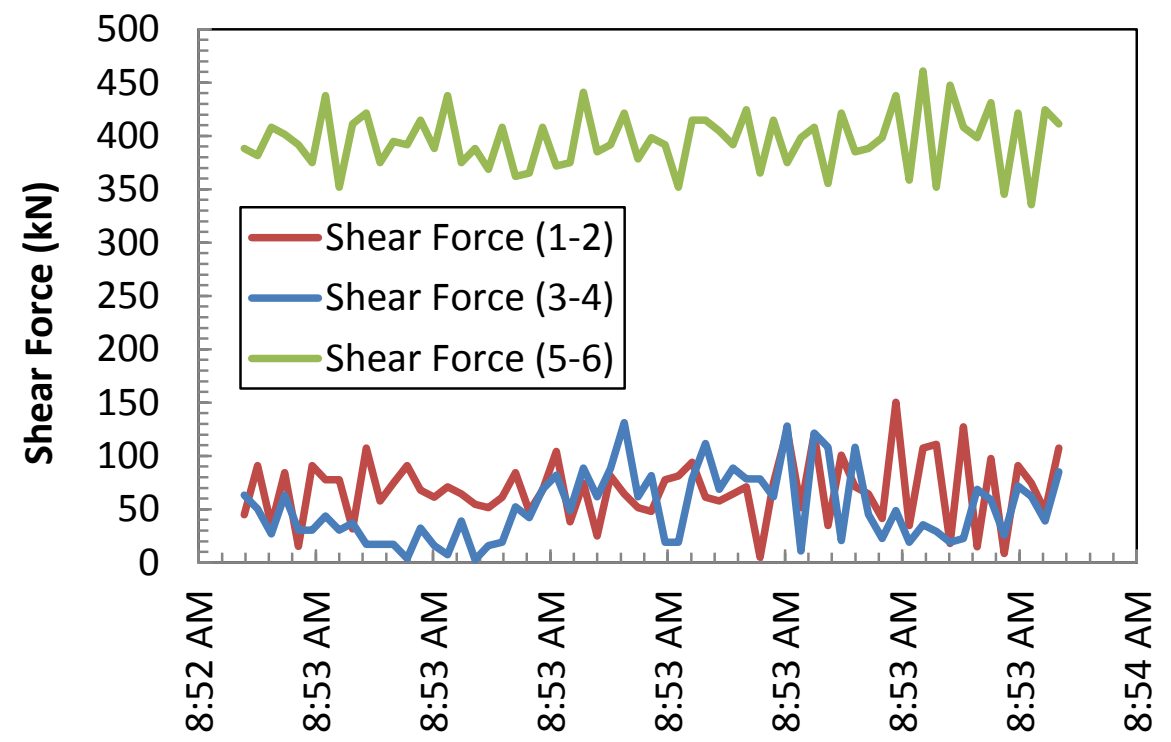

FIG. 4.40 Shear forces between strain gauges 1-2, 3-4, and 4-6 on 10/30/13 Site B. 


\section{CONCLUSIONS AND RECOMMENDATIONS}

Shallow, gravity base WTG foundation analysis is unique due to geometry and eccentric, temporal loading conditions. Typically, these foundation systems are octagonal to support moments for which the incipient direction changes as a function of the wind. Furthermore, the large horizontal to vertical force ratios lead to uneven force distributions that, in design practice, are commonly assumed as constant but eccentric soil pressure distributions. This assumed 'effective' distribution is mechanically incorrect; however, the approach simplifies design calculations when a proper measurement of foundation response is not available.

To provide mechanically correct approaches and to validate present approaches, analysis of field data under multiple mechanical and dynamic conditions is warranted. Contact pressure distribution, soil deformation, moment transfer and foundation block rotation analysis provides indications of how to evaluate foundation soil interaction and response for WTG foundations.

The following consequences and recommendations are provided as results of data analysis of WTGs.

Based on this research effort, changes in soil pressure and strain were highly related to wind direction and speed. At normal operating conditions, the most variation in pressure distribution was observed towards the edge of the foundation. Normalized pressure amplitude was around 0.35 (pressure/pressure average of analyzed data set) for the pressure cells locate at the edge of the foundation. Interior pressure cells (e.g., PG-2, PG-3, and PG-4), on the other hand, exhibited lower amplitudes $(\leq 0.10)$. This indicates that the outer portion of the foundation is more susceptible to stress changes. Although pressure was distributed across entire the foundation footprint, pressure response was not uniform. 
Pressure shifts were observed in the cases of startup and shutdown conditions. During the shutdown sequences, greater pressure fluctuations were observed (e.g., $17 \%$ in $\mathrm{PG}-3,48 \%$ in PG-4). Pressure data analysis indicated that maximum and minimum pressures occur during turbine shutdown. Pressure spikes were observed during shutdown varying from $2 \mathrm{kPa}$ to $10 \mathrm{kPa}$ depending on the location of the pressure cell.

Pressure cell - soil stiffness interaction is required for analysis of this type of field data. Under-representation was observed due to pressure drop in pressure cells. These decreases which under-represents the calculated static dead load of $78 \mathrm{kPa}$ are attributed cell-soil stiffness difference and 'bridging' phenomenon.

Soil strain was also non-uniform in distribution, both horizontally and vertically. The highest elastic soil deformation $(0.02 \mathrm{~mm}$ over the gage length of $300 \mathrm{~mm})$ occurred at the leeward site of the predominant wind direction. Moreover, soil deformation decreased systematically with depth. Strain level at full power production was computed as $0.006 \%$ immediately beneath the foundation and approximately $80 \%$ of this strain dissipates within 1.7 m. A commonly assumed cyclic strain level of $0.1 \%$ for design purposes (Det Norske Veritas) may significantly over-estimate strain levels experienced in the field for sites with stiff clay, such as these two instrumented sites in the mid-west. The observed displacement and pressure trends were symmetric depth dependent and highly correlated to wind direction and speed and location.

Thermal dissipation sensors indicated that gravimetric water content was relatively constant through the year $(23 \% \pm 2 \%)$. According to the MEMS accelerometer analysis tilts were computed as $0.38^{\circ}$ at $\mathrm{S} 30 \mathrm{E}, 0.16^{\circ}$ at $90 \mathrm{~W}$, and $0.18^{\circ}$ at $\mathrm{N} 30 \mathrm{E}$. These tilts create approximately $0.5 \mathrm{~m}$ sway (in amplitude) at the top of the WTG. 


\section{FUTURE RESEARCH PLAN}

This research effort will continue to the future. Continued data collection will allow for a more robust understanding of WTG foundation soil behavior under vertical and horizontal loadings. The number of load cycles and soil response will be evaluated, possibly in combination with laboratory tests. Additionally, the data logger may be reprogrammed to observe different conditions and for analysis of data under different sampling time increments. Reprogramming may allow for increased the capture of the dynamic shifts in pressure due to wind events. Furthermore, finite element analysis can be used as a numerical method to predict the response of WTG foundation soil with the ability for site-specific validation. A functional and validated finite element model will allow for the analysis varying load scenarios. Additional resonant column and cyclic triaxial test may be applied to available, undisturbed soil samples to better understand the behavior and response of the soil at small and large strain levels. Strain level and transferred moment amounts can be evaluated to compare design loading conditions. Limited wind data can be extended. At Site A, limited instrumentation data (due to distance of site) and lack of wind data limited the evaluation of the foundation soil interaction. Thus, a goal for Site A would be remote access and control of the data logger

This research and future works related with this research may be contributed to practice of engineering. All the presented methods, approaches and result may be useful for WTG foundation design or in any geotechnical investigation for eccentrically loaded foundations. 


\section{REFERENCES}

Ahlstrom, A. (2006). "Emergency stop simulation using a finite element model developed for large blade deflections." Wind energy, 9, 193-210.

API, API-RP-2A. (2005). "Recommended practice for planning, design and constructing fixed offshore platforms- working stress design.” American Petroleum Institute, Washington, D.C.

Araya, C.S., O'Neill, M., and Pincus, G. (1979). "Design of structures and foundations for vibrating machines." Gulf Pub. Co., Houston, TX.

ASTM Standard D5311/D 5311M-13. (2013). "Standard Test Method for Load Controlled Cyclic Triaxial Strength of Soil." ASTM International, West Conshohocken, PA, www.astm.org.

Balakrishna, C. K., Srinivasa, B. R., and Nagaraj, T. S. (1992). "Stress distribution beneath rigid circular foundation on sand." International Journal for Numerical and Analytical Methods in Geomechanics, vol.16, 65- 72. Bangalore, India.

Bell, F. G. (2004). “Engineering geology and construction.” Spon press London, U.K., pp273

Bowles, J.E. (1988). "Foundation analysis and design.” McGraw-Hill.

Bonnatt, D. (2005). "Wind turbine foundations-Loading, dynamics, and design.” The Structural Engineering 41-45.

Budhu, M. (2007). "Second Edition: Soil mechanics and foundations." Wiley International, New York, NY.

Burland, J. B., and Burbridge, M. C. (1985). "Settlement of foundations on sand and gravel." Proceeding, Institution of Civil Engineers, (78)1: 1325-1382.

Burton, T., Jenkins, N., Sharpe D., and Bossanyi, E. (2011). "Wind energy handbook: John Wiley and Sons Ltd." Chichester, United Kingdom. 
Das, B. M., and Shin, E. C. (1996). "Laboratory model test for cyclic load-induced settlement of a strip foundation on a clayey soil." Geotechnical and Geological Engineering, 14, 213-225

Das, B. M., and Shin, E. C. (1998). "Cyclic load-induced settlement of foundations on clay." 4. International Conference on Case Histories in Geotechnical Engineering, St. Louis, Missouri.

Day, W. R. (1999). "Geotechnical and foundation engineering: design and construction." McGraw-Hill Professional Engineering, New York, NY. Section 6.17.

Det Norske Veritas. (2002). “Guidelines for design of wind turbines.” Ris $\varnothing$ National Laboratory, Copenhagen.

Dunniclidd, J. (1988). “Geotechnical instrumentation for monitoring field performance.” John Wiley Sons, Inc., New York, U.S.

Fang, H. Y. (1991). "Second edition: Foundation engineering handbook." Van Nostrand Reinhold, New York, NY, p.144-154.

Gasch, R., and Twele, J. (2002).” Wind power plants; solarpraxis.” Berlin, Germany.

Geokon Instruction Manual Model 3500 Earth pressure Cells (2013). Geokon Inc.

Gurit (2012)."Wind turbine blade aerodynamics." WE Handbook-2 Aerodynamics and Loads.

Holtz, R. D., and Kovacs, W. D. (1981). "An introduction to geotechnical engineering." Prentice-Hall Englewood Cliffs, N.J., 733 pp.

International Electrotechnical Commission. (2005). “61400-1 Wind turbines- part 1: design requirements." International Standard, 1-92.

Jumikis, A. R. (1969). “Theoretical Soil Mechanics.” Van Nostrand Reinhold, New York. 
Kong, C. Bang, J., and Sugiyama, Y. (2005). "Structural investigation of composite wind turbine blade considering various load cases and fatigue life.” Energy, 30, 2101-2114.

Ladd, C. C. (1973). "Settlement analysis for cohesive soil." Research Report R71-2, no.272, Department of Civil Engineering, Massachusetts Institute of Technology, Cambridge, Mass., $115 \mathrm{pp}$.

Lang, P. (2012). "Master Thesis: Sensitivity of shallow wind turbine foundation design and soil response to geotechnical variance with construction cost implications." University of Wisconsin-Madison, Civil and Environmental Engineering.

Lysmer. J (1965), "Vertical motion of rigid footings." Department of civil Engineering, University of Michigan Report to U.S Army Engineer Waterways Experiment Station, C. E., Vicsburg, Miss., Contract Report No. 3-115 under Contract No. DA-22-079-eng-340, also a dissertation in a partial fulfillment of the requirements for the degree of Doctor of Philosophy in the University of Michigan, Ann Arbor, Mich., Aug.

Lysmer, J. and Richart, F. E. Jr. (1966). "Dynamic response of footings to vertical loading." Journal of Soil Mechanics, and Foundation Div., Proc. ASCE 92, NO. SM1, Jan, pp. 65-91.

Meyerhof, G.G. (1953). "The bearing capacity of foundations under eccentric and inclined loads." Proceedings of the Third International Conference on Soil Mechanics and Foundation. Organizing Committee ICOSOMEF. 440-445.

Morgan, K., and Ntambakwa E. (2008). "Wind turbine foundation behavior and design considerations." Garrad Hassan American Inc., Huston: AWEA Wind Conference, 1-14.

Murthy, V.N.S (2003). "Geotechnical engineering: principles and practices of soil mechanics and foundation engineering." Malcer Dekker Inc., New York, NY.

NEHRP. (1994), "Recommended Provisions for Seismic Regulations for New Buildings: Part 2- 
Commentary”, FEMA 223A(Federal Emergency Management Agency), 1995. p. 96.

Pasten, C., Santamarina, C. J. (2011). "Energy geo-storage-analysis and geomechanical implications." KSCE Journal of Civil Engineering vol. 15, no. 4, pp. 655-667

Perloff, W. H. (1975). "Pressure distribution and settlement." Foundation Engineering Handbook H. F Winterkorn and H. Y. Fang, eds., Chapter 4, Van Nostrand Reinhold, New York, NY, p.148-196.

Richart, F. E., Hall, J.R., and Woods, R.D. (1970). "Vibrations of soils and foundations." Englewood Cliffs: Prentice Hall.

Santamarina, J. C., Fam, M. A., and Klein, K. A. (2001). “Soils and waves.” Wiley Chichester.

Schmertmann, J. H. (1970). "Static cone to compute settlement over sand." Journal of the Soil Mechanics and Foundations Division 96: 1011-1043.

Schmertmann, J. H. (1970). "Static cone to compute static settlement over sand." Journal Soil Mechanics and Foundations Division, ASCE 96, No. SM3.

Schmertmann, J.H., Hartman, J.P., and Brown, P.R. (1978). "Improved strain influence diagrams." Journal of the Geotechnical Engineering Division 104: 1131-1135.

Schmertmann, J. H. (1978). "Guidelines for cone penetration test performance, and design." Federal Highway Administration, Report FHWA-TS-78-209.

Schubell, P. J., and Crossley, R. J. (2012). "Wind turbine blade design.” Energies 2012, 53425 3449,doi:103390/en5093425. ISSN 1996-1073.

Schubert, S (2013). "Master Thesis: Instrumentation of a shallow octagonal wind turbine foundation." Civil and Environmental Engineering, UW-Madison. 
Seed, H. B., Wong, R.T., Idriss, I. M., Tokimatsu, K. (1986). "Moduli and damping factors for dynamic analyses of cohesionless soils." Journal of Geotechnical Engineering, ASCE 112, no. 11:1016-1032.

Shroff, A. V., and Shah, D. L. (2003). "Soil mechanics and geotechnical engineering." A.A. Balkema (printed in India) p.356.

Tinjum, J.M., and Christensen, R.W. (2010). "Site investigation, characterization and assessment for wind turbine design and construction." In Wind Energy Systems, edited by John D. Sorensen and Jens N. Sorensen, 26-45. Woodhead Publishing.

Tinjum, J. M., and Lang, P. (2012). “Wind energy geotechnics.” Geo Strata, 2012: 18-26.

Vestas V82-1.65 MW. Vestas Wind System A/S, Denmark. www.vestas.com.

Winterkorn H.F., and Fang, H.Y. (1975). "Foundation engineering handbook." Van Nostrand Reinhold Company, New York, NY. p.556.

Wu, Z. (2014). "Master Thesis: Measuring dynamic properties of wind turbine foundation soil in resonant column-Issues and challenges." University of Wisconsin-Madison, Civil and Environmental Engineering. 
APPENDIX A- SITE A 
Table A.1 Soil Sieve Analysis (Shallow Soil)

\begin{tabular}{|c|c|c|c|c|r|r|}
\hline $\begin{array}{c}\text { Sieve } \\
\text { Number }\end{array}$ & $\begin{array}{c}\text { Diameter } \\
(\mathrm{mm})\end{array}$ & $\begin{array}{c}\text { Mass of } \\
\text { Empty } \\
\text { Sieve(g) }\end{array}$ & $\begin{array}{c}\text { Mass of } \\
\text { Sieve + Soil } \\
\text { Retained(g) }\end{array}$ & $\begin{array}{c}\text { Soil } \\
\text { Retained(g) }\end{array}$ & $\begin{array}{c}\text { Percent } \\
\text { Retained }\end{array}$ & $\begin{array}{r}\text { Percent } \\
\text { Passing }\end{array}$ \\
\hline 4 & 4.75 & 515.22 & 546.52 & 31.3 & 5.40 & 94.60 \\
\hline 10 & 2 & 418.39 & 424.18 & 5.79 & 1.00 & 93.61 \\
\hline 20 & 0.84 & 424.77 & 429.5 & 4.73 & 0.82 & 92.79 \\
\hline 40 & 0.425 & 371.63 & 374.7 & 3.07 & 0.53 & 92.26 \\
\hline 60 & 0.25 & 361.59 & 363.96 & 2.37 & 0.41 & 91.85 \\
\hline 120 & 0.125 & 352.01 & 354.04 & 2.03 & 0.35 & 91.50 \\
\hline 200 & 0.075 & 187.65 & 292.15 & 104.5 & 18.02 & 73.48 \\
\hline Pan & & 375 & 801.21 & 426.21 & 73.48 & 0.00 \\
\hline
\end{tabular}

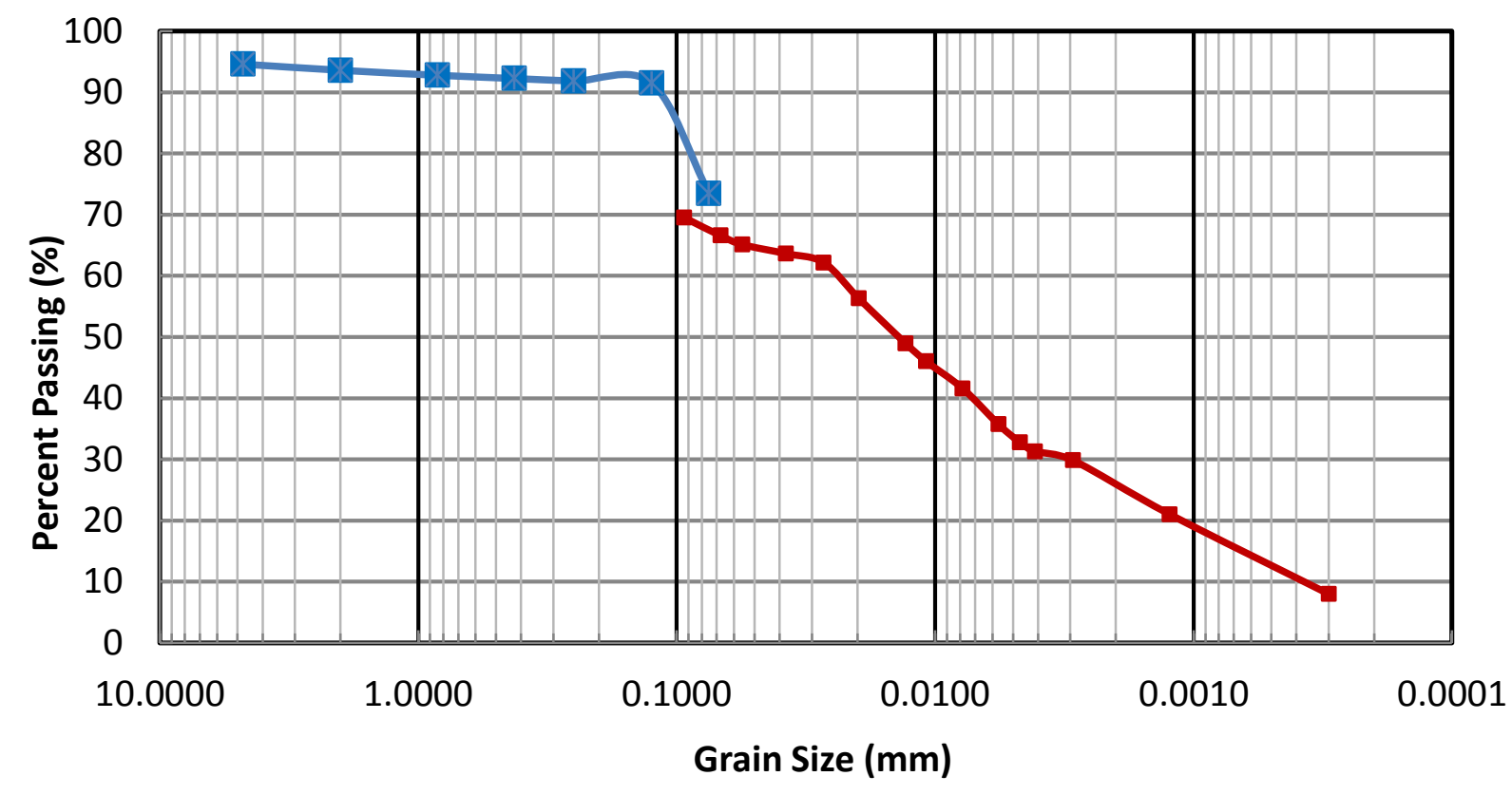

$\rightarrow-$ Hydrometer $\quad-\mathbb{a}$-Sieve Analysis

FIG. A.1 Soil grain size distribution (Shallow Soil). 
Table A.2 Soil Sieve Analysis (Deep Soil)

\begin{tabular}{|c|c|c|c|c|r|r|}
\hline $\begin{array}{c}\text { Sieve } \\
\text { Number }\end{array}$ & $\begin{array}{c}\text { Diameter } \\
(\mathrm{mm})\end{array}$ & $\begin{array}{c}\text { Mass of } \\
\text { Empty } \\
\text { Sieve(g) }\end{array}$ & $\begin{array}{c}\text { Mass of } \\
\text { Sieve+ Soil } \\
\text { Retained(g) }\end{array}$ & $\begin{array}{c}\text { Soil } \\
\text { Retained(g) }\end{array}$ & $\begin{array}{c}\text { Percent } \\
\text { Retained }\end{array}$ & $\begin{array}{r}\text { Percent } \\
\text { Passing }\end{array}$ \\
\hline 4 & 4.75 & 515.22 & 523.54 & 8.32 & 1.51 & 98.49 \\
\hline 10 & 2 & 418.39 & 421.99 & 3.6 & 0.65 & 97.83 \\
\hline 20 & 0.84 & 424.77 & 429.85 & 5.08 & 0.92 & 96.91 \\
\hline 40 & 0.425 & 371.63 & 376.91 & 5.28 & 0.96 & 95.95 \\
\hline 60 & 0.25 & 361.59 & 367.21 & 5.62 & 1.02 & 94.93 \\
\hline 120 & 0.125 & 352.01 & 358.84 & 6.83 & 1.24 & 93.69 \\
\hline 200 & 0.075 & 187.65 & 191.11 & 3.46 & 0.63 & 93.06 \\
\hline Pan & & 375 & 886.81 & 511.81 & 93.06 & 0.00 \\
\hline
\end{tabular}

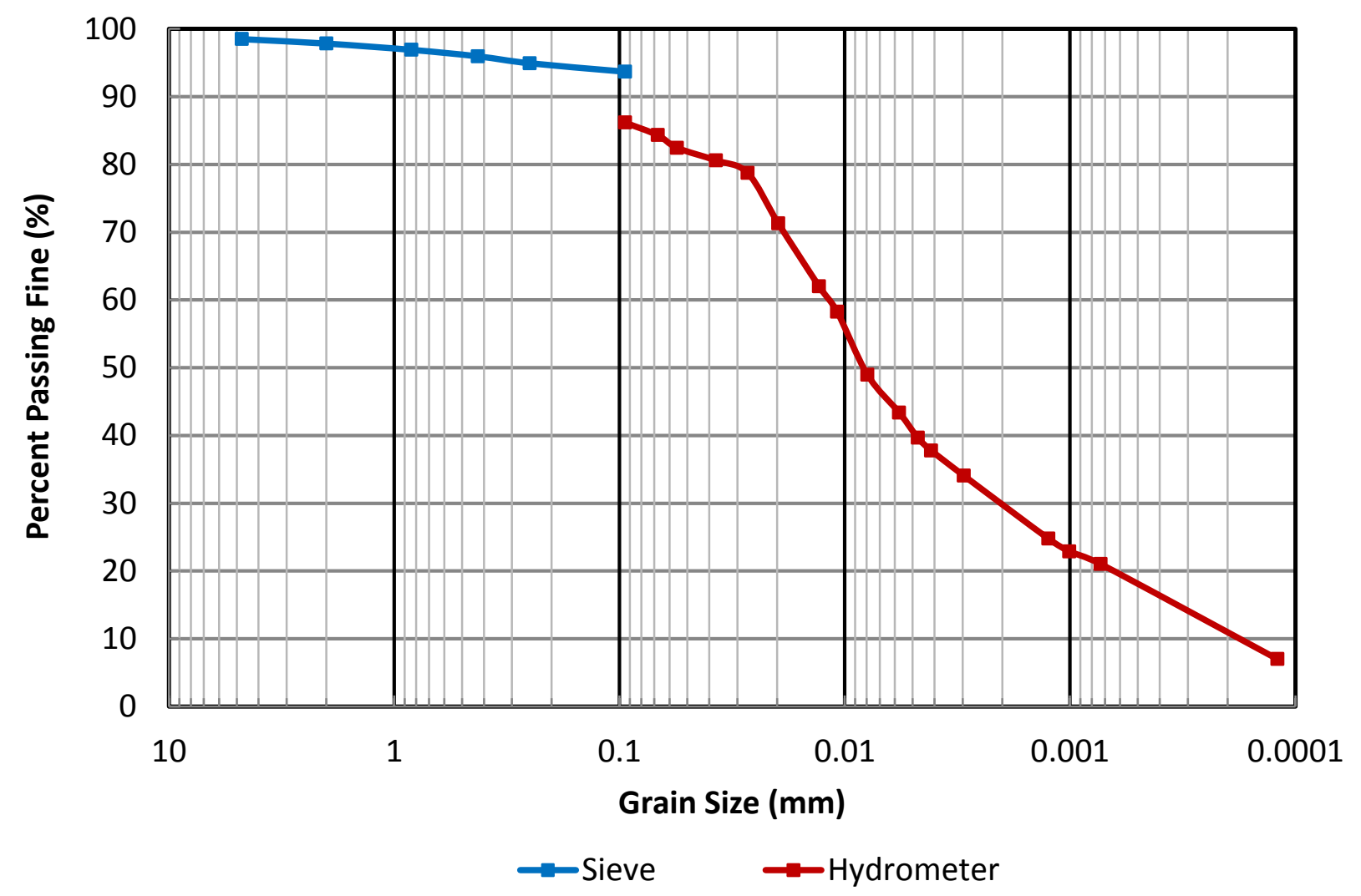

FIG. A.2 Soil grain size distribution (Deep Soil). 


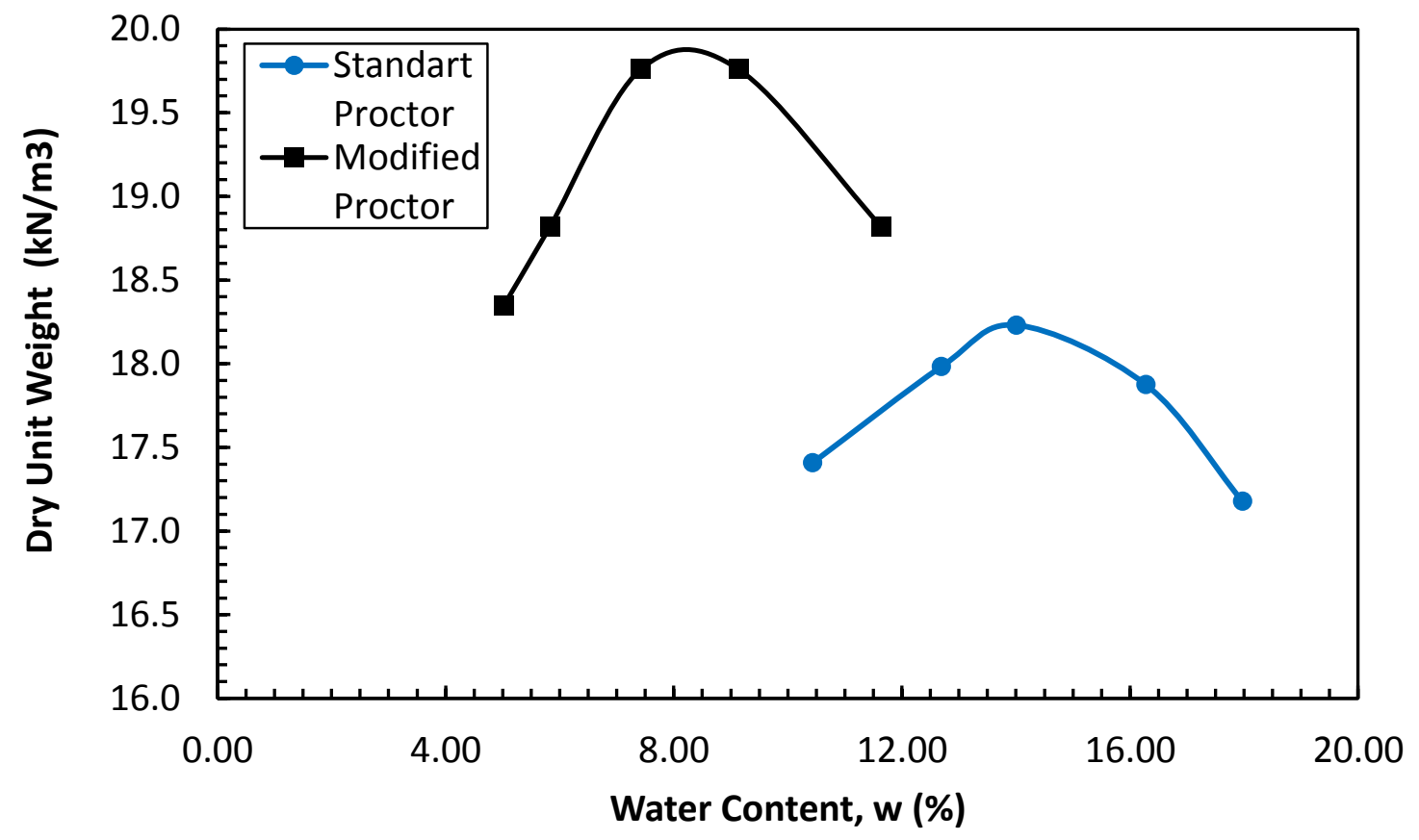

FIG. A.3 Compaction curve (Shallow Soil).

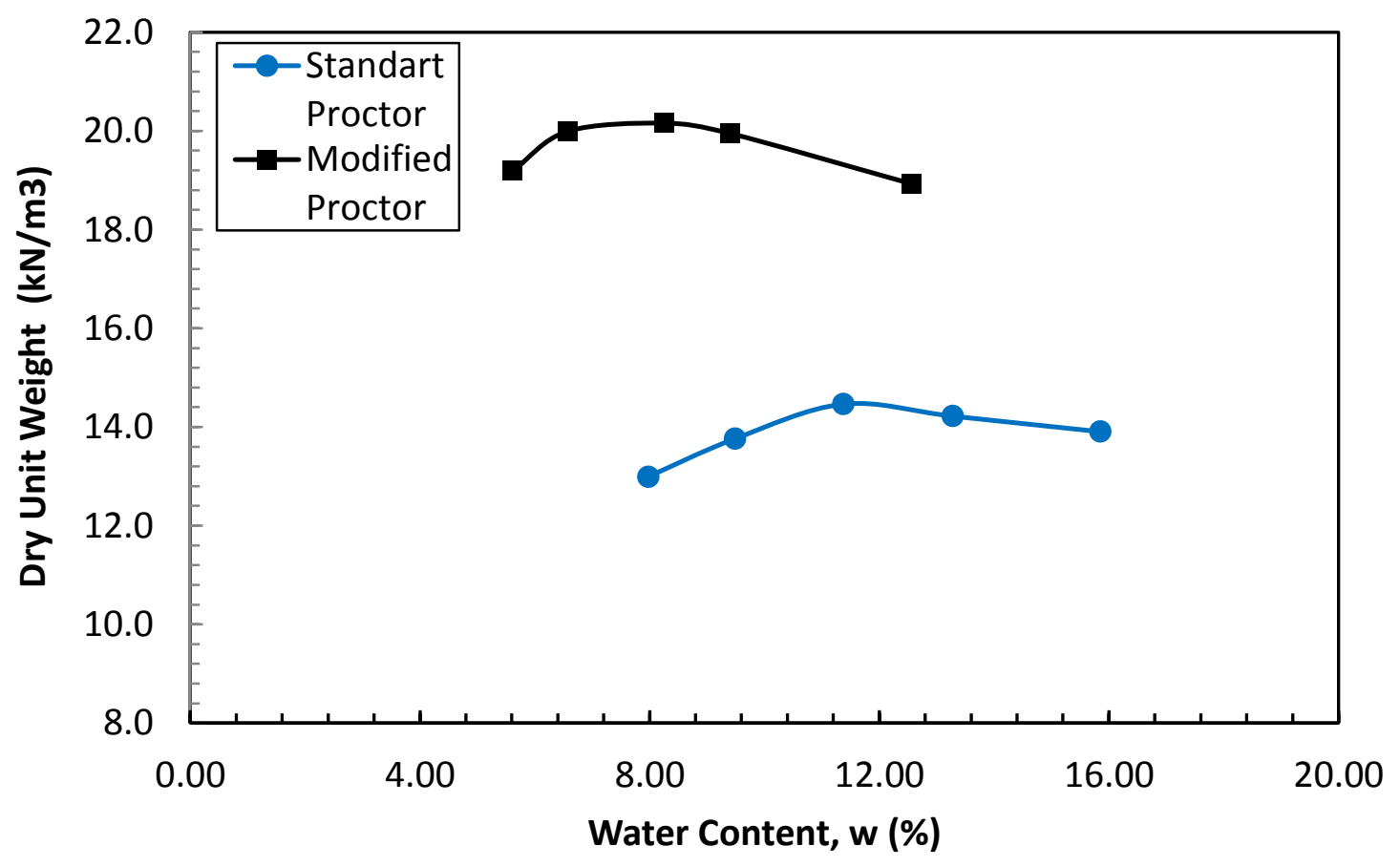

FIG. A.4 Compaction curve (Deep Soil). 


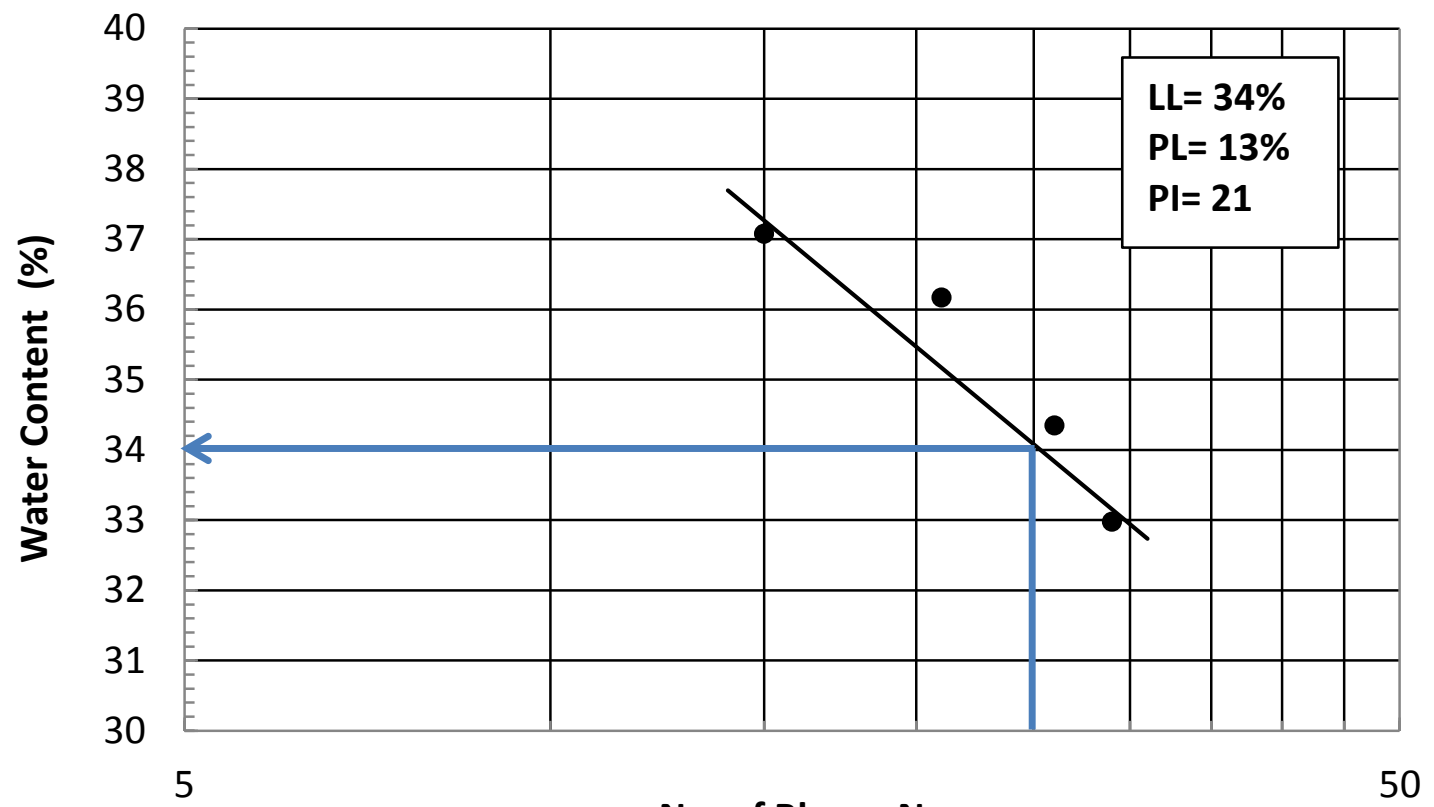

No. of Blows, $\mathbf{N}$

FIG. A.5 Liquid limit test (Shallow Soil).

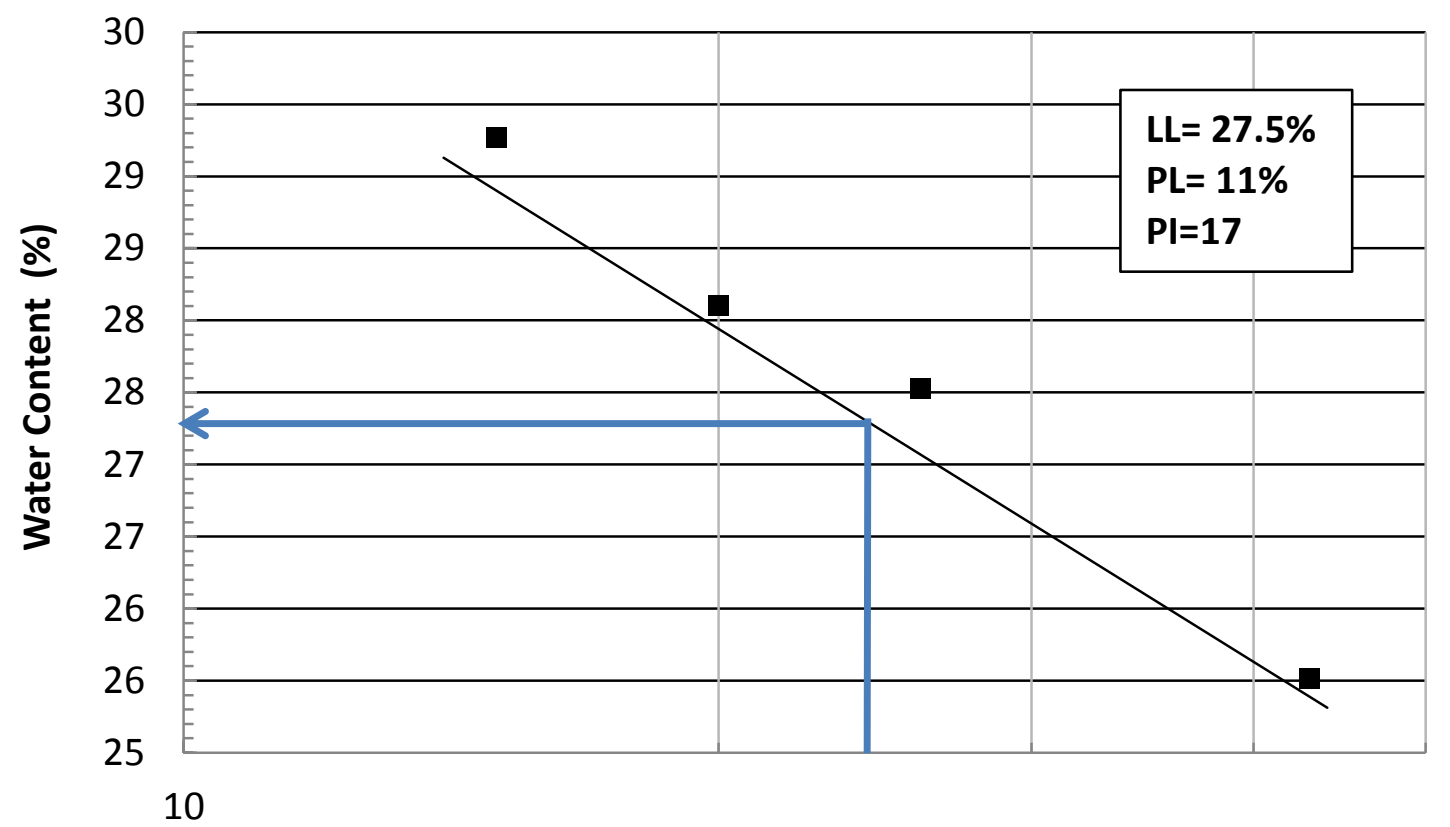

No. of Blows, $\mathrm{N}$

FIG. A.6 Liquid limit test (Deep Soil). 


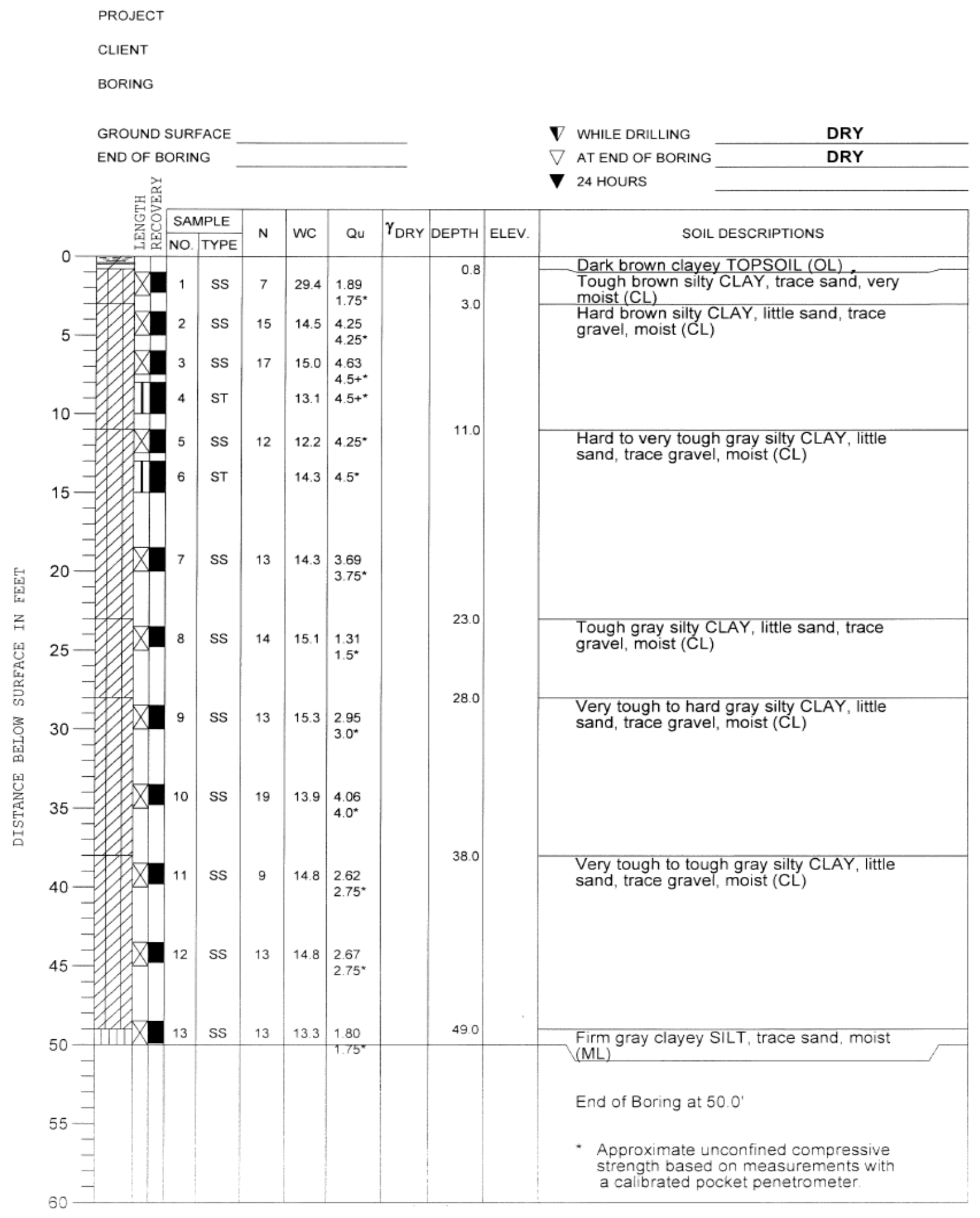

FIG. A.7 Soil boring log. 


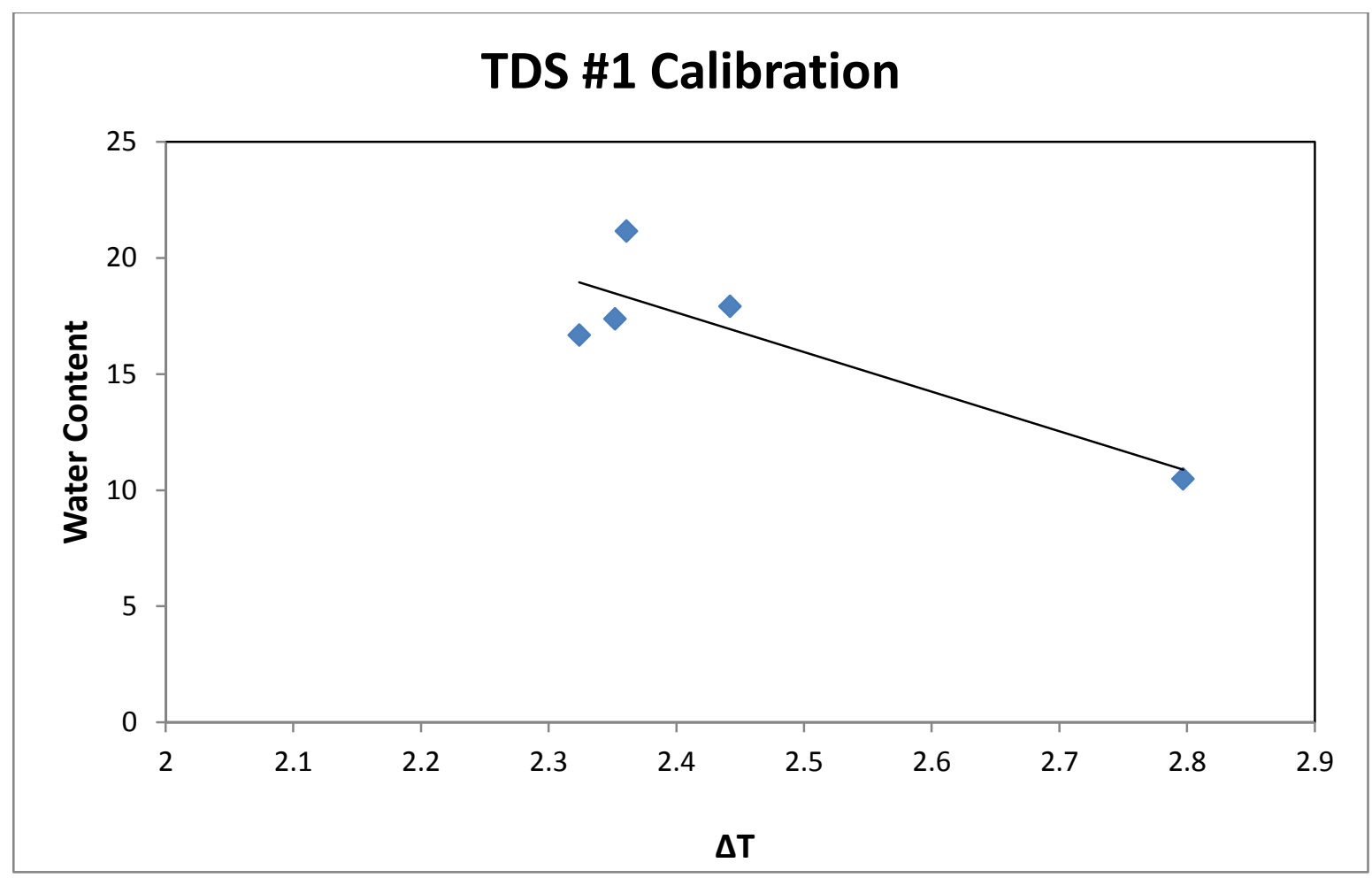

FIG. A.8 Thermal dissipation sensor TD-1 calibration curve.

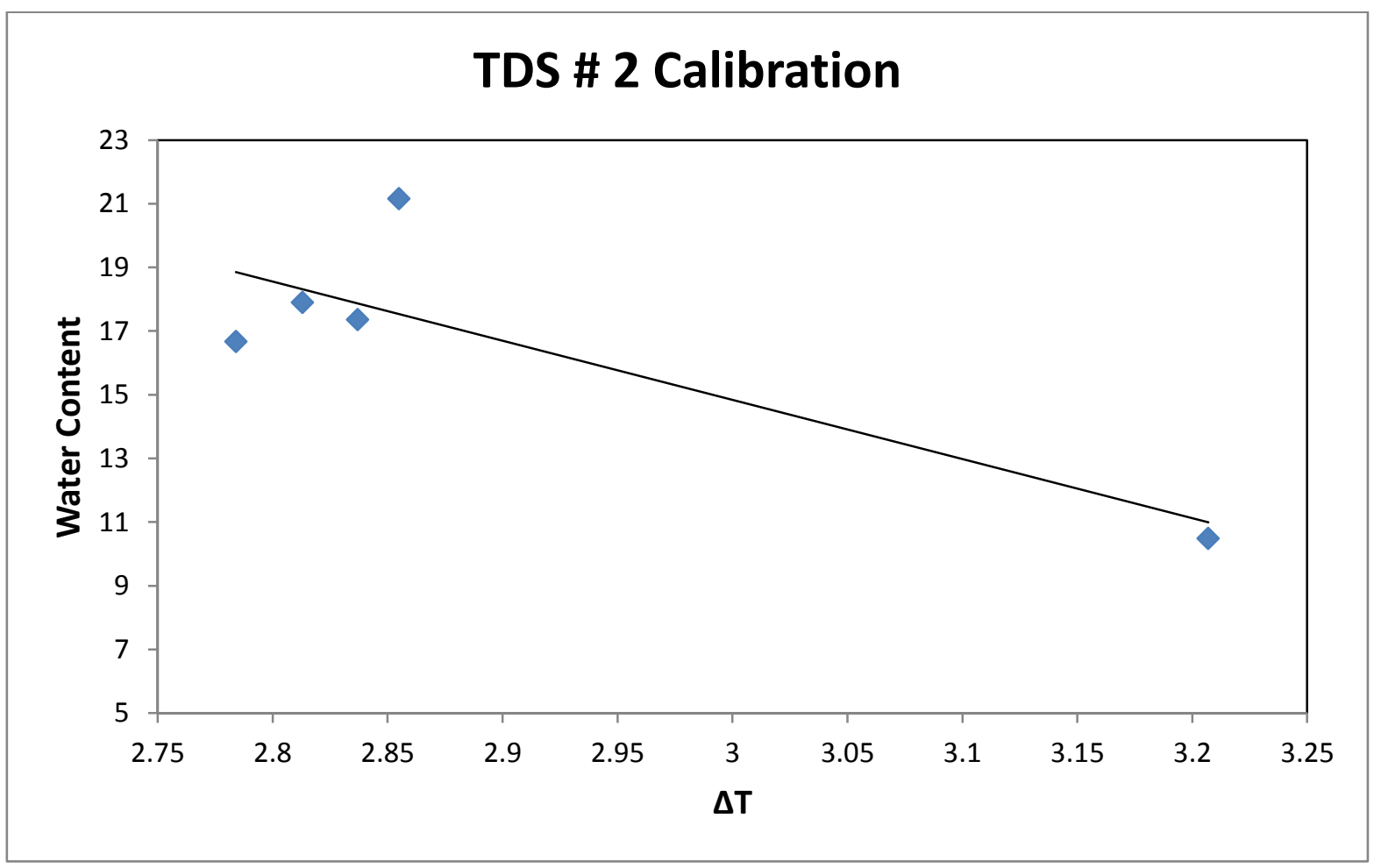

FIG.A.9 Thermal dissipation sensor TD-2 calibration curve. 


\section{TDS \#3 Calibration}

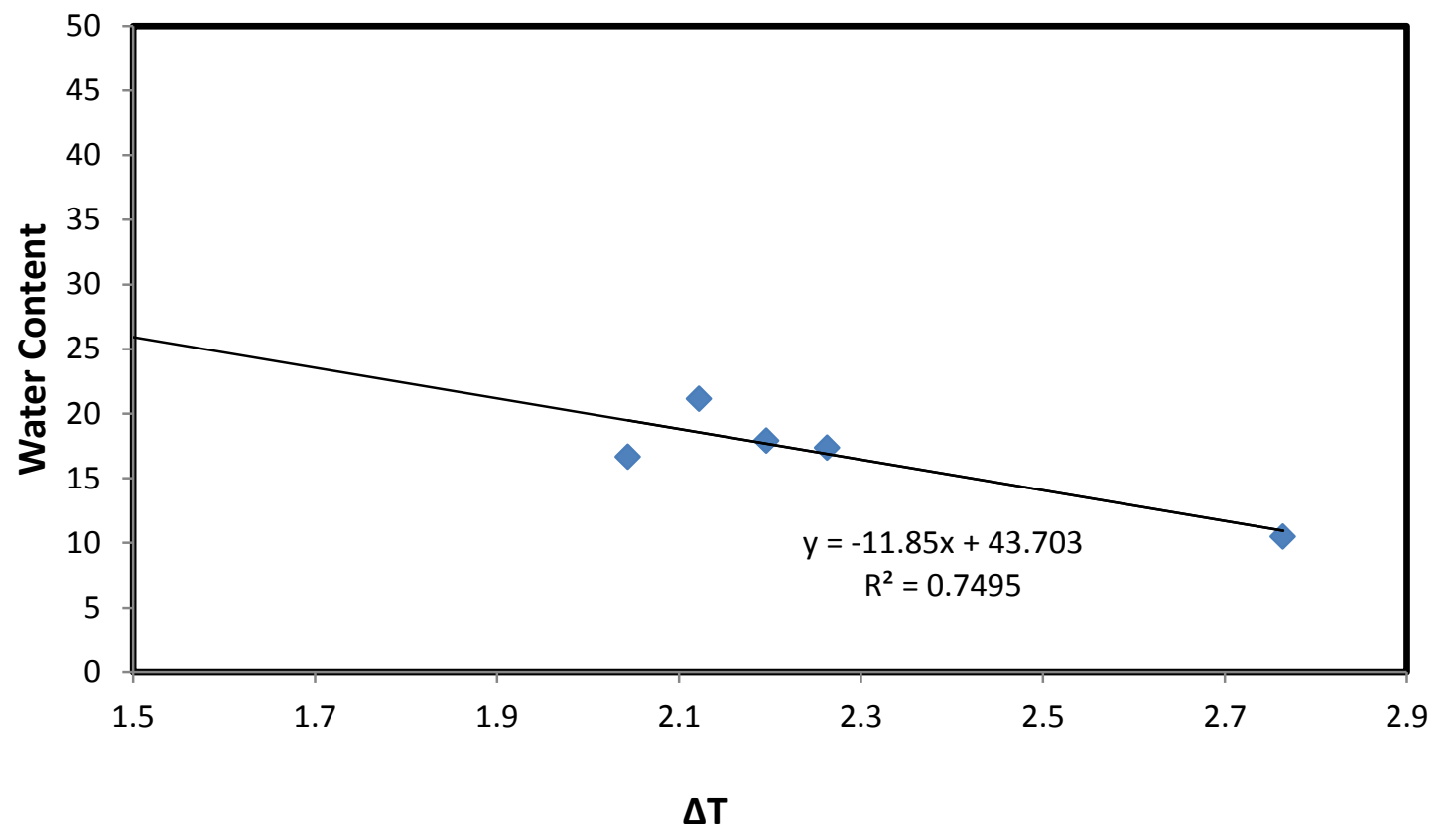

FIG. A.10 Thermal dissipation sensor TD-3 calibration curve.

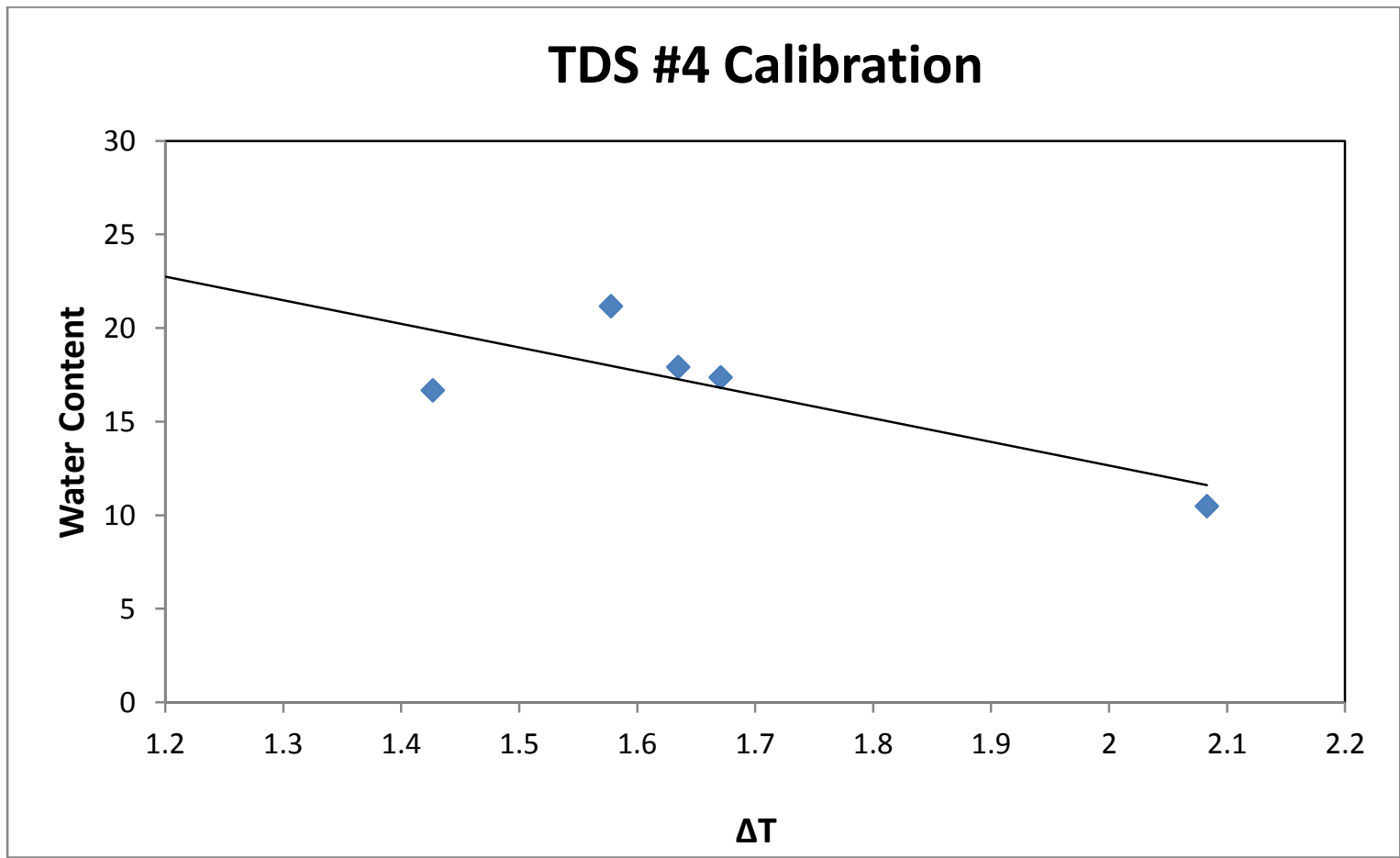

FIG. A.11 Thermal dissipation sensor TD-4 calibration curve. 
APPENDIX B-SITE B 


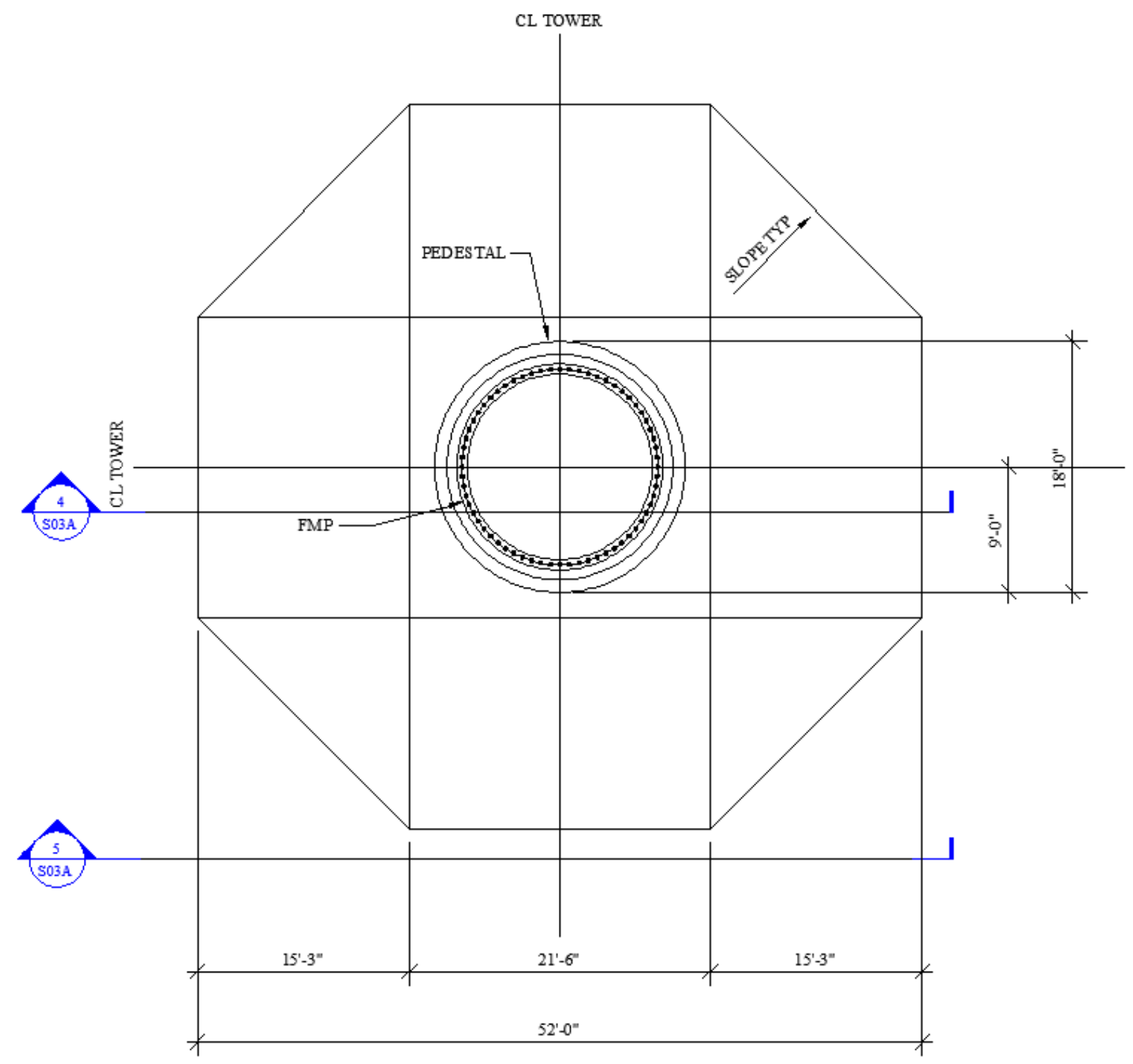

FIG. B.1 Plan view. 


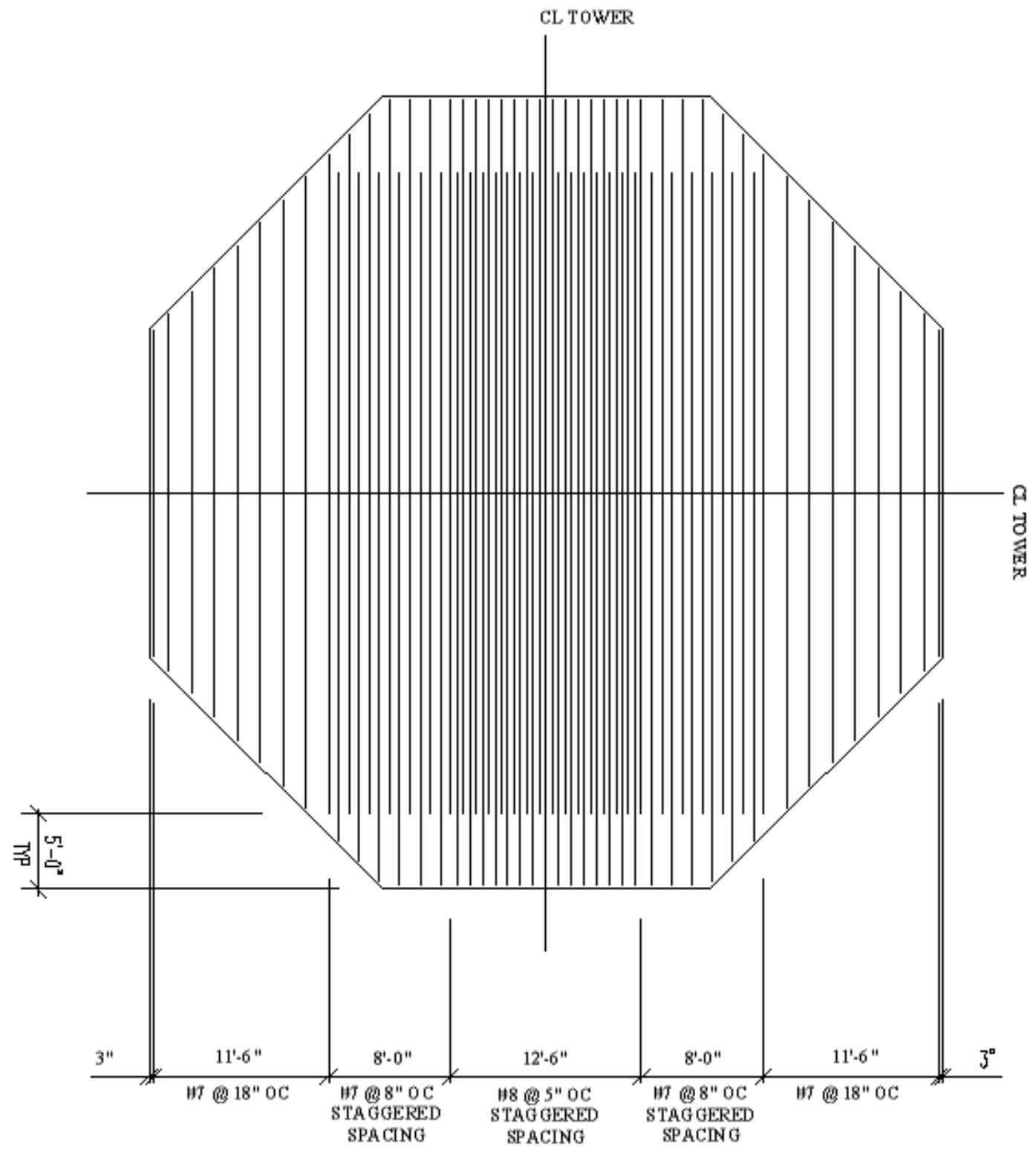

FIG. B.2 Bottom mat reinforcing plan. 


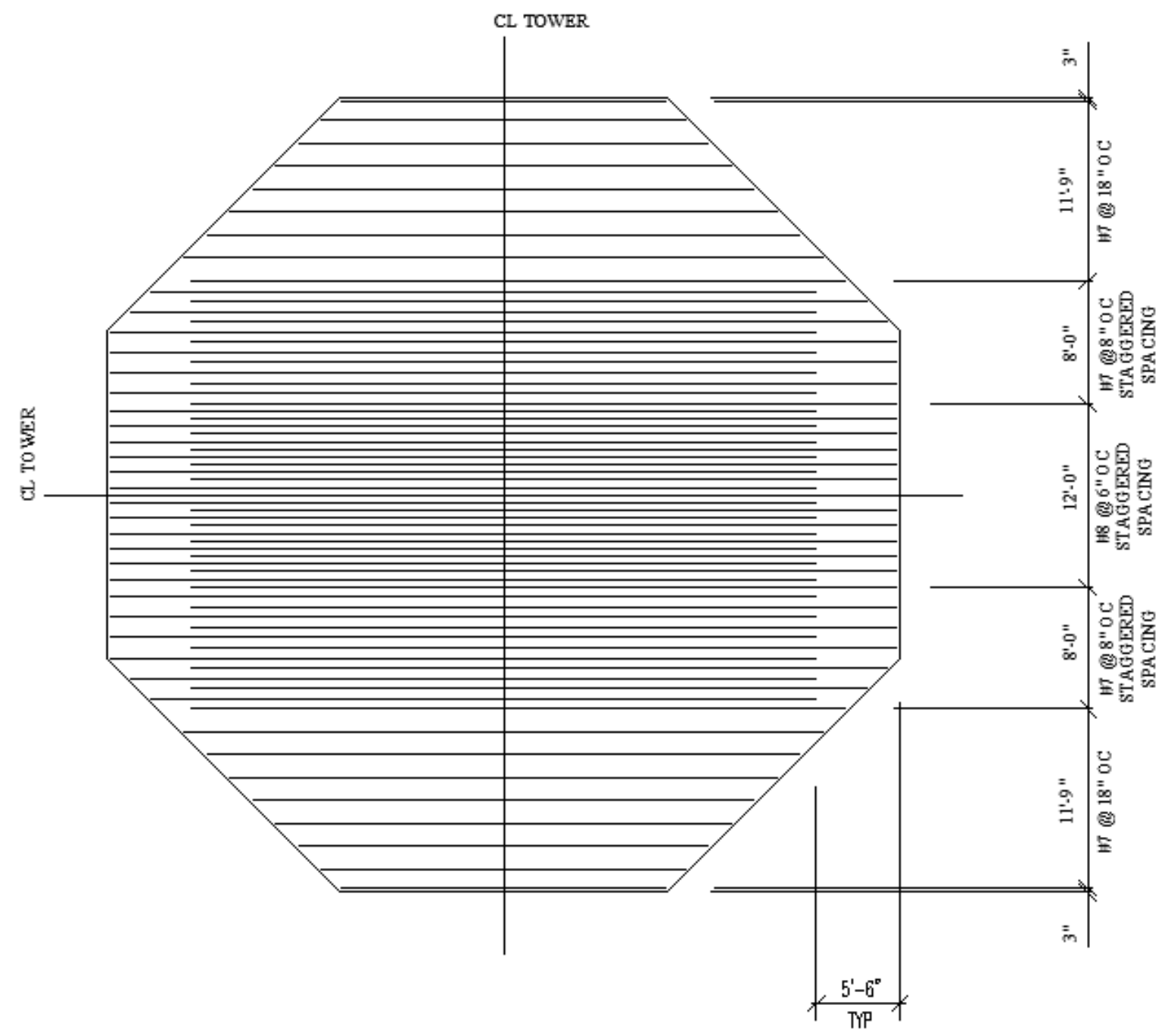

FIG. B.3 Top mat reinforcing plan. 


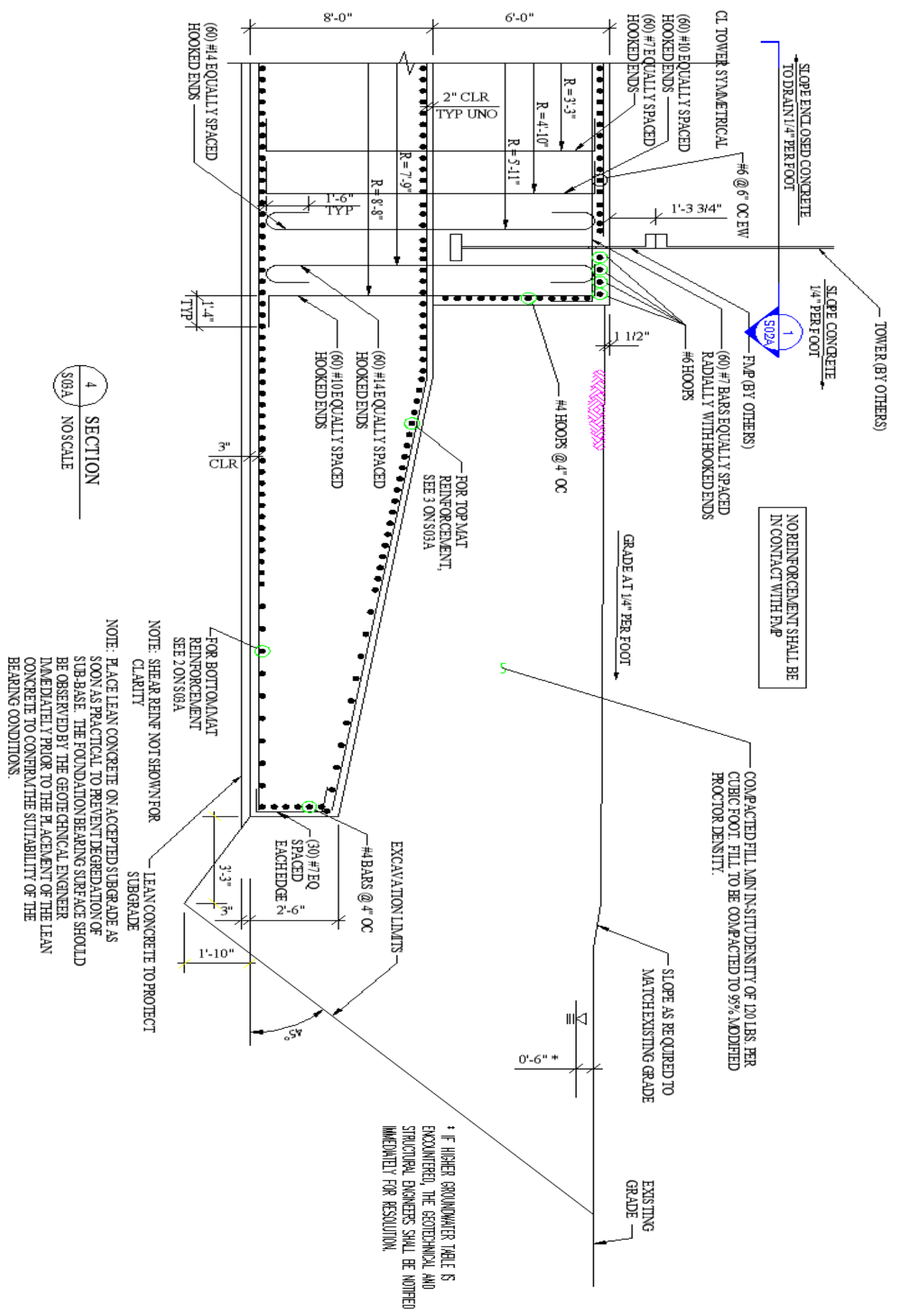

FIG. B.4 Foundation cross-section. 


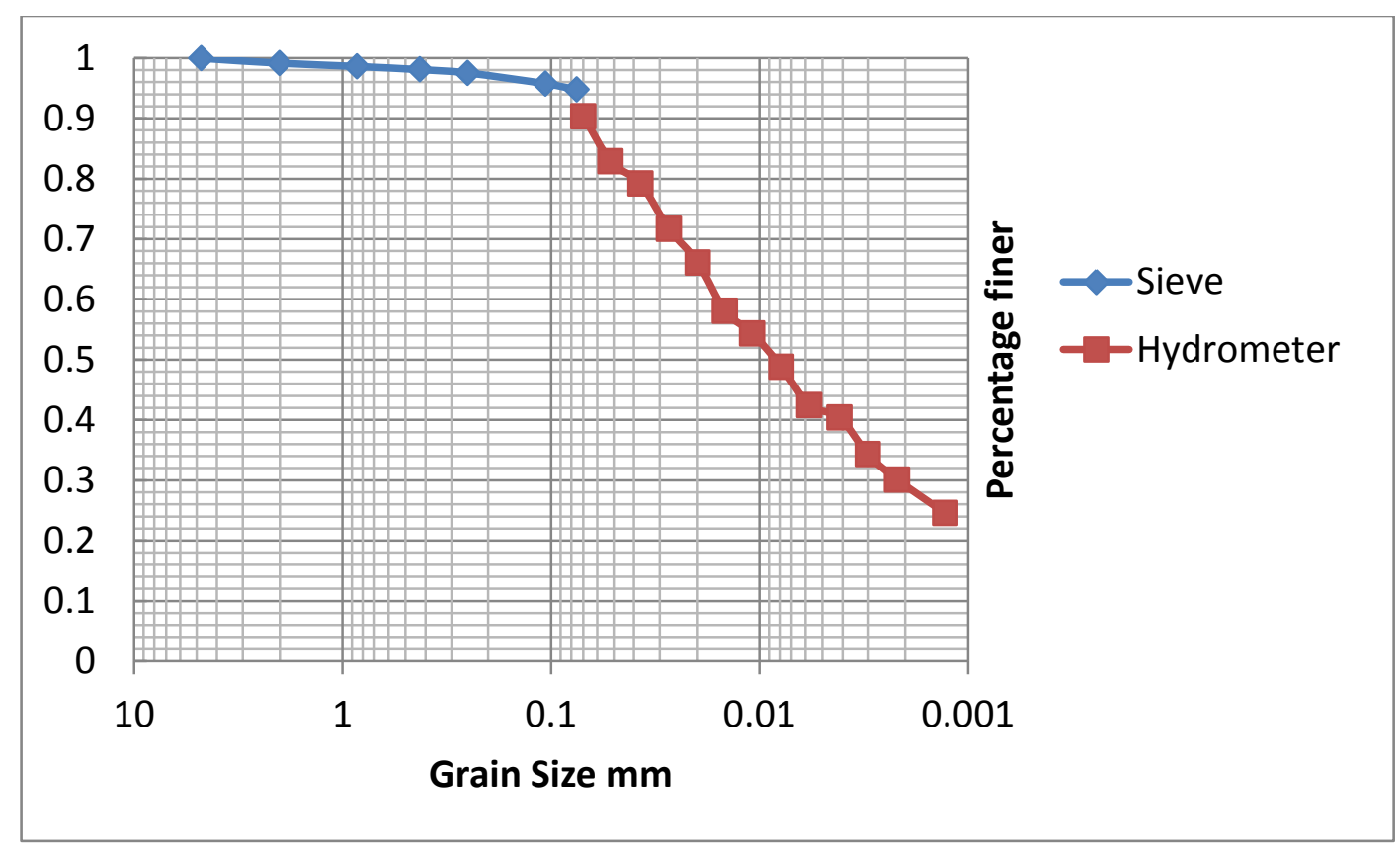

FIG.B.5 Soil grain size distribution (W5B1).

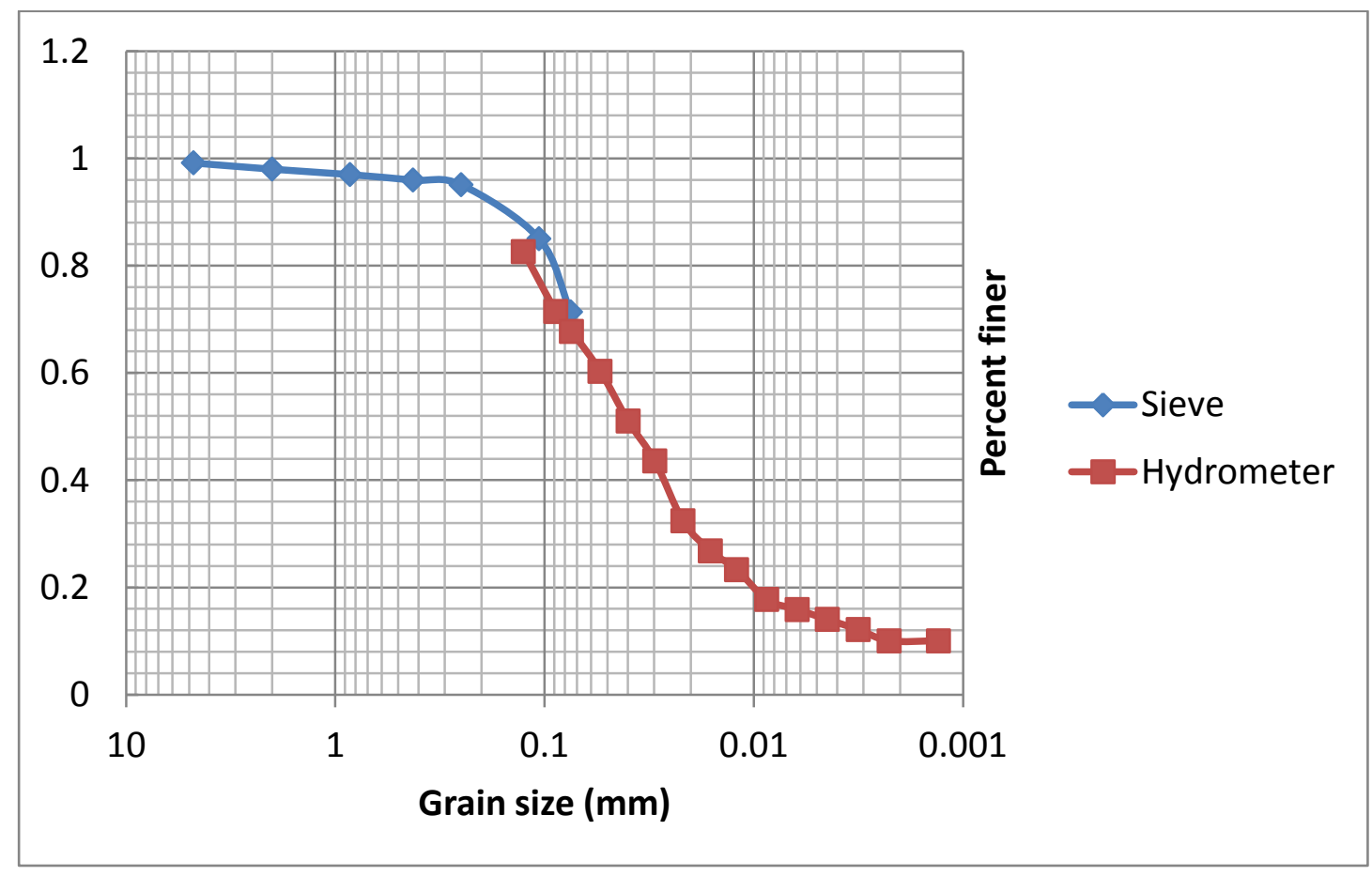

FIG. B.6 Soil grain size distribution (E1A1). 


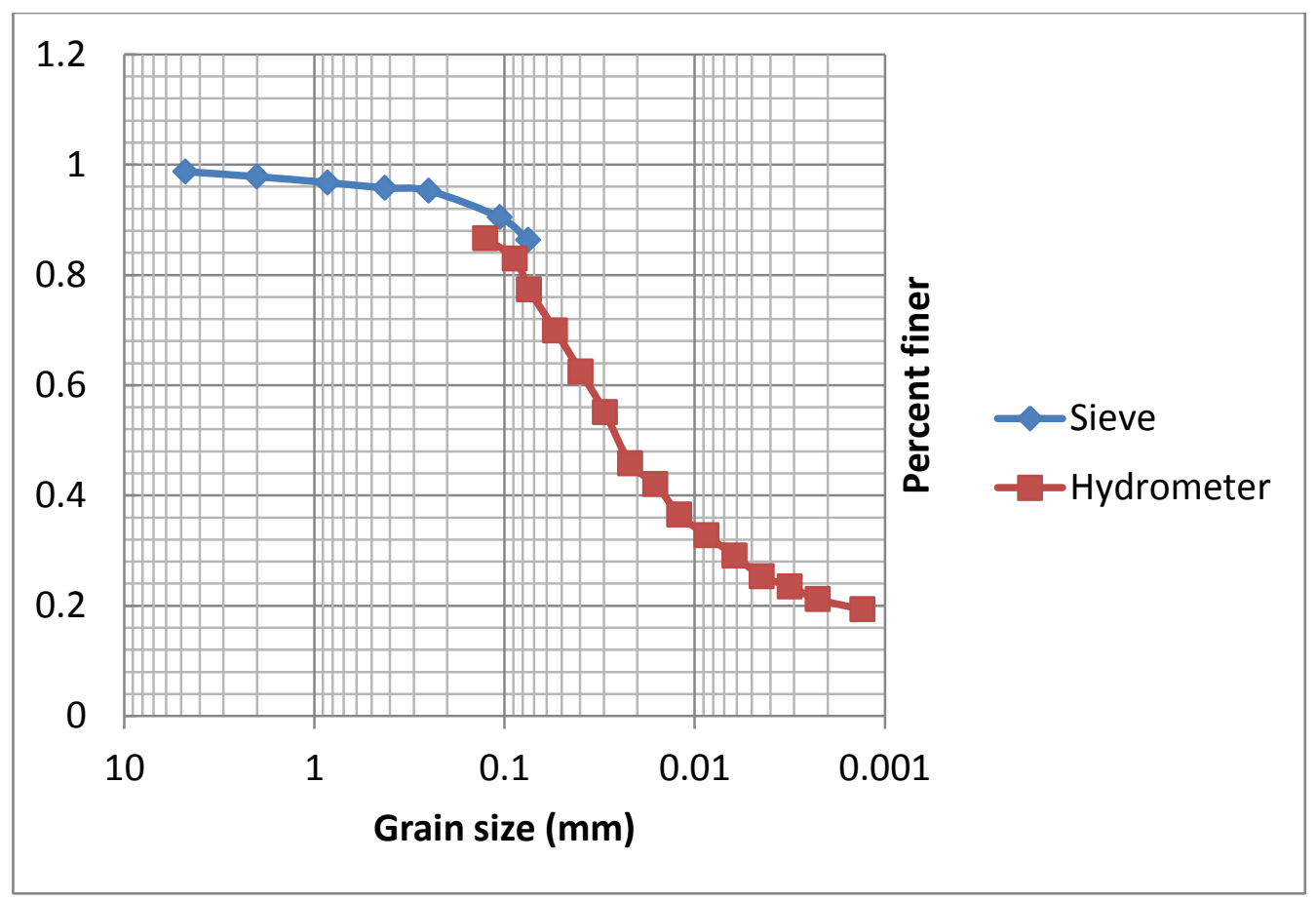

FIG. B.7 Soil grain size distribution (E3A2).

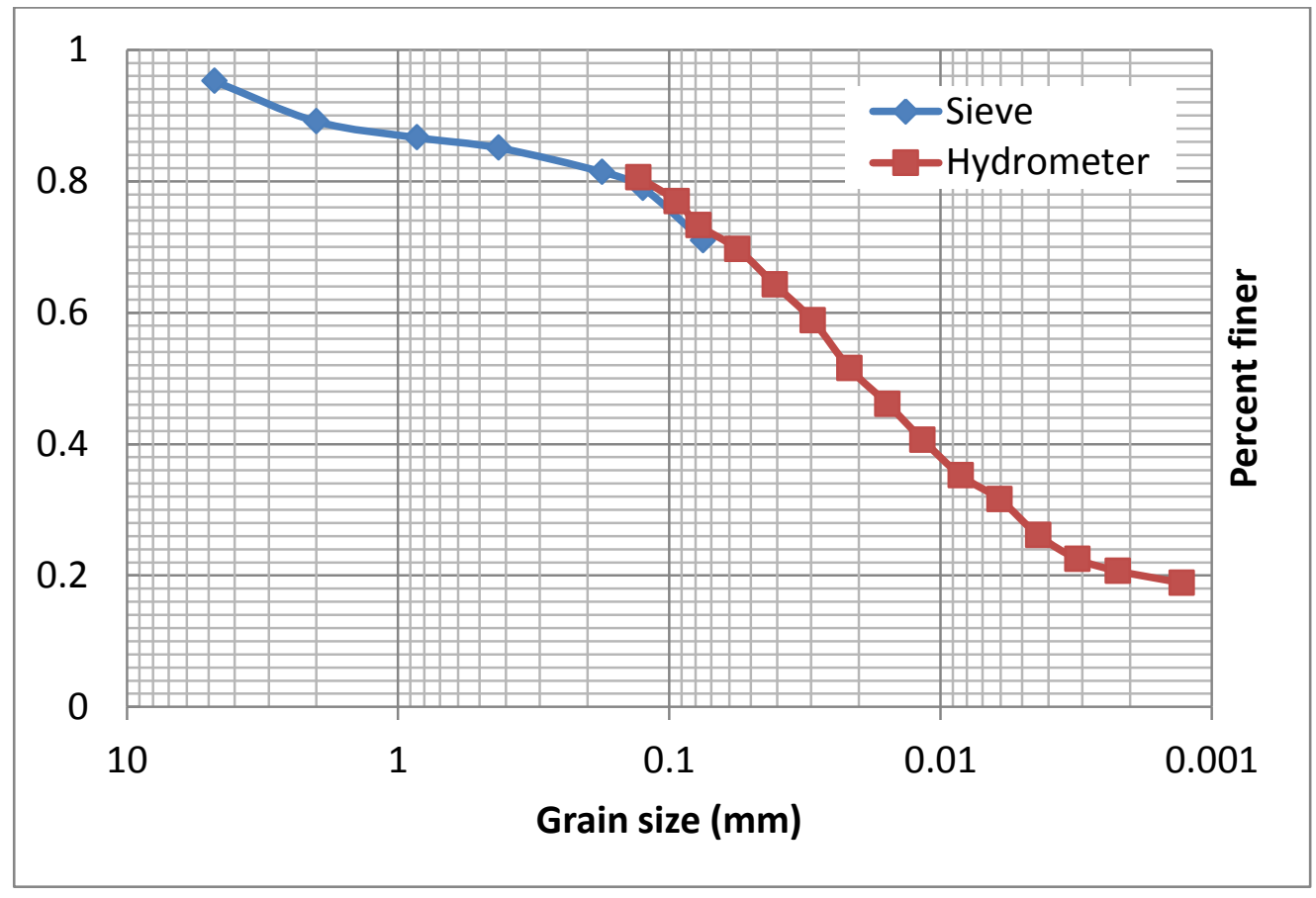

FIG. B.8 Soil grain size distribution (SG-3 Top) 


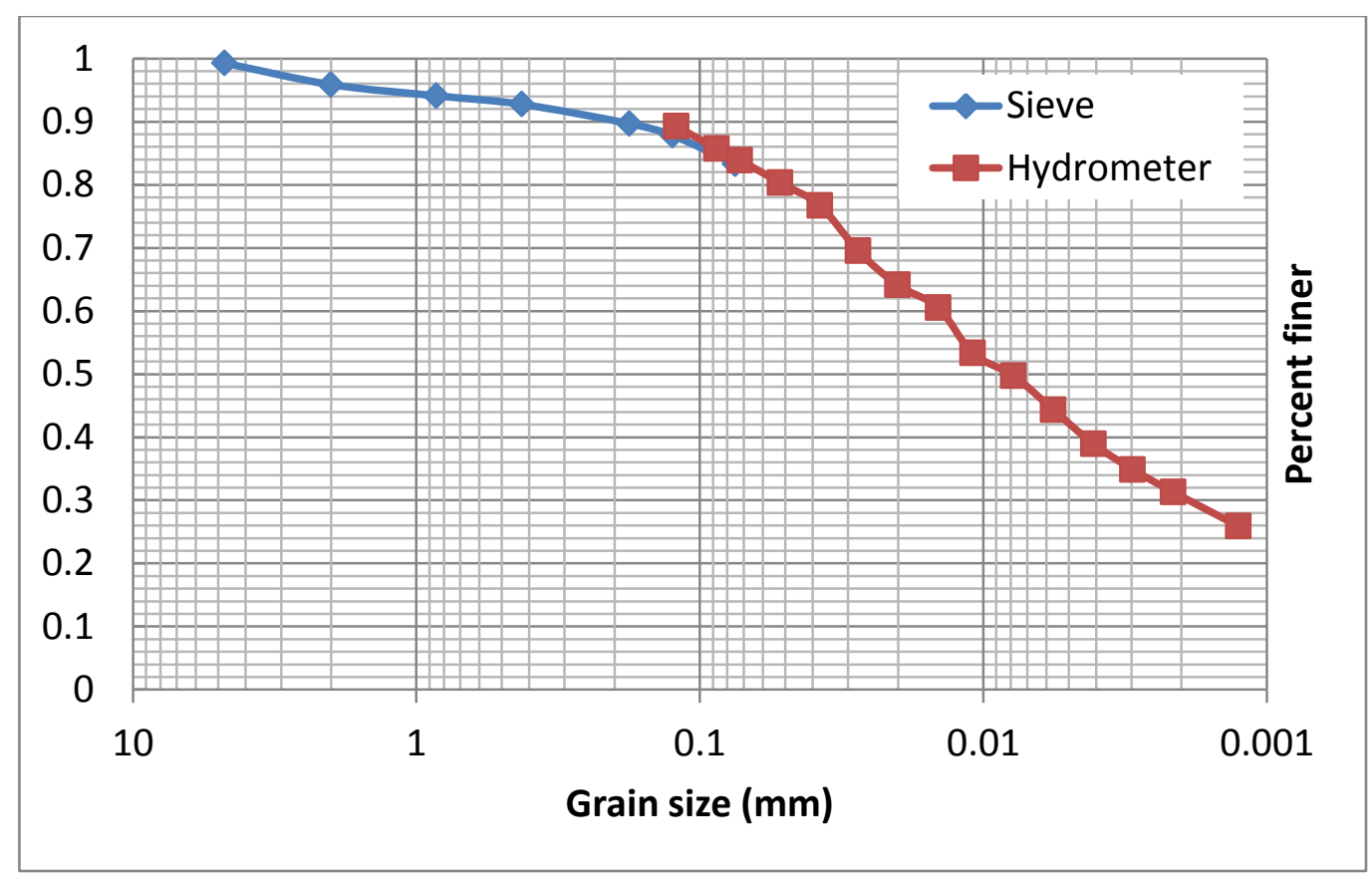

FIG. B.9 Soil grain size distribution (SG-3 Middle)

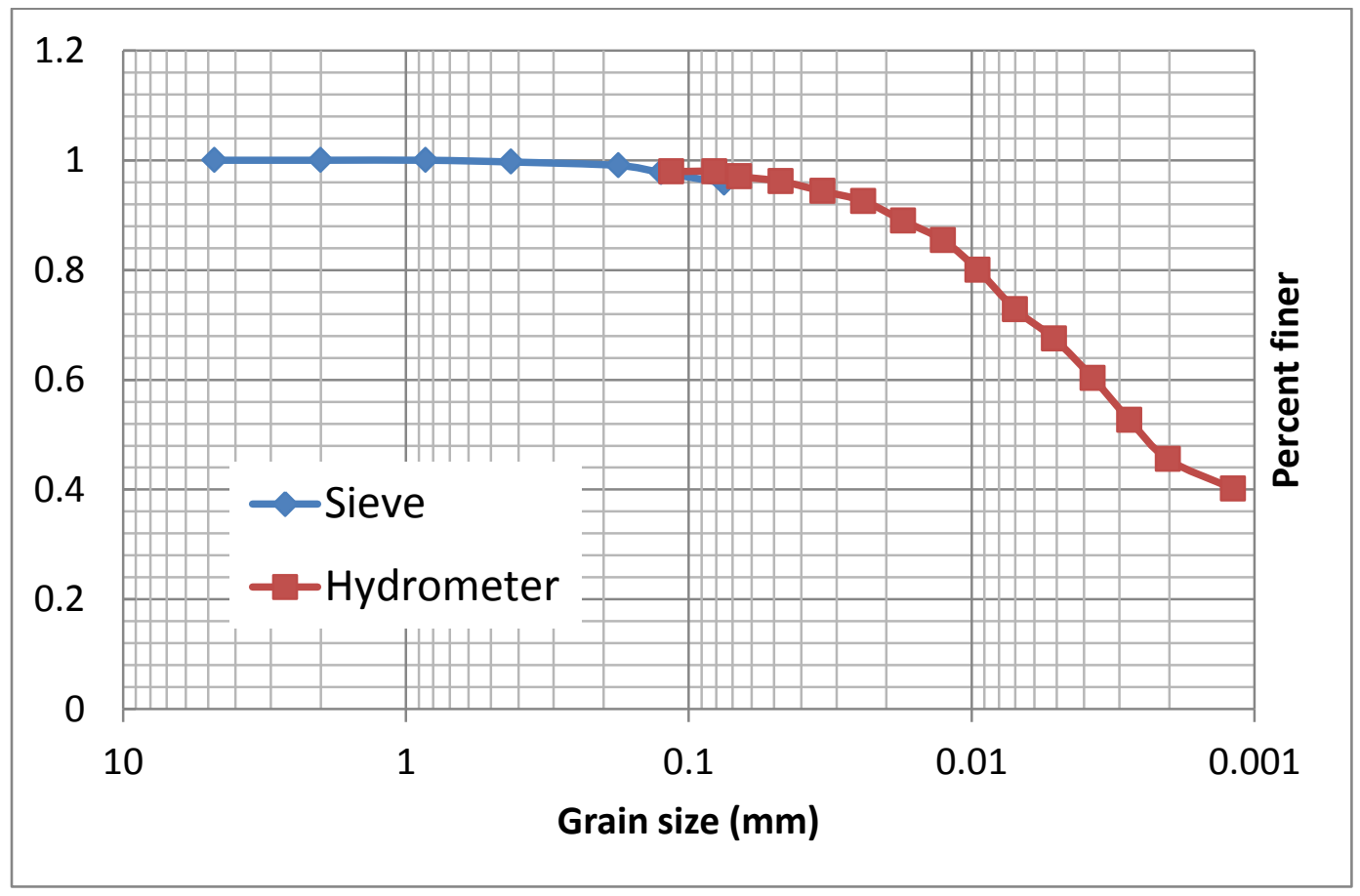

FIG. B.10 Soil grain size distribution (SG-3 Bottom) 


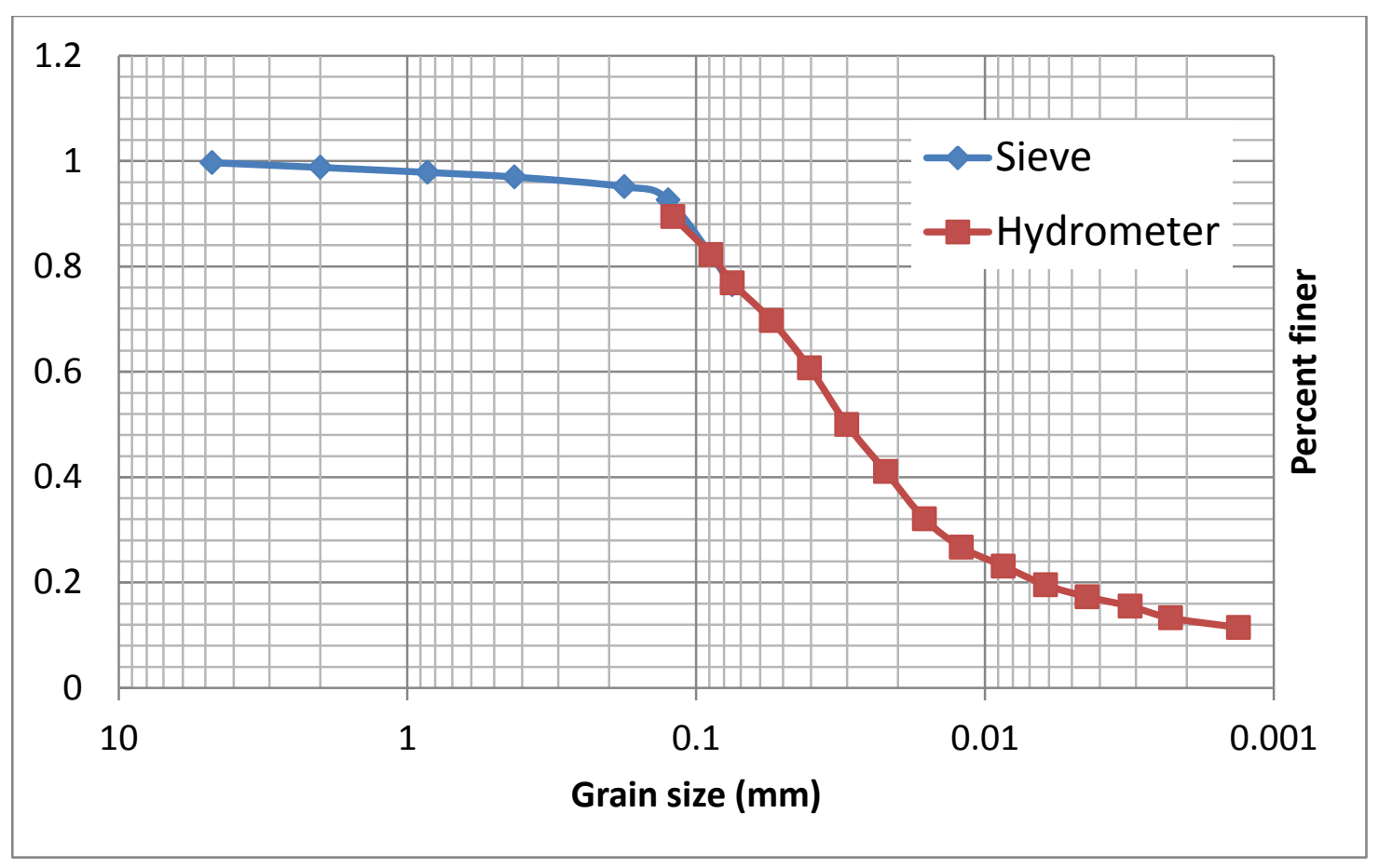

FIG. B.11 Soil grain size distribution (SG-5A)

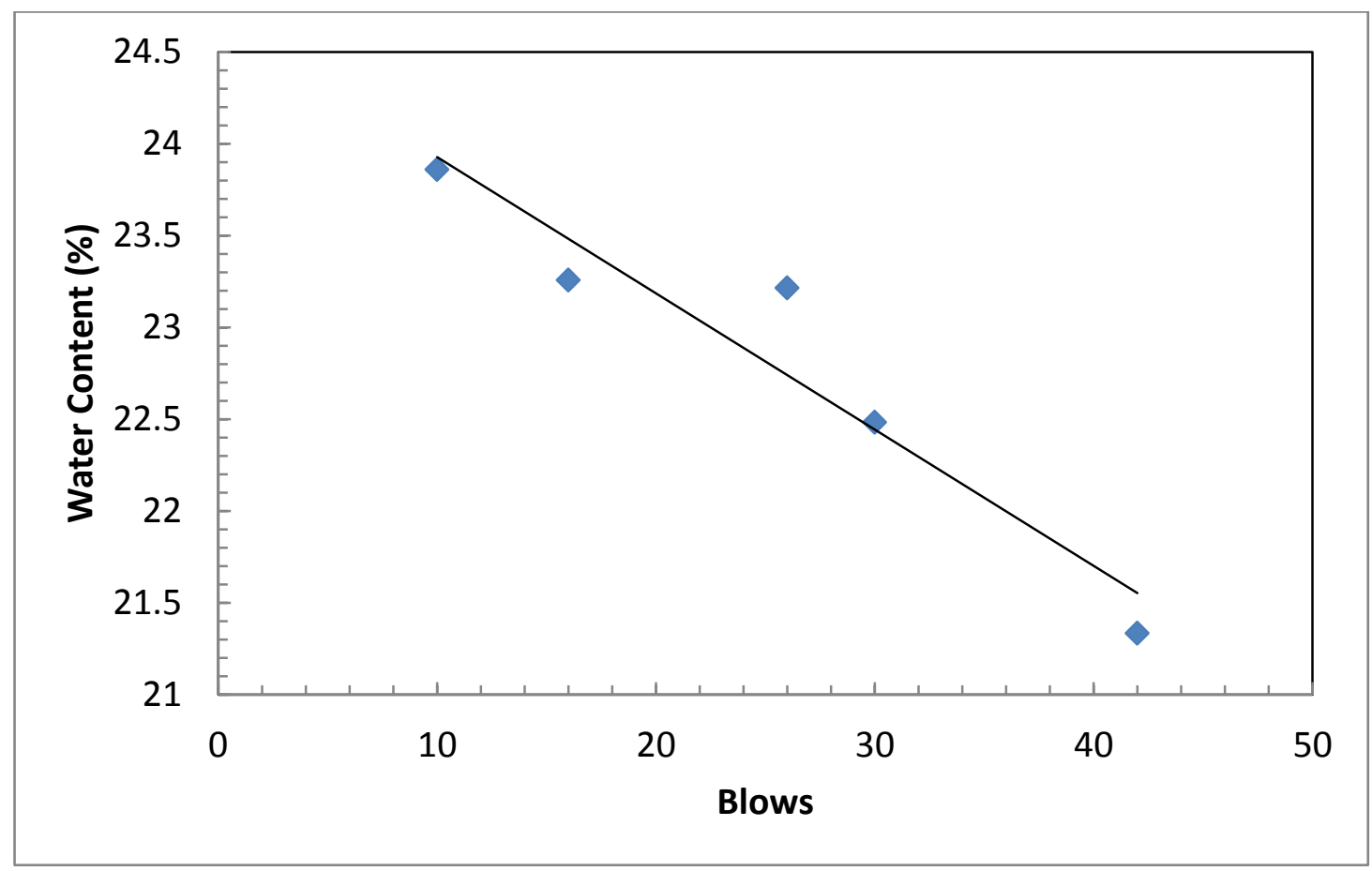

FIG. B.12 Liquid limit (W5B1). 


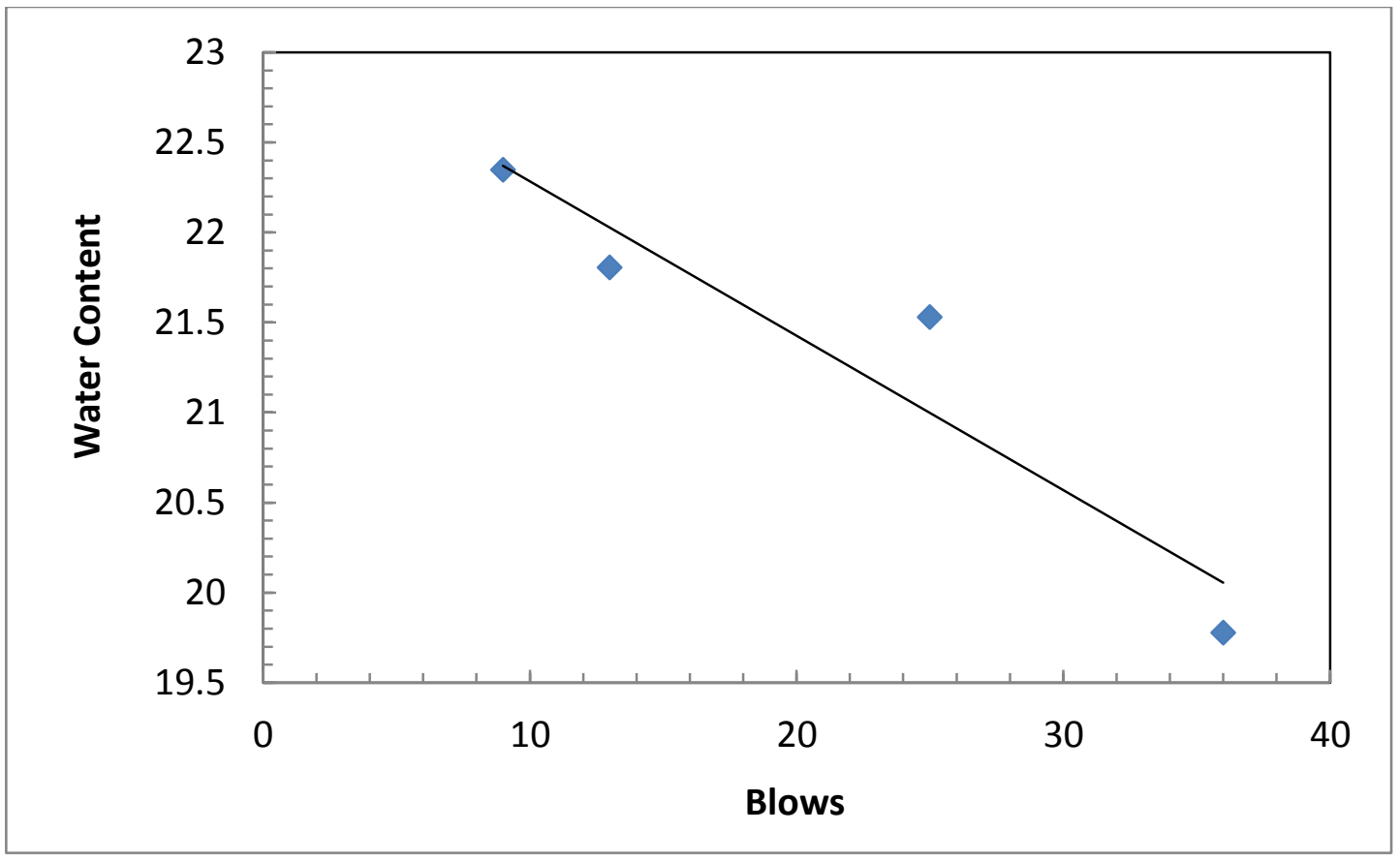

FIG. B.13 Liquid limit (E1A1).

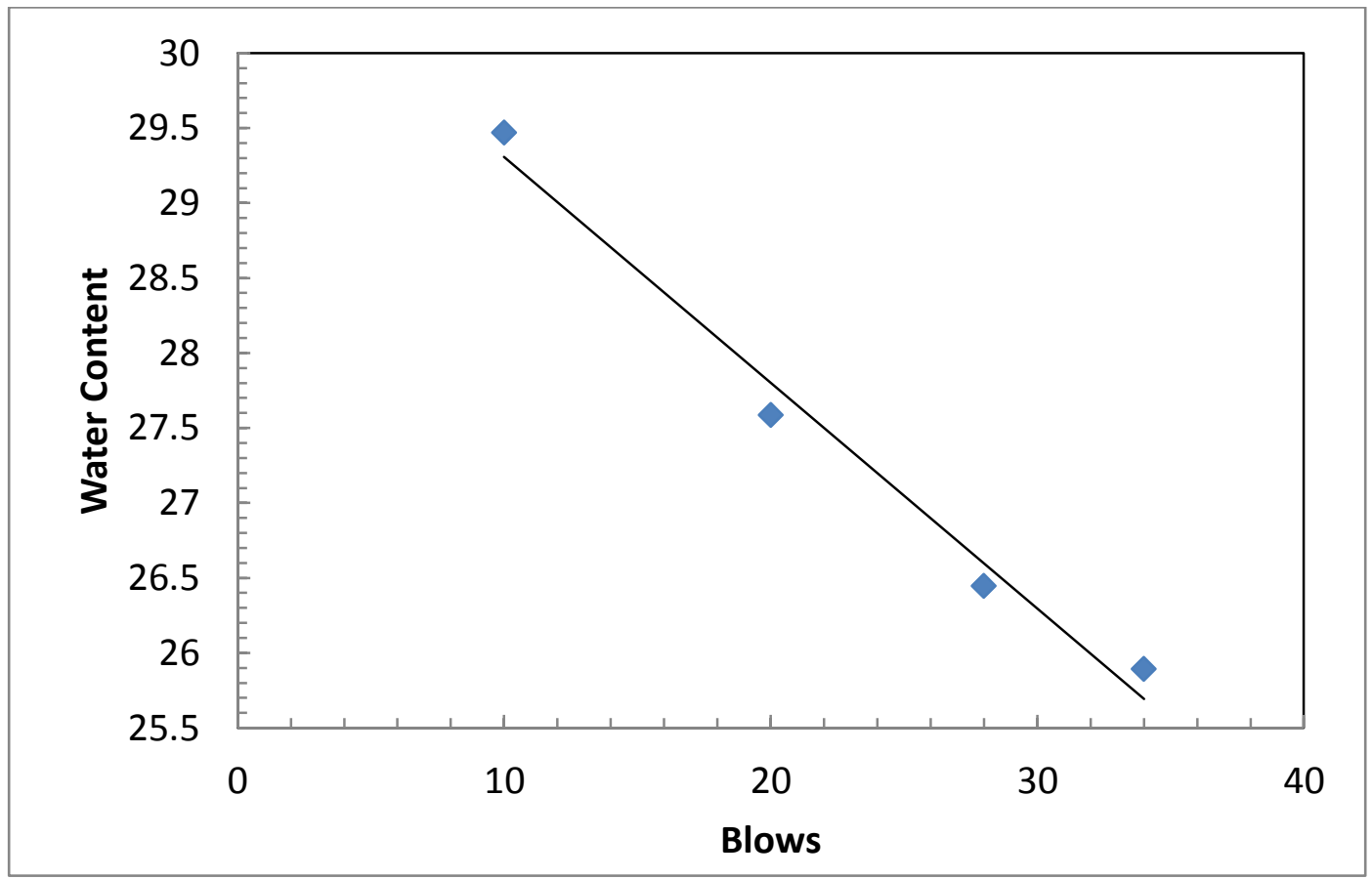

FIG. B.14 Liquid limit (E3A2). 


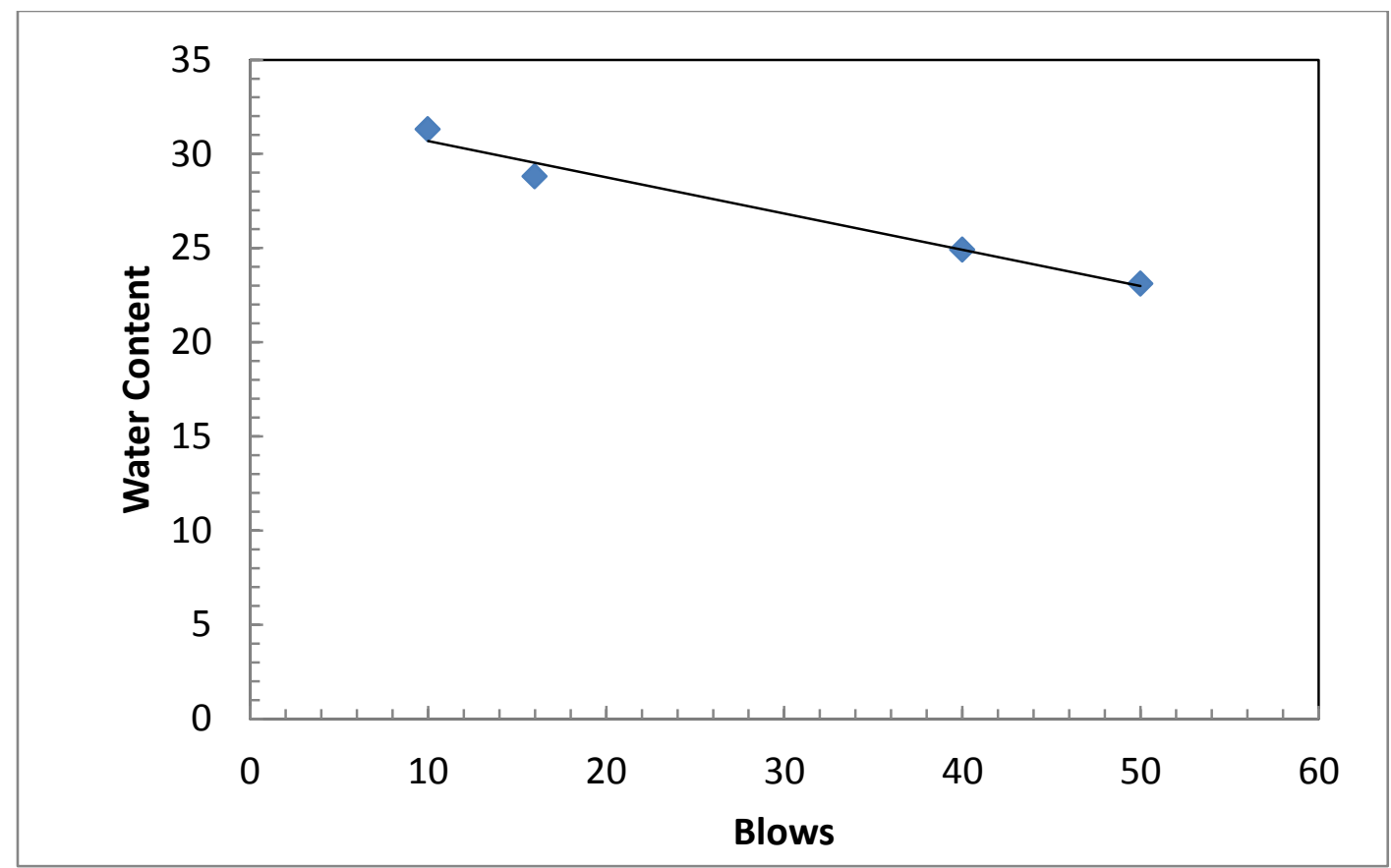

FIG. B.15 Liquid limit (SG-3 Middle).

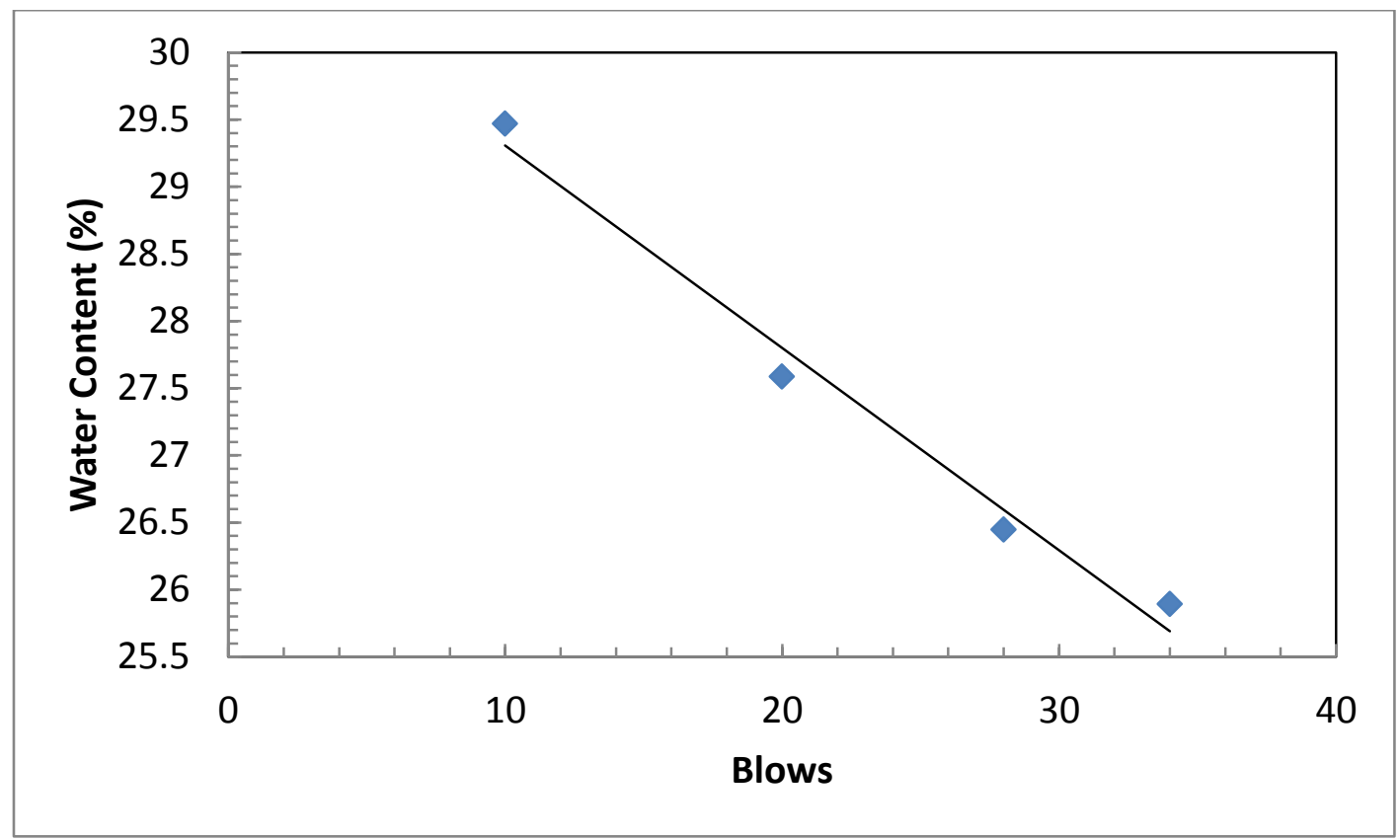

FIG. B.16 Liquid limit (SG-2 Bottom). 


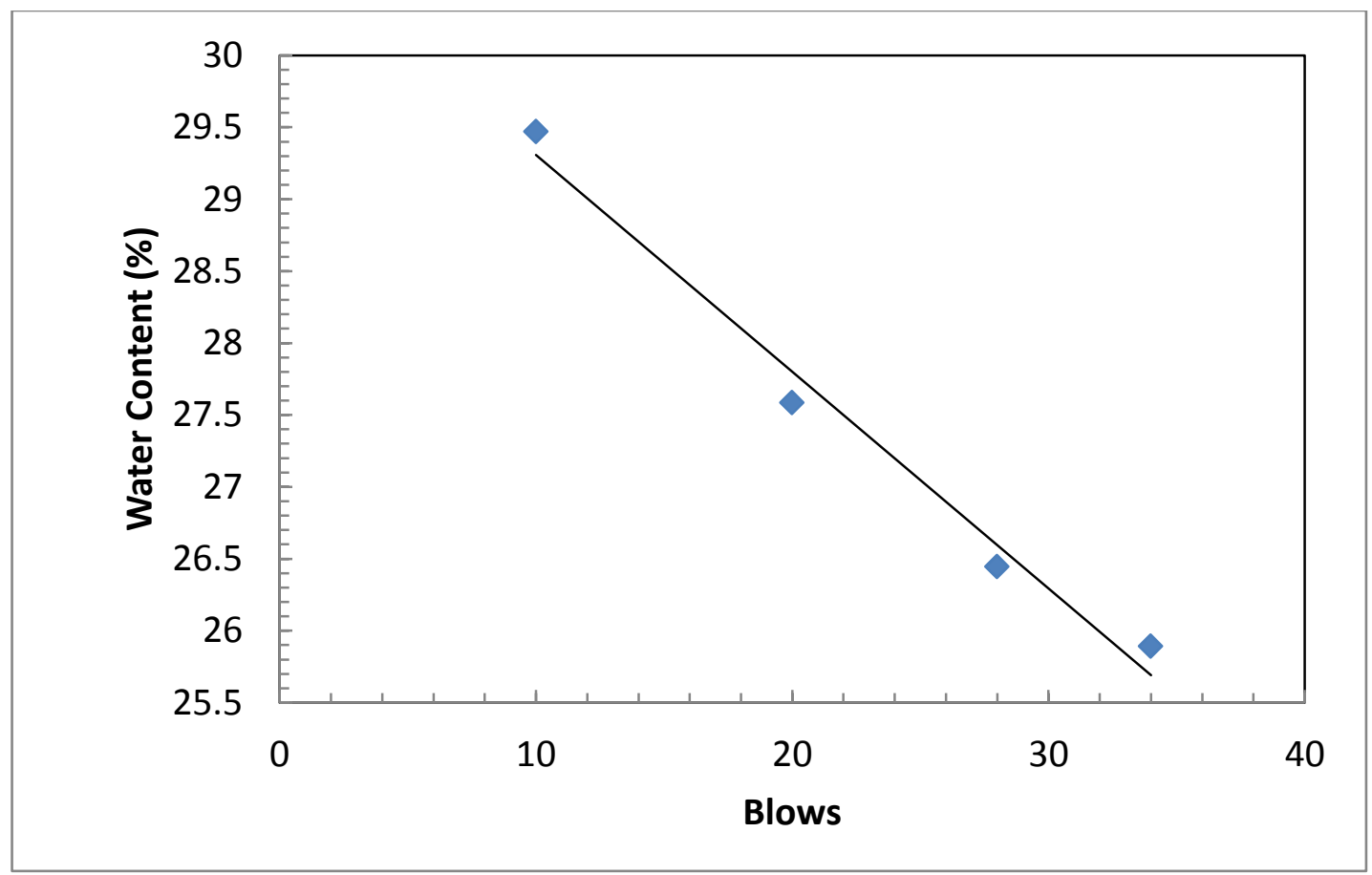

FIG. B.17 Liquid limit (SG-5A). 


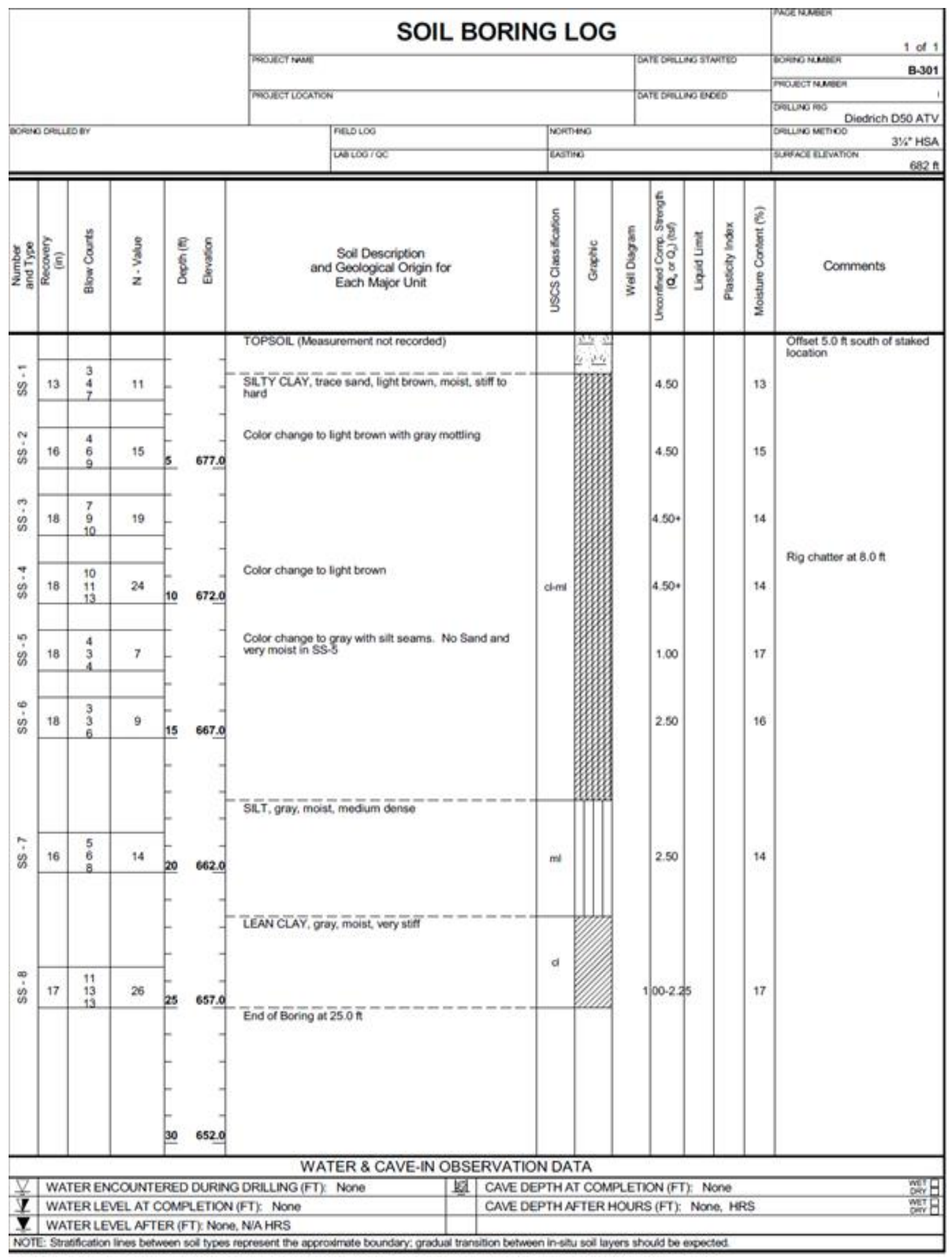

FIG. B.18 Soil boring log. 


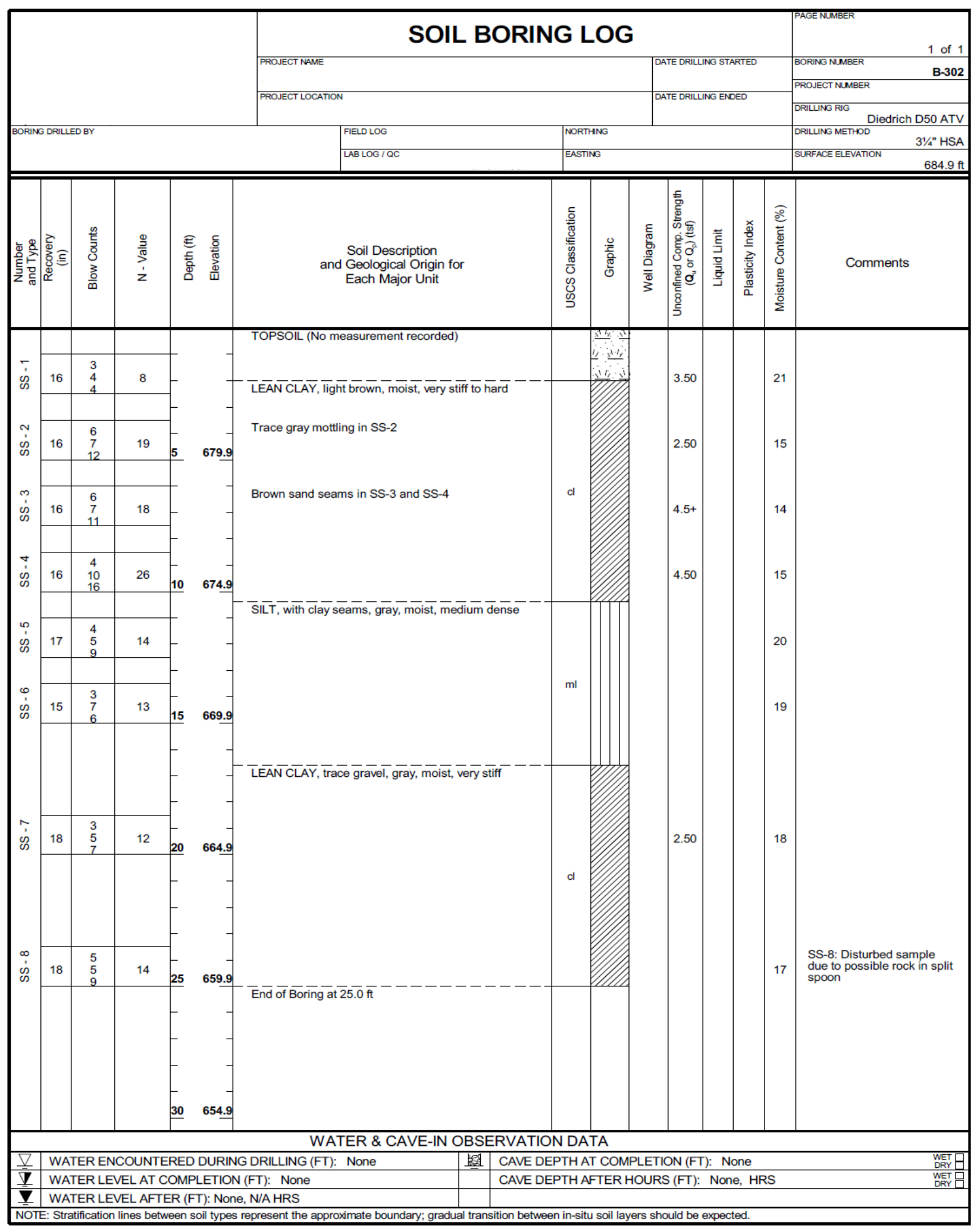

FIG. B.19 Soil boring log-2. 